\title{
The insider perspective: Three emic studies about sensemaking and organizational change over time
}

\author{
By \\ Laura Gover
}

A thesis submitted to the Faculty of Graduate and Postdoctoral Affairs in partial fulfillment of the requirements for the degree of

Doctor of Philosophy

in

Management

Carleton University

Ottawa, Ontario

(C) 2016

Laura Gover 


\begin{abstract}
Scholars contend that our understanding of organizational change would benefit from research that more closely represents the lived reality of organizational change. Research on sensemaking is particularly valuable in this vein because of its focus on the individual's experience and understanding. Existing empirical work on sensemaking about organizational change, however, is largely based on retrospective interview data and/or focuses on a narrow window of time during change implementation and thus does not thoroughly consider how individuals' make sense of change over time. This thesis seeks to address this limitation through three complementary studies aimed at understanding how individuals make sense of organizational change over time from an emic (or insider) perspective.
\end{abstract}

All three papers are interpretive process-oriented case studies, which use grounded theory data analysis techniques to analyze interview data for the same 26 hospital employees collected at three points in time over a five year period of organizational change. Paper one is about the interpretation stage of sensemaking. This paper identifies four stable sensemaking lenses and develops two new concepts related to how individuals make sense of organizational change over time: (1) sensemaking constancy and (2) sensemaking scope. Paper two considers sensemaking triggers and explores how individuals' retrospective sensemaking compares to their real-time assessments during change. Findings indicated that in "real-time" the experience of change varied in somewhat stable way between groups but that when "looking back" over the change, change agents tended to view the changes more positively than change recipients. Finally, paper three looks at the enactment stage of the sensemaking process 
and examines individuals' strategies for coping with excessive change. Coping (from cognitive appraisal theory) and sensemaking are positioned as overlapping processes that individuals use to make sense of and respond to excessive organizational change. Five patterns, or stories about how individuals cope with and make sense of excessive change over time, emerged. Taken as a group, the three papers contribute to the research and practice of organizational change by offering novel insights and theoretical contributions related to how individuals experience and make sense of change over time. 


\section{Preface}

I, Laura Gover, am the sole author of this dissertation and the lead author of each of the three papers. At the time of the initial thesis submission all three papers had been submitted for publication consideration at peer review journals. These three submissions, and any proceeding publications, all list Laura Gover as the first author and Dr. Linda Duxbury (my thesis supervisor) as the co-author. Dr. Linda Duxbury provided valuable guidance throughout this research process primarily by providing feedback, partaking in spirited discussions about the research decisions and direction and by offering editorial support. Aside from my thesis supervisor there are no other co-authors.

I was fully involved in the setting up and conducting of the research included in this thesis. I conducted all of the interviews and was also responsible for the data analysis steps reported in each paper as well as the preparing and writing up of the materials presented in each paper. When citing material from this thesis, please reference it as:

Gover, L. (2016) “The insider perspective: Three emic studies on sensemaking about organizational change over time," PhD. Dissertation, Sprott School of Business, Carleton University. 


\section{Acknowledgements}

My dissertation journey has been a long and winding road and reaching my final destination would not have been possible without the help and support of others, for which I am truly grateful. My thesis supervisor, Dr. Linda Duxbury, helped me find my way when I was lost (more times than I would like to admit!). She is the single person I credit for my decision to pursue doctoral studies and I am honoured to learn from her. I am incredibly thankful for every single hour, minute and second that she has spent mentoring me throughout this process and attribute my growth as a researcher and writer to her. I am also thankful to my dissertation committee members Dr. Gerry Grant, Dr. Karen March and Dr. Roy Suddaby for their time and energy. I would like to specifically thank Dr. Leighann Neilson for opening my eyes (wider) to the world of interpretive research. Credit is also due to the Canadian Institutes of Health Research, which funded our study of organizational change in community healthcare settings and made all of this research possible over time. Finally, I am indebted to each individual that was interviewed. The value of their support in the form of candor and time is immeasurable.

This thesis is dedicated to my family: My mom, who has been my rock, counselor, and childcare provider making this all possible; My dad, whom I inherited the overanalytical "Gover" mind from - a blessing and a curse but certainly an important part of this thesis; My husband, who helps keep my feet on the ground and knows when to give me a shoulder to cry on and when to leave jujubes by my computer; My daughter, who is both a delightful procrastination method and a reason to persevere and complete my Ph.D.; My cat, who has singlehandedly logged the most hours at my side while working on my thesis - if only she could proofread! 


\section{Table of Contents}

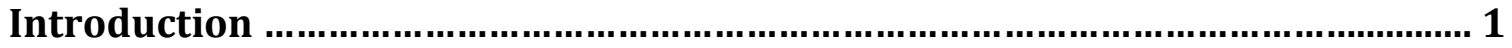

1.1 Approaches to studying change .................................................................6 6

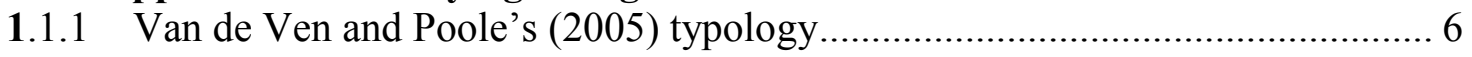

1.1.2 Approach employed in this thesis........................................................... 9

1.2 Sensemaking ....................................................................................................... 10

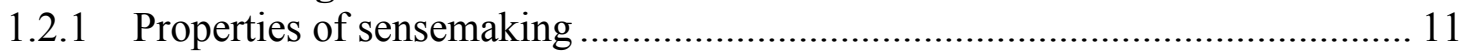

1.2.2 The sensemaking process .................................................................... 12

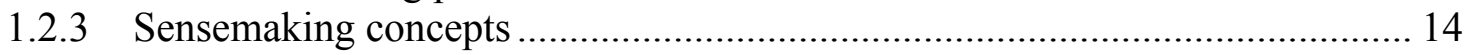

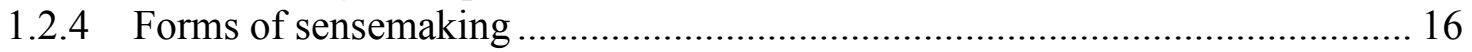

1.3 Sensemaking about organizational change ............................................... 18

1.3.1 Procedure for identifying articles ........................................................... 19

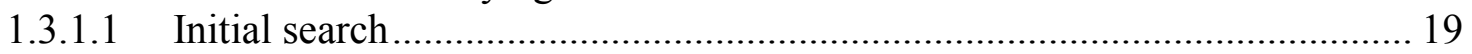

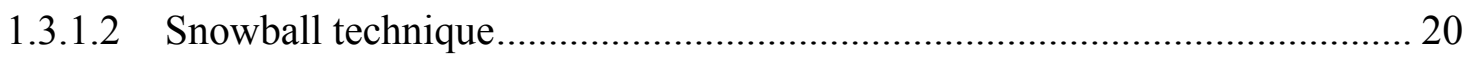

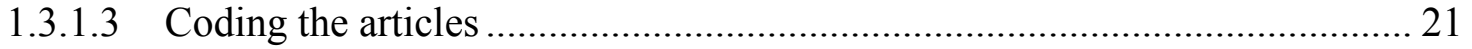

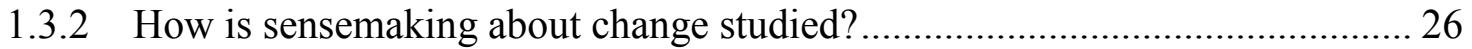

1.3.2.1 Methodological approach ........................................................................ 26

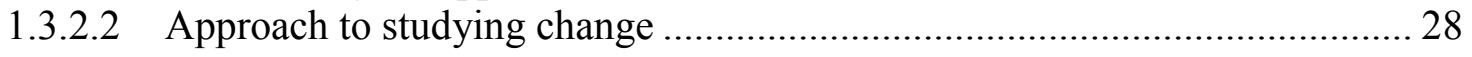

1.3.2.3 How sensemaking about change was studied from process orientation........ 29

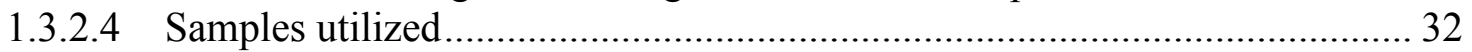

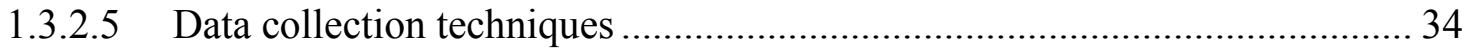

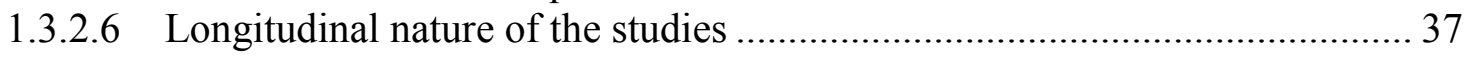

1.3.3 What do we know about sensemaking and change? .................................. 40

1.3.3.1 Findings about properties of sensemaking ............................................... 42

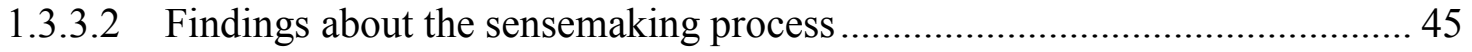

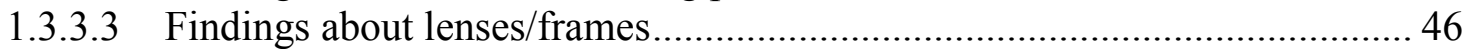

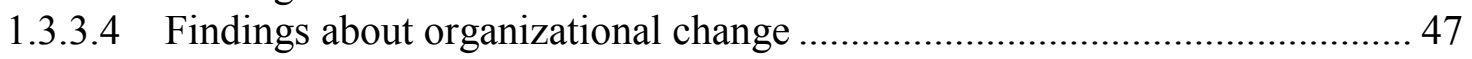

1.4 Gap in the literature and implications for thesis ....................................... 53

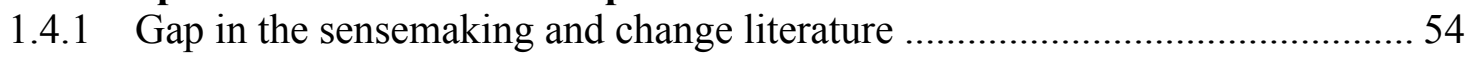

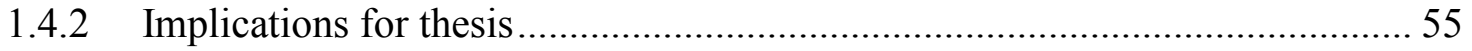

Chapter 2: Methods ....................................................................................... 57

2.1 Qualitative research epistemologies ......................................................59

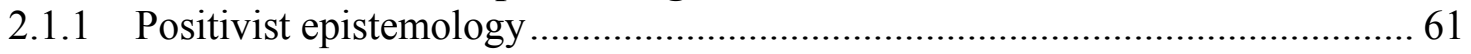

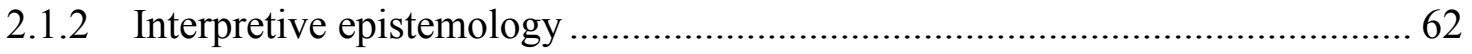

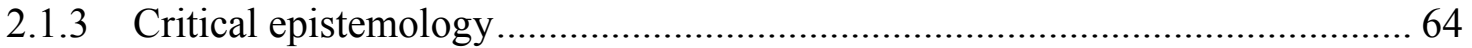

2.2 Methodological approach............................................................................6 65

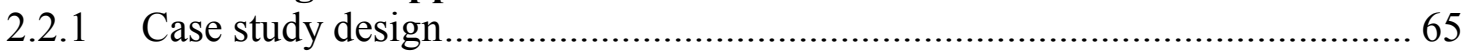

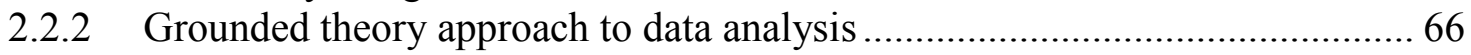

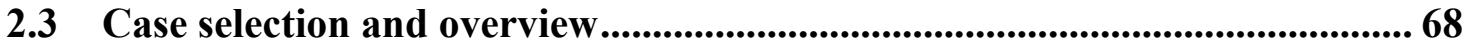

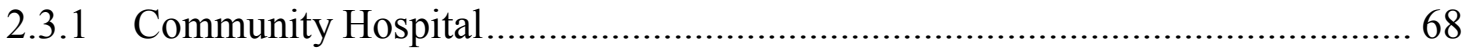

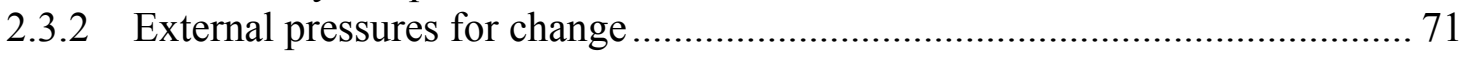

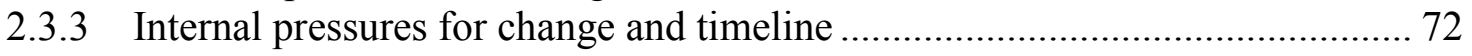

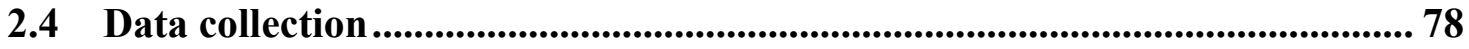

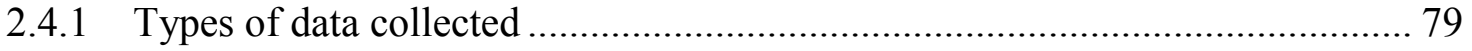

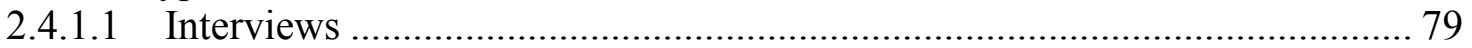




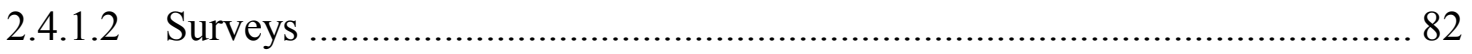

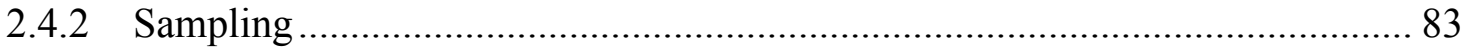

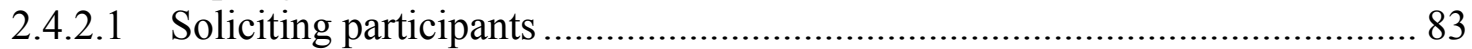

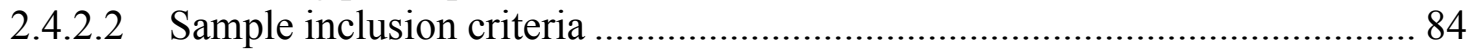

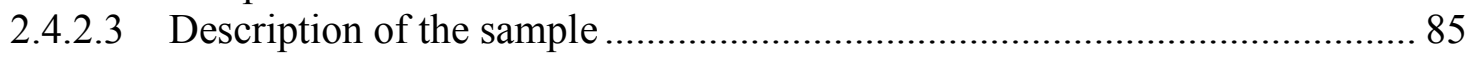

2.5 Data analysis.......................................................................................................... 87

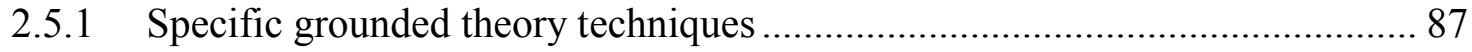

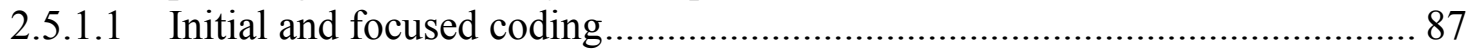

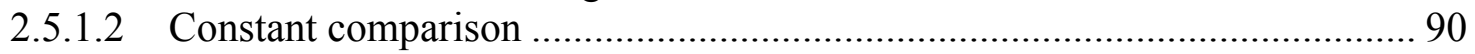

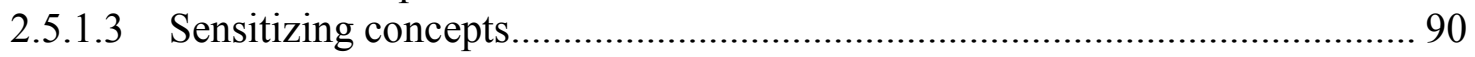

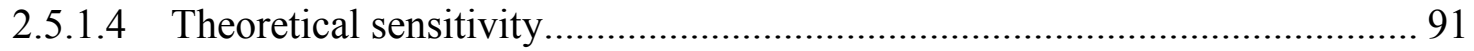

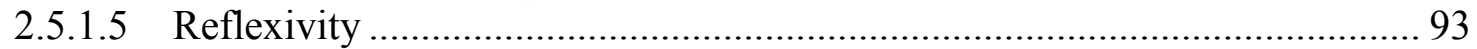

2.5.2 Organizing and coding data for the thesis ...................................................... 94

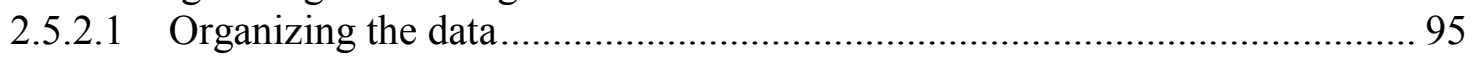

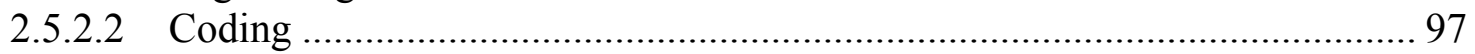

2.6 Evaluating quality of research products..............................................................98

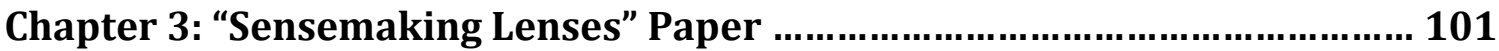

3.1 Introduction.............................................................................................................. 101

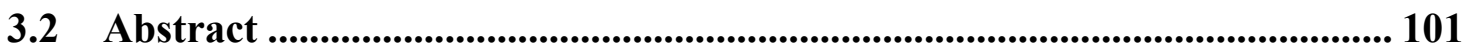

3.3 "Sensemaking Lenses" paper .............................................................................. 102

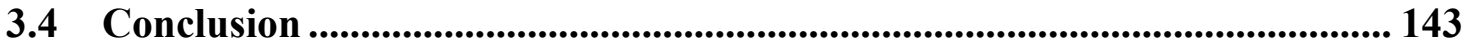

Chapter 4: "Retrospective Versus Real-time" Paper ...................................... 144

4.1 Introduction................................................................................................................. 144

4.2 Abstract ................................................................................................................ 144

4.3 "Retrospective Versus Real-time" paper............................................................. 145

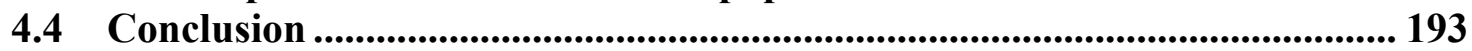

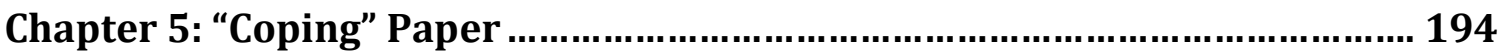

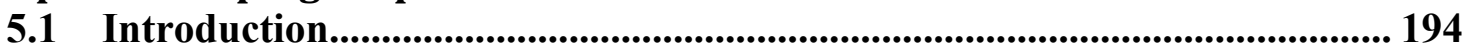

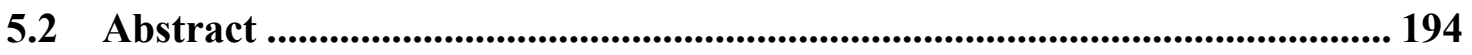

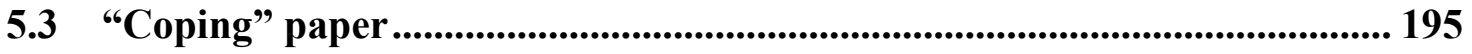

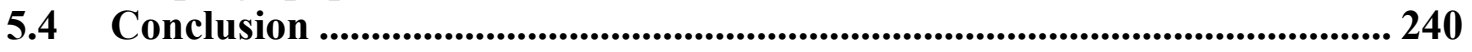

Chapter 6: Conclusion .............................................................................. 241

6.1 Research on sensemaking about organizational change …….......................... 241

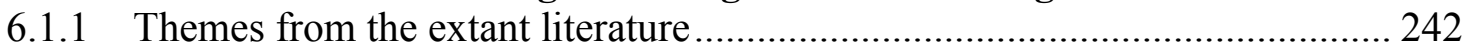

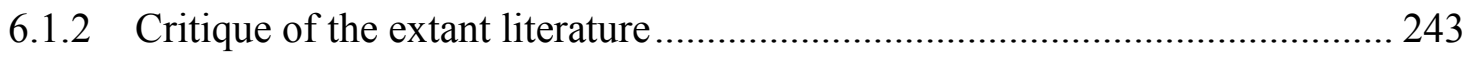

6.2 Contribution of thesis.................................................................................. 245

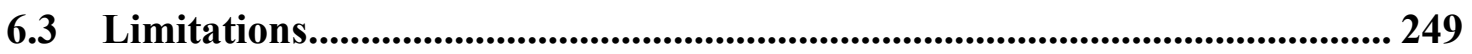

6.4 Implications for future research....................................................................... 252

6.5 Implications for practice ................................................................................. 253

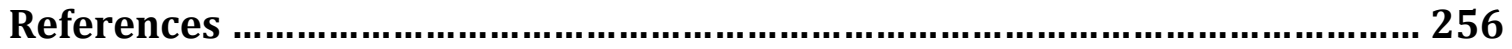

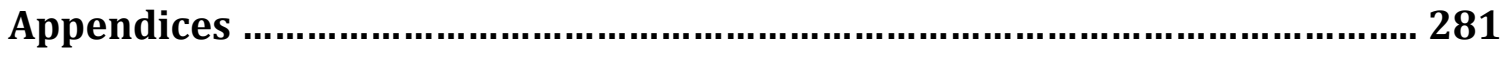




\section{List of Tables}

Table 1-1: Sensemaking related constructs (Maitlis \& Christianson, 2014, p. 69) ...........15

Table 1-2: Forms of sensemaking (Maitlis \& Christianson, 2014, p. 68) .........................17

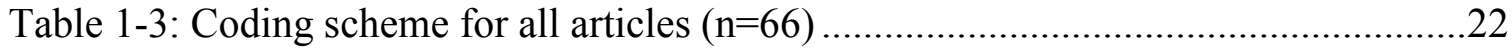

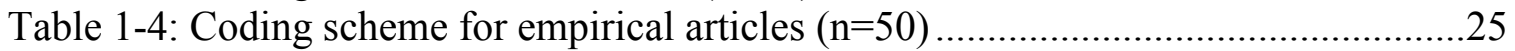

Table 1-5: Methodological approach for studying sensemaking about change................28

Table 1-6: General descriptions of how sensemaking about change was studied .............31

Table 1-7: Samples for studying sensemaking and change ...........................................

Table 1-8: Data collection techniques for studying sensemaking and change ................36

Table 1-9: Research on sensemaking about change over time at the individual level ......38

Table 1-10: Findings about sensemaking and change ..............................................42

Table 2-1: Three epistemologies in qualitative management research (based on Lincoln et

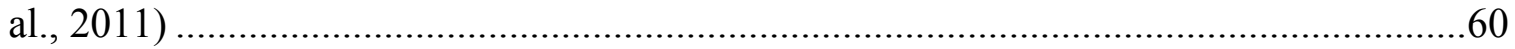

Table 2-2: Implications of using interpretive epistemology for thesis .........................63

Table 2-3: Objectivist vs constructivist grounded theory (from Charmaz, 2009, p. 141).67

Table 2-4: Larger data set data collection at Community Hospital over time ...................79

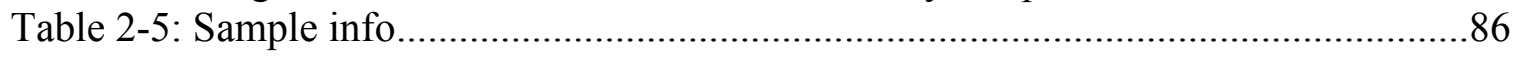

Table 2-6: Trustworthiness criteria (from Shah \& Corley, 2006, p. 1830) .....................99

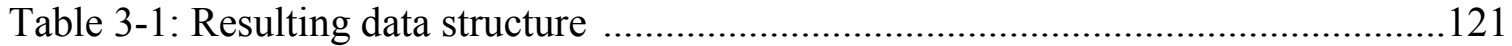

Table 4-1: Retrospective sensemaking about work environment change (from T3

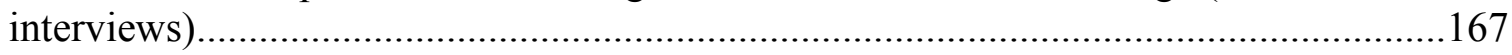

Table 4-2: Retrospective sensemaking about work environment change (\% change role,

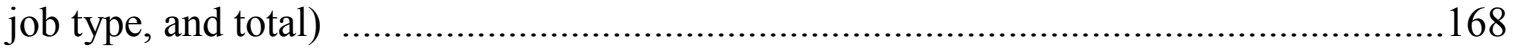

Table 4-3: Findings ( $\%$ by change role, job type and total)......................................173

Table 4-4: Real-time assessment of work environment versus retrospective accounts of

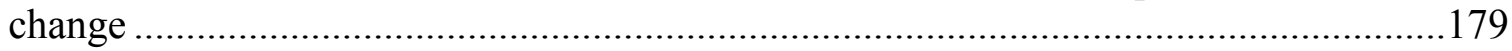

Table 5-1: Resulting data structure (coping with organizational change) ......................217

Table 5-2: Resulting data structure (sensemaking about organizational change)............223 


\section{List of Figures}

Figure 1-1: Approaches to studying change (Van de Ven \& Poole, 2005: p. 1387) ..........8

Figure 1-2. Number of sensemaking about change articles by publication year ..............24

Figure 1-3: Research on sensemaking about change over time at the individual level .....37

Figure 2-1: Research approach in three papers...........................................................58

Figure 2-2: Timeline of change and data collection .................................................... 73

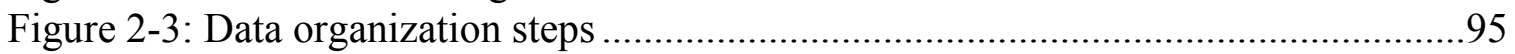

Figure 3-1: Timeline of change at Community Hospital ...........................................114

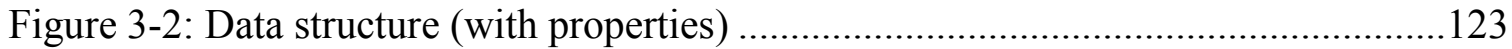

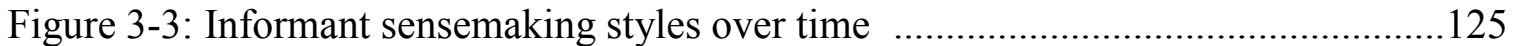

Figure 4-1: Timeline of reorienting change and data collection...................................149

Figure 4-2: Real-time assessment of work environment patterns ................................176

Figure 5-1: Comparing the coping and sensemaking processes .................................206

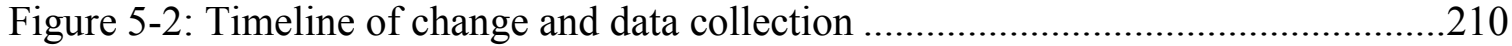

Figure 5-3: Sensemaking styles based on dual sensemaking frames............................227

Figure 5-4: Final data structure, coping style patterns mapped onto sensemaking styles

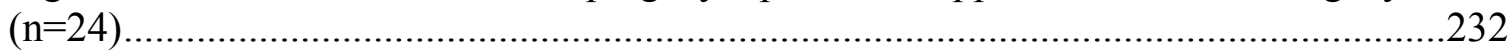

Figure 6-1: Contributions to our understanding of the sensemaking process over time .246

Figure 6-2: Parallel macro level cognitive processes in "Retrospective versus Real-time"

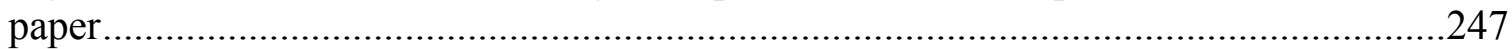

Figure 6-3: Processes within a process in the "Sensemaking Lenses" paper .................248

Figure 6-4: Parallel processes in the "Coping" paper .................................................249 


\section{List of Appendices}

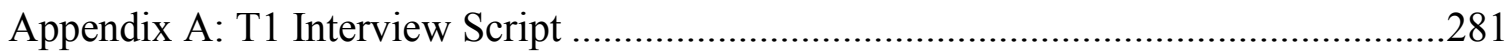

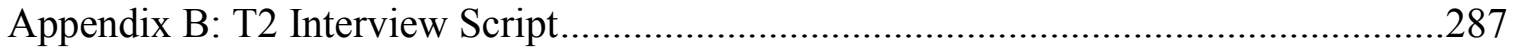

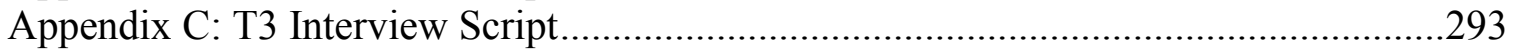

Appendix D: Examples of Observations Conducted ..................................................297

Appendix E: Examples of Available Documents ...................................................298 


\section{Introduction}

In order to survive and thrive in an increasingly turbulent and competitive business environment many organizations undergo change. These changes range from large scale planned organizational wide transformations to structure and culture to changes to organizational leadership, membership and/or the way work is done in particular areas/units (Huber, Sutcliffe, Miller, \& Glick, 1993). Much of the extant research on change management tends to focus on larger scale planned change initiatives (Burke, Lake, \& Paine, 2009). These studies have reported that most organizational change initiatives fail (Burnes, 2009; Senturia, Flees, \& Maceda, 2008). Other scholars note that change takes a long time (between two and 15 years) (Smith, 2003) to implement successfully because each organizational level and unit involved needs time to go through the process of understanding and integrating the changes (Heracleous \& Barrett, 2001; Riesenmy, 2010; Stensaker, Falkenberg, \& Gronhaug, 2008). It follows, therefore, that research that focuses on how individuals make sense of organizational change over time would allow researchers and practitioners to better understand the circumstances and processes related to successful (and/or unsuccessful) change implementation.

Traditional research that considers individuals and organizational change focuses on individuals' attitudes towards change (Choi, 2011) and their responses to change (Bouckenooghe, 2010). This literature, while robust, is limited by the fact that most of these empirical studies tend to employ variance, as opposed to process oriented, research methods (Bouckenooghe, 2010; Oreg, Vakola, \& Armenakis, 2011). Variance research studies of organizational change often utilize quantitative data and focus on antecedents 
and consequences of change (Van de Ven \& Poole, 2005). Process oriented studies, however, focus on how the process of change unfolds over time (Van de Ven \& Poole, 2005 ) and would be particularly helpful for understanding how individuals make sense of organizational change over time.

Despite the dominance of variance studies in the extant literature on individuals and organization change, there is a small but growing body of work on sensemaking and organizational change (Maitlis \& Christianson, 2014) which is mostly comprised of process-oriented studies. This is not surprising given Langley's (1999) observation that sensemaking itself is a process and is best understood through the use of process research methods (Langley, 1999). Sensemaking refers to the iterative and ongoing process by which individuals make plausible sense retrospectively of their situation (Weick, Sutcliffe, \& Obstfeld, 2005). This thesis contributes to the sensemaking about organizational change literature by undertaking three longitudinal studies at a community hospital (herein called "Community Hospital") undergoing planned transformative organizational change.

Community Hospital is a rural hospital that employs about 400 individuals (including appointed contracted physicians). The sheer amount of change that Community Hospital has experienced since 2009 - the time that the data collection efforts associated with this thesis began - makes this hospital an "extreme" case of the phenomena I wish to study (i.e. organizational change). An extreme case is a case selected for its potential to yield rich data that is likely to lead to revelatory findings (Langley \& Abdallah, 2011). The involvement of Community Hospital in this longitudinal case study, therefore, gives me the kind of rich data needed to appreciate and 
better understand informants' sensemaking (Langley \& Abdallah, 2011) about organizational change over time.

The underlying objective of the three qualitative studies featured in this thesis is to understand how individuals make sense of organizational change over time from an emic (i.e. insider) perspective. The first study explores the lenses that individuals' use to make sense of significant organizational change over time. This paper identifies the particular sensemaking lenses informants use and examines how these lenses act over time at the individual-level (i.e. the variation or constancy of the sensemaking lens). The second study focuses on individuals' retrospective sensemaking about organizational changes. This study considers how sensemaking and cognitive bias theories can be used in a complementary way to explain how informants' retrospective sensemaking about change (i.e. when "looking back in time at change") compares with their real-time assessments captured throughout the course of the organizational change. Finally, the third study adds to our understanding how individuals cope with organizational change over time. This paper, which conceptualizes coping and sensemaking as overlapping cognitive processes, explores what individuals do (behaviorally and emotionally) to deal with organizational change and looks at how these coping strategies vary over the course of a five-year period of organizational change.

All three studies are interpretive case studies that employ grounded theory data techniques to analyze qualitative longitudinal data gathered from surveys, focus groups, observations and interviews undertaken at Community Hospital. The interview data that forms the backbone of the three papers were taken from an organizationally representative sample of 26 hospital employees (managers, doctors, nurses, other staff) at 
three different points in time $(2009,2012$ and 2013). Transcripts from these 26 sets of interviews serve as the focus of the data analysis.

The papers that are featured in this thesis differ in a number of key ways from existing work on sensemaking about organizational change. First, to date, much of the research on sensemaking has not thoroughly explored individuals' sensemaking about change over time (Langley, Smallman, Tsoukas, \& Van de Ven, 2013). The studies that comprise the thesis enhance researchers' and practitioners' understanding of organizational change by illuminating how organizational change is experienced and viewed from an insider perspective over time. Methodologically, the study makes use of longitudinal interview data. The benefit of this approach is that findings from these three studies yield novel insights related to how individuals view and experience change over time. Managers and practitioners can use findings from these studies on how individuals make sense of change over time to develop strategies for implementing change, which should increase the chances that a planned change initiative will be accepted by the individuals involved in the change. Findings from empirical research about individuals and change show that such involvement is critical for the long-term success of organizational changes (Bouckenooghe, 2010; Oreg et al., 2011). Second, findings from this thesis also add to the growing body of literature that takes a process approach to study organizational change. Process oriented research has been praised by scholars for more closely reflecting the lived realities of organizational change over time (Langley et al., 2013; Van de Ven \& Poole, 2005).

This thesis is structured into six different chapters. Chapter 1 is the literature review, which aims to familiarize the reader with the approaches to researching 
organizational change, the sensemaking perspective and work on sensemaking and organizational change that is relevant to the thesis. This chapter also identifies and explains a gap in this work, which motivates the overall objective for the thesis. Chapter 2 is the methods chapter, which provides an overview of the common methodological assumptions (i.e. interpretive and constructivist), study design (i.e. case study) and data analysis approach (i.e. grounded theory techniques) that are utilized in the three studies. An overview of the case organization, Community Hospital, as well as the data collection techniques employed in these studies are also provided in this chapter. Chapters 3, 4 and 5 are the "Research Paper" chapters, which include the three papers that comprise this thesis. Chapter 3 includes paper one, called the "Sensemaking Lenses" paper, which is about the lenses individuals use to make sense of organizational change over time. Paper two is named the "Retrospective versus Real-time" paper. This paper looks at individuals" retrospective sensemaking about organizational change and is presented in Chapter 4. The third paper, called the "Coping" paper, is about how individuals cope with organizational change over time. This paper is featured in Chapter 5. Finally, Chapter 6 is the conclusion to this thesis. In this chapter some limitations of this thesis are discussed and key contributions of the research are summarized. 


\section{Chapter 1: Literature Review}

The purpose of this chapter is to familiarize the reader with the relevant work on sensemaking and organizational change that forms the background of the thesis. This chapter is structured as follows. Section 1.1 explains different approaches for researching change and clarifies the approach adhered to in the thesis. Next, section 1.2 describes sensemaking, the theoretical lens for the studies included in the thesis. Section 1.3 reviews the empirical work on sensemaking about organizational change. The findings from this review are used to identify gaps in this area that serve as the motivation for the thesis. These gaps and the objective of the thesis are identified and explained in section

\section{4 .}

\subsection{Approaches to studying change}

This section of the literature review clarifies for the reader the overall approach to studying organizational change taken in this thesis. According to Van de Ven and Poole (2005) there are four different approaches to studying change. These approaches are discussed in detail here to give the reader a strong sense of the overall strategy for studying change used in the thesis. Section 1.1.1 provides a brief description of Van de Ven and Poole's (2005) typology of ways to study change. Section 1.1.2 presents a more detailed discussion of the approach adhered to in the study (i.e. process narrative, also referred to as "process" approach).

\subsubsection{Van de Ven and Poole's (2005) typology}

Van de Ven and Poole (2005) suggest that a researcher's method for studying organizational change depends first on how they conceptualize "change" and second on 
how they conceptualize the "organization". They note that researchers can conceptualize "change" as either a process or a variable. Researchers that view change as a variable employ what Van de Ven and Poole (2005) refer to as a "variance method", which defines change as "an observed difference over time in an organizational entity" (Van de Ven \& Poole, 2005, p. 1380). Researchers that view change as a process, on the other hand, use what is referred to as "process narrative", which defines change as "a narrative describing a sequence of events on how development and change unfold" (Van de Ven \& Poole, 2005, p. 1380). Van de Ven and Poole (2005) also distinguish between researchers who define "organizations" as a noun (i.e. social actor, "thing") versus a verb (i.e. a process of organizing, emergent flux) (Van de Ven \& Poole, 2005). Van de Ven and Poole (2005) use the above distinctions to propose a typology, which describes four different approaches to researching change (see Figure 1-1). Van de Ven and Poole (2005) also note that most studies do not explicitly identify which of the four approaches they adhere to but rather can be more easily differentiated as following a process narrative or variance study approach in their examination of organizational change. 
Figure 1-1: Approaches to studying change (Van de Ven \& Poole, 2005: p. 1387)

\begin{tabular}{|c|c|c|c|}
\hline & \multicolumn{2}{|c|}{$\begin{array}{c}\text { Ontology } \\
\text { An organization is represented as being: }\end{array}$} \\
\hline & & $\begin{array}{l}\text { A noun, a social actor, a } \\
\text { real entity ('thing') }\end{array}$ & $\begin{array}{l}\text { A verb, a process of } \\
\text { organizing, emergent flux }\end{array}$ \\
\hline 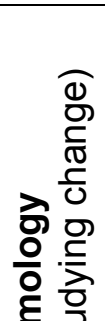 & Variance method & $\begin{array}{l}\text { Approach I } \\
\text { Variance studies of change } \\
\text { in organizational entities by } \\
\text { causal analysis of } \\
\text { independent variables that } \\
\text { explain change in entity } \\
\text { (dependent variable) }\end{array}$ & $\begin{array}{l}\text { Approach IV } \\
\text { Variance studies of } \\
\text { organizing by dynamic } \\
\text { modeling of agent-based } \\
\text { models of chaotic } \\
\text { complex adaptive } \\
\text { systems }\end{array}$ \\
\hline 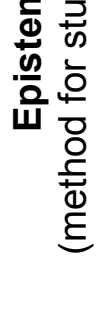 & Process narrative & $\begin{array}{l}\text { Approach II } \\
\text { Process studies of change } \\
\text { in organizational entities } \\
\text { narrating sequence of } \\
\text { events, stages or cycles of } \\
\text { change in the development } \\
\text { of an entity }\end{array}$ & $\begin{array}{l}\text { Approach III } \\
\text { Process studies of } \\
\text { organizing by narrating } \\
\text { emergent actions and } \\
\text { activities by which } \\
\text { collective endeavors } \\
\text { unfold }\end{array}$ \\
\hline
\end{tabular}

Variance approaches are commonly used by researchers studying planned organizational change (Lee, Weiner, Harrison, \& Belden, 2013) as well as those investigating individuals and organizational change (Bouckenooghe, 2010; Oreg et al., 2011). In Lee et al.'s (2013) review of 56 studies of planned organizational change $86 \%$ of the studies reviewed focused on antecedents and/or consequences of planned change and only $25 \%$ considered the process(es) of change. In Bouckenooghe's (2010) review of empirical studies about change recipients attitudes $89 \%$ of the 48 reviewed studies relied on quantitative data collection and variance based methods. Furthermore, Oreg et al.'s (2011) review of reactions to organizational change focused exclusively on quantitative empirical studies ( $\mathrm{n}=79$ ), which could be seen as indicative of the prevalence of quantitative methods for studying individuals and change. 
There is growing sentiment among scholars and practitioners that extant research and theory does not represent the lived reality of organizational change (Beech \& Johnson, 2005; Burnes \& Cooke, 2012; Marshak, 2002; Oswick, Grant, Michelson, \& Wailes, 2005; Tsoukas \& Chia, 2002; Van de Ven \& Sun, 2011). The prevalence of variance methods for studying individuals and change can be seen as additional evidence of this gap, which is reflective of the etic epistemology (Morris, Kwok, Ames, \& Lickel, 1999). Epistemology refers to one's philosophical "assumptions about knowledge, and how it can be obtained" (Myers, 2009, p. 35). It is tightly linked with ones' ontology (i.e. view of the nature of reality) and can range along a continuum of subjective to objective (Morgan \& Smircich, 1980). Etic research is more tightly aligned with objectively oriented epistemologies and ontologies and studies human beliefs and behavior by focusing on identifying an objective perspective of what is happening (i.e. an outsider/researcher perspective) (Kottak, 2006; Morris et al., 1999). Emic research, on the other hand, is more closely aligned with subjectively oriented epistemologies and ontologies and studies human beliefs and behavior by focusing on uncovering the perspective of the insider (i.e. the individual or group being studied) (Denison, 1996; Morris et al., 1999). The variance method for studying change is consistent with the etic epistemology while the process narrative approach is more closely aligned to the emic epistemology.

\subsubsection{Approach employed in this thesis}

The study undertaken in this thesis can be characterized as employing what in Van de Ven's and Poole's (2005) typology is labeled Approach II. Approach II conceptualizes change as a process and the organization as a thing (Van de Ven \& Poole, 
2005). This thesis conceptualizes change as a process in hopes that its findings will more closely reflect the "emic" lived experience of organizational change (Langley, 1999). The organization is viewed as a thing, on the other hand, because this is consistent with how both the author and the study participants conceptualize Community Hospital (as a social actor or "real" entity).

The use of the process narrative approach in this thesis has three key implications for how the research is done. First, process narrative studies adopt process methodologies. This means that rather than focusing on antecedents and outcomes of change, process narratives are primarily interested in research questions that examine how change unfolds within organizations over time (Van de Ven \& Poole, 2005). Second, because process narrative studies are interested in understanding how change unfolds by understanding change from the emic (i.e. informants') perspective this approach pairs well with qualitative data collection and analysis. Third, process narrative methodologies encourage researchers to examine sensemaking (Van de Ven \& Poole, 2005). Accordingly, the remainder of this literature review is focused on explaining sensemaking and reviewing the body of empirical work on sensemaking about organizational change.

\subsection{Sensemaking}

Organizational cognition is an area of organizational research that focuses on how managers process information (Hodgkinson \& Healey, 2008). Its five major theoretical streams include: (1) schema theory, which investigates mental models, (2) behavioral decision theory, which examines cognitive biases, (3) attribution theory, which looks at 
how individuals make inferences about behaviour, (4) social identity theory, which considers the impact of social group membership on intergroup behaviours, and (5) sensemaking. Sensemaking is defined as a process that individuals use in order to understand unexpected, ambiguous or confusing events (Maitlis \& Christianson, 2014). Sensemaking involves "the ongoing retrospective development of plausible images that rationalize what people are doing" (Weick et al., 2005, p. 409).

The objective of this section of the literature review is to introduce the sensemaking perspective ${ }^{1}$, which is the theoretical lens utilized in the three studies that make up this thesis. This part of the literature review is comprised of four sections. First, section 1.2.1 reviews the seven properties of sensemaking. Second, section 1.2.2 describes the three aspects of the sensemaking process. Third, in section 1.2.3 the literature is used to explain key sensemaking concepts (e.g., sensegiving) of relevance to the thesis. Finally, section 1.2.4 reviews what is known about some specific forms of sensemaking in order to familiarize the reader with the "forms of sensemaking" that have been identified by scholars.

\subsubsection{Properties of sensemaking}

Sensemaking is a recipe for understanding how individuals make sense of their environment (Weick, 1995). Seven properties of sensemaking were identified by Weick in the 1995 seminal book Sensemaking in Organizations. These seven properties can be summarized as follows: (1) Sensemaking is grounded in identity construction, meaning

\footnotetext{
${ }^{1}$ Sensemaking has been referred to by others as a perspective (Weick, 1999), theory(Allard-Poesi, 2005), framework and lens (Maitlis \& Christianson, 2014) According to Sandberg and Tsoukas (2015) the "sensemaking perspective" is the most common phrase used to refer to this approach for studying organizational phenomena. Sensemaking "perspective" is also the phrase used by Weick (1995). Accordingly, consistent with work by Weick (1995) and Sandberg and Tsoukas (2015) this thesis proposal uses the term "sensemaking" to refer to the "sensemaking perspective".
} 
individuals' identities will influence how they interpret events. (2) Sensemaking is retrospective, meaning it is a process by which individuals can interpret past events. (3) Sensemaking is enactive, meaning that it is a process that allows individuals to translate meaning into action. (4) Sensemaking is social, meaning individuals consult others and talking is central to how sense is made of events. (5) Sensemaking is ongoing and iterative, meaning the individual concurrently influences and is influenced by their environment. (6) Sensemaking is driven by plausibility rather than accuracy, meaning that individuals will select meaningful explanations over others regardless of accuracy. And, (7) Sensemaking focuses on extracted clues, meaning that individuals will observe environmental cues that further support their beliefs or cause them to abandon certain beliefs (Weick, 1995).

Taken together these seven properties reflect Weick's view that the sensemaking process is "not about truth and getting it right. Instead, it is about continued redrafting of an emerging story so that it becomes more comprehensive, incorporates more of the observed data, and is more resilient in the face of criticism" (Weick et al., 2005, p. 415).

\subsubsection{The sensemaking process}

Theoretically, the process of sensemaking is conceptualized as consisting of three distinct yet related processes named triggering, interpretation and action (Brown, Colville, \& Pye, 2014; Maitlis \& Christianson, 2014; Sandberg \& Tsoukas, 2015). The first step in the sensemaking process is often referred to as "triggering" (Maitlis \& Christianson, 2014). Researchers contend that sensemaking occurs when the sensemaking process is triggered by ambiguous or unexpected events and situations (Maitlis \& Christianson, 
2014). In the organizational context the types of events believed to "trigger" sensemaking vary and include major and minor, planned and unplanned events that disrupt organizational members' ongoing activities in a way that causes individuals to retrospectively make sense of the event (Sandberg \& Tsoukas, 2015). The types of trigger events typically studied include organizational crises (e.g., Bhopal disaster research by Weick, 1988, 2010), threats to social identities (e.g., research on organizational identity threat and ambiguity by Corley \& Gioia, 2004), and planned organizational change interventions (e.g., research about how middle managers make sense of change by Balogun, 2003, 2006).

Interpretation, the second part of the sensemaking process, refers to the specific process that individuals undergo when attempting to make sense of the ambiguous or unexpected events (Weick, 1995). The interpretation process involves assessing the information gained during the initial triggering stage of the sensemaking process in order to develop "it into a more complete and narratively organized sense" of the situation or event (Sandberg \& Tsoukas, 2015, p. S14). It is at this stage in the sensemaking process that individuals may label and categorize aspects of the situation they are making sense of (Weick et al., 2005). The use of cognitive frames or schemas to simplify information for interpretation (Balogun \& Johnson, 2004), also referred to as "framing" (Kaplan, 2008, 2011) can occur during this stage of sensemaking. Conceptually, cognitive frames, also called "mental models", are thought to guide one's interpretation of events and act as a lens through which one interprets organizational phenomena (Kaplan, 2008).

After an individual makes sense of the triggering event or situation the final stage of sensemaking is hypothesized as involving "action" or enactment (Sandberg \& Tsoukas, 
2015). According to Weick (1988) action is a central component of sensemaking because it allows the individual to explore their provisional understanding (which accumulated during the triggering and interpretation stages of the sensemaking process) and it creates more information for future sensemaking. Action (or enactment) is seen to occur when one acts based on their newfound understanding of the situation (Weick et al., 2005).

These three processes are conceptualized as a cycle that recurs until the individual is able to resolve the unexpected event and any related unexpected or ambiguous situations that unfold (Sandberg \& Tsoukas, 2015).

\subsubsection{Sensemaking concepts}

Researchers have introduced a number of different sensemaking related constructs over the years (see Table 1-1). Examples of such constructs include: sensedemanding which refers to intense efforts to obtain and process information (Vlaar, van Fenema, \& Tiwari, 2008); "sense-exchanging" which is about the negotiation of organizational identity (Ran \& Golden, 2011); "sensebreaking" when meaning is broken down or destructed (Pratt, 2000); "sensehiding" when alternative views of situations are marginalized (Vaara \& Monin, 2010); and "sense specification" which involves the creation and use of norms for sensemaking (Monin, Noorderhaven, Vaara, \& Kroon, 2013). These constructs contribute to varying degrees to the current understanding of how sensemaking occurs. 
Table 1-1: Sensemaking related constructs (Maitlis \& Christianson, 2014, p. 69)

\begin{tabular}{|l|l|}
\hline \multicolumn{1}{|c|}{ Construct } & \multicolumn{1}{c|}{ Definition } \\
\hline Sensegiving & $\begin{array}{l}\text { "attempting to influence the sensemaking and meaning construction } \\
\text { of others toward a preferred redefinition of organizational reality." } \\
\text { (Gioia \& Chittipeddi, 1991, p. 442) }\end{array}$ \\
\hline Sensebreaking & "the destruction or breaking down of meaning." (Pratt, 2000, p. 464) \\
\hline Sensedemanding & $\begin{array}{l}\text { "strenuous efforts to acquire and process information so as to } \\
\text { establish 'a workable level of uncertainty' and equivocality (Weick } \\
1969, \text { p. 40)." (Vlaar et al., 2008, p. 240) }\end{array}$ \\
\hline $\begin{array}{l}\text { Sense- } \\
\text { exchanging }\end{array}$ & $\begin{array}{l}\text { "different conceptions of organization are negotiated to socially } \\
\text { construct the identity of an organization." (Ran \& Golden, 2011, p. } \\
421)\end{array}$ \\
\hline Sensehiding & $\begin{array}{l}\text { "silencing alternative senses of integration or marginalization of } \\
\text { particular voices." (Monin et al., 2013, p. 262) }\end{array}$ \\
\hline $\begin{array}{l}\text { Sense } \\
\text { specification }\end{array}$ & $\begin{array}{l}\text { "specification of explicit or implicit norms . . . coining of principles, } \\
\text { exemplary decisions and actions, symbolization, and quantification." } \\
\text { (Monin et al., 2013, p. 262) }\end{array}$ \\
\hline
\end{tabular}

With one exception (sensegiving) the majority of these sensemaking constructs have not received much attention in the research literature. The sensegiving construct is, however, quite popular among scholars (Maitlis \& Christianson, 2014) and, as such, requires additional explanation.

Sensegiving is defined as "attempting to influence the sensemaking and meaning construction of others toward a preferred redefinition of organizational reality" (Gioia \& Chittipeddi, 1991, p. 44). Sensegiving is important to our understanding of the sensemaking construct because it illustrates how individuals can purposefully attempt to impact how others make sense of situations and events. In other words, sensegiving typically involves the creation of meanings by leaders for a target audience (Gioia \& Chittipeddi, 1991; Maitlis \& Christianson, 2014). The sensegiving construct is particularly popular within the sensemaking research about planned organizational change (e.g., Dunford \& Jones, 2000; Hope, 2010; Kezar, 2013) and as such is relevant to 
the thesis, which seeks to look at how individuals make sense of organizational change over time.

\subsubsection{Forms of sensemaking}

Research on sensemaking has also lead to the development of a number of different constructs that Maitlis and Christianson (2014) refer to as "forms of sensemaking". These "forms of sensemaking", defined in Table 1-2, relate to sensemaking in one of four ways. First, some refer to the context within or for which the sense is made. For example, "ecological sensemaking" is about sensemaking of ecological processes (Whiteman \& Cooper, 2011) and "market sensemaking” (Kennedy, 2008) looks at the sensemaking of markets. Second, some refer to the nature of the triggers of the sensemaking. For example, intercultural sensemaking occurs when individual sensemaking is triggered by cultural values and cultural history (Fisher \& Hutchings, 2013), and interpersonal sensemaking is triggered by cues from others at work (Wrzesniewski Dutton, \& Debebe, 2003). Third, some of the forms of sensemaking included in Table 1-2 were identified by researchers who were challenging particular assumptions about the properties of sensemaking and/or the sensemaking process. Two examples of this are prospective (Gioia, Thomas, Clark, \& Chittipeddi, 1994) and futureoriented sensemaking (Gephart, Harrison, \& Trevino, 2010), both of which refer to temporality and potentially challenge the retrospective nature of sensemaking. 
Table 1-2: Forms of sensemaking (Maitlis \& Christianson, 2014, p. 68)

\begin{tabular}{|l|l|}
\hline \multicolumn{1}{|c|}{ Form } & \multicolumn{1}{c|}{ Definition } \\
\hline $\begin{array}{l}\text { Ecological } \\
\text { sensemaking }\end{array}$ & $\begin{array}{l}\text { "the process used to make sense of material landscapes and } \\
\text { ecological processes." (Whiteman \& Cooper, 2011, p. 889) }\end{array}$ \\
\hline Market sensemaking & $\begin{array}{l}\text { "a macro version of Weick's approach to meaning construction in } \\
\text { organizations." (Kennedy, 2008, p. 272). }\end{array}$ \\
\hline $\begin{array}{l}\text { Intercultural } \\
\text { sensemaking } \\
\text { "the process involving the selection of scripts that reflect } \\
\text { individuals' cultural values and cultural history." (Fisher \& }\end{array}$ \\
\hline $\begin{array}{l}\text { Interpersonal } \\
\text { sensemaking }\end{array}$ & $\begin{array}{l}\text { "the role of interpersonal cues from others in helping employees } \\
\text { make meaning from their jobs, roles, and selves at work." } \\
\text { (Wrzesniewski et al., 2003, p. 102) }\end{array}$ \\
\hline $\begin{array}{l}\text { Prospective } \\
\text { sensemaking }\end{array}$ & $\begin{array}{l}\text { "the conscious and intentional consideration of the probable future } \\
\text { impact of certain actions, and especially nonactions, on the } \\
\text { meaning construction processes of themselves and others." (Gioia } \\
\text { et al., 1994, p. 378) }\end{array}$ \\
\hline $\begin{array}{l}\text { Future-oriented } \\
\text { sensemaking }\end{array}$ & $\begin{array}{l}\text { "Sensemaking that seeks to construct intersubjective meanings, } \\
\text { images, and schemes in conversation where these meanings and } \\
\text { interpretations create or project images of future objects and } \\
\text { phenomena." (Gephart et al., 2010, p. 285) }\end{array}$ \\
\hline $\begin{array}{l}\text { Prosocial } \\
\text { sensemaking }\end{array}$ & $\begin{array}{l}\text { "process in which employees interpret personal and company } \\
\text { actions and identities as caring." (Grant et al., 2008, p. 898) }\end{array}$ \\
\hline $\begin{array}{l}\text { Environmental } \\
\text { sensemaking }\end{array}$ & $\begin{array}{l}\text { "actors make sense not only of the event itself, but of the broader } \\
\text { organizational field." (Nigam \& Ocasio, 2010, p. 826) }\end{array}$ \\
\hline $\begin{array}{l}\text { Resourceful } \\
\text { sensemaking }\end{array}$ & $\begin{array}{l}\text { "the ability to appreciate the perspectives of others and use this } \\
\text { understanding to enact horizon-expanding discourse." (Wright et } \\
\text { al., 2000, p. 807) }\end{array}$ \\
\hline
\end{tabular}

Finally, some of the forms of sensemaking included in this table refer to specific goals or outcomes of the sensemaking process. For instance, prosocial sensemaking describes how individuals can undertake sensemaking to interpret a firm as particularly “caring' (Grant, Dutton, \& Rosso, 2008), environmental sensemaking allows individuals' to make sense of a broader organizational environment (Nigam \& Ocasio, 2010), and resourceful sensemaking results in individuals' having a broader understanding of a situation through their appreciation of others' perspectives (Wright, Manning, Farmer, \& Gilbreath, 2000). Findings from this thesis could include implications for the forms of 
sensemaking developed by other scholars. Alternatively, some thesis findings may point to the need for additional forms of sensemaking related to organizational change.

\subsection{Sensemaking about organizational change}

Organizational change is defined in this thesis as differences over time "in how an organization functions, who its members and leaders are, what form it takes or how it allocates its resources" (Huber et al., 1993, p. 216). Change is a dominant topic within the organizational sensemaking literature (Maitlis \& Christianson, 2014; Maitlis \& Sonenshein, 2010), probably due to the fact that change provides a salient context for sensemaking activities. Many change and sensemaking scholars note that organizational change events create ambiguity for individuals, which acts as a trigger for individual and collective sensemaking processes (Balogun, 2003; Balogun \& Johnson, 2005; Maitlis \& Sonenshein, 2010; Weick, 1995). Furthermore, some posit that sensemaking and sensegiving processes are key activities during organizational change (Balogun, 2003; Luscher \& Lewis, 2008; Rouleau, 2005).

The objective of this part of the literature review is to review the existing empirical and conceptual work on sensemaking about organizational change in order to identify both what research has already been done in this area as well as determine any gaps in this body of work. The identification of these gaps is important as they motivate the research objectives for this thesis.

The following part of the chapter is comprised of three sections. First, the procedure used to identify the group of 66 articles on sensemaking about organizational change is described in section 1.3.1. Next an in-depth review of the 50 empirical articles 
identified is provided in sections 1.3.2 and 1.3.3. This review identifies a gap in this literature that is used to develop the primary objective of the thesis. Section 1.3.2 summarizes the approaches to studying sensemaking about change, including methodological approaches, how sensemaking about change is studied, data collection techniques, and samples. Section 1.3.3 presents key findings related to sensemaking about change.

\subsubsection{Procedure for identifying articles}

The following procedure was used to identify the relevant articles on sensemaking about change that are reviewed in this section. For the purpose of this literature review the term "relevant" refers to articles that look at sensemaking about organizational change. This means that articles about sensemaking but not in the context of or related to organizational change were not included in the review. Similarly, articles about organizational change that do not specifically consider sensemaking were also not included in this review.

\subsubsection{Initial search}

Initially, scholarly papers about sensemaking and organizational change published within peer-reviewed management journals were sought out via an electronic data base search. A Boolean search using the terms "sensemaking" and "organizational change" was conducted using Business Source Complete. The initial search produced 122 results. The titles and abstracts for each of these 122 articles were reviewed in order to determine relevance (i.e. did the papers look at sensemaking about organizational change). Many of the search results were "irrelevant" to this review of sensemaking about organizational 
change because they related to one but not both of these topics. Examples of papers uncovered by the initial search that were deemed to be outside the scope of this review include Thomas, Clark and Gioia's (1993) study about sensemaking and organizational performance and Reissner's (2010) study about identity and organizational change. In total 40 of the 122 articles from the search were deemed relevant to sensemaking about organizational change.

\subsubsection{Snowball technique}

At this point I read each of the 40 articles that made it through the "first triage" of the papers identified through the database search and noticed that these articles often cited other papers that appeared to be related to sensemaking about organizational change but that did not appear in the list of 122 papers that were identified by searching Business Source Complete. These discrepancies suggested that a more complete list of relevant papers could be compiled by undertaking a second search using snowball techniques (i.e. I followed Ridley's (2012) suggestion and looked at the text and bibliographies of the articles that were already identified as being relevant to see if there were any other papers that may be "a match"). According to Ridley (2012) the snowball technique is useful when the following two conditions are met. First, when a literature review becomes more focused, as is the case here with the specific focus on sensemaking about organizational change. Second, when the researcher has acquired some familiarity with the literature. This second condition is met in this case as the researcher had extensive exposure to the organizational change literature (via coursework, conference papers and publications on this topic) prior to her beginning this research. For this review the snowball technique involved reading the 40 relevant articles from the initial search in order to identify 
additional potentially relevant articles. When potentially relevant articles were cited in these texts, these articles were sought out and read to determine if they were in fact appropriate. If applicable, they were added to the body of articles reviewed. Each related article identified through the snowball technique was also read in search of additional articles. This process continued until all relevant articles were identified.

In total 66 relevant articles were identified for inclusion in this literature review. The group of 66 articles includes 40 articles from the electronic search results and 26 additional articles that were identified through the snowball sampling technique.

\subsubsection{Coding the articles}

After the group of 66 articles was identified the researcher read and coded each article. A coding scheme (see Tables 1-3 and 1-4) was developed in order to facilitate the comparison of the articles. Table 1-3 includes the coding scheme used for all articles (empirical and conceptual), whereas Table 1-4 includes the coding scheme that applied exclusively the empirical articles. A Microsoft Excel document was used to capture the codes assigned to each article. All of the categories included in the coding scheme (listed in the left column of Tables 1-3 and 1-4) and some of the codes (in the right column of Tables 1-3 and 1-4) were predetermined based on particular aspects of articles typically considered in a literature review (e.g., type, journal, publication year, sample, data collection technique, findings). However, most of the specific codes (in the right column of Table 1-4) used when coding the empirical articles were emergent and created by the author when the articles were reviewed. Further details on the five-step process used to develop the coding scheme used in this literature review are provided below. 
Table 1-3: Coding scheme for all articles $(\mathrm{n}=66)$

\begin{tabular}{|c|c|}
\hline Category & Codes \\
\hline Type & $\begin{array}{l}\text { - } \text { Conceptual* }^{*}(\mathrm{n}=16) \\
\text { - } \text { Empirical* }^{(n=50)}\end{array}$ \\
\hline Journal & 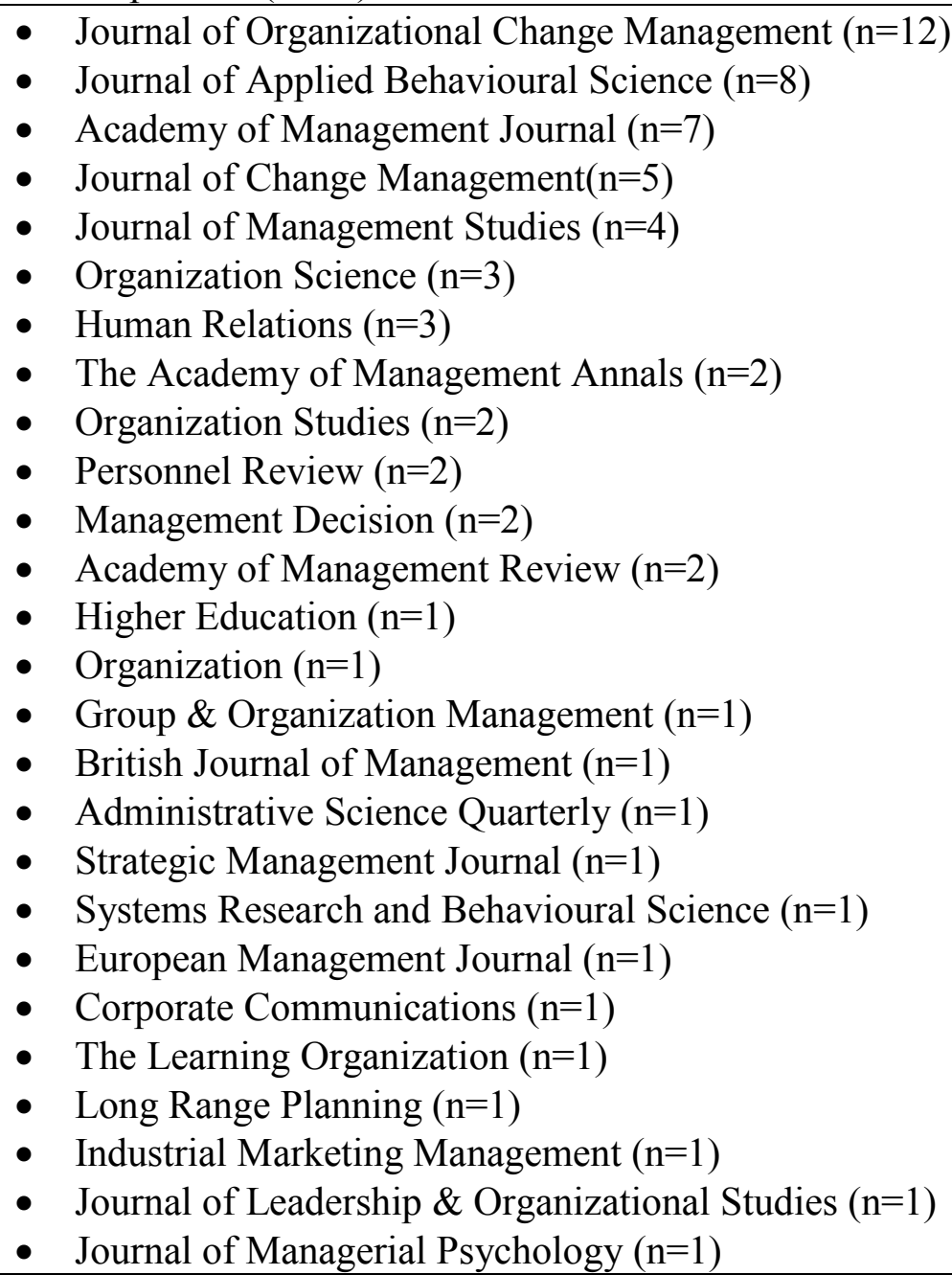 \\
\hline Publication year & $\begin{array}{ll}\text { - } & 1990-1999(\mathrm{n}=5) \\
- & 2000-2004(\mathrm{n}=9) \\
\text { - } & 2005-2009(\mathrm{n}=18) \\
\text { - } & 2010-2014(\mathrm{n}=28) \\
\text { - } & 2015(\mathrm{n}=6)\end{array}$ \\
\hline
\end{tabular}

*symbol to the right of the code indicates that the codes was predetermined

First, articles were coded according to whether they were conceptual or empirical.

The group of 66 articles identified as relevant to sensemaking about organizational change includes 50 empirical studies and 16 conceptual papers (see Table 1-3). The 
group of 16 conceptual papers consists of four literature reviews (Balogun, Jacobs, Jarzabkowski, Mantere, \& Vaara, 2014; Bartunek, Balogun, \& Do, 2011; Maitlis \& Christianson, 2014; Maitlis \& Sonenshein, 2010), three papers that present ideas related to change leaders' sensemaking or sensegiving (Kraft, Sparr, \& Peus, 2015; Moon, 2009; Weick, 2011), one paper that developed a research agenda for communication and sensemaking during change (Van Vuuren \& Elving, 2008), and another paper that applies the sensemaking perspective to Van de Ven and Poole's (2005) approaches to studying change and articulates how these approaches are useful for marketing research (Cederlund, 2015). The other seven conceptual papers propose models or frameworks related to particular aspects of sensemaking and change such as psychological contracts (Chaudhry, Wayne, \& Schalk, 2009), strategic alliances (Das \& Kumar, 2010), emotions (Steigenberger, 2015), change resistance (Ford, Ford, \& D'amelio, 2008), motivation and behavior (Kuntz \& Gomes, 2012), organizational silence (Morrison \& Milliken, 2000), and social change (Sharma \& Good, 2013).

Second, the articles were coded according to what journal they were published in (refer to Table 1-3). In total, 14 journals published only one paper on sensemaking about change. Another seven journals published two or three papers, including Human Relations and Organization Studies. Finally, a handful of high impact management journals such as the Academy of Management Journal (7 articles) and the Journal of Management Studies (4 articles) published between 4 and 12 papers on sensemaking about change.

Third, the articles were coded for their publication year (refer to Table 1-3). While the publication dates for the group of 66 articles range from 1990 to 2015, the 
majority of these manuscripts ( 61 out of 66 , or $92 \%$ ) were published after the year 2000 (see Figure 1-2 for a visual representation). The relatively recent increase in number of publications on the topic of sensemaking and change could be viewed as indicative of a surge of interest in this area and speaks to the timeliness of a thesis on this subject.

Figure 1-2. Number of sensemaking about change articles by publication year

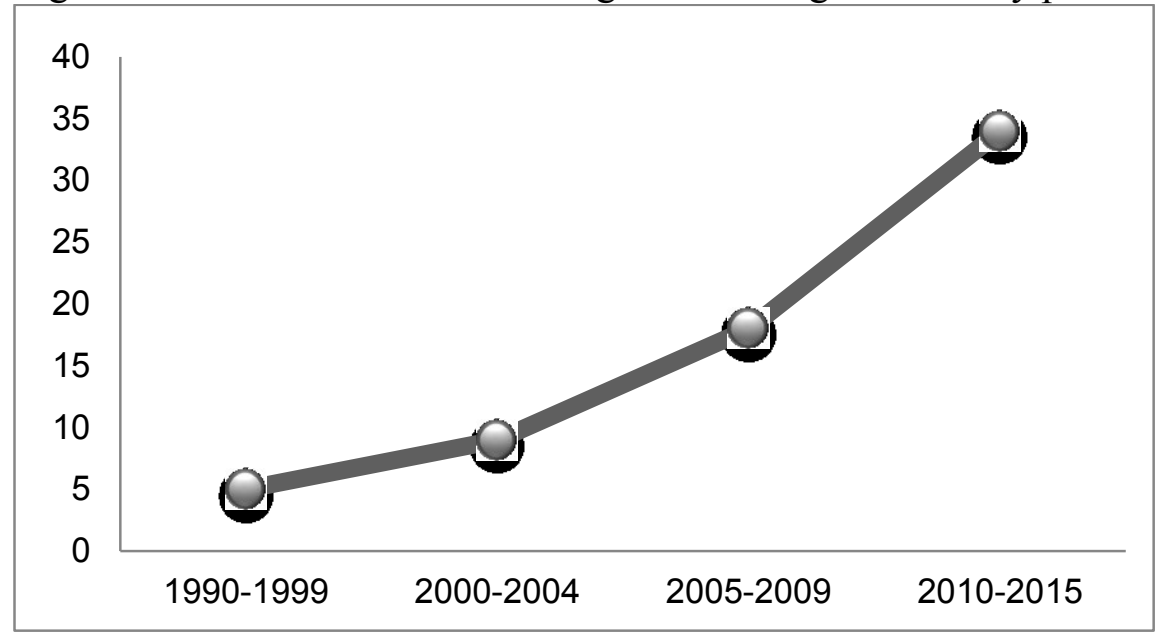

Fourth, the 50 empirical articles were coded for their approach to studying sensemaking about change. More specifically, Table 1-4 shows the codes that were created to capture how change was studied (i.e. process vs. variance), methodological approaches (i.e. qualitative, quantitative, mixed-method), how sensemaking about change is studied (i.e. terms used to describe study design and data analysis), samples used, data collection techniques, and the longitudinal aspect of each article. With one exception, "variance" and "process" methods, the codes for these categories were emergent. The variance and process codes were predetermined in order to be consistent with Van de Ven and Poole's (2005) typology for approaches to studying organizational change (explained above in section 1.1). These results of this stage of the coding process are presented in section 1.3.2. 
Table 1-4: Coding scheme for empirical articles $(\mathrm{n}=50)$

\begin{tabular}{|c|c|}
\hline Category & Codes \\
\hline $\begin{array}{l}\text { Approach to study } \\
\text { change }\end{array}$ & $\begin{array}{ll}\text { - } & \text { Process* }(n=47) \\
\text { - } & \text { Variance* }(n=3)\end{array}$ \\
\hline $\begin{array}{l}\text { Methodological } \\
\text { approach }\end{array}$ & $\begin{array}{ll}\text { - } & \text { Qualitative } \\
\text { - } & \text { Quantitative } \\
\text { - } & \text { Mixed method } \\
\end{array}$ \\
\hline $\begin{array}{l}\text { How sensemaking } \\
\text { about change is } \\
\text { studied from } \\
\text { process orientation }\end{array}$ & $\begin{array}{ll}\text { - } & \text { Case study } \\
\text { - } & \text { Grounded theory } \\
\text { - } & \text { Narrative discourse } \\
\text { - } & \text { Cthnography } \\
\text { - } & \text { Action research } \\
\text { - } & \text { Content coding } \\
\text { - } & \text { Mixed method } \\
\end{array}$ \\
\hline Data collection & $\begin{array}{ll}\text { - } & \text { Interview } \\
\text { - } & \text { Documents } \\
\text { - } & \text { Survey } \\
\text { - } & \text { Diaries } \\
\text { - } & \text { } \text { Mecus groups } \\
\end{array}$ \\
\hline Samples & $\begin{array}{ll}\text { - } & \text { Multiple groups } \\
\text { - } & \text { Middle Managers only } \\
\text { - } & \text { Senior managers only } \\
\text { - } & \text { Trontline staff only } \\
\text { - } & \text { Students }\end{array}$ \\
\hline $\begin{array}{l}\text { Longitudinal } \\
\text { nature of interview } \\
\text { data }\end{array}$ & \begin{tabular}{|l} 
- Observations \\
- Interview data \\
$\circ$ From one point in time \\
$\circ$ At $>1$ point in time \\
\\
$\quad$ - Different informants \\
\\
- Same informants \\
\end{tabular} \\
\hline Findings & $\begin{array}{ll}\text { - } & \text { Properties of sensemaking } \\
\text { - } & \text { Sensemaking process } \\
\text { - } & \text { Lenses/frames } \\
\text { - } & \text { Change related findings: } \\
\text {-Individuals } \\
\text {-Implementation } \\
\text {-Middle Managers } \\
\text {-Narratives }\end{array}$ \\
\hline
\end{tabular}

*symbol to the right of the code indicates that the codes was predetermined 
Fifth, the 50 empirical articles were coded for key findings related to sensemaking and change. The codes created are listed in Table 1-4. The results of this coding process (which was also emergent) are presented in section 1.3.3.

\subsubsection{How is sensemaking about change studied?}

This section reviews the 50 empirical articles on sensemaking about change in order to determine how researchers typically study this phenomenon. More specifically, this section reports on how change was studied (i.e. process vs. variance), methodological approaches (i.e. qualitative, quantitative, mixed method), how sensemaking about change was studied (i.e. terms used to describe study design and data analysis), samples utilized, data collection techniques, and the longitudinal aspect of the 50 empirical studies reviewed. In the interest of clarity and to avoid the use of overly complex lengthy sentences, tables are used throughout this section 1.3.2 and the two sections that follow (1.3.3 and 1.3.4) to provide citation details about the specific patterns mentioned in the text.

\subsubsection{Methodological approach}

Details on the results of the analysis of the methodological approaches used in the 50 empirical papers on sensemaking about change are included in Table 1-5.

Examination of Table 1-5 demonstrates that the methodologies utilized in the extant empirical research on sensemaking about organizational change were overwhelmingly qualitative, with virtually all of the studies describing the use of qualitative methods (46 out of 50, or 92\%). Three studies used a mixed method approach as they included both quantitative and qualitative data analysis. These three papers included work by Bartunek 
Rousseau, Rudolph and DePalma (2006) who used regression analysis to investigate the relationship between change recipients' participation in change implementation and their assessments of the change impacts, Marmenout (2010) who employed structural equation modeling to examine the impact of merger deal characteristics on employee attitudes towards change, and Gioia and Thomas (1996) who undertook a 2-phase (one qualitative, one quantitative) study to investigate top management team sensemaking in higher education institutions. Only one study (Chaudhry, Coyle-Shapiro, \& Wayne, 2011) employed an exclusively quantitative approach. Chaudhry et al. (2011) used confirmatory factor analysis to investigate context factors that act as sensemaking frames, which impact how organizational change effects individuals' psychological contracts. 
Table 1-5: Methodological approach for studying sensemaking about change

\begin{tabular}{|c|c|c|c|}
\hline Method & $\begin{array}{c}\text { Number } \\
\text { of } \\
\text { Studies }\end{array}$ & $\begin{array}{c}\text { \% of } \\
\text { Studies } \\
\text { (out of 50) }\end{array}$ & References \\
\hline Qualitative & 46 & $92 \%$ & $\begin{array}{l}\text { Abolafia, 2010; Apker, 2004; Balogun, } \\
\text { 2003, 2006;Balogun \& Johnson, 2004, } \\
\text { 2005; Balogun et al., 2015; Bean \& } \\
\text { Eisenberg, 2006; Bean \& Hamilton, 2006; } \\
\text { Brown, \& Humphreys, 2003; Chreim, 2006; } \\
\text { Chreim \& Tafaghod, 2012; Dawson et al., } \\
\text { 2014; Dunford \& Jones, 2000; Dutton et al., } \\
\text { 2001; Gazi, 2013; Gioia \& Chittipeddi, } \\
\text { 1991; Gioia et al., 1994; Guiette \& } \\
\text { Vandenbernpt, 2013; Greenberg, 1995; } \\
\text { Hensmans, 2015; Heracleous \& Barrett, } \\
\text { 2001; Hernes et al., 2015; Hope, 2010; } \\
\text { Kezar, 2013; Kyriakidou, 2011; Isabella, } \\
\text { 1990; Lockett et al., 2014; Luscher \& } \\
\text { Lewis, 2008; Maclean et al., 2014; Reissner, } \\
\text { 2011; Riesenmy, 2010; Rouleau, 2005; } \\
\text { Rouleau \& Balogun, 2011; Smollan, 2014; } \\
\text { Sonenshein, 2009; Sonenshein, 2010; } \\
\text { Stensaker et al., 2008; Stensaker \& } \\
\text { Falkenberg, 2007; Stensaker \& Meyer } \\
\text { 2012; Teulier \& Rouleau, 2013; Thurlow \& } \\
\text { Helms-Mills, 2009; Van der heijden et al., } \\
\text { 2012; Weber \& Manning, 2001; Wetzel \& } \\
\text { Dievernich, 2014 }\end{array}$ \\
\hline Mixed Method & 3 & $6 \%$ & $\begin{array}{l}\text { Bartunek et al., 2006; Gioia \& Thomas, } \\
\text { 1996; Marmenout, } 2010\end{array}$ \\
\hline Quantitative & 1 & $2 \%$ & Chaudhry et al., 2011 \\
\hline
\end{tabular}

\subsubsection{Approach to studying change}

The methodological approach employed in each of the 50 studies overlaps with the approach to studying change (i.e. variance versus process methods described in Section 1.1). All of the 46 qualitative studies are distinctly process based, meaning that change is conceptualized as a process as opposed to a variable (Van de Ven \& Poole, 2005). This is consistent with the sensemaking perspective, which typically seeks to 
answer the question "what's the story?" - which necessitates looking at a process over time (Weick et al., 2005). The remaining four quantitative $(n=1)$ and mixed methods $(n=3)$ studies employed variance based approaches (Bartunek et al., 2006; Chaudhry et al., 2011; Marmenout, 2010) or a combination of variance and process based approaches (Gioia \& Thomas, 1996) to study organizational change. Gioia and Thomas's (1996) mixed method study involved two studies. The first was a qualitative case study of organizational change consistent with a process based orientation whereas the second was a quantitative survey study consistent with a variance approach to studying organizational change (Van de Ven \& Poole, 2005).

\subsubsection{How sensemaking about change was studied from process orientation}

In the 47 studies that employed a process orientation when investigating sensemaking about change the descriptions of research design and data analysis often used general terms. Occasionally studies clearly described their approach to design and data collection (e.g., ethnographic) and data analysis (e.g., narrative/discourse analysis). More often, however, papers' methodologies were vague and would cite the use of multiple approaches (e.g., ethnography and grounded theory) or describe an approach to data analysis (e.g., content coding) but would neglect to articulate the overall approach to study design (e.g., case study). This made it difficult for us to group the studies based on these more specific dimensions. We elected, therefore, to create codes for the terms from the process oriented papers that referred to how sensemaking about change was studied (i.e. study design and/or data analysis). The results are in Table 1-6. A large proportion of these studies (29 out of 47 , or $62 \%$ ) acknowledged the use of a case study approach. 
About one in five studies used the specific qualitative approaches of narrative $\mathrm{e}^{2}$ and discourse analysis ( 9 out of 47 , or $19 \%$ ) or ethnography ( 8 out of 47 , or $17 \%$ ). A handful of studies ( 7 out of 47 , or $15 \%$ ) cite the use of grounded theory data analysis techniques. Other approaches mentioned include cognitive cause mapping (used in one study) as well as content coding and action research methods, each of which was used in two studies.

\footnotetext{
${ }^{2}$ The term narrative can be used to refer to a theoretical lens through which to view organizations (Boje, 2001) or as particular elements of the research process including actual data (i.e. interview transcripts as narratives), data analysis techniques (examining data for stories, plots, etc.), and a particular format for presenting findings (presenting results/theory as a story) (Buchanan \& Dawson, 2007; Brown et al., 2009; Pentland, 1999). In this section of the literature review "narrative" is referred to as a data analysis strategy - but later, in Section 1.3.3 the term narrative is used to refer to the nature of findings from some of the studies reviewed.
} 
Table 1-6: General descriptions of how sensemaking about change was studied

\begin{tabular}{|c|c|c|c|}
\hline Terms & \begin{tabular}{|c|}
$\begin{array}{c}\text { Number } \\
\text { of } \\
\text { Studies }\end{array}$ \\
\end{tabular} & $\begin{array}{c}\text { \% of } \\
\text { Studies } \\
\text { (out of } \\
\left.47^{*}\right)\end{array}$ & References \\
\hline Case study & 29 & $62 \%$ & $\begin{array}{l}\text { Apker, 2004; Balogun , 2003, 2006; } \\
\text { Balogun \& Johnson, 2003, 2005; Balogun } \\
\text { et al., 2015; Bean \& Eisenberg, 2006; } \\
\text { Brown, \& Humphreys, 2003; Chreim \& } \\
\text { Tafaghod, 2012; Greenberg, 1995; Gioia \& } \\
\text { Thomas, 1996; Guiette \& Vandenbernpt, } \\
\text { 2013; Hensmans, 2015; Heracleous \& } \\
\text { Barrett, 2001; Hernes et al., 2015; Hope, } \\
\text { 2010; Kezar, 2013; Kyriakidou, 2011; } \\
\text { Lockett et al., 2014; Riesenmy, 2010; } \\
\text { Rouleau, 2005; Stensaker et al., 2008; } \\
\text { Sonenshein, 2009; 2010; Stensaker \& } \\
\text { Falkenberg, 2007; Stensaker \& Meyer } \\
\text { 2012; Teulier \& Rouleau, 2013; Van der } \\
\text { heijden et al., 2012; Wetzel \& Dievernich, } \\
\text { 2014 }\end{array}$ \\
\hline $\begin{array}{l}\text { Narrative and } \\
\text { discourse }\end{array}$ & 9 & $19 \%$ & $\begin{array}{l}\text { Abolafia, 2010; Balogun et al., 2015; } \\
\text { Chreim, 2006; Thurlow \& Helms-Mills, } \\
\text { 2009; Maclean et al., 2014; Reissner, 2011; } \\
\text { Rouleau \& Balogun, 2011; Sonenshein, } \\
\text { 2010; Stensaker \& Falkenberg, 2007; }\end{array}$ \\
\hline Ethnography & 8 & $17 \%$ & $\begin{array}{l}\text { Bean \& Eisenberg, 2006; Bean \& } \\
\text { Hamilton, 2006; Brown \& Humphreys, } \\
\text { 2003; Dawson et al., 2014; Gazi, 2013; } \\
\text { Gioia \& Chittipeddi, 1991; Landau \& Drori, } \\
\text { 2008; }\end{array}$ \\
\hline $\begin{array}{l}\text { Grounded theory } \\
\text { techniques }\end{array}$ & 7 & $15 \%$ & $\begin{array}{l}\text { Abolafia, 2010*; Brown \& Humphreys, } \\
\text { 2003; Dunford \& Jones, 2000; Isabella, } \\
\text { 1990; Gioia et al., 1994; Reissner, 2011; } \\
\text { Sonenshein, 2009; }\end{array}$ \\
\hline Action research & 2 & $4 \%$ & $\begin{array}{l}\text { Dawson et al., 2014; Luscher \& Lewis, } \\
2008\end{array}$ \\
\hline Content coding & 2 & $4 \%$ & Dutton et al., 2001; Kyriakidou, 2011; \\
\hline Cause mapping & 1 & $2 \%$ & Weber \& Manning, 2001 \\
\hline
\end{tabular}

$*_{n}=47$ because this table includes only the 47 out of the 50 empirical papers reviewed that were process oriented. Bartunek et al. (2006), Chaudhry et al. (2011) and Marmenout (2010) are not included in this table because they employed variance methods exclusively for studying organizaitonal change. 


\subsubsection{Samples utilized}

The group of 50 empirical studies (i.e. 46 process studies, 1 process/variance combination study and 3 variance studies) varies with respect to their samples. A broad range of organizations are represented including education institutions (Brown \& Humphreys, 2003; Gioia et al., 1994; Gioia \& Chittipeddi, 1991; Gioia \& Thomas, 1996; Kezar, 2013), financial institutions (Chreim, 2006; Heracleous \& Barrett, 2001; Isabella, 1990), consulting firms (Greenberg, 1995), government departments (Weber \& Manning, 2001) and committees (Abolafia, 2010), healthcare organizations (Bartunek et al., 2006; Dutton et al., 2001; Riesenmy, 2010), insurance companies (Hope, 2010), a private defense laboratory (Landau \& Drori, 2008), an engineering firm (Teulier \& Rouleau, 2013), a clothing manufacturer (Rouleau, 2005), retailers (Sonenshein, 2009, 2010010) and even a toy manufacturer (Luscher \& Lewis, 2008). The extant research on sensemaking about change has explored this phenomenon in both public and private sector organizations, including a number of organizations from the healthcare sector. Accordingly, selecting a public hospital as the case organization for this thesis is consistent with the types of organizations that other scholars have deemed well-suited for the study of sensemaking about organizational change.

Details on the types of individuals sampled in each study are included in Table 17. The studies differ in terms of which individuals serve as the focus of the data collection (e.g., who is interviewed/surveyed/observed). A number of studies focus specifically the middle manager group (10 out of 50,20\%), while a smaller number look explicitly at senior managers (6 out of $50,12 \%)$ or front line staff ( 5 out of $50,10 \%)$. Almost half of the studies ( 24 out of $50,48 \%$ ), however, include mixed samples, meaning 
they include at least two groups from different hierarchical levels within the organization (e.g., senior and middle managers or middle managers and front-line staff) or samples that include an entire team (4 out of 50,8\%). This is likely related to the fact that most studies employed multiple techniques for data collection. One study (Marmenout, 2010), utilized a sample of students. Although the extant research varies with respect to sample homogeneity, studies often focus exclusively on the sensemaking of managers (i.e. middle and/or senior managers - e.g., Dutton et al., 2001; Stensaker et al., 2008) or change recipients (i.e. front-line staff - e.g., Bartunek et al., 2006). In the interest of contributing to a more comprehensive "emic" understanding of how individuals make sense of organizational change this thesis includes individuals from all levels of the organizational hierarchy in its sample (i.e. front-line staff, middle managers and senior managers). 
Table 1-7: Samples for studying sensemaking and change

\begin{tabular}{|c|c|c|c|}
\hline Sample & $\begin{array}{l}\text { Number } \\
\text { of } \\
\text { Studies }\end{array}$ & $\begin{array}{c}\% \text { of } \\
\text { Studies } \\
\text { (out of } 50 \text { ) }\end{array}$ & References \\
\hline Multiple groups & 24 & $48 \%$ & $\begin{array}{l}\text { Apker, 2004; Bean \& Eisenberg, 2006; Bean \& } \\
\text { Hamilton, 2006; Brown, \& Humphreys, 2003; } \\
\text { Chreim \& Tafaghod, 2012; Dawson et al., 2014; } \\
\text { Dutton et al., 2001; Gazi, 2013; Guiette \& } \\
\text { Vandenbernpt, 2013; Hensmans, 2015; } \\
\text { Heracleous \& Barrett, 2001; Isabella, 1990; } \\
\text { Landau \& Drori, 2008; Lockett et al., 2014; } \\
\text { Reissner, 2011; Smollan, 2014; Sonenshein, } \\
\text { 2009; 2010; Stensaker et al., 2008; Stensaker \& } \\
\text { Falkenberg, 2007; Stensaker \& Meyer 2012; } \\
\text { Thurlow \& Helms-Mills, 2009; Weber \& } \\
\text { Manning, 2001; Wetzel \& Dievernich, } 2014\end{array}$ \\
\hline $\begin{array}{l}\text { Middle managers } \\
\text { only }\end{array}$ & 10 & $20 \%$ & $\begin{array}{l}\text { Balogun , 2003, 2006; Balogun \& Johnson, } \\
\text { 2003, 2005; Greenberg, 1995; Hope, 2010; } \\
\text { Luscher \& Lewis, 2008; Rouleau, 2005; } \\
\text { Rouleau \& Balogun, 2011; Teulier \& Rouleau, } \\
2013\end{array}$ \\
\hline $\begin{array}{l}\text { Senior managers } \\
\text { only }\end{array}$ & 6 & $12 \%$ & $\begin{array}{l}\text { Balogun et al., 2015; Dunford \& Jones, 2000; } \\
\text { Gioia \& Chittipeddi, 1991; Gioia et al., 1994; } \\
\text { Gioia \& Thomas, 1996; Maclean et al., } 2014\end{array}$ \\
\hline Frontline staff only & 5 & $10 \%$ & $\begin{array}{l}\text { Bartunek et al., 2006; Chaudhry et al., 2011; } \\
\text { Chreim, 2006; Kyriakidou, 2011; Riesenmy, } \\
\text { 2010; }\end{array}$ \\
\hline Team & 4 & $8 \%$ & $\begin{array}{l}\text { Abolafia, 2010; Hernes et al., 2015; Kezar, } \\
\text { 2013; Van der heijden et al., } 2012\end{array}$ \\
\hline Students & 1 & $2 \%$ & Marmenout, 2010 \\
\hline
\end{tabular}

\subsubsection{Data collection techniques}

Details on the data collection techniques for each study are included in Table 1-8.

Most of the studies ( 32 of 50, or 64\%) rely on more than one source of data for their analysis. The types of data collected reflect the high proportion of studies that employed qualitative approaches. The majority of studies ( 43 of 50, or $86 \%$ ) collect interview data, which serves as the focal point of analysis. Other data sources utilized include documents ( 23 of 50 , or $46 \%$ ) such as annual reports and observations of meetings ( 20 of 50 , or 
$40 \%$ ). A smaller proportion of the studies included in the review use survey data ${ }^{3}$ ( 6 of 50 , or $12 \%$ ), participant diaries ( 5 of 50 , or $10 \%$ ) or focus groups ( 5 of 50 , or $10 \%$ ). Meeting transcripts were used by one study.

\footnotetext{
${ }^{3}$ Sonenshein's 2009 and 2010 qualitative studies analyzed the responses to open-ended survey questions.
} 
Table 1-8: Data collection techniques for studying sensemaking and change

\begin{tabular}{|c|c|c|c|}
\hline $\begin{array}{c}\text { Data } \\
\text { collection } \\
\text { technique }\end{array}$ & $\begin{array}{c}\text { Number } \\
\text { of } \\
\text { Studies }\end{array}$ & $\begin{array}{c}\% \text { of } \\
\text { Studies } \\
\text { (out of 50) }\end{array}$ & References \\
\hline Interview & 43 & $86 \%$ & $\begin{array}{l}\text { Apker, 2004; Balogun , 2003, 2006;Balogun \& Johnson, 2003, 2005; Balogun et al., 2015; Bean } \\
\text { \& Eisenberg, 2006; Bean \& Hamilton, 2006; ; Brown, \& Humphreys, 2003; Chreim \& } \\
\text { Tafaghod, 2012; Dawson et al., 2014; Dunford \& Jones, 2000; Dutton et al., 2001; Gazi, 2013; } \\
\text { Gioia \& Chittipeddi, 1991; Gioia \& Thomas, 1996; Gioia et al., 1994; Guiette \& Vandenbernpt, } \\
\text { 2013; Hensmans, 2015; Heracleous \& Barrett, 2001; Hernes et al., 2015; Hope, 2010; Kezar, } \\
\text { 2013; Kyriakidou, 2011; Isabella, 1990; Lockett et al., 2014; Luscher \& Lewis, 2008; Maclean et } \\
\text { al., 2014; Reissner, 2011; Riesenmy, 2010; Rouleau, 2005; Rouleau \& Balogun, 2011; Smollan, } \\
\text { 2014; Sonenshein, 2009; Sonenshein, 2010; Stensaker et al., 2008; Stensaker \& Falkenberg, } \\
\text { 2007; Stensaker \& Meyer 2012; Teulier \& Rouleau, 2013; Thurlow \& Helms-Mills, 2009; Van } \\
\text { der heijden et al., 2012; Weber \& Manning, 2001; Wetzel \& Dievernich, } 2014\end{array}$ \\
\hline Documents & 23 & $46 \%$ & $\begin{array}{l}\text { Balogun , 2003; Balogun et al., 2015; Bartunek et al., 2006; Bean \& Eisenberg, 2006; Bean \& } \\
\text { Hamilton, 2006; Brown, \& Humphreys, 2003; Chreim, 2006; Chreim \& Tafaghod, 2012; Gioia } \\
\text { \& Chittipeddi, 1991; Gioia et al., 1994; Greenberg, 1995; Hensmans, 2015; Heracleous \& } \\
\text { Barrett, 2001; Hernes et al., 2015; Kezar, 2013; Lockett et al., 2014; Rouleau, 2005; Maclean et } \\
\text { al., 2014; Sonenshein, 2009; Sonenshein, 2010; Stensaker \& Falkenberg, 2007; Teulier \& } \\
\text { Rouleau, 2013; Van der heijden et al., 2012; }\end{array}$ \\
\hline Observation & 20 & $40 \%$ & $\begin{array}{l}\text { Balogun \& Johnson, 2003, 2005; Balogun et al., 2015; Bean \& Eisenberg, 2006; Bean \& } \\
\text { Hamilton, 2006; Brown, \& Humphreys, 2003; Chreim \& Tafaghod, 2012; Gazi, 2013; Gioia \& } \\
\text { Chittipeddi, 1991; Gioia et al., 1994;Greenberg, 1995; Hensmans, 2015; Hernes et al., 2015; } \\
\text { Landau \& Drori, 2008; Lockett et al., 2014; Rouleau, 2005; Sonenshein, 2010; Stensaker et al., } \\
\text { 2008; Stensaker \& Falkenberg, 2007; Teulier \& Rouleau, 2013; }\end{array}$ \\
\hline Survey & 6 & $12 \%$ & $\begin{array}{l}\text { Bartunek et al., 2006; Chaudhry et al., 2011; Gioia \& Thomas, 1996; Marmenout, 2010; } \\
\text { Sonenshein, 2009; Sonenshein, 2010; }\end{array}$ \\
\hline Diaries & 5 & $10 \%$ & Balogun \& Johnson, 2003, 2005; Balogun, 2003, 2006; Hope, 2010; \\
\hline Focus groups & 5 & $10 \%$ & $\begin{array}{l}\text { Balogun , 2003; Balogun et al., 2015; Hensmans, 2015; Marmenout, 2010; Rouleau \& Balogun, } \\
2011\end{array}$ \\
\hline $\begin{array}{l}\text { Meeting } \\
\text { transcripts }\end{array}$ & 2 & $4 \%$ & Abolafia, 2010; Gazi, 2013 \\
\hline
\end{tabular}




\subsubsection{Longitudinal nature of the studies}

Additional analysis was conducted on the process articles included in this review $(n=47)$ in order to determine the extent to which their methods captured how individuals make sense of organizational change over time. More specifically, codes were created so that we could identify which papers referred to interviews that were conducted at more than one point in time with the same informants (i.e. longitudinal panel data). This additional analysis is described below and visually represented in Figure 1-3 with relevant citations appearing in Table 1-9.

Figure 1-3: Research on sensemaking about change over time at the individual level

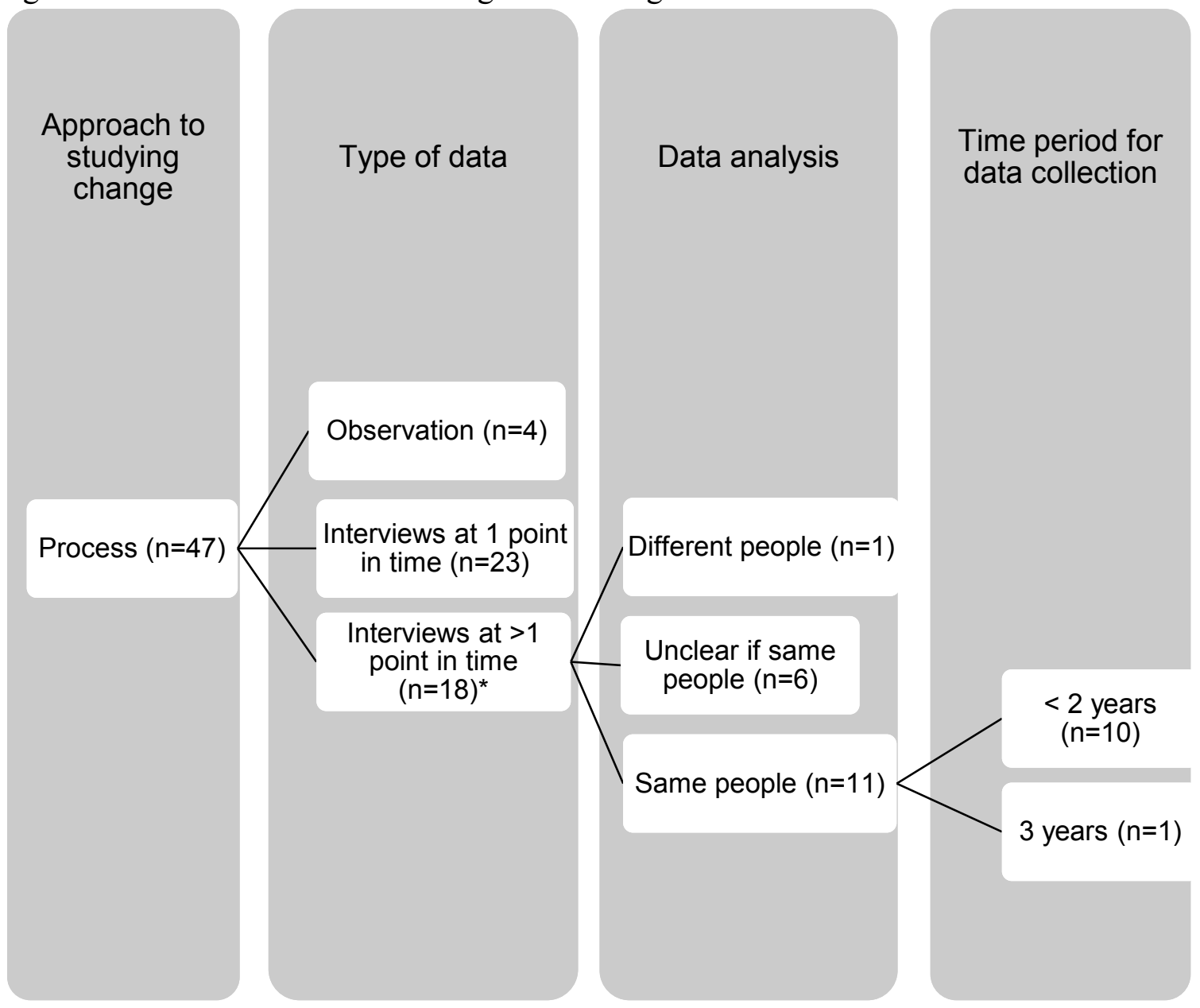


Table 1-9: Research on sensemaking about change over time at the individual level

\begin{tabular}{|c|c|c|c|}
\hline Focus of study & $\begin{array}{l}\text { Number } \\
\text { of } \\
\text { Studies }\end{array}$ & $\begin{array}{l}\text { \% of } \\
\text { Studies } \\
\text { (out of } \\
47 * \text { ) }\end{array}$ & References \\
\hline Observation & 4 & $8 \%$ & $\begin{array}{l}\text { Abolafia, 2010; Bean \& Eisenberg, 2006; } \\
\text { Greenberg, 1995; Rouleau, 2005; Teulier } \\
\& \text { Rouleau, } 2013\end{array}$ \\
\hline $\begin{array}{l}\text { Interviews at one } \\
\text { point in time }\end{array}$ & 23 & $47 \%$ & $\begin{array}{l}\text { Apker, 2004; Chreim, 2006; Chreim \& } \\
\text { Tafaghod, 2012; Dawson et al., 2014; } \\
\text { Dunford \& Jones, 2000; Dutton et al., } \\
\text { 2001; Gazi, 2013; Gioia \& Chittipeddi, } \\
\text { 1991; Guiette \& Vandenbernpt, 2013; } \\
\text { Hensmans, 2015; Hope, 2010; Isabella, } \\
\text { 1990; Kyriakidou, 2011; Luscher \& Lewis, } \\
\text { 2008; Maclean et al., 2014; Reissner, } \\
\text { 2011; Riesenmy, 2010; Rouleau \& } \\
\text { Balogun, 2011; Sonenshein, 2009, } \\
\text { 2010010; Stensaker \& Meyer, 2012; } \\
\text { Thurlow \& Helms-Mills, 2009; Wetzel \& } \\
\text { Dievernich, 2014 }\end{array}$ \\
\hline $\begin{array}{l}\text { Interviews at }>1 \\
\text { point in time (sub- } \\
\text { themes below): }\end{array}$ & 18 & $38 \%$ & $\begin{array}{l}\text { Balogun, 2003, 2006; Balogun \& Johnson, } \\
\text { 2003, 2005; Bean \& Hamilton, 2006; } \\
\text { Brown \& Humphreys, 2003; Balogun et } \\
\text { al., 2015; Gioia et al., 1994; Gioia \& } \\
\text { Thomas, 1996; Heracleous \& Barrett, } \\
\text { 2001; Hernes et al., 2015; Landau \& Drori, } \\
\text { 2008; Lockett et al., 2014; Kezar, 2013; } \\
\text { Stensaker et al., 2008; Stensaker \& } \\
\text { Falkenberg, 2007; Van der heijden et al., } \\
\text { 2012; Weber \& Manning, } 2001\end{array}$ \\
\hline $\begin{array}{l}\text { Different people } \\
\text { interviewed } \\
\text { each time }\end{array}$ & 1 & $2 \%$ & Landau \& Drori, 2008 \\
\hline $\begin{array}{l}\text { Unclear if } \\
\text { different or } \\
\text { same people }\end{array}$ & 6 & $13 \%$ & $\begin{array}{l}\text { Heracleous \& Barrett, 2001; Lockett et al., } \\
\text { 2014; Kezar, 2013; Stensaker et al., 2008; } \\
\text { Stensaker \& Falkenberg, 2007; Van der } \\
\text { heijden et al., 2012; }\end{array}$ \\
\hline $\begin{array}{l}\text { Same people } \\
\text { interviewed } \\
\text { each time }\end{array}$ & 11 & $23 \%$ & $\begin{array}{l}\text { Balogun, 2003, 2006; Balogun et al., 2015; } \\
\text { Balogun \& Johnson, 2003, 2005; Bean \& } \\
\text { Hamilton, 2006; Brown, \& Humphreys, } \\
\text { 2003; Gioia \& Thomas, 1996; Gioia et al., } \\
\text { 1994; Hernes et al., 2015; Weber \& } \\
\text { Manning, 2001 }\end{array}$ \\
\hline
\end{tabular}

${ }^{*} \mathrm{n}=47$ because this table includes only the 47 out of the 50 empirical papers reviewed that were process oriented. Bartunek et al. (2006), Chaudhry et al. (2011) and Marmenout (2010) are not included in this table because they employed variance methods exclusively for studying organizational change. 
Figure 1-3 visually depicts how the process studies included in this review $(n=47)$ have gone about investigating sensemaking about organizational change. The majority of these studies $(n=27)$ rely primarily on retrospective accounts of change taken from interviews conducted at one point in time $(n=23)$ or observations $(n=4)$. Although a number of studies $(n=18)$ conducted interviews at two $(n=17)$ or three $(n=1)$ points in time it was unclear for six of these studies if the same informants were interviewed at both points in time. This is likely because the analysis in these studies did not attempt to connect individual informants' data over time. One paper, by Landau and Drori (2008), mentioned that different people were interviewed at each point in time.

The remaining eleven papers that included at least two sets of interviews appeared to include interviews with the same informants at the different points in time. Weber and Manning's (2001) study used 2 interviews with each informant $(n=28)$ over the course of 6 months in order to produce and validate "cause-maps" of informants" mental schema about a strategic change. Bean and Hamilton's (2006) ethnographic study involved reflexive interviews with 40 participants, most of whom where interviewed two times over the course of 1.5 years. Balogun's group of studies about middle manager sensemaking (Balogun, 2003, 2006; Balogun \& Johnson, 2004, 2005) used a diary approach and interviewed each of the 26 informants at two points in time (over the course of 10 months). Hernes, Hendrup, and Schaffner (2015) conducted two interviews with each member of a change pilot team within a customer service department over the course of three months. The two studies by Gioia and colleagues (i.e. Gioia \& Thomas, 1996; Gioia et al., 1994) provided fewer interview details but mentioned that interviews were conducted with key informants at multiple points in time over the period of 6 
months. Brown and Humphreys (2003) conducted interviews with 75 informants during their study of a merger, eight of whom were interviewed twice over the course of one year. Finally, Balogun, Bartunek and Do (2015) conducted interviews with about 35 senior managers "regularly" over the course of three years to capture how they made sense of the strategic organizational change they were implementing.

All but one of the studies that collected longitudinal individual level data collected the data over a period of less than two years. This can be considered a limitation of the literature on sensemaking about change for two reasons. First, prior research (e.g., Smith, 2003) suggests that planned organizational change initiatives tend to take at least two years (i.e. between two and 15 years) to implement. Second, scholars (Langley et al., 2013; Van de Ven \& Poole, 2005) have noted the need for more empirical research about how the process of organizational change unfolds over time. Taken together these two notions imply that empirical research that utilizes longitudinal data that spans a more substantial period of time (e.g., more than two years) in relation to how long it takes to implement change could provide us with a more comprehensive emic understanding of how individuals make sense of organizational change over time. This thesis, therefore, will utilize interview data that spans 4.5 years (i.e. a period of time that is greater than two years).

\subsubsection{What do we know about sensemaking and change?}

This section reviews the findings from the 50 empirical articles on sensemaking and change as a means of capturing what the current state of knowledge is on this subject. The key findings from each study were coded and emergent codes were created to summarize the types of findings. In total four emergent codes were created to describe 
the types of findings from the 50 empirical papers: (1) findings about properties of sensemaking (section 1.3.3.1), (2) findings about the sensemaking process (section 1.3.3.2), (3) findings about lenses/frames (section 1.3.3.3) and (4) findings about organizational change (section 1.3.3.4). The codes are not mutually exclusive meaning that two different codes could be used to describe the findings from a particular study. Table 1-10 summarizes the categorizing of the articles based on their findings related to sensemaking and change. 
Table 1-10: Findings about sensemaking and change

\begin{tabular}{|c|c|c|c|}
\hline Type of finding & $\begin{array}{l}\text { Number } \\
\text { of } \\
\text { Studies }\end{array}$ & $\begin{array}{c}\text { \% of } \\
\text { Studies } \\
\text { (out of 50) }\end{array}$ & References \\
\hline $\begin{array}{l}\text { Properties of } \\
\text { sensemaking }\end{array}$ & 11 & $22 \%$ & $\begin{array}{l}\text { Apker, 2004; Bean \& Eisenberg, 2006; Bean } \\
\text { \& Hamilton, 2006; Chreim, 2006; Gioia \& } \\
\text { Thomas, 1996; Hernes et al., 2015; Maclean } \\
\text { et al., 2014; Stensaker \& Meyer, 2012; } \\
\text { Thurlow \& Helms-Mills, 2009; Van der } \\
\text { heijden et al., 2012; Wetzel \& Dievernich, } \\
2014\end{array}$ \\
\hline $\begin{array}{l}\text { Sensemaking } \\
\text { process }\end{array}$ & 3 & $6 \%$ & $\begin{array}{l}\text { Isabella, 1990; Rouleau, 2005; Weber \& } \\
\text { Manning, 2001 }\end{array}$ \\
\hline Lenses/frames & 8 & $16 \%$ & $\begin{array}{l}\text { Balogun \& Johnson, 2004; Bean \& } \\
\text { Eisenberg, 2006; Chaudhry et al., 2011; } \\
\text { Chreim \& Tafaghod, 2012; Guiette \& } \\
\text { Vandenbernpt, 2013; Lockett et al., 2014; } \\
\text { Luscher \& Lewis, 2008; Sonenshein, } 2009\end{array}$ \\
\hline $\begin{array}{l}\text { Change related } \\
\text { findings (sub- } \\
\text { themes below): }\end{array}$ & 33 & $66 \%$ & \\
\hline $\begin{array}{l}\text { Individuals } \\
\text { responses to } \\
\text { change }\end{array}$ & 11 & $22 \%$ & $\begin{array}{l}\text { Balogun et al., 2015; Bartunek et al., 2006; } \\
\text { Chreim, 2006; Kyriakidou, 2011; Greenberg, } \\
\text { 1995; Landau \& Drori, 2008; Riesenmy, } \\
\text { 2010; Smollan, 2014; Stensaker \& } \\
\text { Falkenberg, 2007; Stensaker \& Meyer, 2012; } \\
\text { Stensaker et al., 2008 }\end{array}$ \\
\hline Implementation & 5 & $10 \%$ & $\begin{array}{l}\text { Gioia \& Chittipeddi, 1991; Gioia et al., 1994; } \\
\text { Hensmans, 2015; Kezar, 2013; Marmenout, } \\
\text { 2010; }\end{array}$ \\
\hline $\begin{array}{l}\text { Middle } \\
\text { Managers }\end{array}$ & 7 & $14 \%$ & $\begin{array}{l}\text { Balogun, 2003, 2006; Balogun \& Johnson, } \\
\text { 2003, 2005; Dutton et al., 2001; Hope, 2010; } \\
\text { Rouleau \& Balogun, } 2011\end{array}$ \\
\hline $\begin{array}{l}\text { Narratives, } \\
\text { discourse and } \\
\text { stories }\end{array}$ & 9 & $18 \%$ & $\begin{array}{l}\text { Abolafia, 2010; Brown \& Humphreys, 2003; } \\
\text { Dawson et al., 2014; Dunford \& Jones, 2000; } \\
\text { Gazi, 2013; Heracleous \& Barrett, 2001; } \\
\text { Reissner, 2011; Sonenshein, 2010; Teulier \& } \\
\text { Rouleau, 2013 }\end{array}$ \\
\hline
\end{tabular}

\subsubsection{Findings about properties of sensemaking}

One in five of the empirical studies included in this review (11 papers out of 50) on sensemaking about change presented findings that related to four of the seven properties 
of sensemaking (described in section 1.2.1): social identity, the retrospective aspect of sensemaking, how sensemaking is social and the ongoing and iterative nature of the sensemaking process. Findings from three of these studies highlight the central role that identity plays during sensemaking and change, particularly professional identity (Apker, 2004) and organizational identity (Chreim, 2006; Gioia \& Thomas, 1996; Thurlow \& Helms-Mills, 2009). Apker (2004) analyzed interview data from 24 nurses at an organization undergoing changes in the way that care is provided and concluded that the nurses faced a paradox of change in that the aspects of the change that they ideologically agreed with were in conflict with aspects their professional identity. Chreim (2006) developed a typology of responses to change based on whether an individual perceives that the change will benefit or cause harm to their role identity (i.e. their job) and/or the organizational identity (i.e. their perceptions of the organization). Gioia and Thomas's (1996) mixed-method study about organizational change in higher education institutions concluded that top management team members' perceptions of the organizational identity and the future desired identity are a key part of their sensemaking about change. Thurlow's and Helms-Mills' (2009) critical discourse analysis of an organization undergoing a merger, on the other hand, concluded that talk (i.e. discourse) is used to alter and maintain organizational identity during change.

The retrospective nature of sensemaking during change was illuminated in the findings of both Maclean, Harvey, Sillince and Golant's (2014) and Wetzel and Dievernich's (2014) studies. Maclean et al. (2014) introduced the term "ideological sensemaking" to describe how senior executives make sense of organizational change in a way that involves making sense of organizational history in a manner that causes them 
to feel a sense of heritage and an implied responsibility to carry out change in a particular manner. Wetzel and Dievernich (2014) drew attention to the importance of the "postchange" period for making sense of change retrospectively. They claim that this period involves three steps (provide stability in identity frames, develop sensemaking patterns and develop and stage contradictions) and that this period of time can act as a driver for future change.

The way that sensemaking is driven by social interaction was highlighted in three studies (Bean \& Hamilton, 2006; Bean \& Eisenberg, 2006; Hernes, Hendrup, \& Schaffner, 2015). The former two studies employed ethnographic approaches to investigate a Scandinavian mobile phone company's shift to "nomadic" working practices. Bean and Eisenberg (2006) looked at how employees and managers made sense of the changes and found that individuals experience dissonance about identity, culture or structure during the change but that they were able to overcome this by engaging in sensemaking with other employees. Bean and Hamilton (2006), on the other hand, focused on leader sensegiving and found the lack of physical boundaries (i.e. employees physically present in the same space) that accompanied the shift to nomadic work made it challenging for leaders to engage in sensegiving. Hernes et al. (2015) looked at two different change initiatives at a multinational corporation and found that the initial rational provided for the change did not impact the success of the change but rather that the social dynamics that impacted individual sensemaking during change implementation were key in explaining why the initiatives experienced varied results.

Findings from two studies spoke to the ongoing and iterative nature of sensemaking during change (Stensaker \& Meyer, 2012; Van der Heijden, Cramer, \& 
Driessen, 2012). Van der Heijden et al. (2012) examined change agent sensemaking about sustainability driven change and concluded that sensegiving, like sensemaking, is an ongoing, emergent and unpredictable process. Stensaker and Meyer (2012), conversely, looked at change recipient sensemaking over time and produced a typology of reactions to change, which are associated with one's prior change experience. These findings suggest that sensemaking about change is ongoing as one's prior change experiences can shape how they make sense of current and future experiences in an iterative manner.

\subsubsection{Findings about the sensemaking process}

Findings from 3 (out of 50 , or $6 \%$ ) of the empirical studies reviewed relate specifically to one or more aspects of the sensemaking process (i.e. triggering, interpretation or action stages) described in section 1.2.2. These papers (Isabella, 1990; Rouleau, 2005; Weber \& Manning, 2001) developed process models for sensemaking during organizational change. Isabella's (1990) seminal study presented a model for how managers construe events as organizational change unfolds over time. The four stages in this model are anticipation, confirmation, culmination and aftermath (Isabella, 1990). Rouleau's (2005) process model, based on research at a high-end clothing company, presents four micro practices of sensemaking and sensegiving during change; (1) translating the orientation, (2) overcoding the strategy, (3) disciplining the client, (4) justifying the change. The "integrated model of sensemaking", a process model developed in Weber's and Manning's (2001) study which utilized a cause-mapping methodology, includes a cycle with four stages named "initiators of sensemaking", "existing reality", "influences on sensemaking", and "results of sensemaking". 


\subsubsection{Findings about lenses/frames}

A number of the studies ( 8 out of 50) had findings that relate specifically to the lenses, cognitive frames, mental models and schemas used when individuals make sense of organizational change. Four of these studies (Balogun \& Johnson, 2004; Bean \& Hamilton, 2006; Chreim \& Tafaghod, 2012; Guiette \& Vandenbernpt, 2013) looked at the process for developing new lenses or "reframing". Balogun and Johnson (2004) uncovered a replacement pattern involved in schema development for middle managers during change. Guiette and Vandenbernpt (2013) identified five "determinants" of the development of team mental models; (1) coherence of organizational routines, (2) equivocality of expectations, (3) dominance of organizational discourse, (4) shift in organizational identification, and (5) cross-understanding between thought words. Chreim and Tafaghod's (2012) study of an acquisition concluded that the adoption of new frames is strongly connected to the relationships (and tensions) between the acquired and acquiring firms' managers. Bean's and Hamilton's (2006) examination of an organization's shift to nomadic work practices, which was followed by a downsizing, found that employees made sense of the initial shift to nomadic work through the use of frames provided from leaders via sensegiving but that after the downsizing employees "reframed" how they viewed the initial changes.

The other three studies in this grouping suggested that the lenses individuals use to make sense during periods of change could be related to particular themes. For example, Sonenshein's (2009) research on a Fortune 500 retailer implementing strategic change suggested that ethical issues emerge as a theme that influences how individuals reframe strategic change. Luscher's and Lewis's (2008) action research study found that 
paradox can act as a lens for managerial sensemaking during change. Three particular paradoxes observed in their sample of middle managers are: (1) performing, which is related to how they complete their work during change; (2) belonging, which relates to trust and team-building during change; and, (3) organizing, which relates to maintaining new work practices for self and others during change. Lockett, Currie, Finn, Martin and Waring (2014) proposed that social position is a lens for sensemaking about organizational change and coin the terms profession-centrism (i.e. an orientation towards one's professional group, which may limit ones viewpoint) and allo-centrism (i.e. the degree to which one is aware that their own ability to create change is dependent upon others).

\subsubsection{Findings about organizational change}

Over half of the empirical articles about sensemaking and change (i.e. 33 out of 50, or $66 \%$ ) have findings that are particularly relevant to organizational change and change management. These 33 articles can be further categorized as relating to individuals and change, the implementation of organizational change, middle managers and change and narratives about change.

Individuals and change. In total, nine of the articles included findings that specifically related to how individuals make sense of and respond to organizational change. Four of these studies (Bartunek et al., 2006; Greenberg, 1995; Riesenmy, 2010; Stensaker et al., 2008) focused particularly on how individuals' sensemaking about change can lead to acceptance or resistance of change. According to this research, participation and involvement of change recipients in the planning process is linked to 
positive sensemaking about change (Bartunek et al., 2006; Stensaker et al., 2008) and change readiness (Riesenmy, 2010). Greenberg (1995) noted the role that symbolic processes play when making sense of change and reports that the role of symbolic processes (i.e. phrases, rituals, stories or objects that take on a greater meaning during sensemaking), when underestimated, can act as a major barrier to organizational change.

Five empirical studies (Chreim, 2006; Kyriakidou, 2011; Landau \& Drori, 2008; Stensaker \& Falkenberg, 2007; Stensaker \& Meyer, 2012) in this grouping proposed typologies for how individuals respond to change. For example, Chreim's (2006) typology of responses to change includes acceptance, resigned compliance, avoidance/opposition and ambivalence. In their study of transformational change Landau and Drori (2008) established a typology of how individuals react to change. They contend that individuals use aspects of the organizational culture as a sensemaking lens and that this is connected to how one reacts to the change (Landau \& Drori, 2008). Kyriakidou (2011) studied transformational change at an academic institution and concluded that employees interpret organizational change as either "attractive" or "non-engaging" Kyriakidou (2011) notes that this finding differs from the traditional change management assumption that change will be viewed as either a "threat" or "opportunity". Stensaker and Falkenberg (2007) looked at change implementation in different business units at a Norwegian oil company and identified five interpretive responses at the individual level that are impact how each unit integrates the changes. The five responses are: convergent response, divergent response, unresolved sensemaking, creative response and noncompliance (Stensaker \& Falkenberg, 2007). Stensaker and Meyer (2012) produced a typology of reactions to change based on one's prior change experience. Stensaker's and 
Meyer's (2012) reactions to change are categorized according to whether the responses are active or passive and whether the responses could act as a barrier to or support for the change. The reactions are labeled BOHICA (bend over, here it comes again), paralysis, loyalty (compliance or acceptance), take control, sabotage, and exit. This typology is based on one presented in earlier papers (Stensaker, Meyer, Falkenberg, \& Haueng, 2001, 2003), which also discusses the concept of "excessive change".

Excessive change is organizational change that occurs when (1) "the organization pursues several, seemingly unrelated and sometimes conflicting changes at the same time" or (2) "the organization introduces new changes before the previous change is completed and evaluated" (Stensaker et al., 2001: p. G3). The excessive change concept is relevant to sensemaking and change because, according to the research, whether or not one views a change as excessive is related to how they make sense of the change. More specifically, mid and low level managers are likely to view change as excessive whereas higher level managers tend to view the larger picture and may see the seemingly "excessive" changes as interconnected (Stensaker et al., 2001). The excessive change concept is useful in this thesis because this term could be used to describe the changes that Community Hospital has faced over the course of data collection for this thesis. Accordingly, "excessive change" serves as a sensitizing concept for one of the three thesis papers (i.e. paper three, which is about how individuals cope with excessive change).

The other two studies in this group produced findings that related to individuals' responses to organizational change in two different ways. First, one study (Smollan, 2014) interviewed 24 individuals from various organizations, occupations and industries in order to explore their affective experiences about change. Smollan (2014) analyzed the 
metaphors individuals used to make sense of change and found that individuals' sensemaking about change included a broad spectrum of emotions. Second, the other study (Balogun et al., 2015) used longitudinal interview data to explore how senior managers make sense of strategic change over time. This study concluded that senior manager sensemaking is heterogeneous and complex - as they tend to oscillate between change agent and change recipient roles and are impacted by their relational context (Balogun et al., 2015).

Change implementation. Five studies about sensemaking and change focus on sensemaking and the change implementation process (rather than on how individuals respond to change) (Gioia \& Chittipeddi, 1991; Gioia et al., 1994; Hensmans, 2015; Kezar, 2013; Marmenout, 2010). Two of these studies focus on the role of leaders during change implementation (Gioia \& Chittipeddi, 1991; Hensmans, 2015). In their 1991 ethnographic study about strategic change Gioia and Chittipeddi identified four stages for initiating strategic change (envisioning, signaling, re-visioning and energizing). They introduce the concept of "sensegiving" as a key activity that the CEO must undertake in order for the change initiation to be successful (Gioia \& Chittipeddi, 1991). Hensmans (2015) studied executives' sensegiving at two organizations involved in a merger. Findings from this study suggest that the change implementation process can be likened to a three step reciprocal sensegiving process between executives and employees that involves (1) symbolic management, (2) friendly favour exchange and (3) giving into custodians of continuity.

The remaining three studies included broader findings related to the link between sensemaking or sensegiving and the implementation of organizational change. In their 
1994 paper that used interviews to explore the role of a change implementation team, Gioia et al. proposed a process model that speaks to the role of sensemaking during strategic change. They contend that the sensemaking process moves from being internally focused towards being externally focused over the course of the strategic change initiative. Kezar (2013) investigated bottom-up (as opposed to top down) change at 28 education institutions and concluded that shared sensemaking and sensegiving are critical for this type of change. Finally, in a study about mergers Marmenout (2010) shows how deal characteristics (e.g., culture clash, position in deal structure) can influence individual sensemaking and result in actions that are helpful (i.e. collaboration) or detrimental (i.e. conflict) to the merger effort.

Middle managers. There were seven articles that concentrated specifically on the role of the middle manager in organizational change and sensemaking (Balogun, 2003, 2006; Balogun \& Johnson, 2003, 2005; Dutton et al., 2001; Hope, 2010; Rouleau \& Balogun, 2011). These articles focused primarily on sensegiving and how middle managers act as sensegivers during organizational change. Dutton and Ashford (2001) identified three issue-selling (i.e. sensegiving) moves, named packaging, involvement and timing, that managers use to direct senior managers' attention during change. Similarly, Hope (2010) concluded that middle managers use political tactics to influence change. In another study that examined the sensegiving tactics of middle managers during change, Rouleau and Balogun (2011) identified two discursive activities that middle managers use to enact change, named (1) performing the conversation and (2) setting the scene. Balogun (2003) claims that the sensegiving role undertaken by middle managers during change is often overlooked and can lead to overload for these 
individuals. Balogun and Johnson (2005) explore these notions further and suggest that inter-recipient sensemaking (i.e. between middle manager and change recipient) is unpredictable and can lead to unintended consequences including lack of empowerment and inter-divisional tensions during planned change. In a study conducted at a utility company undergoing a restructuring Balogun (2006) showed that during change implementation middle managers' (i.e. change agents) sensemaking activities rely on multiple "communication genres", including both formal and informal communication about the change.

Narratives, discourse and stories. The remaining nine empirical articles included in our review involve findings that center on the role of narrative and discourse in sensemaking during change. These studies conclude that narratives can be used by individuals to make sense of change (Dunford \& Jones, 2000; Sonenshein, 2010) and by managers to freeze and unfreeze organizational change (Sonenshein, 2010).

Three of the studies noted the important role of stories during organizational change (Dawson, Sykes, McLean, Zanko, \& Marciano, 2014; Gazi, 2013; Reissner, 2011). In their action research study in three healthcare organizations Dawson et al. (2014) found that individuals used stories to make sense retrospectively and prospectively during a period of organizational change. Reissner (2011) used interview data from three different manufacturing firms to identify three types of stories that individuals use to make sense of change: (1) stories about the good old days, (2) stories about deception, taboo and silence and (3) stories about influence. Gazi (2013) posits that stories can be used as a powerful tool for sensemaking and bringing people together during periods of organizational change. Heracleous and Barrett (2001), on the other 
hand, examine IT change and find that how stakeholders talk about change (i.e.

discourse) impacts both their interpretation and action stages of sensemaking during the change. Another IT change study (Teulier \& Rouleau, 2013) conceptualizes sensemaking as a "translation" process and identifies the following four places where it took place in their case study of middle managers from five different engineering firms: (1) intensive working sessions, (2) industrial visits, (3) writing sessions, and (4) organizational meetings and talks. Abolafia (2010) analyzed meeting transcripts from a federal government committee to develop a process model that conceptualizes sensemaking during change as based on shared narrative construction. According to Abolafia (2010) sensemaking of change is a social process that involves the stages of abduction, plotting and selective retention. Finally, Brown and Humphreys(2003) find that managers and subordinates report different narrative accounts of organizational change, where senior managers' accounts have epic narrative themes and subordinates' accounts have tragic narrative themes.

\subsection{Gap in the literature and implications for thesis}

The extant empirical work on sensemaking and organizational change is small but growing. Researchers have begun to establish an understanding of sensemaking about organizational change, particularly so over the past two decades. Despite this emerging stock of knowledge there remains a substantial gap in the current state of research on sensemaking and organizational change, which is discussed here. The goal of this section of the literature review is to summarize the gap in the empirical research on sensemaking about organizational change (in section 1.4.1) and outline the implication of this gap for this thesis (section 1.4.2). 


\subsubsection{Gap in the sensemaking and change literature}

A gap which scholars have identified with respect to the fields of sensemaking and organizational change is the lack of studies that look at the processes (of sensemaking and of change) over time at the individual level. Sensemaking research, on the one hand, has been criticized for its lack of empirical investigations that look at the sensemaking process over time as studies tend to focus on one or two select aspects of the process (Brown et al., 2014; Sandberg \& Tsoukas, 2015). Organizational change research, on the other hand, has also been criticized for its lack of empirical investigations that look at the entire organizational change process over time, particularly at the individual level of analysis (Langley et al., 2013; Van de Ven \& Poole, 2005). In the group of 50 studies reviewed in this thesis it appears at first glance that this critique may not apply because virtually all of the studies $(n=47)$ employ a process-oriented approach to study change. Closer examination of the methodological details of these studies, however, reveals a limitation in this group of studies - only one paper (Balogun et al., 2015) explicitly looked at sensemaking about organizational change by analyzing individual level longitudinal data over a period of time greater than two years.

Furthermore, in Balogun et al.'s (2015) study about strategic change and sensemaking the focus was exclusively on the sensemaking processes of senior managers.

The analysis provided in section 1.3.2.6 demonstrated that the extant work on sensemaking about organizational change tends to rely on retrospective interviews at one point in time or longitudinal interviews over a short course of time within organizational change. This pattern in how sensemaking about change is studied begs the question: Has the extant work on sensemaking about change thoroughly considered how individuals 
make sense of organizational change over time? The lack of empirical work that examines sensemaking about change over time at the individual level potentially limits our understanding of the process of organizational change. Accordingly, the three studies in this thesis will use longitudinal panel interview data (i.e. 3 interviews with each informant over the course of 5 years) from an organizationally representative sample of employees (i.e. not just senior managers) in order to look at the process of sensemaking about organizational change over time.

\subsubsection{Implications for thesis}

Scholars and practitioners have criticized organizational change research and theory for not representing the lived experience of change (Beech \& Johnson, 2005; Burnes \& Cooke, 2012; Marshak, 2002; Oswick et al., 2005; Tsoukas \& Chia, 2002; Van de Ven \& Sun, 2011). It has been suggested that in order to address this critique scholars must engage in research that revisits and challenges fundamental assumptions regarding change, both the nature of organizational change and how individuals experience organizational change (By, Burnes, \& Oswick, 2011). Empirical investigations of sensemaking and change that explore processes over time at the individual level are fruitful ways in which this issue can be addressed.

The primary objective of this thesis, therefore, is to understand how individuals make sense of organizational change over time from an emic (i.e. insider) perspective. This objective serves as the underlying theme that unites the three studies, each of which uses an emic approach to examine a different aspect of sensemaking and change. The first paper, "Sensemaking Lenses", explores emic views of the organizational change 
process over time. More specifically, this paper examines the lenses individuals use to make sense of significant organizational change over time. The second paper, "Retrospective versus Real-time", looks at the retrospective nature of sensemaking and explores the similarities and differences across individuals' retrospective sensemaking accounts (after change) and their real-time assessments (during change). Finally, the third paper, "Coping", explores individuals' strategies for coping with change over time. More specifically it investigates: (1) what types of strategies individuals use to cope with excessive change over time, (2) how individuals make sense of excessive change over time, and (3) to what extent these coping and sensemaking patterns overlap. 


\section{Chapter 2: Methods}

The purpose of this chapter is to explain the methodological approach used in this thesis. Although this study is interested in exploring individual (i.e. employee) sensemaking about change, the term "sensemaking" can also be used to describe what the researcher does with process data (Langley, 1999). In the interest of clarity, however, the decision was made not to include "sensemaking" in the description of the thesis's methods (i.e. Chapter 2). In order to avoid confusion key ideas related to researcher "sensemaking" about process data are instead stated using terms like "analyzing" process data and "conducting" process research.

All three papers in the thesis are qualitative process oriented case studies that use the same data collection techniques, sample (i.e. 26 individuals interviewed at three points in time) and, as shown in Figure 2-1, employ the same grounded theory data analysis techniques (namely constant comparison and the initial, focused and theoretical coding practices). The studies' methods do, however, differ in that each study uses different data (i.e. responses to different interview questions). The data analyzed in each paper are comprised of informants' responses to the interview questions that correspond with the sensitizing concepts for that particular paper. Sensitizing concepts are theories, frameworks and ideas from the literature that can help the researcher to see, organize and understand experiences reported in the data (Charmaz, 2000). They often serve as starting points for data interpretation (Charmaz, 2000). Details regarding the sensitizing concepts and corresponding interview questions for each study are provided in Chapters 3, 4 and 5 within the methodology section for each paper. 
Figure 2-1: Research approach in three papers

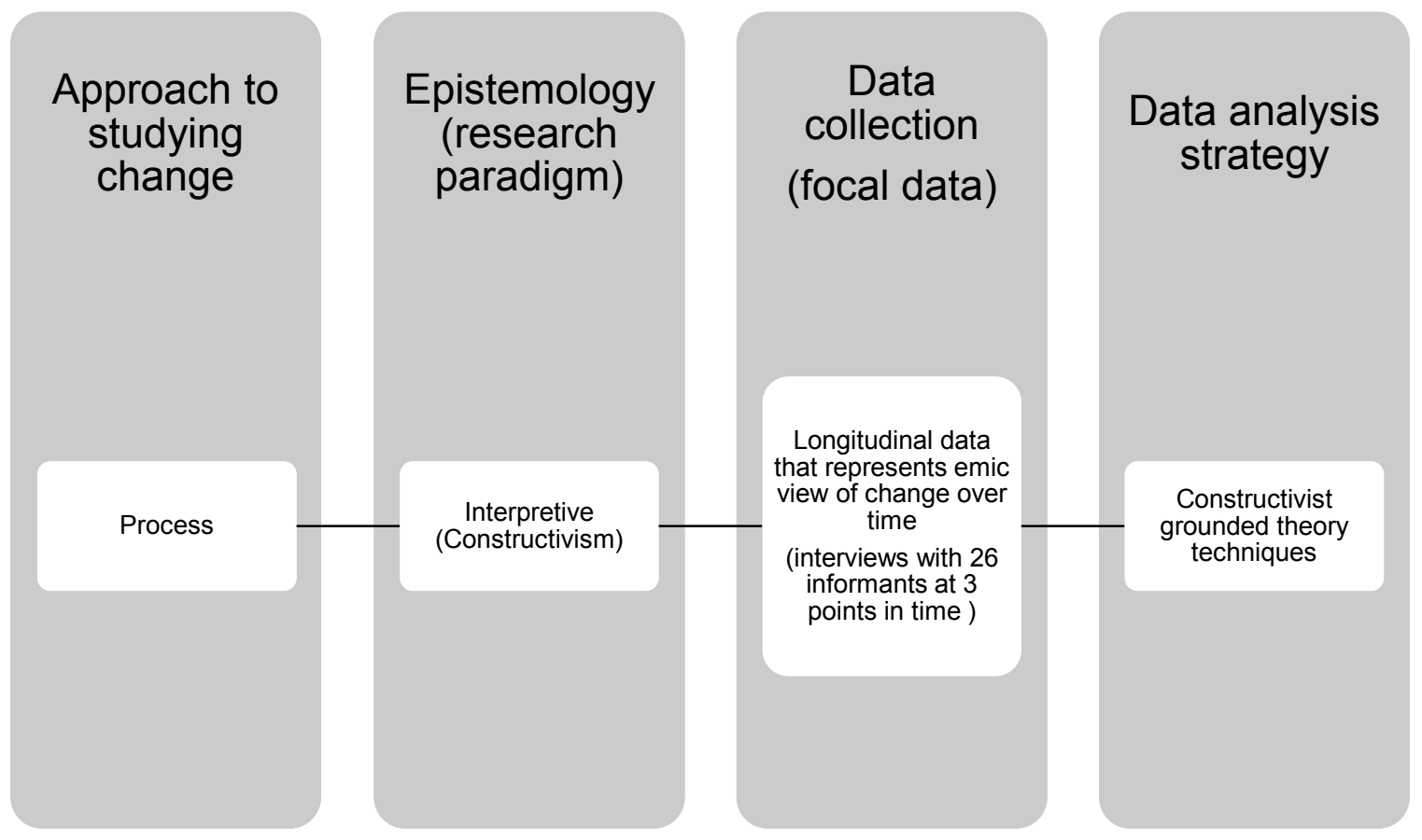

This chapter has six sections. First, section 2.1 reviews the three common epistemologies used by researchers undertaking qualitative research in management (i.e. positivist, interpretive and critical) and identifies and justifies the stance adopted for the thesis (i.e. interpretive). Second, section 2.2 describes the overall methodological approach to the thesis - case study using constructivist grounded theory data analysis techniques. Next, section 2.3 familiarizes the reader with the case organization (i.e. Community Hospital) and the changes it has faced over the duration of the study's timeframe. The data collection procedures, including sampling techniques and the types of data collected, are reported in section 2.4. Section 2.5 explains the grounded theory data analysis techniques that were employed in all three studies. Finally, section 2.6 
presents and describes the criteria that can be employed to evaluate the quality of the research conducted in the thesis.

\subsection{Qualitative research epistemologies}

According to Van de Ven and Poole (2005), a qualitative approach is most appropriate when one is undertaking a process study of sensemaking and organizational change from an emic view. They do not, however, provide direction with respect to how this qualitative research should be done. One of the major challenges associated with qualitative research is the plethora of terms for articulating assumptions, approaches, and procedures. For example, terms such as interpretive and constructivist are common in qualitative research, yet these words may mean different things within or across different fields, or niches.

According to Myers (2009) "all research, whether quantitative or qualitative, is based on some underlying assumptions about what constitutes "valid" research and which research methods are appropriate" (p. 35). Lincoln, Guba and Lynham (2011) claim that five qualitative research "paradigms" exist (positivism, post-positivism, critical theory, constructivism, and participatory) - each with their own epistemologies, ontologies and accompanying implications for research design and evaluation. Myers (2009) suggests that qualitative research in management tends to be conducted according to one of three different sets of epistemologies, or philosophical assumptions about knowledge (positivist, interpretive, and critical) each with a unique set of implications for research design. The goal of this section is to explain to the reader the three common qualitative research epistemologies in management research, articulate their underlying assumptions 
and clarify the approach used in this thesis. Table 2-1 summarizes the assumptions and implications of each approach, which are also described below. In the interest of clarity this section of the thesis uses the terms from Myers (2009) because these refer specifically to the qualitative research epistemologies common in management research, whereas Lincoln et al.'s (2011) paradigms are not specific to management research. In this section Myer's (2009) description of each epistemology is supplemented with information from corresponding research paradigms discussed by Lincoln et al. (2011).

Table 2-1: Three epistemologies in qualitative management research (based on Lincoln et al., 2011)

\begin{tabular}{|l|l|l|l|}
\hline Epistemology & Positivist & Interpretive & Critical \\
\hline Definition & $\begin{array}{l}\text { "the natural science model } \\
\text { of social research and } \\
\text { assumes that reality is } \\
\text { objectively given." } \\
\text { (Myers, 2009, p. 260) }\end{array}$ & $\begin{array}{l}\text { Focuses on the } \\
\text { social construction } \\
\text { of meaning and } \\
\text { sensemaking in } \\
\text { organizations } \\
\text { (Myers, 2009) }\end{array}$ & $\begin{array}{l}\text { "assumes that } \\
\text { reality is socially } \\
\text { constructed but } \\
\text { focuses on social } \\
\text { critique of current } \\
\text { conditions" (Myers, } \\
\text { 2009, p. 257 }\end{array}$ \\
\hline Ontology & Critical realism & Relativist & Historical realism \\
\hline Methodology & $\begin{array}{l}\text { Hypothetical deductive } \\
\text { method - hypothesize, } \\
\text { deduce and generalize }\end{array}$ & Naturalistic & Participatory \\
\hline Axiology & $\begin{array}{l}\text { Closer understanding of } \\
\text { "concrete" reality }\end{array}$ & $\begin{array}{l}\text { Instrumental } \\
\text { knowledge }\end{array}$ & $\begin{array}{l}\text { Empowerment and } \\
\text { change }\end{array}$ \\
\hline $\begin{array}{l}\text { Research } \\
\text { product }\end{array}$ & $\begin{array}{l}\text { Nomothetic theory and } \\
\text { testable propositions }\end{array}$ & $\begin{array}{l}\text { Process models and } \\
\text { novel concepts }\end{array}$ & $\begin{array}{l}\text { Structural and } \\
\text { historical insights }\end{array}$ \\
\hline $\begin{array}{l}\text { Quality } \\
\text { criteria }\end{array}$ & $\begin{array}{l}\text { Rigor and objectivity of } \\
\text { inquiry }\end{array}$ & Trustworthiness & $\begin{array}{l}\text { Contribution } \\
\text { towards the creation } \\
\text { of a more fair } \\
\text { society }\end{array}$ \\
\hline Inquiry aim & $\begin{array}{l}\text { Explanation: prediction } \\
\text { and control }\end{array}$ & $\begin{array}{l}\text { Understanding: } \\
\text { reconstructing } \\
\text { meaning }\end{array}$ & Transformation \\
\hline
\end{tabular}




\subsubsection{Positivist epistemology}

Qualitative research in the positivist tradition is prevalent in management research (Myers, 2009). Positivist research refers to "the natural science model of social research and assumes that reality is objectively given.” (Myers, 2009, p. 260). Although Myers (2009) uses the term "positivist", Lincoln et al. (2011) refer to qualitative research that is consistent with the natural science model as "post-positivist" (because true positivist research would not use qualitative data). The ontological stance, or the assumptions regarding the nature of reality, of this research is "critical realism" - which views reality as concrete and objective (Lincoln et al., 2011). Accordingly, research undertaken using this paradigm employs methods that utilize hypothetical deductive reasoning meaning data collection and analysis seeks to verify or falsify hypotheses (Lincoln et al., 2011). The goal, or axiology, of this type of research is to create knowledge that represents an accurate view of the "concrete" reality (Lincoln et al., 2011). This means that the quality of such work is evaluated based on the level of objectivity achieved during inquiry as measured by validity (both internal and external) and reliability (Lincoln et al., 2011). High quality positivist research seeks to minimize any bias throughout the research process such that the product of the research can most accurately depict the concrete reality of the phenomena under study (Myers, 2009). The overall aim of positivist research is to provide explanation; explanation of how research constructs can be predicted and controlled (Lincoln et al., 2011).

Eisenhardt's case study method (Eisenhardt, 1989) is an example of qualitative management research consistent with the positivist/post-positivist epistemology (Langley \& Abdallah, 2011). This method seeks to develop nomothetic theory that yields testable 
propositions (Langley \& Abdallah, 2011). Eisenhardt's approach commonly cites earlier methodological texts by Yin (2009) and Miles and Huberman (1994). The "Eisenhardt" method uses qualitative data to search for facts (Eisenhardt, 1989).

\subsubsection{Interpretive epistemology}

Interpretive research in management studies tends to focus on the social construction of meaning and sensemaking in organizations (Myers, 2009). Interpretive research is less wide spread in management research compared to positivist research but has experienced increased acceptance among scholars over the past 20 years (Myers, 2009). This is the epistemology adhered to in this thesis, it is consistent with what Lincoln et al. (2011) refer to as the constructivism paradigm for qualitative research.

Details on the implications of the interpretive epistemology for this thesis are outlined in Table 2-2. The ontological stance of interpretive research is relativist, meaning "people construct their own understanding of reality and construct meaning based on interaction with surroundings"(Denzin \& Lincoln, 2011, p. 13). Methodologically, interpretive research calls for naturalistic procedures for data collection, which involve interview and observational techniques (Angen, 2000) that permit the studying of "subjects in their natural settings... to interpret phenomena in terms of the meanings people bring to them" (Denzin \& Lincoln, 2011, p. 13). This approach uses qualitative data to capture the meanings that informants assign to organizational events (Langley \& Abdallah, 2011). The axiology, or goal, of this research is to understand and reconstruct individual experience such that findings may inform practice (Lincoln et al., 2011). This means that the researcher and the subject co-create 
understandings and the researcher tries to capture and model the subject's meanings and understandings (Denzin \& Lincoln, 2011). These types of studies seek to produce process models and/or novel concepts (Langley \& Abdallah, 2011). The overall aim of interpretive research is to provide understanding through the "reconstruction" of research informants' experiences (Lincoln et al., 2011). In this type of study the emphasis is not on removing researcher bias, as is common in positivist studies, but rather on acknowledging the researchers' role in the co-creation of findings and evaluating outputs according to trustworthiness (Lincoln et al., 2011). Trustworthiness includes four components: credibility, transferability, dependability and confirmability, (Lincoln \& Guba, 1985; Shah \& Corley, 2006) - details for how each of these criteria are assessed in this thesis are included in Section 2.6 (Evaluating quality of research products) of this chapter.

Table 2-2: Implications of using interpretive epistemology for thesis

\begin{tabular}{|l|l|l|}
\hline \multicolumn{1}{|c|}{$\begin{array}{c}\text { Aspect of } \\
\text { paradigm }\end{array}$} & Assumptions & \multicolumn{1}{c|}{ Implications for thesis } \\
\hline Ontology & Relativist & $\begin{array}{l}\text { Individuals construct own meanings and understanding } \\
\text { of reality }\end{array}$ \\
\hline Epistemology & Interpretive & $\begin{array}{l}\text { Researcher and informant co-create understandings; } \\
\text { researcher tries to capture informant understandings }\end{array}$ \\
\hline Methodology & Naturalistic & $\begin{array}{l}\text { Interview and observation techniques used to allow } \\
\text { researcher to investigate the meaning individuals } \\
\text { assign to phenomena of interest }\end{array}$ \\
\hline Axiology & $\begin{array}{l}\text { Instrumental } \\
\text { knowledge }\end{array}$ & $\begin{array}{l}\text { Create/share an understanding of individuals' } \\
\text { experiences that may inform practice }\end{array}$ \\
\hline $\begin{array}{l}\text { Quality } \\
\text { criteria }\end{array}$ & Trustworthiness & $\begin{array}{l}\text { Achieved via credibility, transferability, dependability } \\
\text { and confirmability }\end{array}$ \\
\hline
\end{tabular}

The interpretive epistemology, and its accompanying ontological, methodological and axiological assumptions, are well suited for this study because they advocate a focus 
on understanding phenomena (i.e. organizational change) from the perspective of the subject (i.e. emic or individual within organization) and producing results that ultimately inform practice in a substantive area (e.g., change management).

\subsubsection{Critical epistemology}

Finally, critical research "assumes that reality is socially constructed but focuses on social critique of current conditions" (Myers, 2009, p. 257). Research carried out using a critical epistemological approach is, in many ways, similar to that conducted using the interpretive view in that both approaches focus on the social construction of phenomena. This epistemology differs from the interpretive view, however, in that it focuses more on social critique (of power structures, politics and other widely held beliefs) than on reconstructing informant's understandings (Myers, 2009).

Critical research is significantly less well known among management scholars in comparison with research carried out in the positivist and interpretive traditions (Myers, 2009). The ontology of critical research is historical realism, which views reality as shaped by "social, political, cultural, economic, ethnic, and gender values" (Lincoln et al., 2011, p. 100). The methods involved in critical research focus on participatory research styles that work to empower oppressed groups with the goal (i.e. axiology) of promoting social transformation (Lincoln et al., 2011). Accordingly, quality in this type of research is achieved when research outputs impart actions that can contribute to the development of a more fair society (Lincoln et al., 2011). The overall aim of critical research is to inspire transformation through critique that motivates restitution and emancipation (Lincoln et al., 2011). 


\subsection{Methodological approach}

This thesis is an interpretive case study that utilizes grounded theory data analysis techniques. The purpose of this section of the Methodology chapter is to describe the case study approach (section 2.2.1) and to explain the rationale for using grounded theory data analysis techniques (section 2.2.2). More details on the specific grounded theory data analysis techniques that are employed in the thesis can be found in section 2.5 (data analysis).

\subsubsection{Case study design}

The term case study refers to an empirical study that examines a phenomenon within its real-life context (Yin, 2009). Conducting a case study of a single organization is a common approach in business research (Myers, 2009). The case study method is well suited for this thesis for two key reasons. First, case studies are useful when boundaries between the phenomenon of interest and the context are not clear (Myers, 2009; Yin, 2009), as is the case with sensemaking about organizational change. Second, the case study method is useful for answering how and why questions and looking at social processes (e.g., how do individuals make sense of change over time?) (Yin, 2009). Case studies can be conducted in accordance with the positivist, interpretive or critical research paradigms described above (Myers, 2009). This thesis undertakes an interpretive case study because this type of case study seeks to understand phenomena from the perspective of people in the case study organization (Myers, 2009) and is, therefore, most closely aligned with the primary objective of this thesis. 


\subsubsection{Grounded theory approach to data analysis}

Grounded theory is one of a number of strategies that can be used to analyze process data (Langley, 1999). Although many scholars use the term "grounded theory" to refer to generic inductive theorizing, it in fact refers to a specific approach that consists of "systematic yet flexible guidelines for collecting and analyzing qualitative data to construct theories 'grounded' in the data themselves" (Charmaz, 2006, p. 2). The original grounded theory method text (Glaser \& Strauss, 1967) has been criticized for its foundation on shaky epistemological grounds (Charmaz, 2009). Over time this critique has been addressed through the identification of two branches of grounded theory: objectivist and constructivist (Charmaz, 2006). Objectivist grounded theory, on the one hand, resides in the positivist tradition and thus views data as real and representative of a concrete reality (Charmaz, 2006). It involves an etic approach where the researcher takes the role of an outside observer of the research subjects, analyzing their world from the outside expert point of view. Constructivist grounded theory, on the other hand, is consistent with the interpretive epistemological stance as it places priority on the phenomena of study and sees both data and analysis as created from shared experiences and relationships with participants (Charmaz, 2006). It involves an emic approach where the researcher seeks to understand how members (i.e. insiders) construct their own experiences. Table 2-3 is from Charmaz (2009) and is useful for clarifying the differences between the two approaches to grounded theory. 
Table 2-3: Objectivist vs. constructivist grounded theory (from Charmaz, 2009, p. 141)

\begin{tabular}{|l|l|}
\hline Objectivist Grounded Theory $\rightarrow$ & \multicolumn{1}{c|}{$\leftarrow$ Constructivist Grounded Theory } \\
\hline \multicolumn{2}{|c|}{ Foundational Assumptions } \\
\hline Assumes an external reality & Assumes multiple realities \\
\hline Assumes discovery of data & $\begin{array}{l}\text { Assumes mutual construction of data through } \\
\text { interaction }\end{array}$ \\
\hline Assumes conceptualizations emerge from data & Assumes researcher constructs categories \\
\hline Views representation of data as unproblematic & $\begin{array}{l}\text { Views representation of data as problematic, } \\
\text { relativistic, situational, and partial }\end{array}$ \\
\hline $\begin{array}{l}\text { Assumes the neutrality, passivity, and authority } \\
\text { of the observer }\end{array}$ & $\begin{array}{l}\text { Assumes the observer's values, priorities, } \\
\text { positions, and actions affect views }\end{array}$ \\
\hline \multicolumn{1}{|c|}{ Objectives } \\
\hline Aims to achieve context-free generalizations & $\begin{array}{l}\text { Views generalizations as partial, conditional, } \\
\text { and situated in time, space, positions, action } \\
\text { and interactions }\end{array}$ \\
\hline $\begin{array}{l}\text { Aims for parsimonious, abstract } \\
\text { conceptualizations that transcend historical and } \\
\text { situational locations }\end{array}$ & $\begin{array}{l}\text { Aims for interpretive understanding of } \\
\text { historically situated data }\end{array}$ \\
\hline Specifies variables & Specifies range of variation \\
\hline $\begin{array}{l}\text { Aims to create theory that fits, works, has } \\
\text { relevance and is modifiable (Glaser) }\end{array}$ & $\begin{array}{l}\text { Aims to create theory that has credibility, } \\
\text { originality, resonance, and usefulness }\end{array}$ \\
\hline $\begin{array}{l}\text { for } \\
\text { Data Analysis }\end{array}$ \\
\hline $\begin{array}{l}\text { Views data analysis as an objective process } \\
\text { analysis }\end{array}$ & $\begin{array}{l}\text { Acknowledges subjectivities throughout data } \\
\text { analysis }\end{array}$ \\
\hline Sees reflexivity as one possible data source & $\begin{array}{l}\text { Recognizes co-construction of data shapes } \\
\text { analysis }\end{array}$ \\
\hline Engages in reflexivity \\
\hline ates and voice & $\begin{array}{l}\text { Seeks and (re)represents participants' views } \\
\text { and voices as integral to the analysis }\end{array}$ \\
\hline
\end{tabular}

The thesis utilizes constructivist grounded theory techniques, a choice that is consistent with both the objective and the use of an interpretive epistemology. Grounded theory techniques are the best strategy for analyzing process data in this thesis for three reasons. First, grounded theory data analytic techniques yield research outputs (i.e. theory and/or theoretical concepts) that are "grounded" in the data themselves (Charmaz, 
2006). This is consistent with the "emic" portion of this thesis's objective (i.e. this study seeks to explore individuals' sensemaking about change from an insider, or emic, viewpoint). Second, the use of grounded theory strategies to analyze process data enhances the researcher's ability to identify meanings and patterns in qualitative data over time (Langley, 1999). This is consistent with the longitudinal aspect of this thesis, which seeks to look at individuals' sensemaking about change over time. Third, grounded theory methods are known for developing "context-based process oriented descriptions and explanations of organizational phenomena" (Myers, 2009, p. 106). This characteristic of grounded theory makes it particularly well suited to the study of organizational change, where the consideration of context is paramount (Pettigrew, 1990).

\subsection{Case selection and overview}

This part of the methodology chapter familiarizes the reader with the case study organization and some of the internal and external changes that have occurred at this organization. This portion of the chapter is structured as follows. First, section 2.3.1 provides a brief description of the organization. Next, section 2.3.2 summarizes the external pressures for change at the hospital. Finally, section 2.3.3 explains the internal pressures for change at the hospital over the years including a timeline.

\subsubsection{Community Hospital}

The case organization for this research is a primary care hospital located in eastern Ontario, Canada. It is located approximately one hour driving distance away from an urban center, which has a population of close to 900,000 . The hospital is located in a small town, which has a population of about 2,500. In addition to providing care for the 
residents of this town, the hospital (referred to as Community Hospital in this thesis) also provides care for a number of neighboring towns in the rural farming region. It is one of the key employers for this region. Community Hospital has approximately 400 staff (including appointed contracted physicians). The 63-bed hospital hosts inpatient, outpatient and diagnostic imaging and laboratory services on site including medical and surgical care, obstetrical care, complex continuing care, enhanced care, emergency care, clinics, general x-ray and CT scans. The hospital was first officially opened as a 32-bed hospital in 1948. When Community Hospital first opened there was a parade, which was widely attended by residents of the surrounding region, many of whom had been responsible for raising money so that the hospital could be built.

The strategy that led to the selection of Community Hospital as the case organization for this thesis is two-fold. First, a context that provides "high potential for developing new insight into an understudied phenomenon" (Langley \& Abdallah, 2011, p. 214) was sought out. For this thesis, the healthcare sector serves as an ideal context because this sector faces significant pressures for change including: (1) demographic shifts (Statistics Canada, 2010, 2012) that will affect both the supply and demand for healthcare, (2) the introduction of new technologies (e.g., electronic health record) that profoundly impact how care is managed and delivered, (3) the political nature of the funding structures and governance mechanisms (e.g., Zeytinoglu, Denton, Davies, Baumann, Blythe, \& Boos, 2007), (4) the push towards more patient centered care delivery models (CIHI, 2009), and (5) leadership turnover at the provincial and federal levels in Canada (Romanow, 2007). For more details about these pressures for change and their impact on Community Hospital refer to sections 2.3.2 and 2.3.3 below. 
Second, an organization that serves as an "extreme" case of the phenomenon of interest was identified (Charmaz, 2006; Langley \& Abdallah, 2011). "Extreme" cases are important because they can provide researchers with the rich data necessary when conducting interpretive studies, which rely on detailed data to reveal informants' understandings and meanings attached to organizational phenomena (Langley \& Abdallah, 2011). The sheer amount of change that Community Hospital has experienced since 2009 - the time that the data collection for this thesis began - makes this healthcare organization an "extreme" case of organizational change (i.e. the phenomena of interest for this thesis). More specifically, between 2009 and 2013 the hospital experienced what could be considered an above average number of significant organizational changes. Further details on these and other additional changes can be found in the following sections: "2.3.2 External pressures for change" and "2.3.3 Internal pressures for change and timeline".

Although Community Hospital was well suited for this study some features of the hospital served as constraints throughout the research process. More specifically, Community Hospital's size and the fact that it was located in a small town where everyone knew each other presented some challenges with respect to reporting results. While indicating the job type of an interview respondent when a quote is provided is common practice, the size of the hospital and the fact that everyone knew each other meant that by reporting such data we ran the risk of compromising the confidentiality and anonymity that was promised to all informants. 


\subsubsection{External pressures for change}

A number of strong external pressures for change have affected Community Hospital over the past decade. This section reviews three of these pressures (population demographics, technology, and government) and highlights ways that the hospital has responded.

A large proportion of the Canadian population is aging and will be of retirement age within the next decade (Statistics Canada, 2010). The impact that this shift in population demographics has on the Canadian healthcare environment is twofold. First, the increase in the proportion of Canadian healthcare personnel that are of retirement age could result in labour shortages for healthcare organizations (Romanow, 2002). Second, the aging population will likely result in an increased demand for healthcare services in Canada because individuals over the age of 65 are more likely to experience a number of ailments that require healthcare treatment (Statistics Canada, 2010). One way that Community Hospital has responded to this pressure is by integrating care for an aging population into the hospital's long-term strategic plan. In 2012 Community Hospital completed the acquisition of a long-term care facility located next to the hospital.

A number of researchers have observed that new technologies are impacting how care is provided in the healthcare sector (e.g., Kaur, Forducey, Smith, \& ScheidemanMiller, 2004; Lowe, 2001; Nicolini, 2007; Spratt \& Dickson, 2008). The development of new technologies has also been a significant driver for change at Community Hospital. The introduction of the electronic health record (EHR) is one technological development that is affecting Canadian healthcare organizations (CIHI, 2009). Community Hospital 
officially implemented the EHR in the summer of 2012. This implementation has changed the way that staff provides care. For example, the new EHR system requires that patient identification bracelets be electronically scanned when administering bedside care.

Finally, the government and the shifting political priorities, changes in public leadership and new government mandates have considerably influenced healthcare organizations. The push by the Canadian federal and provincial governments towards patient centered care is changing the way that healthcare organizations are funded (CIHI, 2009; Government of Ontario, 2012). The full implications of mandates related to the “pay for care” model (e.g., Ontario’s “Action Plan”) are not yet clear. In 2006 the Ontario government introduced regional regulatory bodies for healthcare organizations called Local Health Integration Networks (LHINs). The LHINs are responsible for implementing government mandates, such as Ontario’s “Action Plan” (Government of Ontario, 2012), which may result in forced changes to Community Hospital. Potential changes that the LHINs could impose include a forced merger with another hospital, the closure of Community Hospital's emergency department and other changes to service offerings. In 2011 Community Hospital formalized an agreement to merge with a significantly larger hospital from the nearby urban center in order to decrease the likelihood that the LHINs would consider Community Hospital as a potential target for restricting services.

\subsubsection{Internal pressures for change and timeline}

In order to cope with these external pressures for organizational change Community Hospital undertook a planned organizational change initiative that began in 
2002. A number of changes were implemented as part of this initiative such as the construction of and move to a new facility, leadership turnover (including CEO succession) and a variety of other strategic changes that were implemented as part of ensuring the hospital's long-term survival. Over the course of the planned change initiative (2002-2011) the number of significant changes introduced within the hospital suggests that employees within Community Hospital were exposed to what Stensaker et al. $(2001,2003)$ have defined as excessive change (see discussion in section 1.3.2.4).

Figure 2-2 outlines some of the key changes that took place at the hospital from 2009 through 2013 (the time period which these studies focuses on). The changes included in the figure are described below.

Figure 2-2: Timeline of change and data collection

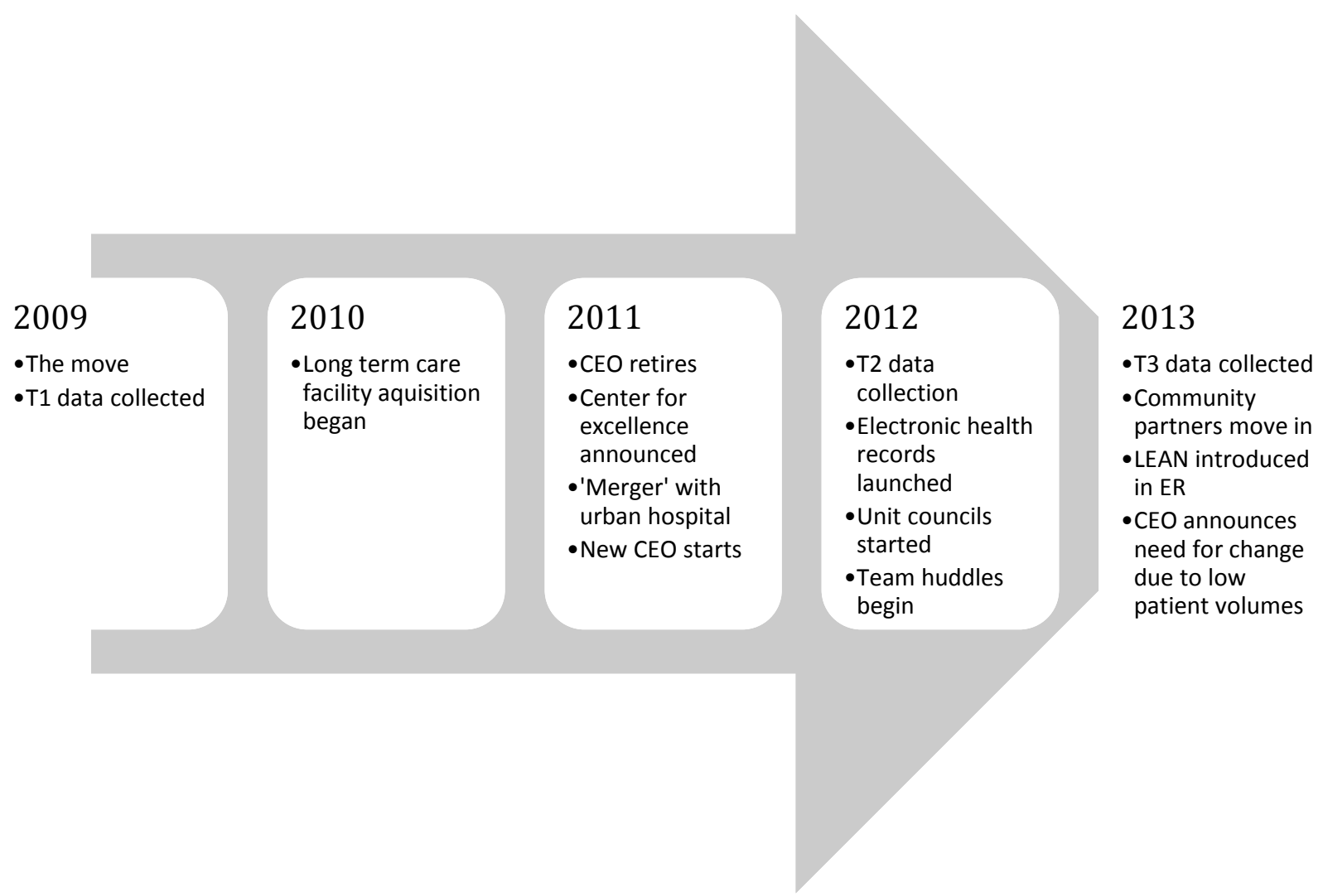


Before 2009. A decade of organizational change kicked off with the "vision" fundraising campaign, which was launched in 2002 in order to raise money to build a new hospital. In 2004 a new CEO was hired by Community Hospital's board of directors in order to lead the organization through the major changes. The CEO was an external hire who had begun her career as a nurse but more recently had experience serving in administrative roles. Community Hospital was the first time she had served as a CEO for an organization. Between 2004 and 2007 she made a number of changes to the Senior Management team at the hospital. More specifically she hired five new individuals to serve on the small team of eight.

2009. In March of 2009 the new hospital officially opened (i.e. "the move"). Although Community Hospital was outperforming its peers on benchmarks including patient satisfaction and overhead cost per case, the CEO was concerned about morale at the hospital. A 2009 survey, carried out by a third party group (NRC Picker), had found low job satisfaction among organizational members. It was at this point in time that the CEO contacted the researcher's supervisor (Dr. Linda Duxbury) to conduct an in-depth "staff satisfaction" study at the hospital. The initial "staff satisfaction" study lasted approximately six months (from June 2009-December 2009) and included interviews (conducted and analyzed by the author) and a quantitative staff survey. The results of this initial study indicated that there were major rifts at the hospital between the different occupational groups. There also appeared to be "cliques" at the hospital based on tenure (i.e. whether individuals were long time employees or not) and where individuals resided (i.e. whether they were from the small town/surrounding region or the nearby urban center) (Gover \& Duxbury, 2012). 
2010-2011. After the initial study was completed the researchers publicly shared the results from the initial survey and interview study with the hospital as a whole in February of 2010. Post presentation in Spring 2010 the researchers conducted a series of focus groups to identify possible solutions to the issues identified from the survey/interviews. The results from the focus groups resembled earlier findings; an unhealthy, conflict-ridden relationship between the clinical (i.e. physicians and nurses) and administrative (i.e. management) groups within the hospital.

Despite the initial commitment from Community Hospital to share the focus group results with organizational members, the researchers were not given the opportunity to communicate results with staff or physicians. From 2009 to 2010 (the time of the "staff satisfaction" study and the follow-up focus groups) Community Hospital continued to implement new technologies and work processes intended to assist in the provision of patient centered care. In late 2010 a working group called the physician engagement group was formed within the hospital and area experts were engaged specifically to address issues related to the poor relationship between the physician and management groups. Physician leaders, the CEO, and a few Senior Managers were members of this working group. Aside from the establishment of the physician engagement group, it was unclear if any additional steps were taken to address the issues at Community Hospital identified in the initial phase of data collection.

Throughout 2010 the board of directors encouraged the CEO to retire, which she did in June of 2011 (i.e. "CEO retires"). Prior to the retirement she had launched a new vision for the hospital: that Community Hospital "would be a Centre of Excellence for Rural Health and Education in Ontario" (i.e. "Center for Excellence announced"). As part 
of this vision a number of partnerships with local and regional healthcare providers were formed. For example, in 2010 the hospital began negotiations for the acquisition of a nearby long-term care facility (i.e. "long term care facility acquisition") and in early 2011 the hospital signed an agreement to merge with a much larger urban hospital (i.e. "merger with urban hospital").

The selection process for the new CEO occurred over the summer of 2011 and in September 2011 the new CEO started (i.e. "new CEO"). The new CEO, another external hire, did not have a clinical background but had past experience serving in CEO roles at similarly sized hospitals. The new CEO was a man, the CEO he replaced was a woman. In addition to carrying out the Centre of Excellence plans set in motion by the former CEO, the new CEO focused his efforts on a number of activities including: (1) improving the relationships between the different groups within the organization, (2) integrating the eldercare facility into the hospital, and (3) determining how the merger with the larger hospital should proceed. Although the organization was continuing to perform well, the sense was that intergroup relationships were still poor and appeared to be negatively impacting the day-to-day experiences of organizational and community members. In order to determine ways to address this issue the new CEO agreed in Fall 2011 to participate in an action research study in collaboration with the research team. A steering committee was created in Fall 2011 to guide the focus and overall execution of the study. Steering committee members included individuals in Senior Management, the CEO, the Chief Nursing Officer and the Chief of Staff (i.e. Physicians). The committee members identified a number of priorities for the action research study, including the 
physician engagement work-group's interests and the goal of "making Community Hospital a better place to work".

2012-2013. Interviews with staff were conducted in the spring of 2012 as part of this action research study. The pace of change at Community Hospital did not wane with the hiring of the new CEO. Some changes implemented by the new CEO in 2012 were changes to work processes in order to strengthen the organizational culture such as the introduction of unit councils for nursing staff (i.e. "unit councils started"), team huddles in all departments (i.e. "team huddles begin") and new technologies such as the electronic health record (i.e. "Electronic Health Records").

In 2013 there were even more changes. For instance, partnerships were made with other healthcare organizations that leased space in a building constructed next to the hospital (i.e. "community partners move in") and LEAN was implemented in the emergency department (i.e. "LEAN introduced in ER"). Shortly after the implementation of LEAN, in September of 2013, the new CEO announced that the hospital would need to make changes in response to the low patient volumes in many departments (i.e. "CEO announces need for change due to low patient volumes"). At the time, the CEO did not specifically address how these changes would be implemented or what form they would take. Follow-up interviews as part of the 2011-2012 action research study were conducted with staff in September and October of 2013.

In summary Community Hospital is an ideal research site for the thesis study for three reasons. First, it is an organization that has undergone excessive change over the past decade and that faces substantial change in the future. As such it is ideally suited for a study of how individuals' make sense of change over time. Second, the small size of 
this organization, compared to urban hospitals, facilitates the use of the qualitative techniques that are recommended for process based change research (Van de Ven \& Poole, 2005). Third, the researcher's long-term research involvement with this organization $(2009$ - 2013) means that the longitudinal data necessary for addressing the research objectives has been collected. More specifically, the research conducted in 2009 with the prior CEO permitted the collection of the first set of interview data with the 26 informants, whose recollections of change are featured in this thesis. The researcher then had the opportunity under the new CEO to interview these same 26 people in 2012 and 2013. This set of interviews ( 26 people, 3 points in time) and the fact that they were conducted during conditions of excessive change provide the researcher with a fairly unique opportunity to explore individual perceptions of change over time.

\subsection{Data collection}

While a number of different techniques were used to collect data used in the thesis including interviews, surveys, focus groups, observation and documents, interview data are key to the analysis because of their ability to help us understand how individuals make sense of organizational change over time from an emic/insider perspective. More specifically, interviews capture contextual details related to the process of organizational change (Langley, 1999). Interviews also reflect individual's sensemaking and can be considered constructions or reconstructions of experience (Charmaz, 2006).

The objective of this part of the Methodology chapter is to provide the reader with an understanding of the data collection strategy for this research. This part of the chapter is comprised of two sections. First, section 2.4.1 explains the types of data collected and 
describes the tools used for collecting these data. Next, section 2.4.2 provides specific information about how the sample data was derived from the larger data set and describes the interview sample.

\subsubsection{Types of data collected}

The sample data to be utilized in this thesis comes from a larger data set (see Table 2-4) comprised of surveys, focus groups, interviews and observations obtained as part of the research team's (i.e. the author of the thesis and her thesis supervisor) involvement with Community Hospital from 2009 until 2013. The timing of these research activities in relation to the changes that were occurring at Community Hospital is described in the section about internal pressures for change at Community Hospital (section 2.3.3) and shown pictorially in Figure 2-2 (Timeline of change and data collection). The use of observations and documents is described later (see section 2.5.1.4). This section, therefore, describes the interview and survey data including the rationale for using each technique and the procedures for collection.

Table 2-4: Larger data set data collection at Community Hospital over time

\begin{tabular}{|c|c|c|c|c|c|}
\hline & 2009 & 2010 & 2011 & 2012 & 2013 \\
\hline Surveys & $\mathrm{n}=83$ & & & $\mathrm{n}=179$ & $\mathrm{n}=41$ \\
\hline Interviews & $\mathrm{n}=59$ & & & $\mathrm{n}=59$ & $\mathrm{n}=41$ \\
\hline Observations & \multicolumn{5}{|c|}{ Conducted throughout. } \\
\hline Documents & & $\mathrm{Co}$ & 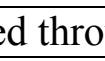 & ut. & \\
\hline
\end{tabular}

\subsubsection{Interviews}

Interviews were used in the first (i.e. T1), second (i.e. T2) and third (i.e. T3) stages of data collection for the thesis. One on one interviews are valuable instruments 
for data collection in constructivist studies where both the method and the instrument are "open-ended yet directed, shaped yet emergent, and paced yet unrestricted" (Charmaz, 2006, p. 28). Interviews were selected as a primary mode of data collection in this thesis because interview data is valuable for process-oriented research about sensemaking and organizational change (Langley, 1999; Myers, 2009). Interviews are a way to capture individuals' sensemaking about change, comparing interviews for one informant over time will allow analysis to explore sensemaking about change over time (from an emic view) - which is central to the objective of this thesis.

The type of interview utilized in this thesis is a semi-structured interview (Gioia, Corley, \& Hamilton, 2013), meaning that while there is a pre-set list of open-ended questions for the interviewer to ask the respondent, the interviewer also has the opportunity to ask follow-up and probing questions of their choice to encourage interviewees to further elaborate on incidents. Copies of the complete interview scripts can be found in Appendix A (T1 interview), Appendix B (T2 interview) and Appendix C (T3 interview). Interviewees were given the option of partaking in an interview in person (in a private room at the hospital) or over the phone at a time that was convenient for them. In earlier stages of the study (e.g., T1) virtually all informants opted have a face-toface interview. By later stages of the study (e.g., T3), however, virtually all of the interviews took place over the phone. This could be because the leadership team at the hospital promoted the research team's efforts less with each successive data collection stage (i.e. T1, T2 and T3) - perhaps leading informants to become more private about their participation. An alternative, but complementary, explanation for the increase in phone interviews over time could be that work loads had increased over time and 
interviewees found it easier to complete the interview over the phone during their own time versus attempting to fit it into their schedule at work. All interviews were audio recorded and transcribed for data analysis.

Over the course of the research the interviewer (and author) also employed a number of ethnographic qualitative interview techniques in order to understand the language and culture of respondents and present oneself in a manner that would make informants at ease in order to gain informant trust and establish rapport (Fontana \& Frey, 2005). In the interest of clarity, the paragraphs below, which describe these steps, are written in first person.

Understanding the language and culture of the respondents is critical for meaningful data interpretation (Fontana \& Frey, 2005). More specifically, appreciating the rural location of the organization and understanding the types of healthcare provided in each unit were critical in establishing a common language with informants. Many informants used healthcare jargon and phrases that referred to goings on in the local communities, my understanding of such terms was, therefore, important to my ability to interact with the informants and to interpret the data. Accordingly, I sought out additional documents and materials on the hospital and common acronyms from a contact at the organization. I also made a practice of reading Community Hospital's newsletter and frequently visiting their website to check for news and events.

Deciding how to present myself was a significant challenge that was apparent to me at the onset of the first stage of interviews. At the time tensions between groups at the hospital were high, individuals at the organization were skeptical as to the purpose of 
the study especially given the fact that it was the CEO who had reached out to my supervisor. In order to put the informants at ease prior to beginning the interview I would initiate an informal conversation with the informant (not recorded) in order to emphasize my role as a researcher from academia. During these discussions I also emphasized how I personally would be involved in the storage and analysis of the data for the research project and how I would use this data for my thesis. Presenting myself as a "researcher" was intentional in order to make clear to the respondents that I was not associated with any particular area of the hospital (i.e. the CEO or management). At times I even disclosed to informants that both of my parents are nurses, a fact that immediately appeared to soften the tough demeanor of some of the more skeptical clinical staff members.

I believe that these steps were critical in gaining informants' trust and establishing rapport. Despite the fact that many informants expressed displeasure about the focus group results never being shared openly, the relationships that I was able to establish with these individuals influenced their decision to participate in the second and third interviews, and contributed to my ability to assess the data in terms of the meanings and messages that informants were trying to convey (Fontana \& Frey, 2005).

\subsubsection{Surveys}

While a significant proportion of the analysis conducted is based on the one-onone interviews demographic information lends itself well to measurement via survey. More specifically, gender, age, hours at work (per week), job type, organizational tenure 
(years at Community Hospital), and role tenure (years in current job) were all captured using survey data and were useful during data analysis for each of the three papers.

Survey data also provides data to facilitate a more complete view of how individuals in this sample make sense of organizational change over time. The collection of survey data to complement the qualitative interview data is also consistent with recommendations made by Van de Ven and Poole (2005) and Langley (1999) who suggest that process studies can and, in many cases, should utilize both qualitative and quantitative types of data in order to provide a fuller depiction of the phenomena under study.

Surveys were administered in all three stages of data collection (i.e. 2009, 2012, and 2013) for the broader study. All T2 and T3 surveys can be matched to interviews for each individual in the sample. It should be noted, however, that the researcher is unable to link T1 survey data with particular informants. Survey participation was voluntary. Copies of the surveys are available from the author upon request.

\subsubsection{Sampling}

Below the procedure for soliciting participants (section 2.4.2.1), the sample criteria for the thesis (section 2.4.2.2) and a description of the sample for the thesis (section 2.4.2.3) are provided.

\subsubsection{Soliciting participants}

The procedure for soliciting participation in the initial "staff satisfaction" study (done in 2009) was as follows. The first stage of the "staff satisfaction" study involved an 
organization wide survey. Volunteers for surveys were solicited through email, organizational memos, information mailed with paystubs, and announcements made at organization wide meeting and events. Surveys included a question at the end asking survey respondents who were willing to participate in follow-up interviews to provide their name, and email address or phone number where they could be reached. The researcher used this information to contact these volunteers to set up an interview. In some instances, where there were not enough volunteers from a particular occupation group, managers and clinical leaders personally encouraged organizational members to volunteer for interviews. Additional interview participants were also solicited via email, organizational memos, information mailed with paystubs and announcements. At the end of each interview individuals were asked if it would be ok for researchers to contact them again in the future for additional follow-up. Individuals who indicated that it would be ok were contacted again by the researcher in 2012 and 2013 for additional follow-up interviews.

\subsubsection{Sample inclusion criteria}

Grounded theory techniques require that researchers determine sample size based on "theoretical saturation", not population representativeness (Charmaz, 2006; Gioia et al., 2013; Morse, Noerager Stern, Corbin, Bowers, Charmaz, \& Clarke, 2009). Saturation refers to the point at which "the collection of new data does not shed any further light on the issue under investigation" (Mason, 2010, p. 1). Mason's (2010) analysis of $560 \mathrm{PhD}$ thesis abstracts concluded that sample sizes in interview studies are determined by multiples of 5 or 10 (i.e. most studies had samples of 20,25 or 30 individuals), rather than by the principle of "saturation". This finding is arguably related to the fact that 
saturation is very difficult for a researcher to demonstrate (Mason, 2010). Accordingly some grounded theorists have provided guidelines regarding approximate sample sizes in order to reach saturation in grounded theory studies using interviews. Some recommended sample sizes for grounded theory interview studies are 20-30 (Creswell, 1998), 30-50 (Morse, 1994) and 25 (Charmaz, 2006). Charmaz (2006) notes that larger sample sizes are necessary when the findings of the study make claims that significantly contradict existing knowledge. Based on the recommendations provided by established grounded theory researchers, the target sample size for the thesis is 25-35 individuals.

The primary criteria used to determine the sample for the thesis is that longitudinal data is needed because this thesis is interested in sensemaking about change "over time". More specifically, panel interview data that can be connected to an informant for more than two points in time would be useful for examining patterns overtime and is, arguably, likely to yield more complex and rich findings about the process of change than data from just two points in time (Langley, 1999). The sample for this thesis was restricted, therefore, to individuals who participated in interviews at all three points in time including 2009 (T1), 2012 (T2) and 2013 (T3).

\subsubsection{Description of the sample}

In total 26 individuals met the sampling criteria. Information on the sample at $\mathrm{T}^{4}$ is provided in Table $2-5$. The majority of the sample is female ( $\mathrm{n}=20,77 \%$ of the sample)

\footnotetext{
${ }^{4}$ The drop in interview response rate over time is likely due to the fact that management did not allow the researchers to present the focus group findings to staff after T1. We base this conclusion on the fact that many of the staff mentioned this issue in T2 interviews. This would suggest that the response rate drop over time was reflective of declining trust in management as opposed to a lack of commitment to this research.
} 
a finding that is consistent with norms in the healthcare industry and this particular organization. The informants represent a variety of occupational groups (i.e. job types) including managers ( $n=3,12 \%$ of the sample), nurses ( $n=7,27 \%$ of the sample), physicians ( $\mathrm{n}=5,19 \%$ of the sample), other licensed healthcare professionals known within healthcare settings as Allied Health professionals ( $\mathrm{n}=3,12 \%$ of the sample), and non-managerial administrative staff ( $\mathrm{n}=7,27 \%$ of the sample). The sample also varies in terms of how many years informants have worked for Community Hospital (ranges from 4 years to 52 years), with an average organizational tenure of 16.3 years (mode $=4$ years). It should be noted that due to incomplete data for some individuals (e.g., some informants did not provide answers to some interview questions) the sample size for each individual paper varies between 24 and 26 informants as follows: "Sensemaking Lenses" paper $(\mathrm{n}=24)$, "Retrospective versus Real-time" paper $(\mathrm{n}=26)$, and "Coping" paper $(\mathrm{n}=24) . \mathrm{A}$ detailed description for each sample is provided within the methodology section of each paper.

Table 2-5: Sample info

\begin{tabular}{lc}
\hline & $\%(\mathbf{n})$ \\
\hline Male & $23 \%(6)$ \\
Female & $77 \%(20)$ \\
\hline Manager & $12 \%(3)$ \\
Physician & $19 \%(5)$ \\
Nurse & $27 \%(7)$ \\
Clinical support (i.e. Allied) & $12 \%(3)$ \\
Non-Clinical support & $27 \%(7)$ \\
\hline
\end{tabular}




\subsection{Data analysis}

The purpose of this section is to give the reader an understanding of five specific grounded theory techniques (i.e. constant comparison, initial and focused coding, sensitizing concepts, theoretical sensitivity and researcher reflexivity) and how they are employed in this thesis. This section is structured as follows. First, the five specific grounded theory data analysis techniques are described (section 2.5.1). Next, the steps for organizing the data for this thesis and the approach for coding the data are outlined (section 2.5.2).

\subsubsection{Specific grounded theory techniques}

The original grounded theory method texts have been criticized for providing insufficient explanations regarding the analytical processes of the method (Goulding, 2002; Locke, 1996, 2001). More recently, however, sociologists such as Charmaz (2006) and Morse et al. (2009) have provided more detailed explanations of the data analysis techniques. Charmaz's (2006) text Constructing Grounded Theory helps researchers to understand how to employ grounded theory techniques from a constructivist perspective and is a particularly useful methods text for the thesis. The five techniques (initial and focused coding, constant comparison, sensitizing concepts, theoretical sensitivity and reflexivity) are overlapping and, often, interdependent but are described separately in the sub-sections below to help the reader understand what each term specifically refers to.

\subsubsection{Initial and focused coding}

Coding is "the process of defining what the data are about" (Charmaz, 2006, p. 186). Constructivist grounded theory coding differs from other coding practices in that 
grounded theorists create codes based on what emerges from the data, not on preconceived categories. There are two phases of coding in grounded theory development: initial and focused coding (Charmaz, 2006). The initial coding phase is concerned with naming each segment of data whereas the focused stage is more selective and attempts to "sort, synthesize, integrate and organize large amounts of data" (Charmaz, 2006, p. 46). Initial coding can follow a few different approaches, including word-byword, line-by-line or incident-by-incident analysis depending on the type of data researchers are coding (Charmaz, 2006). Incident-by-incident coding, which is employed in this thesis, involves the coding and comparison of multiple "incidents" of data (Charmaz, 2006). For this thesis an "incident" is operationalized as an informants" response to a particular interview question. More details on this process are provided in section 2.5.2 (organizing and coding the data).

There are also a number of approaches and frameworks available to guide the secondary, focused coding, phase. One such approach is theoretical coding, which invites the researcher to assign initial codes to categories and explore possible theoretical relationships between categories (Charmaz, 2006). Theoretical coding may draw upon existing concepts and theory to specify the relationships between categories developed during the initial coding phases (Charmaz, 2006). However, the use of existing concepts and theory is not mandatory for theoretical coding as long as the codes are useful for describing theoretical relationships that the researcher is observing in the data (Charmaz, 2006). While Charmaz (2006) notes that theoretical coding is useful in that it tends to clarify patterns in the data and provides a coherent framework for analysis she also states that it is important that theoretical frameworks not be applied prematurely during data 
analysis to minimize the risk of the researcher forcing data into predetermined theoretical categories rather than allowing such categories to emerge from the data.

Axial coding is another focused coding approach that examines the properties and dimensions of categories that have emerged from initial coding (Charmaz, 2006). In axial coding the researcher seeks to weave relationships around the "axis" of a category (Charmaz, 2006), it is useful for bringing data back together (after the fracturing of data that occurs in initial coding). Although none of the three studies explicitly used axial coding, the ideas that underlie this practice (i.e. bringing data back together) drove the way that focused and/or theoretical coding was performed in each study.

This thesis employs the incident-to-incident initial coding and focused coding practices as these techniques offer a systematic approach for making sense of the dynamic social processes in organizations (Fendt \& Sachs, 2008). One important aspect of the focus coding stage for this thesis is the search for patterns over time. Therefore, during focused coding the researcher included an additional step to organize and view the results from initial and focused or theoretical coding in a manner that considers the "temporality" of the data. The steps taken to organize the data in Nvivo (described in section 2.5.2) permit the researcher to look at patterns over time for each informant as well as for groups of informant (e.g., by job type, organizational tenure group etc.). When, at the time of focused coding, theoretical coding based on existing concepts did not seem like a natural fit with the emerging findings from the data then theoretical coding without relying on concepts from the literature occurred (Charmaz, 2006). These theoretical codes are concerned with explaining how and why particular patterns occur in the data. 


\subsubsection{Constant comparison}

The constant comparison process is central to grounded theory analysis techniques and is used to assist researchers in achieving rigor, or "methodological soundness" (Gulati, 2007). Constant comparison is the "exploration of similarities and differences across incidents in the data" (Goulding, 2002, p. 169). Constant comparison requires the iterative collection and analysis of data (Glaser \& Strauss, 1967) and requires the researcher to examine and code pieces of data to determine meaningful categories and identify the relationship between categories. Constant comparison is used in the thesis during coding (described in more detail below in section 2.5.2). Constant comparison was also employed throughout the initial and focused coding stages because data was coded iteratively, not linearly. This means that as new codes were identified during initial coding the data incidents that had already been coded were revisited to see if the new code applied or related to them.

\subsubsection{Sensitizing concepts}

The term "sensitizing concepts" refers to concepts that act as "tentative tools" that the researcher uses to better understand data (Charmaz, 2006). Sensitizing concepts provide the researcher with "points of departure" that are useful as a starting point, but not an end point for looking at data (Charmaz, 2006). The difference between sensitizing concepts and theoretical coding is that theoretical coding occurs during the later focused coding stages of data analysis. Sensitizing concepts, on the other hand, can be present (implicitly or explicitly) at various stages of the analysis including the focused coding stage. The sensitizing concepts employed in each of the three studies vary, with one 
exception, and are identified and described in each paper (i.e. Chapters 3, 4 and 5). The exception is sensemaking, which is a sensitizing concept for all three studies in that it is the perspective that serves to orient each of the studies.

When analyzing the data it became apparent that many of the informants were using sensemaking processes when evaluating the changes within the hospital (i.e. informants seeking to make sense of and understand the changes they perceived). These findings prompted us to use sensemaking as a sensitizing concept within this research. While the data analysis drove the theorizing (i.e. sensemaking was identified as a sensitizing concept first and then literature on sensemaking was reviewed), when deciding how best to structure the thesis for reasons of parsimony and to most effectively convey the contributions of this research we elected to present a literature review first and describe the methods and data analysis later.

\subsubsection{Theoretical sensitivity}

Theoretical sensitivity refers to "a personal quality of the researcher. It indicates an awareness of the subtleties of meaning of data... [it] refers to the attribute of having insight, the ability to give meaning to data, the capacity to understand, and capability to separate the pertinent from that which isn't”' (Strauss \& Corbin, 1990, p. 41-42).

Theoretical sensitivity is developed through familiarity with the relevant literature and past experience (Strauss \& Corbin, 1990).

For this study theoretical sensitivity was developed in two ways. First, before and during the data collection and analysis stages the researcher sought to familiarize herself with relevant literature on sensemaking and change. Second, over time the researcher 
developed interactional expertise (Collins, 2004), which refers to the researchers' ability to "converse expertly about a practical skill or expertise, but without being able to practice it, learned through linguistic socialization among practitioners" (Collins, 2004, p. 125). Interactional expertise was developed through participating in observations at Community Hospital and reviewing relevant documents from the organization (details below) as well as engagement in a number of other research projects conducted at healthcare organizations.

Observation. The "participant-observation" strategy for conducting observations means that the researcher attended organizational events primarily for the purpose of observing the events but was occasionally involved in that their opinion would be sought on certain organizational issues. Instead of acting as a removed or distant "observer" this researcher used the participant-observer role as an opportunity to engage with organizational members and informants and to develop interactional expertise (e.g., familiarity with committee names, departmental service offerings, organizational processes, etc.). Please see Appendix D for a list of events observed over the duration of this research study.

Documents. A number or documents produced by the organization, the government and by local media were collected and are also available for analysis. Data analysis in the thesis does not focus on these documents explicitly but the process of collecting and reviewing these documents allowed the researcher to acquire interactional expertise and "tacit knowledge" about the organizational context (Dawson, 2000). For more details on the types of documents obtained over the duration of this study refer to Appendix E. 


\subsubsection{Reflexivity}

According to Hall and Callery (2001), researchers that use theoretical sensitivity are at risk for forcing data to fit theory and must engage in researcher reflexivity in order to avoid this methodological trap. Reflexivity is a process through which the researcher scrutinizes their role in the research process and provides the reader with information such that they may assess "how and to what extent the researcher's interests, positions and assumptions influenced inquiry" (Charmaz, 2006, p. 188). In the constructivist approach reflexivity on the behalf of the researcher plays a huge role throughout the research process, as the findings are not independent from the researcher and their biases (Charmaz, 2009). Reflexivity is a constructivist practice about informing the audience of the research (Charmaz, 2006), it is not about removing all bias and increasing objectivity, as is often the approach in positivist and post positivist studies.

The thesis utilized two reflexive practices, memo-ing (Charmaz, 2006) and insider-outsider checks (Gioia et al., 2013). Memo-ing involves the researcher writing informal analytical notes throughout the research process (e.g., during data collection or when conducting analysis). It is important because it encourages the academic to analyze data early in the research process and reflect on how their own perspective and background may influence the direction of the research (Charmaz, 2006). Throughout the data collection and analysis stages of this study the researcher engaged in cluster and freewriting memo-ing. Cluster memos allow the researcher to map their work in a visual and non-linear way (Charmaz, 2006). The researcher writes their central idea, circles it and then writes and connects additional ideas in circles as a means of diagraming potential relationships in the data (Charmaz, 2006). Freewriting is a memo-ing technique 
that involves the researcher writing "anything that comes to mind" (Charmaz, 2006, p. 88) in the interest of putting thoughts on paper until ideas begin to emerge.

Insider-outsider checks are a practice advised by Gioia et al. (2013) who typically employ a team approach to their research where some researchers are heavily involved in data collection (insiders) and others are not (outsiders). This research team structure encourages the "insider" researchers to explain hunches and findings to the "outsider" researchers in an attempt to minimize the influence of perceptual biases on the eventual direction of the research. The thesis attempts to employ this practice through frequent meetings between the author and her supervisor and the author and other PhD students not involved in this research to discuss analytical procedures and emerging findings. These formal and informal conversations served as a type of "insider-outsider check" throughout the data analysis phase of this study.

\subsubsection{Organizing and coding data for the thesis}

Due to the inductive and emergent nature of constructivist studies it is difficult to predict what themes may emerge from the data and ultimately result in the development of theories, concepts or frameworks related to how individuals make sense of organizational change over time. To cope with this level of uncertainty the researcher employed strategies to organize the incidents of data so that these "incidents" could be coded (Charmaz, 2006). The purpose of this part of the Methodology chapter is to give the reader an idea of how the researcher used constructivist grounded theory techniques (described above in section 2.5.1) to analyze interview data in the three studies. This 
section includes two sub-sections. First, section 2.5.2.1 explains how the data was organized. Next, section 2.5.2.2 describes the process for coding the data.

\subsubsection{Organizing the data}

The thesis uses QSR-Nvivo, Version 10, a software that facilitates qualitative data analysis, to sort and code the interview data. All 78 interviews (i.e. 3 interviews over time from 26 informants) were transcribed and imported into Nvivo. In order to prepare the interview data for coding, it needed to be organized into a format that facilitates systematic analysis. The three steps that were then taken to organize the interview data set in Nvivo are visually represented in Figure 2-3 and discussed in the section below.

Figure 2-3: Data organization steps

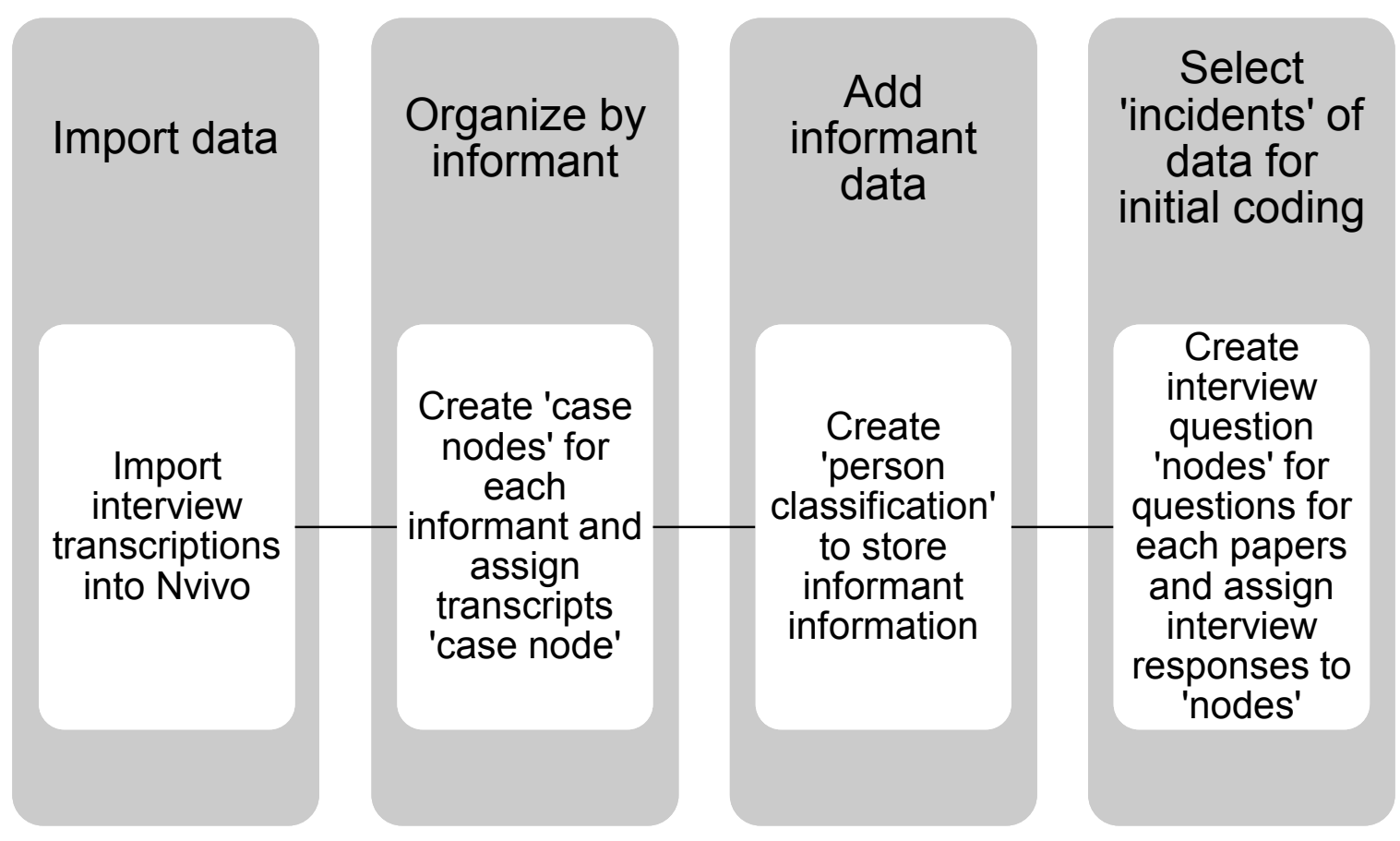


First, "case nodes" for each of the 26 informants were created and used to organize each informant's interviews. The "case nodes" allow the researcher to assign interviews to a particular informant. For instance, all three interviews for "Jane" (pseudonym) would be assigned to the "case node" named Jane. The use of "case nodes" means that the researcher will be able to easily link interviews for each informant over time (i.e. connect data from each informant's T1, T2 and T3 interview).

Second, each "case node" was assigned a "person classification". The "person classification" allows the researcher to store information about the "case node", such as demographic information. Initially, the following information for each informant was added to their "person classification" under their "case node": (1) job type, (2) gender, (3) organizational tenure, and (4) work unit. The use of the "person classification" function is important because once data has been coded the researcher will be able to run searches and generate tables that facilitate the comparison of initial and focused codes according to informant information (e.g., show what proportion of informants whose data received a particular code are also nurses). Nvivo's classification schemes can be updated throughout data analysis and, when needed, the researcher added additional information that might prove useful for understanding patterns in the data. These first two steps (creating case nodes and classification schemes) served to create the data set that was used in all three papers.

The third step in organizing the data is concerned with separating interview transcripts into smaller more manageable pieces. In this case pieces were created to correspond with each of the three papers included in the thesis. According to Langley (1999), the grounded theory strategy for analyzing process data requires many incidents 
of text that the researcher uses to determine categories and themes that describe overall patterns and meanings that informants ascribe to the phenomena of interest. This is known as incident-to-incident coding (Charmaz, 2006). For this thesis informants' responses to specific interview questions served as the incidents of data (i.e. one informant's answer to one interview question $=$ one incident of data).

In the interest of clarity the procedure for separating these incidents of data is described below in bullet-point. The researcher:

- Created "nodes" for each interview question to act as both a label and an electronic folder

- Manually read through each informant's $(n=26)$ three interviews

- Assigned informants' responses to specific interview questions to the corresponding nodes

When the researcher went to analyze the data for each paper these "nodes" were used to access the relevant data (e.g., the researcher could open the node for question A and all responses to question A will be brought up).

\subsubsection{Coding}

The coding was undertaken on a paper-by-paper basis. This means that for Paper one ("Sensemaking Lenses"), the data related to the relevant interview questions that correspond with the sensitizing concepts for this paper were coded. Details on the relevant interview questions for each paper are explained within each paper (i.e. in Chapters three through five). The grounded theory coding techniques employed in the 
thesis have been described in detail in section 2.2.2 and will not be reiterated further here. Chapters three, four and five include more specific details on the procedure and results of the initial and focused coding for each of the three papers.

\subsection{Evaluating quality of research products}

A number of academics have presented frameworks for evaluating qualitative research (e.g. Lincoln \& Guba, 1985; Pratt, 2008; Savall, Zardet, Bonnet, \& Peron, 2008;). However, the idea of generic criteria for qualitative studies should be approached with caution as such criteria could lead those evaluating the research to ignore the fundamental differences which exist among the positivist, interpretive and critical qualitative epistemologies (e.g., their varied ontological assumptions, methodological implications and axiologies). The thesis is consistent with the interpretive epistemology and the quality of the research produced in the thesis should be evaluated according to criteria that are consistent with the assumptions of this approach. Lincoln and Guba (1985) suggested four criteria for evaluating trustworthiness in interpretive qualitative studies (credibility, transferability, dependibility and confirmability) which they paralleled to four criteria commonly used to evaluate positivist studies (internal validity, external validity, reliability and objectivity). Table 2-6 (from Shah \& Corley, 2006) provides description for how researchers can demonstrate each of the four criteria. This standard for evaluating interpretive studies has been supported by a number of qualitative management researchers (Shah \& Corley, 2006; Sinkovics, Penz, \& Ghauri, 2008; Wagner, Lukassen, \& Mahlendorf, 2010). This thesis aims to meet each of the four quality criteria outlined by Lincoln and Guba (1985). 
Table 2-6: Trustworthiness Criteria (from Shah \& Corley, 2006, p. 1830)

\begin{tabular}{lll}
\hline Traditional Criteria & $\begin{array}{l}\text { Trustworthiness } \\
\text { Criteria }\end{array}$ & Methods for Meeting Trustworthiness Criteria \\
\hline Internal Validity & Credibility & $\begin{array}{l}\text { Extended engagement in the field } \\
\text { Triangulation of data types } \\
\text { Peer debriefing } \\
\text { Member checks }\end{array}$ \\
\hline External Validity & Transferability & $\begin{array}{l}\text { Detailed (thick) description of: } \\
\text { - Concepts and categories in grounded theory }\end{array}$ \\
& & $\begin{array}{l}\text { Structures and processes related to processes revealed in } \\
\text { the data }\end{array}$ \\
\hline Reliability & Dependability & $\begin{array}{l}\text { Purposive and theoretical sampling } \\
\text { Informants' confidentiality protected }\end{array}$ \\
& $\begin{array}{l}\text { Inquiry audit of data collection, management, and analysis } \\
\text { processes }\end{array}$ \\
\hline Objectivity & $\begin{array}{l}\text { Explicit separation of } 1^{\text {st }} \text { order and } 2^{\text {nd }} \text { order findings } \\
\text { Meticulous data management and recording: }\end{array}$ \\
& $\begin{array}{l}\text { Confirmability } \\
\text { Careful notes of observations }\end{array}$ \\
& $\begin{array}{l}\text { Clear notes on theoretical and methodological decisions } \\
\text { Accurate records of contacts and interviews }\end{array}$ \\
\hline
\end{tabular}

Credibility, the first of the four criteria for trustworthiness, is achieved through four techniques. First, the researcher (i.e. the author) spent significant time on site at Community Hospital over the duration of the five year study. Second, numerous data types were collected, which permits some triangulation of the findings. Third, peer debriefing was used in that the researcher sought to debrief others in conference workshops at the Academy of Management and informally discuss potential findings with other PhD colleagues. Fourth, member checks took place in the form of results presentations made by the researcher (and her supervisor) after T1 and T2.

Transferability, the second trustworthiness criteria, is demonstrated in the data analysis and findings sections for each of the three papers. These sections of the papers include thick, detailed descriptions of the coding categories and the emerging findings. Whenever possible, tables, figures, and typologies are produced in order to clarify key findings for the reader. 
The third trustworthiness criteria, dependability, is achieved through the use of three techniques. First, purposive sampling was used in the selection of Community Hospital - an "extreme case" of organizational change that is likely to yeild rich data related to individual level sensemaking about organizational change over time. Second, the researcher personally assured every participant that their confidentiality would be protected and has diligently carried out this duty with respect to data storage and findings presentation. Third, details on data collection and analysis procedures are provided in order to make these processes as transparent as possible.

Confirmability, the fourth and final trustworthiness criteria is met in three ways. First, the data analysis and findings sections of the papers in this thesis explicitly differentiate between findings from initial and focused coding. Second, theoretical and methodological decisions are clearly outlined for the reader throughout. Third, the researcher has effectively managed her data throughout the duration of the research. This effective data management is evidenced by her detailed electronic record keeping about interviewees in a series of excel documents. 


\section{Chapter 3: "Sensemaking Lenses" Paper}

This chapter contains the first of three research papers that comprise the empirical research conducted for this thesis. Each of the three research paper chapters (i.e. Chapters three, four and five) follows a similar four-part format. First a brief introduction summarizes the main objectives of the research paper. Second, the abstract, which summarizes key ideas for the paper, is provided. Next, the research paper is presented. Finally, a brief concluding section ties the themes from the paper back to the overall objective of this thesis. Details for all references cited are included in the reference list located at the end of this thesis.

\subsection{Introduction}

The paper referred to in this thesis as the "Sensemaking Lenses" paper is actually entitled "Sensemaking about organizational change: When the only constants are change and how we make sense of it". The study reported in this paper seeks to contribute to a more comprehensive understanding of how individuals make sense of organizational change as it unfolds over time by considering the frames or lenses used for individuallevel sensemaking about change. The two objectives serve to orient this study are: (1) identify the lenses that individuals use when sensemaking about organizational change, and (2) explore the stability of these sensemaking lenses over time.

\subsection{Abstract}

This paper explores the lenses individuals use to make sense of organizational change and how these sensemaking lenses act over time. Existing empirical work on sensemaking about organizational change tends to focus primarily on retrospective 
interview data captured at one point in time or sets of interviews collected over a relatively short period of time compared to how long organizational change initiatives typically take. Findings are presented from an interpretive process-oriented study that analyzed interview data for 26 hospital employees collected at three points in time over a five-year period of organizational change. Data analysis identified four sensemaking lenses ("it's all about me", "it's all about us", "it's all about me and us" and "nature of change") and developed two new concepts related to how individuals make sense of organizational change over time: (1) sensemaking constancy and (2) sensemaking scope. This paper contributes to practice and theory concerned with how individuals experience organizational change over time and is one of few, if any, studies to date that examines sensemaking and the emic (or insider) experience of change at the individual level over time.

\section{3 "Sensemaking Lenses" paper}

\section{Introduction}

Practitioners and scholars alike recognize the paramount role that individuals play during organizational change - a tumultuous, extensive and often unsuccessful process that firms undergo in order to remain competitive in an often hostile and most certainly ever-changing external environment (Burnes, 2009; Senturia, Flees, \& Maceda, 2008). The popular business press is strewn with articles that encourage managers to focus on the human side of transformational organizational change, and suggest manners in which this can be accomplished (e.g., Aguirre \& Alpern, 2014; Clayton, 2015). The academic literature on the subject of individuals and change, which dates back well over a century 
(Burnes, 2004), is vast and includes numerous empirical studies reporting on individuals' attitudes and reactions to organizational change (see reviews by Bouckenooghe, 2010; Choi, 2011; Oreg, Vakola, \& Armenakis, 2011). Of note is the high degree of consensus within both the academic and practitioner literatures that leveraging, engaging, and supporting individuals is the key to successful implementation of organizational change initiatives.

Despite the vast empirical literature on change management, there is growing sentiment among both scholars and practitioners that extant research and theory does not represent the lived reality of organizational change (Beech \& Johnson, 2005; Burnes \& Cooke, 2012; Oswick, Grant, Michelson, \& Wailes, 2005; Tsoukas \& Chia, 2002; Van de Ven \& Sun, 2011). This inadequacy has been linked to the fact that most of the empirical research on individuals and organizational change to date has used an etic epistemology and employed variance-oriented research methods (Bouckenooghe, 2010; Oreg et al., 2011). Researchers who take an etic perspective (sometimes referred to as "outsider," "deductive," or "top-down" approach) to the study of organizational change use as their starting point theories, hypotheses, and conceptual schemes regarded as meaningful by other academics. Variance-based research studies of organizational change based on this epistemology often utilize quantitative data and focus on the antecedents and consequences of change (Morris, Kwok, Ames, \& Lickel, 1999; Van de Ven \& Poole, 2005). Etic research, even when it focuses on human beliefs and behavior, takes an objective perspective of what is happening (Kottak, 2006; Morris et al., 1999).

The variance approach, while it provides numerous insights into organizational change, is not the most appropriate perspective to use in studies seeking to really 
understand how individuals experience organizational change over time (Van de Ven \& Poole, 2005). In such cases, studies using an emic epistemology (sometimes referred to as "insider," "inductive," or "bottom-up" approach) and process-based research methodologies are considered more appropriate as they allow the research to focus on how the individual or group being studied perceives the change unfolding over time (Van de Ven \& Poole, 2005). Emic researchers make every effort to put aside prior theories and assumptions and instead let the data "speak" to them by relying on the perceptions and words of research participants and using research methodologies such as grounded theory to allow themes, patterns, and concepts to emerge from the data. An emic approach is particularly useful in those cases where the context of the study is important (Denison, 1996; Morris et al., 1999).

Despite the dominance of variance studies in the extant literature on individuals and organization change, there is a small but growing body of work on sensemaking and organizational change (Maitlis \& Christianson, 2014). This burgeoning stream of research, much of which takes a process-oriented approach, is increasing our understanding of how individuals experience and make sense of organizational change over time. The idea of "sensemaking lenses", which are used by individuals to guide their interpretation of events or situations (Kaplan, 2008), in particular provide a useful approach to understanding how individuals make sense of change (Guiette \& Vandenbempt, 2013). Unfortunately, our review of the literature on sensemaking about organizational change identified a gap in this body of research that limits our understanding of how individuals experience the organizational change process over time. More specifically, our review of the sensemaking and change literature revealed that 
much of the empirical work on this subject either relies heavily on retrospective interview data (from one point in time), or relies on longitudinal interviews that took place within a relatively short period of time (less than two years). This is unfortunate, given the fact that many substantive change initiatives typically take anywhere from 2 to 15 years to implement (Smith, 2003) and may clarify Langley, Smallman, Tsoukas and Van de Ven's (2013) observation that empirical analysis at the individual level is missing from the larger body of process-oriented research on organizational change.

This gap in our understanding about how individuals experience organizational change over time motivated this study, which uses longitudinal interview data collected at three points in time, from 26 individuals, at an organization undergoing transformational change in order to elucidate the lenses individuals use to make sense of organizational change over time. More specifically, this study seeks answers to the two following research questions: What types of lenses are used to make sense of significant organizational change? Are individuals' sensemaking lenses stable, or do they fluctuate over time?

This paper is structured as follows. First, the literature review describes sensemaking and presents key findings from our review of the literature on sensemaking about organizational change. Second, the objective of this study, which was derived from the gap in the literature, is presented. The methodology section, which explains the case organization, data collection steps, and data analysis procedures, is then presented, followed by an outline of our key findings. The discussion section then summarizes links between findings and the extant literature. Finally, the conclusion section identifies the 
study's limitations as well as the relevant implications of the findings for researchers and practitioners.

\section{Literature Review}

This literature review is comprised of two parts. Sensemaking and some of its key concepts are described first. This is followed by a summary of key findings from our review of the sensemaking about organizational change literature.

\section{Sensemaking}

Sensemaking is defined as a process that individuals use in order to understand unexpected, ambiguous or confusing events (Maitlis \& Christianson, 2014). Sensemaking involves "the ongoing retrospective development of plausible images that rationalize what people are doing" (Weick, Sutcliffe, \& Obstfeld, 2005, p. 409). Theoretically, the process of sensemaking is conceptualized as consisting of three distinct yet related processes named triggering, interpretation, and action (Brown et al., 2014; Maitlis \& Christianson, 2014; Sandberg \& Tsoukas, 2015). These three processes, described below, are conceptualized as a cycle that recurs until the individual is able to resolve the unexpected event and any related unexpected or ambiguous situations that unfold (Sandberg \& Tsoukas, 2015).

The first step in the sensemaking process, "triggering" (Maitlis \& Christianson, 2014), refers to the ambiguous or unexpected events and situations that "trigger" sensemaking by disrupting organizational members' ongoing activities (Sandberg \& Tsoukas, 2015). The types of trigger events typically studied include organizational crises (e.g., Bhopal disaster research by Weick, 1988, 2010), threats to social identities (e.g., 
research on organizational identity threat and ambiguity by Corley and Gioia, 2004), and planned organizational change interventions (e.g., research about how middle managers make sense of change by Balogun, 2003, 2006).

The second part of the sensemaking process, interpretation, refers to the specific process that individuals undergo when attempting to make sense of ambiguous or unexpected events (Weick, 1995). The interpretation process involves assessing the information gained during the initial triggering stage of the sensemaking process in order to develop it "into a more complete and narratively organized sense" of the situation or event (Sandberg \& Tsoukas, 2015, p. 14). It is at this stage in the sensemaking process that individuals may label and categorize aspects of the situation they are making sense of (Weick et al., 2005). The use of cognitive frames or schemas to simplify information for interpretation (Balogun \& Johnson, 2004), also referred to as "framing" (Kaplan, 2008; 2011), can occur during this stage of sensemaking. Conceptually, cognitive frames, also called "mental models" or lenses, are thought to guide one's interpretation of events and act as a lens through which one interprets organizational phenomena (Kaplan, 2008).

The final stage of sensemaking, enactment (Sandberg \& Tsoukas, 2015), occurs when an individual acts based on their newfound understanding of the situation (Weick et al., 2005). Enactment allows the individual to explore their provisional understanding (which accumulated during the triggering and interpretation stages of the sensemaking process) and creates more information for future sensemaking (Weick, 1988). 


\section{Sensemaking About Organizational Change}

The ambiguity that often accompanies large-scale organizational change makes it a context well-suited for research on sensemaking (Weick, 1995). In order to take stock of the current state of this research, we searched for academic literature on the subject of sensemaking about organizational change. We identified and reviewed 66 articles (50 empirical and 16 conceptual). When reviewing the 50 empirical articles it became clear that this body of work represented four branches of research on sensemaking about change: (1) sensemaking and individuals' reactions to organizational change (e.g., Balogun, Bartunek, \& Do, 2015; Bartunek, Rousseau, Rudolph, \& DePalma, 2006; Chreim, 2006; Kyriakidou, 2011; Greenberg, 1995; Landau \& Drori, 2008; Riesenmy, 2010; Smollan, 2014; Stensaker \& Falkenberg, 2007; Stensaker \& Meyer, 2012; Stensaker, Falkenberg, \& Gronhaug, 2008), (2) change implementation and sensegiving (i.e. influencing the sensemaking of others) (e.g., Gioia \& Chittipeddi, 1991; Gioia, Thomas, Clark, \& Chittipeddi, 1994; Hensmans, 2015; Kezar, 2013; Marmenout, 2010), (3) middle managers' role as change sensegivers (e.g., Balogun, 2003; Balogun, 2006; Balogun \& Johnson, 2004, 2005; Dutton et al., 2001; Hope, 2010; Rouleau \& Balogun, 2011), and (4) sensemaking about change through narrative, discourse and stories (e.g., Abolafia, 2010; Brown \& Humphreys, 2003; Dawson, Sykes, McLean, Zanko, \& Marciano, 2014; Dunford \& Jones, 2000; Gazi, 2013; Heracleous \& Barrett, 2001; Reissner, 2011; Sonenshein, 2010; Teulier \& Rouleau, 2013).

A number of the studies ( 7 out of 50) had findings that relate specifically to the lenses, cognitive frames, mental models, and schemas used when individuals make sense of organizational change. Four of these studies (Balogun \& Johnson, 2004; Bean \& 
Hamilton, 2006; Chreim \& Tafaghod, 2012; Guiette \& Vandenbempt, 2013) looked at the process for developing new lenses, or "re-framing". Balogun \& Johnson (2004) uncovered a replacement pattern involved in schema development for middle managers during change. Guiette and Vandenbempt (2013) identified five "determinants" of the development of team mental models (i.e. group-level lenses). Chreim and Tafaghod's (2012) study of an acquisition concluded that the adoption of new frames is strongly connected to the relationships (and tensions) between the acquired and acquiring firms' managers. Bean and Hamilton's (2006) examination of an organization's shift to nomadic work practices, which was followed by a downsizing, found that employees made sense of the initial shift to nomadic work through the use of frames provided from leaders via sensegiving, but that after the downsizing employees "reframed" how they viewed the initial changes.

The other three studies (Lockett, Currie, Finn, Martin, \& Waring, 2014; Luscher \& Lewis, 2008; Sonenshein, 2009) suggested that the lenses individuals use to make sense during periods of change could be related to particular themes. Sonenshein's (2009) research on a Fortune 500 retailer implementing strategic change suggested that ethical issues emerge as a theme that influences how individuals re-frame strategic change. Luscher and Lewis's (2008) action research study found that paradox can act as a lens for managerial sensemaking during change. Lockett et al. (2014) proposed that social position is a lens for sensemaking about organizational change and coined the terms "profession-centrism" (i.e. an orientation towards one's professional group, which may limit one's viewpoint) and "allo-centrism" (i.e. the degree to which one is aware that their own ability to create change is dependent upon others). Findings from this research 
suggest that sensemaking about organizational change involves the use of multiple lenses to interpret cues associated with change.

These findings, while informative, have emerged from research that either uses retrospective interviews conducted at one point in time, or longitudinal data collected across a relatively short period of time. Four of the seven studies that examined lenses for sensemaking about organizational change (i.e. Chreim \& Tafaghod, 2012; Guiette \& Vandenbempt, 2013; Luscher \& Lewis, 2008; Sonenshein, 2009) based their findings on retrospective interviews conducted at one point in time. One study (Lockett et al., 2014) collected interview data at two different points in time approximately two years apart. While laudable, the fact that the sample of people interviewed at Time 1 was totally different from the sample of respondents the researchers interview at Time 2 limits the conclusions that can be drawn from the data. The other two studies (Balogun \& Johnson, 2004; Bean \& Hamilton, 2006) included multiple interviews with the same informants (as well as diaries, in the case of Balogun \& Johnson, 2004) in their research design, but were limited by the amount of time separating the two data collection periods (i.e. 10 months for Balogun and Johnson and 5 months for Bean and Hamilton).

The high reliance that researchers who work in the area of sensemaking about organizational change place on either retrospective interview data or interview data that spans a narrow scope of time was also apparent in the other 43 empirical articles included in our literature review on sensemaking about change (with one exception, Balogun et al., 2015 - who used sets of interviews with the same senior managers collected over the course of three years). This is not to say that the empirical work on sensemaking about change is methodologically flawed. The majority of these studies, in fact, used a 
"contextualism" approach in their research, which is consistent with that advocated by Pettigrew (1990) for capturing dynamic longitudinal processes during organizational change. This approach involves the collection of multiple types of data (observations, archival documents, interviews, etc.) to provide the researcher with both real-time (e.g., observations) and retrospective (e.g., interviews in most cases) data about how change unfolds over time (Pettigrew, 1990). When it comes to the topic of individual sensemaking about organizational change, however, the use of longitudinal panel data at the individual level would, we feel, provide researchers with a much richer understanding of the temporal dynamics of individuals' sensemaking lenses.

\section{Research Objectives}

The extant work on sensemaking about organizational change relies heavily on retrospective interviews at one point in time or longitudinal interviews over a short course of time within organizational change. This pattern in how sensemaking about change is studied begs the following question: Has the extant work on sensemaking about change thoroughly considered how individuals make sense of organizational change over time? To answer this question, we used a longitudinal panel-research design which involved interviewing an organizationally representative sample of hospital employees involved in a major re-orienting change (i.e. three interviews with the same 26 informants over the course of five years) in order to: (1) identify the lenses that individuals use when sensemaking about organizational change, and (2) explore the stability of these sensemaking lenses over time. This study, which includes the perceptions of individuals from multiple stakeholder groups (i.e. not just managers), should contribute to a more 
comprehensive understanding of both how organizational change unfolds over time, and of how individuals make sense of what is happening during this process.

\section{Method}

In order to best address the outlined objectives, a process-oriented interpretive case study utilizing grounded theory data analysis techniques was undertaken at a healthcare organization that had recently undergone significant planned organizational change. The process-oriented case study approach was deemed suitable for this study for two reasons. First, the case study method is fitting when boundaries between context and the phenomenon of interest in a study are not well defined (Myers, 2009; Yin, 2009).

Such is the case with sensemaking about organizational change. Second, process case studies help researchers to look at social processes over time (e.g., how individuals make sense of change over time) (Langley, 1999; Yin, 2009). In the section below we describe Community Hospital, the case subject for this study, and the planned change initiative it has undergone. This is followed by an explanation of the data collection, data analysis and findings from this study. For greater detail of the change at Community Hospital, the reader is directed to Authors (reference to be provided after the paper is reviewed).

\section{Case Organization}

The case organization selected for this study is Community Hospital, a primary care hospital located in eastern Ontario, Canada. The hospital is located in a small town, which has a population of about 2,500. It is approximately one hour of driving distance away from an urban center, which has a population of close to 900,000. In addition to providing care for the residents of this town, the hospital also provides care for people 
living in a number of neighbouring towns in the surrounding rural farming region. Community Hospital is one of the key employers for its region and currently employs approximately 340 staff. The 63-bed hospital hosts inpatient, outpatient, and diagnostic imaging and laboratory services on site.

Community Hospital has been exposed to many pressures for change over the past decade, such as: (1) demographic shifts that impact both the supply and demand for healthcare services (Statistics Canada, 2012), (2) the creation of new technologies that significantly affect the management and delivery of care, (3) modifications to funding structures and governance mechanisms (e.g., Zeytinoglu, Denton, Davies, Baumann, Blythe, \& Boos, 2007), (4) the move towards patient-centered care delivery models, and (5) turnover of provincial and federal leadership. As such, it meets the criteria of an extreme or revelatory case (see Charmaz, 2006), which is ideal for our purposes as such cases are more likely to yield unique insights into the phenomena of interest (i.e. organizational change).

In response to the above noted external pressures for organizational change, Community Hospital launched a major "reorientation" that lasted about 10 years and involved what could be considered to be excessive change. Changes initiated during the reorientation included the construction of, and relocation to, a new $\$ 63$ million (CAD) facility, leadership changes (including CEO succession), and a number of supplementary strategic changes believed to be important for the hospital's future survival. Figure 3-1 outlines some key changes that took place at the hospital from 2009-2013 (the time period for this study). Details on these changes are provided below. 
Figure 3-1: Timeline of change at Community Hospital

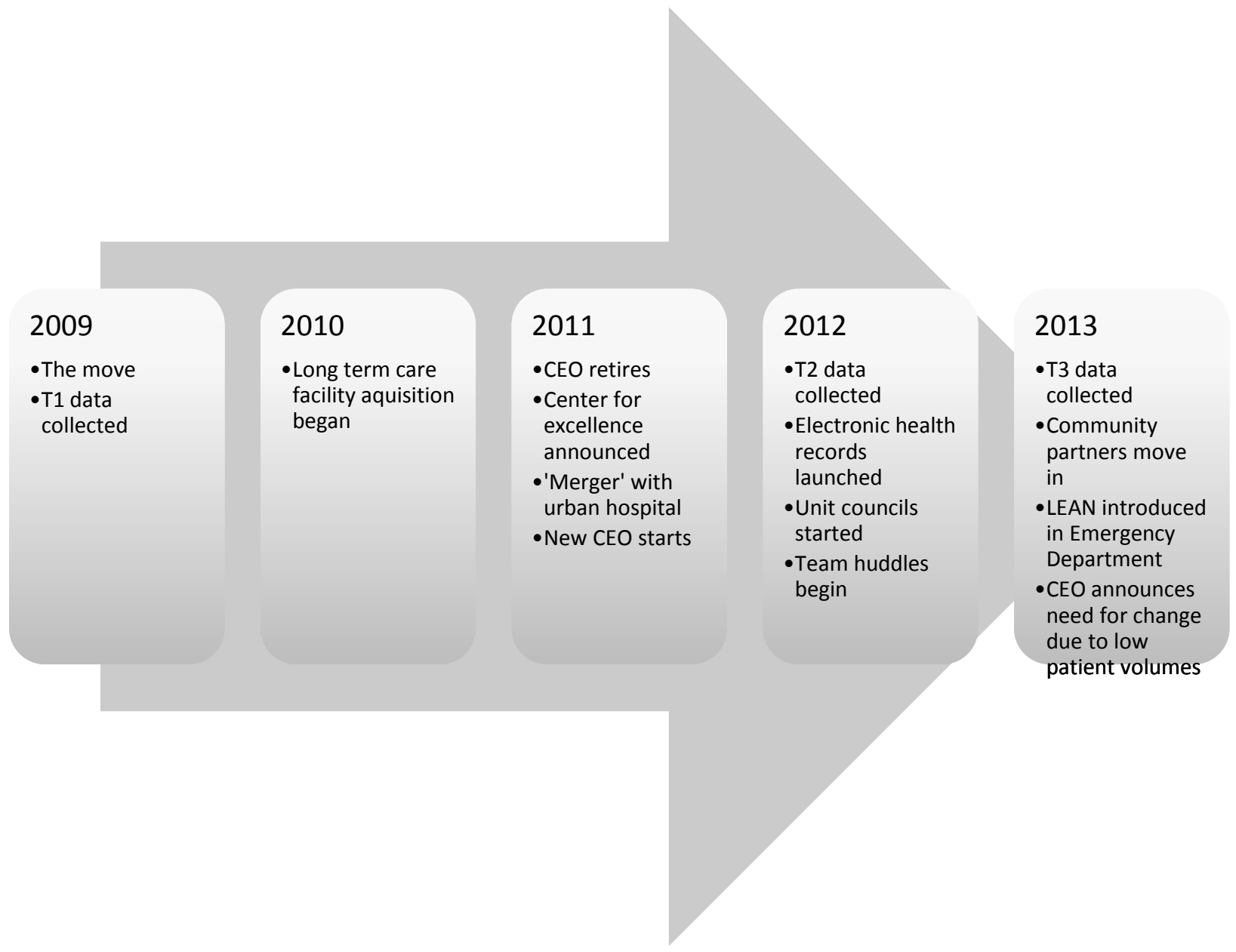

Pre-2009. In 2002 the hospital began fundraising to build a modern, state of the art healthcare facility on the same site as the old hospital. In 2004, Community Hospital's board of directors hired a new CEO to lead the organization through the construction of, and move to, the new facility. The new CEO was an external hire, a former nurse who had served in administrative roles for a number of years but she was a first-time CEO. From 2004 until 2007 she made significant changes to the membership of the management team at the hospital (i.e. appointed five new members to the team of eight). 
2009. The new facility opened in March 2009 (i.e. "the move”), shortly after the hospital's $60^{\text {th }}$ anniversary. While Community Hospital typically outperformed its peers on standard metrics like patient satisfaction and overhead cost per case, a 2009 survey conducted by a third party group indicated low job satisfaction among staff. The CEO contacted the authors, at this time, to conduct an in-depth "staff satisfaction" study at the hospital. Time 1 (T1) interviews were conducted between June and September of 2009. Results were publically shared with all hospital employees in December of 2009.

2010-11. In 2010 and 2011 the board encouraged the CEO to retire, which she did in June 2011 (i.e. “CEO retires”). Before retirement she developed and started to implement a new vision, "that Community Hospital would be a Centre of Excellence for Rural Health and Education in Ontario" (i.e. "Center for Excellence announced”). This vision involved strategic partnerships with local and regional healthcare providers. In 2010, Community Hospital began the acquisition of a long-term care facility (i.e. "long term care facility acquisition”). In early 2011 a merger agreement with a significantly larger urban hospital was formalized (i.e. "merger with urban hospital”).

The new CEO selection process took place in the summer of 2011 and by September 2011 the position was filled with another external hire (i.e. "new CEO”). The new CEO, a male, had no clinical background but had prior experience as CEO at similarly sized hospitals. After September 2011, the hospital began implementing initiatives to carry out the vision set in motion by the former $\mathrm{CEO}$, to improve morale, integrate the new long-term care facility, and advance the merger. 
2012-13. Change at Community Hospital did not slow with the entrance of the new CEO. Rather, new changes were introduced at a seemingly accelerated rate. In 2012 the new CEO introduced changes to work processes and structures in order to improve the organizational culture and aid in the delivery of patient-centered care, such as the introduction of unit councils for nursing staff (i.e. "unit councils started”), team huddles within all departments (i.e. "team huddles begin”) and new technologies such as the electronic health record (i.e. "Electronic Health Records”). Time 2 (T2) interviews were conducted between April and June of 2012.

In 2013 more changes came to pass, including partnerships with other healthcare organizations who became tenants in a building constructed next to the hospital) (i.e. “community partners move in"), and LEAN implementation in the emergency department (i.e. “LEAN introduced in ER”). In September 2013, soon after the implementation of LEAN, the hospital was experiencing low patient volumes in many units, and the $\mathrm{CEO}$ announced that changes were required in order to ensure the hospital's survival (i.e. "CEO announces need for change due to low patient volumes"). The CEO talked generally about change and did not specify in 2013 what form it would take. Time 3 (T3) interviews were conducted between September and October of 2013.

\section{Data Collection}

Following Langley's (1999) advice to researchers engaged in sensemaking research, we used semi-structured one-on-one interviews (Gioia et al., 2012) as our primary mode of data collection. Informants were acquired through the following procedure. An organization-wide survey was undertaken by the authors at Community 
Hospital in 2009. Emails, organizational memos, information mailed with paystubs, and announcements made at organization-wide meetings and events were all used to advertise the survey to hospital staff. Approximately one quarter of the 340 employees in the hospital ( $n=83 / 340,25 \%)$ completed the survey. At the end of the survey we included a question asking survey respondents to provide their name and email address or phone number if they were willing to partake in a follow-up interview. This information was used to contact these volunteers and arrange for a follow-up telephone or in-person interview. At the end of each interview, individuals were asked if researchers could reconnect with them at a later time for additional follow-up interviews. Individuals who responded in the affirmative were contacted again by the researchers in 2012 and 2013 and follow-up interviews were conducted.

The following two criteria were used to identify the individuals to include in this study's sample. First, as noted previously, our objective was to look at how individuals make sense of the process of change over time. Accordingly, we limited the sample to only those individuals who participated in all three sets of interviews: 2009 (T1), 2012 (T2), and 2013 (T3). Second, to gain a comprehensive understanding of sensemaking and change, and increase the transferabilty of our findings, we also wanted our sample to be well distributed with respect to job. Accordingly, the sample was selected to include individuals from a broad range of levels and roles within Community Hospital, with the caveat that they had participated in interviews at $\mathrm{T} 1, \mathrm{~T} 2$, and $\mathrm{T} 3$.

Overall, 26 individuals met our sampling criteria. The sample distributions $(n=26)$ with respect to gender (77\% female) and job type (12\% manager, $23 \%$ physician, $23 \%$ nurse, $12 \%$ clinical support, $27 \%$ non-clinical support) were reflective of the broader 
workforce at the hospital. The sample also varies in terms of how many years informants worked for Community Hospital. The average organizational tenure in our sample is 16.3 years with the number of years working for the hospital ranging from 5 years to 52 years (at the time of the third interview).

The first author of this paper conducted the interviews, virtually all of which were done in person, on site, in a private room at the hospital. The interviews took between 20 and 80 minutes, with the average interview taking approximately 45 minutes. All interviews were audio recorded and transcribed. The interviewer used a pilot tested script, which included questions regarding workers' backgrounds, general work experiences, the work environment at the hospital, and changes at the hospital.

The data used in this paper comes from the portion of the interview that focused on organizational change. To investigate the lenses that informants use to make sense of organizational change over time, the interview asked the informants during each of the T1, T2 and T3 interviews to "Please think back over the last year and pick a change that was most significant to you. Tell me about that change and why it was significant." The interviewer asked follow-up clarification questions as needed in order to ensure that they fully understood the informants' responses (e.g., "Can you explain more?”). The transcribed responses for this portion of the interviews totaled 82 pages single-spaced. There were two informants who did not answer this question at one or more points. These individuals (two females, one nurse and one non-clinical support) were removed from the analysis, leaving a sample of $n=24$. 


\section{Data Analysis}

Grounded theory techniques were employed to analyze the data. Grounded theory techniques encourage the researcher to understand how informants (i.e. insiders) construct their own experiences (Charmaz, 2006; Myers, 2009) and are particularly useful for conducting process research on organizational change (Langley, 1999) that seeks to reflect the insider perspective (Allard-Poesi, 2005). Transcribed interviews were sorted, coded (i.e. labels assigned to pieces of text) and stored in QSR-Nvivo Version 10, a software that facilitates qualitative data analysis. According to Langley (1999), the grounded theory strategy for analyzing process data requires many incidents of text (i.e. pieces of data) that the researcher uses to determine categories and themes that describe overall patterns and meanings that informants ascribe to the phenomena of interest. The transcribed responses that informants provided to the question about significant change serve as these "incidents" of text. In total, 72 incidents of data were analyzed: 24 sets (since the individual is the level of analysis each set represents an individual informant) $\mathrm{X} 3$ incidents (i.e. the response to the question about significant organizational change from the T1, T2 and T3 interviews with that informant) $=72$. Four iterative steps (initial coding, focused coding, identification of properties/patterns, and constructing prototypical narratives) were used to analyze the interviewees' responses to the question about organizational change with a particular focus on understanding how the interviewees made sense of organizational change over time. 


\section{Findings}

\section{Initial and Focused Coding}

The first step, initial coding (Charmaz, 2006), involved the assigning of labels to the data. These codes were emergent, not based on pre-determined categories. The objective of these codes is to stay close to the data, at times employing the exact same terminology as informants (Charmaz, 2006). The second step, focused coding, attempts to "sort, synthesize, integrate and organize large amounts of data" (Charmaz, 2006, p. 46). During this stage the researchers looked at the data and initial codes in order to determine higher level categories that could be used to aggregate some initial codes. In total 15 initial codes and 5 focused codes, or categories (Myers, 2009), were created to categorize individuals' sensemaking about organizational change. Specific focused and initial codes and quotes are presented in Table 3-1. 
Table 3-1: Resulting data structure

\begin{tabular}{|c|c|c|}
\hline $\begin{array}{l}\text { Focused code } \\
\text { (Category) }\end{array}$ & Sample initial codes & Sample quotes \\
\hline \multirow{3}{*}{$\begin{array}{l}\text { Change is good } \\
\text { for me }\end{array}$} & Made my job easier & "It made my workload less...it's made my job satisfaction and my enjoyment of work better" \\
\hline & Opportunity for me & $\begin{array}{l}\text { "I love the building, love the people, love healthcare, I'm so fortunate that I had the opportunity" } \\
\text { "I think you can get very comfortable with just going in and doing things the same wav every dav, and I think }\end{array}$ \\
\hline & Keeps job interesting & $\begin{array}{l}\text { I've become more aware of paying attention to the emails and the things that we get to say this has changed } \\
\text { now and we'll be doing it this way. There's been a lot of that lately, and it is challenging, and as I said, it keeps } \\
\text { you from getting bored." }\end{array}$ \\
\hline $\begin{array}{l}\text { Change is bad } \\
\text { for me }\end{array}$ & I have more work & $\begin{array}{l}\text { "There's more tasks to do. I have what I think my list of things that I need to do...but then I also have } \\
\text { policies and other higher management level things that are added to that" }\end{array}$ \\
\hline \multirow[t]{2}{*}{$\begin{array}{l}\text { Change is good } \\
\text { for us }\end{array}$} & We are excited & $\begin{array}{l}\text { "I'm not saying it was a negative impact on me but it was feeling the hype from staff...not all } \\
\text { negative. They were excited but still there was a lot going on in their minds." }\end{array}$ \\
\hline & $\begin{array}{l}\text { We are better off (i.e } \\
\text { improving, growing) }\end{array}$ & $\begin{array}{l}\text { "The change of the CEO is a big plus and he just came in and made some really positive things, } \\
\text { changes and did things for staff - really helped start to raise the morale." }\end{array}$ \\
\hline $\begin{array}{l}\text { Change is bad } \\
\text { for us }\end{array}$ & We are frustrated & $\begin{array}{l}\text { "We were burnt, we were exhausted. There were days we were crying...It was horrible. I'll never } \\
\text { know who initiated even the thought that it needed to be changed because what we had worked well." }\end{array}$ \\
\hline \multirow[t]{4}{*}{$\begin{array}{l}\text { Abstract view of } \\
\text { change (Nature } \\
\text { of change makes } \\
\text { it significant) }\end{array}$} & Change is complex & $\begin{array}{l}\text { "Just the amount of change in practice that was necessary, and changing routines and there was a } \\
\text { whole transformational model that needed to change...from physicians to the nursing staff to the way } \\
\text { we were doing things, standardizing our workflow" }\end{array}$ \\
\hline & Change is major in scope & $\begin{array}{l}\text { "It was the first really major change...we've had various construction projects in the past but this } \\
\text { was by far the largest and by far the most significant" } \\
\text { "It's just reorganization of your workplace. Everything is in a different spot...it's not what you've } \\
\text { been working in." }\end{array}$ \\
\hline & $\begin{array}{l}\text { I have to do my job differently } \\
\text { Balanced view of change }\end{array}$ & $\begin{array}{l}\text { "For me, it was a completely new place to work in...For us, it was obviously for the better. For other } \\
\text { people, they went to smaller rooms, so then they had to try and cram stuff into smaller spaces." } \\
\text { "When we first moved...it's not something you can plan. So when you put that combination of a }\end{array}$ \\
\hline & $\begin{array}{l}\text { Detached view of } \\
\text { implementation logistics }\end{array}$ & $\begin{array}{l}\text { higher than average [patient] volume with a new facility - any time you move everything's topsy } \\
\text { turvy and then you throw in staff that are either stressed or non-existent." }\end{array}$ \\
\hline
\end{tabular}




\section{Identification of Properties and Patterns}

According to Myers (2009), the categories (i.e. focused codes) that emerge during coding should have detailed properties that can be used to conceptualize patterns in the data. Our initial analysis of the data identified two properties that individuals in our sample used to make sense of organizational change over time: sensemaking scope and affect. We use the term "sensemaking scope" to represent the sensemaking patterns observed in the data. Initial analysis of the data suggests that "sensemaking scope" can be represented as a continuum with individuals who make sense of change by personalizing it (i.e. focus on how the change will impact them) at one end of the continuum, and individuals who take a more abstract or depersonalized view of the change (i.e. place their emphasis on how the change influences key organizational systems and/or the organization itself) on the other. "Affect" refers to the emotional component of an individual's sensemaking about organizational change (Carver \& Scheier, 2011). Initial analysis of the data uncovered instances of positive affect and negative affect, as well as cases when individuals viewed change without affect (i.e. they were detached and unemotional).

These two properties (sensemaking scope and affect) were used to construct a matrix (Figure 3-2) that we then used to classify each of the initial and focused codes that resulted from our initial analysis of the data (see Table 3-1). To help the reader follow our analysis, in Figure 3-2 initial codes are italicized and focused codes underlined. Sensemaking scope is conceptualized as the y axis and includes three groupings: "it's all about me" (including the "change is good for me" and "change is bad for me" focused codes), "it's all about us" (including the "change is good for us" and "change is bad for 
us" focused codes) and "nature of change" (including the "abstract view of change" focused codes). Affect is abstracted as the $\mathrm{x}$ axis and includes only two dimensions: "positive affect" (including the "change is good for me" and "change is good for us" focused codes) and "negative affect" (including the "change is bad for me" and "change is bad for us" focused codes). The "nature of change" group and corresponding codes are not differentiated based on affect, because these respondents uniquely gave responses that did not contain an affective or emotionally evaluative component.

Figure 3-2: Data structure (with properties)

\begin{tabular}{|c|c|c|c|}
\hline & \multicolumn{2}{|c|}{ Affect } \\
\hline & & Positive & \begin{tabular}{|l|} 
Negative \\
\end{tabular} \\
\hline \multirow{4}{*}{ 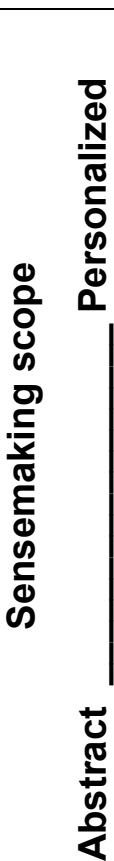 } & It's all about me & $\begin{array}{l}\text { Change is good for } \\
\overline{\text { me }} \\
M Y \text { job easier } \\
M Y \text { job more } \\
\text { interesting } \\
\text { Opportunity for me }\end{array}$ & $\begin{array}{l}\text { Change is bad for me } \\
\text { I have more work } \\
\text { MY job is more difficult }\end{array}$ \\
\hline & It's all about us & $\begin{array}{l}\text { Change is good for us } \\
\text { We are excited } \\
\text { We are better off }\end{array}$ & $\begin{array}{l}\text { Change is bad for us } \\
\text { We are frustrated } \\
\text { I am stressed by others } \\
\text { stress }\end{array}$ \\
\hline & & \multicolumn{2}{|c|}{ Neutral or logical view (no affect) } \\
\hline & Nature of change & \multicolumn{2}{|c|}{$\begin{array}{l}\text { Abstract view of change } \\
\text { Change is complex } \\
\text { Change is major in scope } \\
\text { I have to do my job differently } \\
\text { Balanced view of change } \\
\text { Logistics of implementation }\end{array}$} \\
\hline
\end{tabular}

Next, the researchers consulted the initial codes, focused codes, and raw data for each informant in order to ascertain "constancy of sensemaking lens", which we define as the extent to which each informant used the same sensemaking lens to make sense of change over time. Revisiting the raw data after focused coding and property identification 
was important because it allowed the researchers to stay close to the data and search for patterns related to "how" informants made sense of the changes that had been implemented within their organization over time. In our analysis, constancy of sensemaking lens over time was evaluated with respect to both affect and scope. More specifically, we examined the 24 sets of data to identify incidents where: (1) affect changes but not scope; (2) scope changes but not affect; (3) both scope and affect change; and (4) neither scope nor affect change over time. Two important observations were made after completing this stage of the analysis. First, individuals used the same "sensemaking scope" lens at all three time periods to make sense of changes that were significant (i.e. constancy of scope of sensemaking is high). In other words, all of the informants in our sample made sense of change over time by using a lens that focused exclusively on either: (1) themselves (i.e. the "it's all about me" group); or (2) their group of colleagues (i.e. the "it's all about us" group); or (3) the change itself (i.e. the "nature of change" group); or (4) on themselves and their group of colleagues (i.e. the "it's all about me AND us" group). Second, affect was not stable over time (i.e. constancy of affect of sensemaking is low). The results of this stage of the analysis are shown in Figure 3-3. Each of the four "sensemaking scope" lenses shown on this Figure (i.e. stable lenses for sensemaking about change contained in the thick bordered cells), are described in more detail below. 
Figure 3-3: Informant sensemaking styles over time

\begin{tabular}{|c|c|c|c|}
\hline & & \multicolumn{2}{|c|}{ Affect } \\
\hline & & Positive & Negative \\
\hline & $\begin{array}{c}\text { Stable over } \\
\text { time }\end{array}$ & \multicolumn{2}{|c|}{ Fluctuates over time } \\
\hline \multirow{5}{*}{ 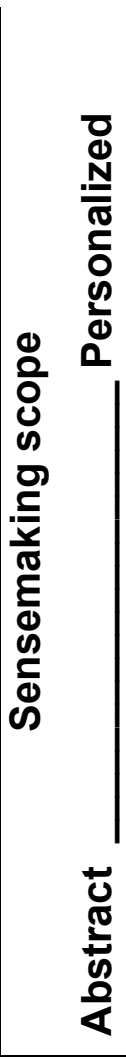 } & $\begin{array}{l}\text { It's all about } \\
\text { me } \\
(n=9)\end{array}$ & $\begin{array}{l}\text { Change is good for me } \\
M Y \text { job easier } \\
M Y \text { job more } \\
\text { interesting } \\
\text { Opportunity for me }\end{array}$ & $\begin{array}{l}\text { Change is bad for me } \\
\text { I have more work } \\
\text { MY job is more difficult }\end{array}$ \\
\hline & $\begin{array}{l}\text { It's all about } \\
\text { me AND us } \\
(n=2)\end{array}$ & & \\
\hline & $\begin{array}{l}\text { It's all about us } \\
(n=7)\end{array}$ & $\begin{array}{l}\text { Change is good for us } \\
\text { We are excited } \\
\text { We are better off }\end{array}$ & $\begin{array}{l}\text { Change is bad for us } \\
\text { We are frustrated } \\
\text { l am stressed by others } \\
\text { stress }\end{array}$ \\
\hline & & \multicolumn{2}{|c|}{$\begin{array}{c}\text { Neutral or logical view } \\
\text { (no affect, no fluctuation over time) }\end{array}$} \\
\hline & $\begin{array}{l}\text { Nature of } \\
\text { change }(n=6)\end{array}$ & \multicolumn{2}{|c|}{$\begin{array}{l}\text { Abstract view of change } \\
\text { Change is complex } \\
\text { Change is major in scope } \\
\text { I have to do my job differently } \\
\text { Balanced view of change } \\
\text { Logistics of implementation }\end{array}$} \\
\hline
\end{tabular}

The informants who viewed change through the "it's all about me" lens consistently made sense of change by focusing on the implications that each change would have for their particular work role and responsibilities. They often used the personal pronouns "I" and "me" when making sense of change. In total 9 of the 24 informants consistently (i.e. at T1, T2 and T3) made sense of change with an "it's all about me" focus. These individuals were typically from jobs in the middle of the organizational hierarchy that were of an administrative nature but unique (i.e. there were no other people at Community Hospital with similar job descriptions). The "it's all about 
me" individuals usually came from a clinical background (e.g., nurse or physician) and had started a new role within the past five years, many just shortly before the move to the new hospital.

Those who interpreted change using the "it's all about us" lens made sense of change by moving back one step and examining the impact of each change on their immediate work group (i.e. the department, their professional group). They often used the terms "us" and "we" when describing significant change in their interviews. In total, 7 of the 24 informants consistently had an "it's all about us" focus when sensemaking about change. These individuals were typically at lower levels of the organizational hierarchy in roles that involved direct patient interaction (in either a clinical or administrative capacity). Many had been with the organization for over 10 years and had served in the same role for most or all of that tenure.

The informants who looked at change through the "nature of change" lens talked about change in an abstract way, explaining change in a logical yet emotionally detached or removed manner. Their sensemaking about significant change typically included a focus on the logistics of the change, including its scope, complexity and/or the impacts of the change from a balanced or distant viewpoint. Of the 24 informants, 6 made sense of significant change with a "nature of change" focus. Most of the physicians in the sample conformed to this style of sensemaking. This group of informants is comprised mainly of individuals who have worked for the hospital for a long time (more than 20 years for most of the cases). 
The remaining two informants (out of 24) did not make sense of change exclusively with the "it's all about me", "it's all about us" or "nature of change" lenses over the course of their three interviews. Rather, their sensemaking about change consistently used an "it's all about me AND us" lens. In all three of their interviews, these two informants talked about how change was both good and bad for themselves AND for their colleagues. Interestingly, the two informants in this group also shared some key demographic characteristics. Both served in a dual role and worked some shifts as front line nurses (interacting with patients) and other shifts in informal leadership roles (supporting the front line nurses). Both had worked at Community Hospital for over 20 years.

For 17 out of the 24 informants, their sensemaking lens (or "sensemaking scope") was stable, consistent and exclusive for their T1, T2, and T3 interviews (e.g., "nature of change" at T1, T2, and T3). For the other seven informants, on the other hand, their sensemaking lens was stable and exclusive for two out of three of their interviews (e.g., "nature of change" at T1 and "it's all about me" at T2 and T3). Closer examination of the data related to these seven exceptions revealed two patterns that appeared to be connected to why these individuals adopted a different sensemaking lens at one point in time. The first pattern describes four of the seven "exceptions." These individuals used a "nature of change" lens at T1 and then consistently "it's all about me" (n=3) or "it's all about us" $(n=1)$ lenses for T2 and T3. All four of these individuals were very focused on the magnitude of the move and the complexity of redevelopment taking place at the organization as part of the reorientation at T1. Re-reading the interviews for these four individuals, one gets the sense that what was going on around them at T1 (i.e. the intense 
period of change for the reorientation) overtook their go-to sensemaking lens (i.e. "it's all about me" or "it's all about us") but that they resumed using this lens in T2 and T3 when the period of change was less intense. The second pattern could be observed in the other three of the seven inconsistent sensemakers. In these cases the inconsistency in sensemaking scope over time could be observed in the T2 data (e.g., nature-me-nature, us-me-us, us-me-me). Delving into the data, we found that all thre of the individuals in this group had received a promotion between the $\mathrm{T} 1$ and $\mathrm{T} 2$ data collection periods. This promotion seemed to account for the shift in their sensemaking lens to one where change was "all about me" at T2. Interestingly, two of these three individuals reverted back to their go-to sensemaking lens at T3. The third informant, who utilized an "it's all about me" lens at T2 and T3 (i.e. us-me-me), differed from the first two in that they received two promotions over the course of the study - one between T1 and T2 and another between $\mathrm{T} 2$ and $\mathrm{T} 3$.

\section{Constructing Prototypical Narratives}

The fourth and final step in the analysis involved the construction of prototypical narratives of informants' sensemaking over the course of organizational change. The data and analysis were used to develop three prototypical narratives that represent the "it's all about me", "it's all about us" and "nature of change" groups. The "it's all about me and us" group contained two individuals with very unique (and similar) demographic characteristics. The researchers promised interview participants anonymity and sharing the demographic information as well as presenting a narrative for this group would make it relatively easy for someone familiar with Community Hospital (i.e. another staff member) to attribute quotes to these two individuals. This meant that the authors had to 
choose between either (1) presenting the demographic information on these individuals but no narrative, or (2) withholding demographic information but presenting a narrative for this group. We elected to present only the demographic information (above) because the fact that both of these respondents were in a dual role seemed to be tightly linked to how they made sense of change. We also felt that the narrative would be difficult (if not impossible) to construct without revealing demographic information as virtually all of the quotes from these two individuals talked about their unique roles at the hospital.

"It's all about me" prototypical narrative. Sandra (pseudonym) is at the middle level of the organizational hierarchy at Community Hospital. She has a clinical nursing background and has worked at Community Hospital for over two decades. About one year before the move to the new hospital, Sandra took on a new role at the hospital, an informal leadership position. While not technically a management position, her duties are markedly different from her old role, with more responsibilities and increased purview over the front-line nursing colleagues in her department.

Sandra's sensemaking about organizational change in her three interviews emphasizes herself and her particular role at Community Hospital. In her first interview, shortly after the move to the new hospital Sandra talks about the change to her role as the significant change from the past year " $\underline{m y}$ job has become more difficult". At the time of the move she finds herself looking for ways to use her new role to support the front-line workers as they settle into their new environment: "IItake more initiative now... writing up reference guides so that people can get the information that they need to be able to access and trying to ensure that those things are there for nurses to refer to". In the second interview she again focuses on her role and explains how she has been impacted 
by changes in the people above her (e.g., new manager or new CEO). She explains " $\underline{m y}$ manager is new... I was looking forward to having less work and less things to do... but $\underline{I}$ haven't found that personally. I have just as much on my plate." This view of change from her unique position in the organization carries over into Sandra's third interview where she talks about what she has been able to achieve in her position" "I do the teaching of the mock code blues and stuff... I can see improvement in that when $\underline{I}$ do have a mock code now I can see the girls are getting it." She remains in the same unique role over the five years that this study was conducted.

"It's about us" prototypical narrative. Pam (pseudonym) is a front-line employee, whose job places her at the low level of the organizational hierarchy at Community Hospital. She has worked for the organization for 12 years and has been in the same job for the duration of this time. She is a clinical professional that works in a department that directly interfaces with patients. Her department is somewhat independent from the other areas at the hospital.

Pam's sensemaking about organizational change in her three interviews refers to her specific department. In her first interview she doesn't talk about the move to the new hospital because her department was not majorly impacted by it. Instead she mentions

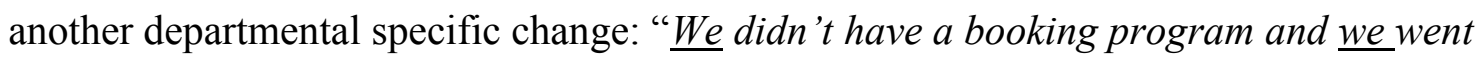
ahead and made our own process. " In her next interview she again talks about change as a departmental phenomenon: "We're always changing in our own department, so we work with people who are very research based. Every time something's new, we pursue it and try to implement it. " In Pam's third interview she talks about a new specialist that has joined her department recently: "We had a [specialist] come on board and that would 
have been through a lot of us advocating... that certainly without a question impacted workload and processes that we have here."

"Nature of change" prototypical narrative. Jim (pseudonym) is a physician at Community Hospital. He has been at the hospital for 22 years and has occasionally served in formal medical leadership positions throughout this time, but he is not currently in a leadership role.

Jim's sensemaking about change views organizational change and its impacts on those at the hospital in a balanced, logical, and somewhat distant or detached way. In his first interview Jim discusses the move to the new hospital as being complex and large in scope: "It was just changing everything - what our patients can see, the type of service, how we deliver the services to the patients." The change was significant because of the logistics required: "because of the amount of work leading up to it, because of the amount of things that were put on hold to wait for the move so to speak. " In his second interview Jim talks about the new CEO. According to Jim, "My sense is that he is more interested in embracing the positive things that we've been talking about than our previous CEO. There are major challenges to do those things because obviously you'll never be able to please all the people all the time." His sensemaking about change reflects an understanding of both the positive outcomes of the change as well as the potential challenges or drawbacks (e.g., to the new CEO's approach). Finally, in his third interview he shifts back to a focus on the logistics of a recent change but is detached when describing the impact on himself. Jim mentions that new IT changes meant that "Reports are generally available a little quicker, but it doesn't necessarily impact on my 
workflow... if I order something in the morning and the results are available an hour or two earlier than they were previously, it doesn't really impact on how I manage people."

\section{Discussion}

Below we describe the two key concepts that emerged during the data analysis in this study: sensemaking scope and sensemaking constancy. We then discuss the implications of our findings with respect to "sensemaking lenses" for both theory and practice.

\section{Sensemaking Scope}

This study is unique in that our relationship with the hospital that is featured in this case allowed us to look at individuals' sensemaking about organizational change at multiple points in time over the course of a five-year period that included a large-scale organizational change initiative. Analysis of longitudinal interview data for 24 informants revealed that, at the individual level, informants' sensemaking about significant organizational change varied in a manner that reflected differences in a concept we have labeled "sensemaking scope". More specifically, analysis of our data suggests that individuals who are involved in organizational change will make sense of this change in one of four ways, which relates to how much they personalize or depersonalize (i.e. abstracted or detached from) the change. The data also supports the idea that "sensemaking scope" can be conceptualized as a continuum which ranges from a very personalized view of change (i.e. do not look at it as an abstract experience) to one that views change as a more abstract phenomena (i.e. low personalization of the change). Individuals who focused almost entirely on themselves when making sense of change (i.e. 
"it's all about me") were at one end of the continuum, while those who totally depersonalized the change and did not talk about themselves or their group when making sense of what was happening - but rather made sense of change in an abstract or detached way - were at the other end (i.e. "nature of change") of the continuum. In the middle of the continuum we observed two other groups of individuals: those who took a view of change that was slightly less personal in that their sensemaking focused on change implications for both themselves and their group (i.e. "it's all about me and us"), and those who did not personalize the change in any manner but were not totally abstract in their view of the situation in that they focused on their group (usually professional group) when making sense of change (i.e. "it's all about us"). The identification of the sensemaking scope concept and the fact that it appears to be stable over time (i.e. people will use the same lens to evaluate change over time) is a major contribution of this research initiative.

The fact that the four different types of sensemaking scopes observed in our data all related to slightly different demographic profiles is another key finding of this study. These findings are largely consistent with similar findings from other studies on sensemaking about organizational change. More specifically, previous research has highlighted the connection between one's sensemaking about organizational change and their job (e.g., Reissner, 2010) or hierarchical level (e.g., Lockett et al., 2014; Sonenshein, 2010). This study supports this link; in our sample, those at lower levels of the organizational hierarchy typically viewed change through the "it's all about us" lens, while those in mid-level positions were more apt to make sense of change using an "it's all about me" lens and physicians almost always employed the "nature of change" lens 
when sensemaking about change. Our findings also support the work of Lockett et al. (2014) in that the sensemaking lens used by the physicians in the sample seems to be a product of profession-centrism.

This study also contributes to the change management literature by showing a link between how employees make sense of change and organizational tenure and role tenure. Organizational tenure, in terms of years employed with the organization, has not received much attention in the extant literature on sensemaking about change. The notion that organizational tenure influences how one experiences change is commonplace, however, in the variance-oriented literature related to individuals and change (Oreg et al., 2011). Scholars have long contended that the number of years that one has been employed at an organization could be related to inertia or dispositional resistance to change because of long-time employees' commitment to the established routines and/or way of doing things (e.g., Boeker, 1997; Katz, 1982). This study supports this claim in some ways, as some connections between participants' tenure at Community Hospital and the lens that they used to make sense of organizational change were apparent in our findings. For instance, those with extremely long tenures (i.e. more than 20 years) tended to adopt a "nature of change" lens whereas those who had been with the organization for a comparatively shorter time (i.e. more than 10 but less than 20 years) often made sense of changes using an "it's all about us" lens. Interestingly, role tenure (i.e. years in current position) also emerged as a demographic characteristic that appeared to be connected to one's sensemaking scope. More specifically, those who were relatively new to a role (i.e. less than 5 years) tended to make sense of change through an "it's all about me" lens regardless of the number of years they had been previously employed with the 
organization. Furthermore, those who had served in their current role for more than 10 years more often viewed change through an "it's all about us" sensemaking lens. To our knowledge, role tenure has not received much attention in the empirical work on individuals and change. Perhaps those who are newer to a position (but not necessarily the organization) view significant change through a different lens than those who have been in their position for longer because their sensemaking is being triggered by different cues (i.e. those in a newer role may encounter more ambiguity and uncertainty as compared to those who have been in the same role for longer).

\section{Sensemaking Constancy}

The second concept that emerged from our analysis is what we called "sensemaking constancy". This label was selected as it can be used to evaluate the extent to which individuals rely on the same sensemaking lens to made sense of different changes at different points of time. Applying this term to our findings we noted that most of the informants ( 17 of 24 ) relied on the same type of sensemaking scope when making sense of significant change in all three of their interviews (i.e. sensemaking scope has

high constancy) but varied with respect to whether their sensemaking involved positive or negative affect over time (i.e. affect has low constancy). The sensemaking constancy idea is consistent with other empirical work that identified themes, like ethics (Sonenshein, 2009) or paradoxes (Luscher \& Lewis, 2008) which served as lenses for interpreting organizational change over time.

Furthermore, all of the instances in which individuals employed different sensemaking scopes over the course of the three interviews (e.g., "nature of change" at 
T1 and "it's all about us" at T2 and T3) could be explained by either (1) the intense period of implementation surrounding the large-scale change at T1 that explained the "nature of change" focus at T1 only, or (2) a promotion experienced by the informant that related to the subsequent "it's all about me" focus. In virtually all of these cases, however, informants "shifted back" to what we contend to be their preferred sensemaking scope. The one exception to this was an individual that experienced two successive promotions - but still fit the above-noted pattern. Therefore, even for the seven individuals that varied over time with respect to sensemaking scope, the finding that each had a "preferred sensemaking scope" is reflective of the sensemaking constancy concept.

Our observations are somewhat contrary to the notion that sensemaking about organizational change is characterized by lens instability (i.e. "re-framing"), which is implicit in the empirical research on this topic (e.g., Balogun \& Johnson, 2004; Bean \& Hamilton, 2006; Chreim \& Tafaghod, 2012; Guiette \& Vandenbempt, 2013). Rather, our study supports the existence of stable patterns over time with respect to individual-level sensemaking about organizational change. This finding is significant in that it suggests that, when engaging in sensemaking about organizational change, individuals will typically use the same interpretive lens during the entire change process. This would imply that if organizations could identify the relevant sensemaking lens used by their personnel during change, they could better support their employees throughout the change process.

Our findings also suggest that the recency of change (whether organization wide or change in role - another type of organizational change) can cause one to make sense of change in a manner that temporarily differs from their go-to sensemaking scope (i.e. a 
break in sensemaking constancy). This finding is aligned with the existing studies that suggest individuals adopt new schemas or lenses during organizational change through a process of re-framing (Balogun \& Johnson, 2004; Bean \& Hamilton, 2006; Chreim \& Tafaghod, 2012; Guiette \& Vandenbempt, 2013). Our findings differ from this work, however, in that looking at the sensemaking scope that each informant used over the course of a major organizational change revealed that, for some, the scope that was used at $\mathrm{T} 1$ (i.e. the intense period of change implementation - the time period that other studies using longitudinal data focused on) was, in fact, not consistent with their preferred sensemaking scope (which was apparent when comparing the T1 scope with the $\mathrm{T} 2$ and T3 scope). Looking at the lenses that individuals used to make sense of organizational change over the course of a major change initiative (i.e. five years) as opposed to relying on retrospective data or longitudinal data from a short period of time (i.e. less than two years) allowed us to uncover this dynamic.

\section{Sensemaking Lenses: Affect or Constancy?}

As we set about analyzing the data and writing up our findings, a key question arose: What are the sensemaking lenses in this study? This question arose as we identified two potential ways to conceptualize sensemaking lenses in our analysis. It is possible, for example, to consider the focused codes (or categories) that represented key themes in individuals' sensemaking about organizational change as the key interpretive lenses. This approach would mean that each cell in the Figure 3-2 matrix would be considered a unique sensemaking lens that included both an affective and a sensemaking scope component as follows: "change is good for me" (positive, personalized); "change is bad for me" (negative, personalized); "change is good for us" (positive, less 
personalized); "change is bad for us" (negative, less personalized); and "abstract view of change" (no affect, abstract/depersonalized).

Alternatively, we could take the approach we adhered to in this paper and conceptualize sensemaking lenses as those aspects of individual level sensemaking about change that were stable over time. Sensemaking scope appeared to represent the stable (or constant) way in which each individual interpreted change and was, therefore, used to identify the four lenses in this study (i.e. "it's all about me", "it's all about us", "it's all about me and us", and "nature of change"). Identifying the four types of sensemaking scope as the lenses is aligned with our research objectives, which sought both to explore lenses for individual level sensemaking about change and also to consider the stability in use of these lenses over time.

This method for identifying sensemaking lenses does differ from the existing empirical work on lenses for sensemaking about change, in that this work tends to conceptualize lenses as either (1) common themes that characterize sensemaking about change (e.g., Luscher \& Lewis, 2008; Sonenshein, 2009) or (2) interpretive frames that are subject to "re-framing", which occurs when individuals make sense of the organizational change (e.g., Balogun \& Johnson, 2004; Bean \& Hamilton, 2006; Chreim \& Tafaghod, 2012). Ultimately, however, our conceptualization of lenses allows for the most parsimonious representation of individual level sensemaking over time.

Furthermore, while affect is part of the sensemaking process, removing affect from how individual level sensemaking lenses are defined in our paper allows us to separate the emotional component of sensemaking (affect - which fluctuated over time) from the interpretive lens (sensemaking scope - which remained stable over time). 


\section{Conclusion}

The overarching contribution of this study is anchored in its unique data set of longitudinal interviews with the same 24 individuals over the course of a five-year period of organizational change. This approach is markedly different from the extant work on sensemaking about organizational change, which empirically examines individuals' sensemaking processes by using interviews from one point in time or from more than one point in time during a short (but intense) period during change implementation. The difference in this study's approach facilitates contributions to the sensemaking and change literature because our findings represent individual level sensemaking about organizational change over a substantial period of time (i.e. five years).

The following key conclusions are supported from this study. First, our analysis revealed that individuals employed one of four relatively stable sensemaking lenses when sensemaking about change. The four lenses identified (i.e. "it's all about me", "it's all about us", "it's all about me and us" and "nature of change") represented different degrees of personalization with respect to how individuals made sense of change. Second, we identified a concept that we labeled "sensemaking scope", which seems to describe the different degrees of personalization/de-personalization that individuals used to make sense of organizational change. Third, we also propose the concept of "sensemaking constancy", which we use to explain our finding that individuals who are going through organizational change seem to have a dominant sensemaking lens that they use to make sense of the change over time. Finally, this study also identified a number of demographic characteristics (e.g., organizational and role tenure, job type, and level of organizational hierarchy) that appear to be linked to the use of a particular sensemaking 
lens as well as a number of situational characteristics (i.e. period of intense change implementation or recent promotion) that were connected to instances in which an individual's stable sensemaking lens was replaced temporarily with an alternate lens.

\section{Implications For Practice}

The findings from this study have a number of implications for those who are responsible for managing organizational change. First, when developing change implementation strategies, managers would be wise to consider how aspects of the change will realistically impact individuals at the organization. Our findings show that people make sense of change differently but that for most individuals the focus is on people, (i.e. on themselves and/or on others). This provides further support to the practitioners' and academics' view that change success depends on the involvement and engagement of individuals throughout the organization. Second, those tasked with designing change implementation strategies and implementing large-scale, long term change would benefit from frequent consultations with those who are exposed to role changes during times of organizational change. This recommendation stems from our findings linking variations in how people make sense of change (i.e. their lens or sensemaking scope) to experiencing a promotion in the midst of a reorientation. Finally, those tasked with implementing change and trying to assess how to best engage individuals and garner support (or overcome resistance) for the organizational change may want to consider sensemaking scope when deciding who to appoint as change champions. For instance, the individuals who view change through a stable "nature of change" lens make sense of change in a way that is neutral. The fact that these individuals who are less likely to be emotional about the changes that are being 
implemented may make them effective sensegivers who are able to calm others who are perhaps more emotional in their sensemaking around change.

\section{Implications for Research}

This study and its findings with respect to sensemaking about organizational change at the individual level over time will, hopefully, motivate practitioners and scholars to further consider how individuals experience and make sense of organizational change over time. Although there are a variety of manners in which these findings could be transferable to other contexts, there are also some limitations worth noting - two of

which are described here and they have implications for future research in this area. First, the interpretive case study approach employed in this study means that findings are not generalizable in the way that much of the "etic" or "variance-based" research on individuals and organizational change is, or strives to be. Instead, findings from this study can be considered potentially "transferable" to other relevant contexts. In particular, two strategies recommended by Lincoln and Guba (1985) and Shah and Corley (2006) and used in this paper to enhance transferability were (1) to include detailed tables and figures to display data and analysis, and (2) to provide the reader with rich contextual details about the case organization. Each technique enables the reader to make their own assessments with respect to how and when particular findings may be transferable to other contexts of interest.

A second limitation is that the use of an even richer and more temporally expanded data set could yield different insights related to sensemaking lens dynamics. For instance, had this study analyzed five or six interviews with the same individuals 
over the course of 10 or 15 years, perhaps the findings would have gone in a different direction (e.g., different lenses or types of sensemaking scope or the development of different concepts all together). Given the existing studies' heavy reliance on interview data that is retrospective or longitudinal but over a short-term period (i.e. less than two years) when investigating lenses for sensemaking about change, this study's ability to consider a longer span of lens dynamics is a contribution. However, the authors do not view this study as one that comprehensively "fills this gap". Rather it is (hopefully) the start to a fascinating stream of research that seeks to extend our understanding of individual-level sensemaking about change over time.

Three potential directions for future research are suggested by this analysis. First, researchers could undertake more studies that utilize individual level longitudinal data to look at the emic view of organizational change over time. For instance, future studies could use longitudinal interview data that spans longer periods of time and/or incorporates a greater number of interviews over time to assess the dynamics of individual lenses for sensemaking about organizational change. Second, scholars examining sensemaking about organizational change could engage in empirical work that seeks to provide a better understanding of the link between sensemaking scope and the enactment or action stage of the sensemaking process (e.g., do the lenses correspond with particular coping behaviours? Other behaviours that help or hinder the change initiative?). The nature of our data leaves us unable to determine whether informants' sensemaking scope was connected to behaviours undertaken by the individual (either supporting or acting against the change). Such an understanding, however, would be particularly useful for those tasked with implementing large-scale organizational change. Finally, future 
research is needed to identify predictors of the lenses identified in this study (e.g., what role might personality play?), explore the conditions related to shifts in lenses (e.g., recent promotion), and determine the consequences for individuals associated with the different types of lenses noted (e.g., does one's lens relate to the experience of more negative or positive outcomes with respect to the change?).

\subsection{Conclusion}

Findings from the "Sensemaking Lenses" paper contribute to the primary objective of this thesis (to understand how individuals make sense of organizational change over time from an emic (i.e. insider) perspective) in two direct ways. First, the

types of sensemaking lenses identified (e.g., "it's all about me", "it's all about us" etc.) indicate that individuals usually make sense of organizational change over time by focusing on the impacts that change has on them and those around them. The exception to this was those who used a "nature of change" lens through with to frame change. Second, the findings related to "sensemaking constancy" show that in most cases individuals make sense of change using stable lenses over the course of time (i.e. high constancy of sensemaking lenses at the individual-level). 


\section{Chapter 4: "Retrospective Versus Real-time" Paper}

This chapter presents the second out of the three papers in this thesis. This paper is referred to as the "Retrospective versus Real-time" paper throughout this thesis and is formally entitled "Making sense of organizational change: Is hindsight really 20/20?"

\subsection{Introduction}

The study reported in this paper seeks to contribute to a more comprehensive understanding of how individuals make sense of organizational change over time by considering the extent to which ones' retrospective sensemaking (after change) differs from ones' real-time assessments (during the implementation of change). Accordingly the primary research objective that serves to orient this study is to explore how individuals' retrospective sensemaking about organizational change compares with assessments these individuals made during the change process (i.e. in "real-time"). These notions are further examined in a secondary research objective, which is to investigate how real-time assessments and retrospective sensemaking patterns relate to job type and change roles (i.e. change agent versus recipient roles).

\subsection{Abstract}

This paper explores the conceptual links between two different approaches to managerial cognition, sensemaking and cognitive bias, in the context of organizational change. A longitudinal case study utilizing both real-time and retrospective data from interviews with 26 hospital employees at three points in time was undertaken. Informants' real-time assessements of their work environment suggested that in some ways the experience of transformational change might be similar for the change recipient and agent 
groups over time. The retrospective data, however, indicated that that when "looking back" over the change, change agents tended to view the changes more positively than change recipients. These and other findings are discussed in terms of sensemaking, cognition, and attribution theories. This study contributes to our understanding of how individuals experience and make sense of organizational change over time, in that (1) little is known about how the process of change unfolds over time at the individual level, and (2) extant research has not investigated the extent to which individuals' retrospective senesmaking about organizational change reflects or diverges from their real-time assessments over the course change.

\section{3 "Retrospective Versus Real-time" paper}

\section{Introduction}

Planned transformational change is often undertaken by organizations seeking to survive and thrive in today's increasingly competitive business environment. These types of largescale organizational changes, also called "reorientations" (Nadler \& Tushman, 1989), can be extremely difficult to successfully implement, largely because they require sustained effort from multiple stakeholders over a significant period of time. Smith (2003), for example, estimates that reorientations take between 2 and 15 years to implement successfully. The fact that each level and business unit included in the organizational change needs time to go through their own process of understanding and integrating the changes that accompany the transformation means that the amount of time needed to implement a reorientation is extensive and variable (Heracleous \& Barrett, 2001; Riesenmy, 2010; Stensaker, Falkenberg, \& Gronhaug, 2008). According to 
Stensaker et al. (2008), this process of understanding and integrating changes within different areas of the organization is driven by sensemaking processes at the individual level. It follows, therefore, that research that focuses on organizational members' sensemaking about organizational change over time would allow researchers and practitioners to better understand the circumstances and processes related to successful (and/or unsuccessful) change implementation.

Sensemaking refers to the iterative and ongoing process by which individuals make plausible sense retrospectively of their situation (Weick, Sutcliffe, \& Obstfeld, 2005). Organizational change is a popular subject among sensemaking scholars (Maitlis \& Sonenshein, 2010) as the uncertainty invoked by change provides a salient context for sensemaking (Weick, 1995). While the extant research on individuals' sensemaking about organizational change has contributed to our knowledge of how individuals make sense of this phenomena, it is limited by its reliance on retrospective accounts of organizational change and/or on longitudinal data that examine a relatively limited portion (typically two years or less) of the change process.

Also problematic is a lack of research exploring how individuals' retrospective sensemaking about change (captured at one point in time) compares to their real-time assessments of change (captured longitudinally over the course of a change). Real-time and retrospective data are commonly used together in studies of organizational change because of the intertwined nature of the phenomenon (i.e. organizational change) with its context (i.e. the organization's internal and external environment) (Pettigrew, 1990). In fact, our review of the extant literature on sensemaking about organizational change found numerous examples of researchers who collected retrospective interview data as 
well as real-time data in the form of observations (Rouleau, 2005), documents (e.g., annual reports - Chreim, 2006, or archival data - Maclean, Harvey, Sillince, \& Golant, 2014) or both observations and documents (Sonenshein, 2010) as a means of capturing collective sensemaking activities (i.e. at the group or organization level) over time. Our review did not, however, undercover any research on sensemaking about organizational change that compared how individuals felt about their situation when they were in the midst of change (i.e. their real-time assessments) compared to their views of this situation after the change had occurred (i.e. retrospective sensemaking). This paper addresses this issue by presenting and discussing key findings from a longitudinal case study which was designed to compare real-time and retrospective accounts of how employees make sense of an organizational reorientation.

This paper is structured as follows. First, a description of the reorienting change undertaken by the sample organization in this study is provided. Second, the literature review familiarizes the reader with sensemaking, presents findings from the extant literature on sensemaking about organizational change, and explains one dimension of cognition with relevance to this study - cognitive bias. Next, the research objective, which is motivated by a gap in the literature, is outlined. After this, the methodology section explains data collection steps and the procedures used to analyze the data. A presentation of the key findings from our analysis follows our discussion of the methodology. The discussion section summarizes links between the findings and the extant literature, while the conclusion identifies relevant implications for researchers and practitioners. 


\section{The Case Organization}

In order to align with the primary objective of this study it was crucial that we select an organization to study that could serve as an "extreme" case of the phenomenon of interest (Charmaz, 2006; Langley \& Abdallah, 2011). Such a case would provide us with the rich data needed to assess individual level sensemaking about transformational (i.e. a reorientation) organizational change over time (Langley \& Abdallah, 2011). Our search for an organization undergoing reorientation where longitudinal data was available at the individual level resulted in the identification of Community Hospital (pseudonym). In the section below we describe Community Hospital and its reorientation initiative. For greater detail of this change the reader is directed to Authors (reference to be provided after the paper is reviewed).

Community Hospital is a 63-bed primary care hospital located in a small town in eastern Ontario, Canada. The hospital is an hour long drive away from a city (population about 900,000). Its catchment area includes a number of small towns in the nearby rural farming region. Community Hospital is a key employer for this region, with approximately 340 staff. The hospital offers inpatient, outpatient, and diagnostic imaging and laboratory services on site.

A number of pressures for change have confronted the hospital over the past ten years, including: (1) demographic shifts that affect both the supply and demand for healthcare (Statistics Canada, 2012), (2) new technologies that affect how care is managed and delivered, (3) shifts to funding structures and governance mechanisms (e.g., Zeytinoglu, Denton, Davies, Baumann, Blythe, \& Boos, 2007), (4) an emphasis on more patient-centered care, and (5) turnover of both provincial and federal leaders. 
In response to these pressures, Community Hospital undertook a major, decadelong "reorientation". The reorientation included constructing and moving to a new $\$ 63$ million (CAD) facility, leadership changes (including CEO succession), as well as other strategic changes that were believed to be important for the hospital's survival. Figure 4-1 outlines the changes at the hospital from 2009-2013 (the time period of focus for this study). Details on these changes are explained below.

Figure 4-1: Timeline of reorienting change and data collection

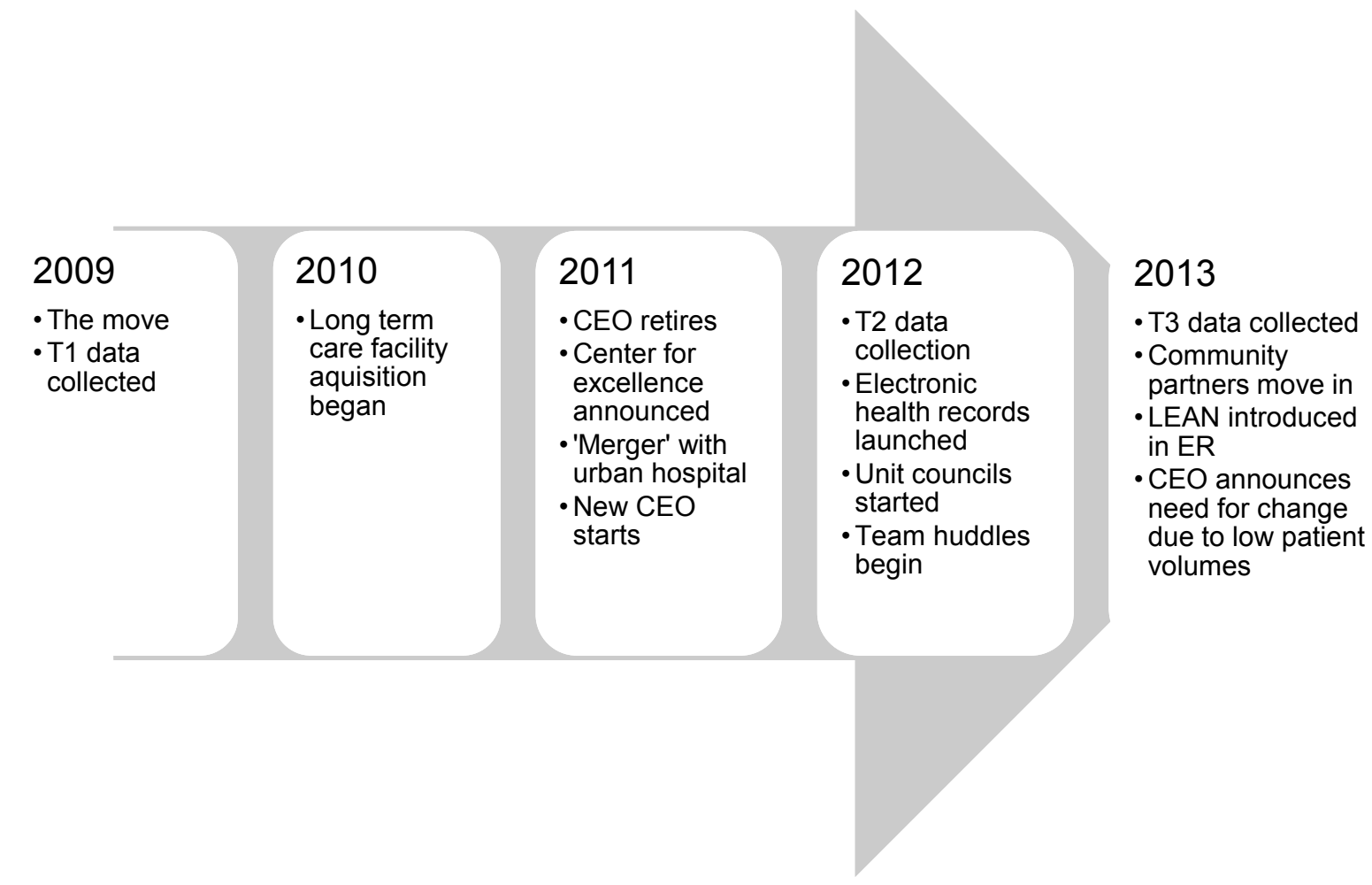

\section{Pre-2009}

In 2002, fundraising began to raise money to build a modern healthcare facility on the same site as the old hospital, with state of the art IT infrastructure and medical equipment. In 2004, Community Hospital's board of directors hired a new CEO to lead 
the organization through the transformational change of building and moving into the new facility. The new CEO was an external hire. She began her career as a nurse, and although she had served in administrative roles for a number of years, this was her first time serving as CEO for a hospital. From 2004 until 2007 the new CEO made significant changes to the senior management team at the hospital (i.e. she appointed five new individuals to the small team of eight).

\section{9}

The new facility was opened in March of 2009 (i.e. "the move"), shortly after the hospital celebrated its $60^{\text {th }}$ birthday. Despite strong organizational performance (Community Hospital outperforms its peers on standard metrics like patient satisfaction and overhead cost per case), results from a 2009 survey conducted by a third party group indicated low job satisfaction among organizational members. It was around this time that the CEO initially contacted the authors to conduct an in-depth "staff satisfaction" study at the hospital. In late 2010, a working group called "the physician engagement group" was formed within the hospital and area experts were engaged specifically to address issues related to the work environment within the hospital at this time (e.g., poor relationship between the physician and management groups). Physician leaders, the CEO, and a few senior managers were members of this working group. Time 1 (T1) data (interviews and a quantitative staff survey) were collected between June and September of 2009, and results were publically shared with all hospital employees in December 2009. 


\section{0-2011}

In 2010 and 2011, the CEO was "encouraged" by the board to retire. She took this advice in June of 2011 (i.e. "CEO retires"). Prior to her retirement she had developed and begun to implement a new vision for Community Hospital: "that Community Hospital would be a Centre for Excellence for Rural Health and Education in Ontario" (i.e. “Center for Excellence announced"). This vision to become a leader in rural health involved a number of strategic partnerships with local and regional healthcare providers. For example, in 2010 Community Hospital began the formal process to acquire a longterm care facility (i.e. "long term care facility acquisition"). Then in early 2011 an agreement to merge with a significantly larger hospital from the nearby urban center was formalized (a letter of intent was signed by both hospitals and publically shared) (i.e. “merger with urban hospital”).

The selection process for a new CEO took place over the summer and by September 2011 the position was filled (i.e. “new CEO”). The new CEO, another external hire, did not have a clinical background but, unlike the previous CEO, was male and had past experience serving in CEO roles at similarly sized hospitals. In 2011, in addition to carrying out the Centre for Excellence plans set in motion by the former CEO, the hospital was implementing initiatives to improve the work environment, integrate the eldercare facility, and determine how the merger with the larger hospital should proceed.

\section{2-2013}

The introduction of change at Community Hospital did not abate with the hiring of the new CEO. In fact, new changes continued to be introduced at what could be considered an accelerated rate. Changes introduced by the new CEO in 2012 included 
modifications to work processes and structures intended to both improve the work environment and assist in the provision of patient-centered care. The following initiatives were introduced in this time period: the introduction of unit councils for nursing staff (i.e. "unit councils started"); team huddles in all departments (i.e. "team huddles begin"); and new technologies such as the electronic health record (i.e. "Electronic Health Record"). Time 2 (T2) data (interviews) were collected between April and June of 2012.

The changes that occurred in 2012 were followed in 2013 by more changes, including partnerships with other healthcare organizations that began to lease space in a building constructed next to the hospital (i.e. "community partners move in"), and the implementation of LEAN in the emergency department (i.e. "LEAN introduced in ER"). In September of 2013, shortly following the implementation of LEAN, the CEO announced that low patient volumes in many of the hospital's departments meant that the hospital would need to make changes to ensure its survival (i.e. "CEO announces need for change due to low patient volumes"). While the CEO talked generally about the need for staffing and work process changes he did not specify in 2013 how these changes were to be implemented, or what form they would take. Time 3 (T3) data (interviews) were collected between September and October of 2013.

\section{Literature Review}

This literature review is divided into three parts. First, sensemaking is described and some of its key properties explained. Next, the research on sensemaking about organizational change is summarized. Finally, the notion of cognitive bias is introduced and used to explain the gap in the literature on sensemaking about organizational change that is addressed in this paper. 


\section{Sensemaking}

Organizational cognition is an area of organizational research that focuses on how managers process information (Hodgkinson \& Healey, 2008). Its five major theoretical streams include: (1) schema theory, which investigates mental models, (2) behavioral decision theory, which examines cognitive biases, (3) attribution theory, which looks at how individuals make inferences about behaviour, (4) social identity theory, which considers the impact of social group membership on intergroup behaviours, and (5) sensemaking. Sensemaking is defined as a process that individuals use in order to understand unexpected, ambiguous, or confusing events (Maitlis \& Christianson, 2014). Sensemaking involves "the ongoing retrospective development of plausible images that rationalize what people are doing” (Weick, Sutcliffe, \& Obstfeld, 2005, p. 409).

Seven properties of sensemaking were identified by Weick in the 1995 seminal book Sensemaking in Organizations. These seven properties can be summarized as follows: (1) Sensemaking is grounded in identity construction, meaning individuals' identities will influence how they interpret events; (2) Sensemaking is retrospective, meaning it is a process by which individuals can interpret past events; (3) Sensemaking is enactive, meaning that it is a process that allows individuals to translate meaning into action; (4) Sensemaking is social, meaning individuals consult others and talking is central to how sense is made of events; (5) Sensemaking is ongoing and iterative; (6) Sensemaking is driven by plausibility rather than accuracy, meaning that individuals will select meaningful explanations over others regardless of accuracy; and (7) Sensemaking focuses on extracted clues, meaning that individuals will observe 
environmental cues that further support their beliefs or cause them to abandon certain beliefs (Weick, 1995).

Taken together, these seven properties reflect Weick's view that the sensemaking process is "not about truth and getting it right. Instead, it is about continued redrafting of an emerging story so that it becomes more comprehensive, incorporates more of the observed data, and is more resilient in the face of criticism" (Weick et al., 2005, p. 415).

\section{Sensemaking About Organizational Change}

We undertook a literature search in order to assess the current state of knowledge on sensemaking about organizational change. In total, 66 articles were collected and reviewed, including 50 empirical articles and 16 conceptual articles. Our analysis of this group of empirical papers determined that they represented four different research streams: (1) sensemaking and individuals' responses to change (e.g., Balogun, Bartunek, \& Do, 2015; Bartunek, Rousseau, Rudolph, \& DePalma, 2006; Chreim, 2006; Kyriakidou, 2011; Greenberg, 1995; Landau \& Drori, 2008; Riesenmy, 2010; Smollan, 2014; Stensaker \& Falkenberg, 2007; Stensaker \& Meyer, 2012; Stensaker et al., 2008); (2) sensegiving (i.e. influencing others' sensemaking) and change implementation (e.g., Gioia \& Chittipeddi, 1991; Gioia, Thomas, Clark, \& Chittipeddi, 1994; Hensmans, 2015; Kezar, 2013; Marmenout, 2010); (3) middle managers as sensegivers during change (e.g., Balogun, 2003; Balogun, 2006; Balogun \& Johnson, 2004, 2005; Dutton et al., 2001; Hope, 2010; Rouleau \& Balogun, 2011); and (4) the role of narrative, discourse and stories when sensemaking about change (e.g., Abolafia, 2010; Brown \& Humphreys, 2003; Dawson, Sykes, McLean, Zanko, \& Marciano, 2014; Dunford \& Jones, 2000; Gazi, 
2013; Heracleous \& Barrett, 2001; Reissner, 2011; Sonenshein, 2010; Teulier \& Rouleau, 2013).

The retrospective nature of sensemaking during change was highlighted in studies done by Maclean et al. (2014) and Wetzel and Dievernich (2014). Maclean et al. (2014) introduced the term "ideological sensemaking" to describe how senior executives make sense of organizational change in a way that involves making sense of organizational history in a manner that causes them to feel a sense of heritage and an implied responsibility to carry out change in a particular manner. Wetzel and Dievernich (2014) drew attention to the importance of the "post-change" period for making sense of change retrospectively. They claim that this period involves three steps (provide stability in identity frames, develop sensemaking patterns, and develop and stage contradictions) and that this period of time can act as a driver for future change. Findings from these studies about the retrospective nature of sensemaking during organizational change highlight the notion that while sensemaking is not about the objective truth of events, it does represent what an individual believes to be true, and as such is important to understand, as it can be linked to attitudes and future behaviour. In this manner the research on sensemaking about change shows us that the objective truth of organizational change does not necessarily matter because what people think happened may in fact be more important.

On a positive note, the extent body of literature relating to sensemaking about organizational change has begun to establish an understanding of how individuals make sense of organizational change over time. For instance, research has found that those leading or implementing change (i.e. change agents) and those on the receiving end of change (i.e. change recipients) tend to make sense of organizational change differently 
(Sonenshein, 2010; Stensaker \& Meyer, 2011). Job type has also been identified as a factor that influences individuals' perceptions and experiences of change, particularly in healthcare organizations (Callan, Gallois, Mayhew, Grice, Tluchowska, \& Boyce, 2007; Lockett, Currie, Finn, Martin, \& Waring, 2014). The majority of this empirical research on individuals' sensemaking about change, however, either relies primarily on retrospective interviews conducted at one point in time, or (with one exception) draws their conclusions from longitudinal interview data that represents a relatively limited segment (typically two years or less) of the change process. The one exception to this observation was a study done by Balogun et al. (2015) which used longitudinal interview data collected over a period of time greater than two years from a sample of senior managers. While the findings from this study inform our understanding of the sensemaking processes used by senior managers to make sense of organizational change, they have limited generalizability beyond this group. Also of relevance to this paper is our observation that none of the empirical studies included in our review on sensemaking about organizational change examined how individuals' retrospective sensemaking about change compares with their real-time assessments of their situation.

\section{Cognitive Bias}

Cognitive bias refers to instances when "human cognition reliably produces representations that are systematically distorted compared to some aspect of objective reality" (Haselton, Nettle, \& Murray, 2015; p. 970). A vast amount of psychological research exists that investigates cognitive biases in individuals (Haselton et al., 2015). The research on cognitive bias conducted by organizational change scholars, however, tends to focus on managers' decision making. These studies, which look at how cognitive 
bias impacts managerial decision making in response to environmental change (e.g., Valle Santos \& Garcia, 2006), draw heavily from research on managerial bias within the strategic management literature (e.g., Keil, Depledge, \& Rai, 2007; Mezias \& Starbuck, 2003). The research on managerial perception and cognitive bias has shown that managers tend to be inaccurate in their assessments of the external environment (Mezias $\&$ Starbuck, 2003). This inaccuracy is blamed chiefly on the presence of specific types of cognitive bias such as simplification bias (i.e. cognition impaired by the simplification that occurs in response to the overwhelming complexity of the situation managers face), or affective influence bias (i.e. when a manager's dispositional or situational affect clouds their cognition) (Valle Santos \& Garcia, 2006).

The streams of research on cognitive bias and sensemaking are similar in that they both seek to illuminate our understanding of individuals' cognitive processes. They differ, however, in that each reflects a different perspective on organizational cognition (computational versus interpretive). Cognitive bias research, on the one hand, is rooted in the computational perspective that centers on the limitations of human actors when processing information and making decisions (Hodgkinson \& Healey, 2008). Sensemaking, on the other hand, is from the interpretive perspective and views the human mind (individually and collectively) as a tool that can be of benefit when attempting to process information in ambiguous and uncertain contexts (Hodgkinson \& Healey, 2008). To date, there is little crossover between the cognitive bias and sensemaking concepts within the research on organizational change. According to scholars, however, these two approaches to organizational cognition "coexist in a dynamic interplay" (Hodgkinson \& Healey, 2008, p. 391). 


\section{Research Objectives}

Three potential gaps in our understanding of how individuals experience organizational change served as the motivation for this study. First, although the body of research on organizational change and on sensemaking about change is substantive, scholars such as Langley Smallman, Tsoukas, and Van de Ven, (2013) and Van de Ven and Poole (2005) have noted the absence of research examining the process of organizational change over time at the individual level. Second, much of the research in the areas of sensemaking and cognitive bias related to organizational change tends to consider only one stakeholder group (usually senior or middle managers), which limits our ability to draw conclusions about how individuals' cognitions about organizational change vary across multiple levels or groups over time (Amis, Slack, \& Hinings, 2004; Lee, Weiner, Harrison, \& Belden, 2013; Whelan-Berry, Gordon, \& Hinings, 2003). Finally, the current understanding of sensemaking about change is limited by the fact that empirical work in the area often relies on retrospective views of what happened and/or interview data collected over a short period of time (i.e. less than two years). Such research does not seem to question the extent to which retrospective views of the change process line up with employees' assessments of the situation made at the time the change was being implemented. Moreover, our review of the literature did not identify any empirical research that compared what people recalled about change (i.e. retrospective sensemaking) to their cognitions at the time the change was happening (real-time assessments). This is unfortunate, as sensemaking theory is based on the assumption that individuals' retrospective cognitions about change will be inaccurate, and empirical work on the topic of cognitive bias has confirmed this. 
This primary objective of this study, which is to explore how individuals' retrospective sensemaking about organizational change compares with assessments these individuals made during the change process (i.e. in "real-time"), addresses this gap in our understanding. The secondary objective of this study is to explore how real-time assessments and retrospective sensemaking patterns relate to job type and change roles (i.e. change agent versus recipient). As noted in the literature review, sensemaking is based on cues in one's environment (Weick, 1995). This secondary objective allows us to examine the extent to which individuals in different roles and jobs use different cues to make sense of the change process retrospectively and in real-time. It will also increase the transferability of our findings.

The objectives are addressed by comparing real-time and retrospective data from 26 staff and managers at Community Hospital. These data were collected over a 4.5 year timeframe, during which the organization introduced a number of changes aimed at improving the work environment within the hospital. In 2009, 2012, and 2013 we asked a number of interview questions to help us understand how hospital employees and managers felt about their work environment at the time the interview was conducted. The responses to these questions provide us with data that help us appreciate how individuals assess change (organizational reorientation) as it is happening (i.e. in "real-time"). At the end of the study (i.e. in 2013), we did one last interview with each of our 26 respondents. At this time we asked them to reflect on how the work environment within Community Hospital had changed between 2009 and 2013. These reflections are the source of the retrospective data examined in the study. 


\section{Methodology}

A process-oriented case study approach was selected as most suitable for the research objective for two reasons. First, case studies are useful when unclear boundaries exist between the phenomena and the context (Myers, 2009; Yin, 2009). This is certainly true in studies such as ours on sensemaking about organizational change. Second, as noted by Langley (1999) and Yin, (2009), process case studies are useful when examining social processes over time (e.g., sensemaking about change over time), as we did in this research. The research design involved longitudinal data collection from 26 individuals, each of whom participated in an interview at three points in time. As is the case with any rigorous qualitative research study, our data analysis and findings were intertwined as the findings from one stage of the analysis drove the next (Charmaz, 2006; Myers, 2009). While the manner in which we analyzed our data enriched our findings, it made it difficult to structure the methodology and findings sections of this paper. To increase readability we elected to divide our discussion of the methodology followed in this paper into two sections. Details on the data collection and the grounded theory data analysis procedures used in this study are provided below. Details on any follow-up analysis triggered by our observations are offered in the findings section as appropriate.

\section{Data Collection}

In 2009, volunteers for an organization-wide survey were solicited through email, organizational memos, information mailed with paystubs, and announcements made at organization-wide meetings and events. In total, $25 \%$ (or 83 of 340 ) of the employees at the hospital completed surveys. The final survey question asked survey respondents to provide their name and contact information if they were willing to participate in follow- 
up interviews. These volunteers were contacted and follow-up interviews were arranged. Participation in the survey and each interview was voluntary.

Overall, 59 individuals participated in a follow-up interview at T1 (2009). For the second set of interviews (i.e. T2 in 2012), the 59 individuals that participated in the 2009 interviews were contacted to seek their participation in a second interview. In total 31 of the 59 individuals took part in a T2 interview. Finally, for T3 (in 2013) the 31 participants from T2 were contacted to seek their participation in a final interview. At the end of T3 the sample included 26 individuals who had participated in interviews at all three points in time. The sample distributions $(n=26)$ with respect to gender $(77 \%$ female $)$ and job type (12\% manager, 23\% physician, 23\% nurse, $12 \%$ clinical support, $27 \%$ nonclinical support) mirrored the hospital workforce.

The interviews were semi-structured. A piloted tested script, which included questions regarding workers' backgrounds, general work experiences, the work environment at the hospital, and changes at the hospital, was used by the interviewer. In each case the informants were provided the choice between interviews done in-person or over the phone. Almost all of the interviewees chose an in-person interview, on site, in a private room at the hospital. All interviews were conducted by the first author of this paper. Interviews were audio recorded and averaged about 45 minutes long (the shortest interview lasted 20 minutes, the longest 80 minutes). All interviews were transcribed.

The data used in this paper comes from the portion of the interview that focused on the respondent's views of the work environment within the hospital at the time the interview was conducted. During the interviews we operationally defined "work environment" to include the individual's perceptions of their working conditions, patterns 
of interactions at work, the organizational climate, and any other work factor that respondents felt impacted their day-to-day work lives. This definition is consistent with Klein et al.'s (2001) conceptualization of this construct. To determine respondents' realtime assessments of their work environment, we asked them the following question during each of the T1, T2 and T3 interviews: "Overall, on a scale of 1 to 5 where 5 is very satisfied, 4 is satisfied, 3 indicates a mixed opinion, satisfied about some things, dissatisfied with others, 2 is dissatisfied, and 1 is very dissatisfied, how satisfied would you say you are right now with the work environment at Community Hospital?"

Responses to these questions provided us with real-time longitudinal panel data regarding how individuals felt about their work environment during the time that the hospital was undertaking reorienting change. We use the phrase "real-time assessment of work environment over time" to refer to these data.

The decision to focus our questions on satisfaction with the work environment is consistent with the fact that many of the changes that were introduced within the hospital between 2009 and 2013 were aimed specifically at improving the work environment. As such, we expect that respondents" "real-time" evaluations of their work environment could vary over time in response to exposure to these change initiatives. Second, because work environment is a generally defined organizational level construct, theoretically it is possible that it changes that were implemented as part of the reorientation at Community Hospital - even changes that were not directed specifically at improving the work environment - would also impact how satisfied employees were with their work environment at the time we asked the question (e.g., Ahuja \& Thatcher, 2005). 
At the end of the study, in the T3 interviews we asked respondents the following question: "Please think back to 2009, to the time of our first interview with you - shortly after the move to the new building. In your opinion has the work environment changed since then? If yes, how?" This second question provides us with respondents'

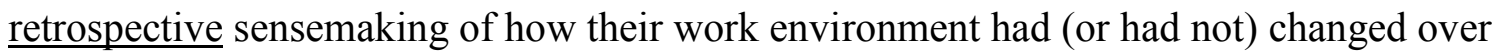
time. The interviewer asked follow-up clarification questions as needed in order to ensure full understanding of the informants' responses (e.g., Can you explain more?). The transcribed responses to the work environment questions (listed above) totaled 65 pages single-spaced. The term "retrospective accounts of change to the work environment over time"is used in this paper to refer to these data.

These two sets of data allow us to compare informants' real-time assessment of their work environment made at $\mathrm{T} 1, \mathrm{~T} 2$, and $\mathrm{T} 3$ to their retrospective accounts of how the work environment has changed over a time period characterized by the implementation of reorienting change. Analysis of these data give us insight into how informants' retrospective sensemaking about changes to their work environment compares to their real-time assessments of their work environment throughout the period of change.

\section{Data Analysis}

We used the classification function in QSR-Nvivo Version 10, a software that facilitates qualitative data analysis, to sort and code our data (i.e. assign labels to pieces of text from the transcriptions). The subsequent analysis of the data involved three stages. First we drew from grounded theory data analysis techniques (Charmaz, 2006; Myers, 2009) to examine the "retrospective accounts of change to the work environment over time" data. Second, we employed a visual mapping strategy (Langley, 1999) to sort and 
analyze the "real-time assessment of work environment over time" data. The third and final stage of analysis involved comparing observations made using the retrospective data to those formed using the real-time data at the individual level. The specific data analysis steps and findings from each of these stage are described in the findings section below.

We also used job type and change role as lenses through which to examine the preliminary findings from each of these three stages of data analysis. This part of the analysis was driven by previous research linking individual sensemaking about change to a person's job type (Reissner, 2010) and their role in the change process (i.e. change agent or change recipient) (Stensaker \& Meyer, 2011). We classified our respondents by job type and change role based on the job description each respondent provided us at the beginning of the T1 interview. For job type the occupational groups include: Senior Managers ( $\mathrm{n}=3)$; Physicians $(\mathrm{n}=6)$; Nurses $(\mathrm{n}=7)$; Clinical Support $(\mathrm{n}=3)$ and Nonclinical support $(\mathrm{n}=7)$. For change role, individuals who described themselves as being at higher levels of the organizational hierarchy (e.g., senior managers, medical leaders) and were responsible for implementing portions of the reorienting change were considered change agents $(\mathrm{n}=5)$. Individuals who described themselves as working in front-line staff roles that were not responsible for, or in control of, any particular aspects of the reorienting change were considered change recipients $(n=21)$. The comparatively small size of the change agent group is reflective of the fact that reorientation type changes tend to be implemented in a top down manner and involve a small number of key individuals as change agents (Nadler \& Tushman, 1989).

We used Nvivo's matrix coding and classification functions to produce the results tables included with this paper in order to facilitate comparison across groups (Miles \& 
Huberman, 1994, p. 11). In all tables we report the percentage of each group giving a particular response to account for differences in group sizes and facilitate the comparison process. In the discussion below we flag between-group differences of $>20 \%$ when identifying possible differences in sensemaking and assessments that can be linked to one's change role or job grouping. While the selection of this cut-off is somewhat arbitrary, it was necessary to draw the line somewhere, both to make the paper more readable and to avoid claims of generalization based on our qualitative analysis.

\section{Findings}

Key findings in each of three areas are presented in the section below: (1) analysis of the "retrospective accounts of changes to work environment over time" data, (2) findings gleaned from the "real-time assessments of work environment over time", and (3) a comparison of the key findings obtained from these two very different types of data. Descriptions of the data analysis steps that unveiled each of our findings are also included in this section. In the interest of clarity, italicized and bold font is used for code and analysis category names.

\section{Retrospective Accounts of Changes to Work Environment Over Time}

The analysis of the retrospective data involved four iterative steps (initial coding, focused coding, identifying patterns for grouping informants, and considering job type and change role trends). In total, five informants felt that the work environment had not changed over time. The other 21 informants felt that it had changed, and explained how. We used grounded theory's initial and focused coding practices (Charmaz, 2006) to analyze the retrospective responses from these 21 informants relating to how the work environment at the hospital had changed since 2009. In initial coding, which involves 
staying close to the ideas that informants express in the data (Charmaz, 2006), we created and assigned codes (i.e. labels) to summarize themes from informants' responses. Next, focused coding was used to identify higher level themes or categories to describe the data captured in the initial codes (Charmaz, 2006; Myers, 2009). All codes were emergent (i.e. not predetermined). Constant comparison was exercised in that each time a new code was created, we would review the responses already coded to check for links to the new codes (Charmaz, 2006; Myers, 2009). In total, eight initial codes and two focused codes were created to summarize the themes that emerged from this analysis on how the work environment had changed since 2009. The initial and focused codes and exemplary quotes are included in Table 4-1, while the frequency with which each initial code is cited can be found in Table 4-2. 
Table 4-1: Retrospective sensemaking about work environment change (from T3 interviews)

\begin{tabular}{|c|c|c|}
\hline $\begin{array}{l}\text { Focused } \\
\text { code } \\
\text { (Category) }\end{array}$ & Sample Initial Codes & Sample quote \\
\hline \multirow[t]{5}{*}{$\begin{array}{l}\text { Changed - } \\
\text { better }\end{array}$} & $\begin{array}{l}\text { Turnover for the better } \\
\text { Better relationships } \\
\text { and improved } \\
\text { collaboration }\end{array}$ & $\begin{array}{l}\text { 'Some of the medical staff who were most anti } \\
\text { management have left the hospital' } \\
\text { 'There's much more collaboration between the } \\
\text { different disciplines.' }\end{array}$ \\
\hline & $\begin{array}{l}\text { People are more } \\
\text { positive now }\end{array}$ & $\begin{array}{l}\text { 'There was a lot of dissatisfaction and grumbling. } \\
\text { Ifeel that that's improved'; 'they were all grumpy } \\
\text { because they were frustrated ... it wasn't very } \\
\text { pleasant for me, but now, everybody's accepted } \\
\text { the move... It's improved.' }\end{array}$ \\
\hline & $\begin{array}{l}\text { Changes to the } \\
\text { physical work } \\
\text { environment for the } \\
\text { better }\end{array}$ & $\begin{array}{l}\text { 'It's progressed in a lot of ways as far as flow and } \\
\text { movement of patients through the department and } \\
\text { equipment and supplies and all that kind of thing. }\end{array}$ \\
\hline & $\begin{array}{l}\text { Focus and direction } \\
\text { improved }\end{array}$ & $\begin{array}{l}\text { 'More focusing on quality, safety....there is } \\
\text { definitely positive change' }\end{array}$ \\
\hline & New CEO has helped & $\begin{array}{l}\text { '[The New CEO] brought with him an emphasis on } \\
\text { values and celebrating our values as well' }\end{array}$ \\
\hline \multirow[t]{2}{*}{$\begin{array}{l}\text { Changed - } \\
\text { worse }\end{array}$} & $\begin{array}{l}\text { Turnover for the } \\
\text { worse }\end{array}$ & $\begin{array}{l}\text { 'I sense people are dissatisfied...we seem to have } \\
\text { more turnover. It seems to be that there are } \\
\text { always new people and people aren't staying as } \\
\text { long as they used to and I'm not really sure why'. } \\
\text { 'Definitely the change in the leadership, the old }\end{array}$ \\
\hline & $\begin{array}{l}\text { New CEO has made } \\
\text { things worse }\end{array}$ & CEO is gone, another senior manager is gone.' \\
\hline
\end{tabular}


Table 4-2: Retrospective sensemaking about work environment change (\% change role, job type, and total)

\begin{tabular}{|c|c|c|c|c|c|c|c|c|}
\hline & \multicolumn{2}{|c|}{ Change role } & \multicolumn{4}{|c|}{ Job type } & \multicolumn{2}{|r|}{ Total } \\
\hline & $\begin{array}{l}\text { Change } \\
\text { Agent } \\
(n=5)\end{array}$ & $\begin{array}{l}\text { Change } \\
\text { Recipient } \\
(\mathrm{n}=16)\end{array}$ & $\begin{array}{l}\text { Manager } \\
(\mathrm{n}=3)\end{array}$ & $\begin{array}{l}\text { Physician } \\
(\mathrm{n}=6)\end{array}$ & $\begin{array}{l}\text { Nurse } \\
(\mathrm{n}=5)\end{array}$ & $\begin{array}{c}\text { Clinical } \\
\text { Support } \\
(n=1)\end{array}$ & $\begin{array}{l}\text { Non- } \\
\text { clinical } \\
\text { support } \\
(\mathrm{n}=5)\end{array}$ & $\begin{array}{l}\text { Total } \\
(\mathrm{n}=21)\end{array}$ \\
\hline $\begin{array}{l}\text { Turnover for the } \\
\text { better }\end{array}$ & $60 \%(3)$ & $19 \%(3)$ & $67 \%(2)$ & $33 \%(2)$ & $40 \%(2)$ & 0 & 0 & $29 \%(6)$ \\
\hline $\begin{array}{l}\text { Better relationships } \\
\text { and improved } \\
\text { collaboration }\end{array}$ & $60 \%(3)$ & $19 \%(3)$ & $33 \%(1)$ & $50 \%(3)$ & $20 \%(1)$ & 0 & $20 \%(1)$ & $29 \%(6)$ \\
\hline $\begin{array}{l}\text { People are more } \\
\text { positive now }\end{array}$ & 0 & $31 \%(5)$ & 0 & $50 \%(3)$ & $40 \%(2)$ & 0 & 0 & $24 \%(5)$ \\
\hline $\begin{array}{l}\text { Changes to the } \\
\text { physical work } \\
\text { environment for the } \\
\text { better }\end{array}$ & 0 & $25 \%(4)$ & 0 & $17 \%(1)$ & $20 \%(1)$ & 0 & $40 \%(2)$ & $19 \%(4)$ \\
\hline $\begin{array}{l}\text { Focus and direction } \\
\text { improved }\end{array}$ & $40 \%(2)$ & $6 \%(1)$ & $33 \%(1)$ & $17 \%(1)$ & 0 & $100 \%(1)$ & 0 & $14 \%(3)$ \\
\hline New CEO has helped & $40 \%(2)$ & 0 & $33 \%(1)$ & $17 \%(1)$ & 0 & 0 & 0 & $10 \%(2)$ \\
\hline $\begin{array}{l}\text { Turnover for the } \\
\text { worse }\end{array}$ & $20 \%(1)$ & $19 \%(3)$ & $33 \%(1)$ & 0 & $20 \%(1)$ & 0 & $40 \%(2)$ & $19 \%(4)$ \\
\hline $\begin{array}{l}\text { New CEO has made } \\
\text { things worse }\end{array}$ & $20 \%(1)$ & 0 & $33 \%(1)$ & 0 & 0 & 0 & 0 & $5 \%(1)$ \\
\hline
\end{tabular}


Almost half of the sample (48\%) talked about turnover when sensemaking about how the work environment had changed since 2009. In just over half of these cases (i.e. six individuals), the respondent indicated that the turnover was for the better and had improved the work environment: "We've had a turnover of staff, which has actually been very positive... because all we were doing was just dealing with negativity. New people bring new experiences and don't have any of that old history". The other four individuals who referred to turnover when making sense of the changes made comments that suggested that they felt that the turnover was for the worse and had negatively impacted their view of their work environment over time: “There's a lot of new staff and a lot of new faces so there's not a lot of familiarity".

One in three (29\%) respondents made sense of the work environment changes by focusing on how relationships within the hospital and collaboration had improved over time. Compared to 2009, one respondent felt that "We are working better together". About one in four (i.e. 24\%) of respondents talked about how the attitudes of employees had improved over time (people are more positive now): "I think people are a little more upbeat. They are not always looking at the negative; they are trying to move forward". Four respondents (i.e. 19\%) mentioned that the physical work environment within the hospital had improved, thereby leading to a better work environment in general: "The new facilities were certainly a big improvement over the old ones". Just over one in ten (14\%) of respondents said that they felt the focus and direction had improved at the hospital, for example: "People guide themselves a bit more in their actions and in their decision making... on a day-to-day level at a team level... we're much more aligned as an organization". 
Finally, 14\% of informants mentioned the new CEO when making sense of how the work environment had changed since 2009. Again, respondents attributed both positive and negative changes in their work environment to the new $\mathrm{CEO}$ in their sensemaking. For example, according to one interviewee, the new CEO has helped by contributing to positive changes in the work environment: "We have a new CEO which has improved doctor management relationships dramatically”. Alternatively, another individual felt the new CEO had made things worse and contributed to negative changes in the work environment: "The work environment change is not for the positive... for me, personally, definitely the change in the leadership, the old CEO is gone, another senior manager is gone. So I think that might have had the biggest impact”.

To identify patterns in the data that could be used to group informants, we revisited the interview data and codes shown in Table 4-1. This led to the identification of four patterns (see the top part of Table 4-3) describing how informants retrospectively made sense of the changes to the work environment (i.e. between 2009 and 2013) which were labeled: changed-better; no change; changed-worse; and changed-mixed.

Half of the individuals $(\mathrm{n}=13)$, when reflecting back, only talked about how the work environment had changed for the better over time (i.e. all their responses were coded under the "change-better" focused code). We refer to this retrospective sensemaking pattern as changed-better. This sensemaking pattern was the dominant one in this sample. The second and third sensemaking patterns were each used by one in five $(\mathrm{n}=5)$ of our informants. Five of these individuals (i.e. no change ) responded to our first interview question by stating that they did not perceive any differences in their work environment over time. The other five individuals represent the changed-worse pattern, 
as all gave responses that dwelt on ways in which they felt that their work environment had changed for the worse over time (i.e. all their responses were coded under the "change-worse" focused code). These two sensemaking patterns are particularly noteworthy given the number of efforts the hospital made to change the work environment for the better over this time period. The remaining respondents' $(n=3)$ sensemaking about the work environment changes was considered to reflect a changedmix pattern as these individuals provided examples of how the work environment had changed for the better (i.e. coded as "changed-better") as well as situations where the environment had changed for the worse (i.e. coded as "changed-worse"). The fact that our informants' accounts of retrospective sensemaking were characterized by these four different themes is consistent with Weick's (1995) idea that, when looking back over time, individuals use different frames or lenses to interpret what has occurred.

The final step in this stage of the analysis involved examination of the retrospective data to help us understand how job type and change role might influence an individual's retrospective sensemaking. Results from this step of the analysis are shown in Table 4-2 and the top section of Table 4-3. These data support the idea that both change role and job type are associated with retrospective perceptions of how the work environment at the hospital had changed over time. Change agents made sense of the changes to the work environment since 2009 in a generally positive way, with $80 \%$ of change agents (versus $43 \%$ of change recipients) talking about how the work environment within the hospital had changed for the better over time (i.e. used the changed-better sensemaking pattern. Change agents were also more apt than change recepients to mention better relationships and collaboration (60\% of agents versus 19\% 
of recipients), turnover for the better (60\% of agents versus $19 \%$ of recipients), improved focus and direction (40\% of agents versus $6 \%$ of recipients), and that the new CEO has helped (40\% of agents versus 0 recipients) as ways in which the work environment changed over time. In a comment that typifies what we heard from this group, one change agent observed: "I think [the work environment] has improved quite a bit over the last three or four years". Change recipients, on the other hand, when sensemaking about how the work environment had changed since 2009 , more frequently gave responses relating to how people are more positive now (mentioned by $31 \%$ of recipients and no agents) and how the physical work environment within the hospital has improved (mentioned by $25 \%$ of recipients and no agents). It is also interesting to note that all five people in the "no change" to the work environment since 2009 group were change recipients. 
Table 4-3: Findings ( $\%$ by change role, job type and total)

\begin{tabular}{|c|c|c|c|c|c|c|c|c|}
\hline & \multicolumn{2}{|c|}{ Change role } & \multicolumn{4}{|c|}{ Job type } & \multicolumn{2}{|r|}{ Total } \\
\hline & $\begin{array}{l}\text { Change } \\
\text { Agents } \\
(\mathrm{n}=5)\end{array}$ & $\begin{array}{l}\text { Change } \\
\text { Recipients } \\
(\mathrm{n}=21)\end{array}$ & $\begin{array}{c}\text { Manager } \\
(\mathrm{n}=3)\end{array}$ & $\begin{array}{l}\text { Physician } \\
(\mathrm{n}=6)\end{array}$ & $\begin{array}{l}\text { Nurse } \\
(\mathrm{n}=7)\end{array}$ & $\begin{array}{c}\text { Clinical } \\
\text { Support } \\
(\mathrm{n}=3)\end{array}$ & $\begin{array}{c}\text { Non- } \\
\text { clinical } \\
\text { support } \\
(\mathrm{n}=7)\end{array}$ & $\begin{array}{l}\text { Total } \\
(\mathrm{n}=26)\end{array}$ \\
\hline \multicolumn{9}{|c|}{ Retrospective accounts of change to work environment over time } \\
\hline Changed-better & $80 \%(4)$ & $43 \%(9)$ & $67 \%(2)$ & $100 \%(6)$ & $43 \%(3)$ & $33 \%(1)$ & $14 \%(1)$ & $50 \%(13)$ \\
\hline Changed-worse & $20 \%(1)$ & $19 \%(4)$ & $33 \%(1)$ & 0 & $29 \%(2)$ & 0 & $29 \%(2)$ & $19 \%(5)$ \\
\hline Changed-mix & 0 & $14 \%(3)$ & 0 & 0 & $14 \%(1)$ & 0 & $29 \%(2)$ & $12 \%(3)$ \\
\hline No change & 0 & $24 \%(5)$ & 0 & 0 & $14 \%(1)$ & $67 \%(2)$ & $29 \%(2)$ & $19 \%(5)$ \\
\hline \multicolumn{9}{|c|}{ Real-time assessment of work environment over time } \\
\hline $\begin{array}{l}\text { Satisfaction dipped at } \\
\text { T2 }\end{array}$ & $20 \%(1)$ & $33 \%(7)$ & 0 & $17 \%(1)$ & $43 \%(3)$ & $33 \%(1)$ & $43 \%(3)$ & $31 \%(8)$ \\
\hline $\begin{array}{l}\text { Satisfaction increased } \\
\text { over time }\end{array}$ & $40 \%(2)$ & $24 \%(5)$ & $33 \%(1)$ & $33 \%(2)$ & $43 \%(3)$ & 0 & $14 \%(1)$ & $27 \%(7)$ \\
\hline $\begin{array}{l}\text { Satisfaction decreased } \\
\text { over time }\end{array}$ & $20 \%(1)$ & $10 \%(1)$ & $33 \%(1)$ & 0 & 0 & 0 & $14 \%(1)$ & $8 \%(2)$ \\
\hline $\begin{array}{l}\text { Satisfaction same } \\
\text { over time }\end{array}$ & $20 \%(1)$ & $38 \%(8)$ & $33 \%(1)$ & $50 \%(3)$ & $14 \%(1)$ & $67 \%(2)$ & $29 \%(2)$ & $35 \%(9)$ \\
\hline \multicolumn{9}{|c|}{ Retrospective accounts versus real-time assessments } \\
\hline Consistent & $60 \%(3)$ & $29 \%(6)$ & $67 \%(2)$ & $33 \%(2)$ & $43 \%(3)$ & $33 \%(1)$ & $14 \%(1)$ & $35 \%(9)$ \\
\hline $\begin{array}{l}\text { Inconsistent - } \\
\text { positive retrospective }\end{array}$ & $40 \%(2)$ & $33 \%(7)$ & $33 \%(1)$ & $67 \%(4)$ & $14 \%(1)$ & $33 \%(1)$ & $29 \%(2)$ & $35 \%(9)$ \\
\hline $\begin{array}{l}\text { Inconsistent - } \\
\text { negative retrospective }\end{array}$ & 0 & $29 \%(6)$ & 0 & 0 & $43 \%(3)$ & 0 & $43 \%(3)$ & $23 \%(6)$ \\
\hline Unclassifiable & 0 & $10 \%(2)$ & 0 & 0 & 0 & $33 \%(1)$ & $14 \%(1)$ & $8 \%(2)$ \\
\hline
\end{tabular}


Informants' sensemaking with respect to how the work environment changed over time also differed according to job type. For instance, of those who thought the work environment had changed since 2009, managers and nurses spoke the most about turnover for the better (67\% of managers, $40 \%$ of nurses). Both the idea that the new CEO has helped and the idea that the new $\mathrm{CEO}$ has made things worse was mentioned mostly by managers. The notion that people are more positive now was most frequently cited by physicians and nurses and better relationships and collaboration was mentioned more often by physicians. Physicians (100\%) and managers (67\%) largely ascribed to the view that the work environment at the hospital had changed for the better over time (i.e. changed-better) while clinical staff (67\%) typically felt that there had been no change to the work environment over time. There was no such consensus within the other job type groupings with approximately equal numbers of respondents reporting that they felt that the work environment had improved (i.e. changed-better), gotten worse (i.e. changedworse), not changed (i.e. no change), or had changed for the better and the worse (i.e. changed-mix) over time.

\section{Real-time Assessments of Work Environment Over Time}

This stage of the analysis involved three steps: coding, identifying patterns for grouping informants, and considering job type and change role trends. In the first step of analysis we coded informants' numerical work environment satisfaction ratings into more meaningful categories that would enable us to look at how these satisfaction scores acted over time (Langley, 1999). The numerical responses (which ranged from 1 to 5) were aggregated into three categories: Satisfied (i.e. rankings of 4 or 5 out of 5), Mixed (i.e. rankings of 3 out of 5), and Dissatisfied (i.e. rankings of 1 or 2 out of 5). Next we used 
Excel software to plot each informant's real-time assessment ( $y$ axis) against time ( $x$ axis) (see Figure 4-2). This approach is similar to what Langley (1999) refers to as a visual mapping strategy for analyzing process data. The visual mapping strategy is useful for representing multiple dimensions (e.g., time and satisfaction with work environment) of process data simultaneously, which allows the researcher (and reader) to more easily identify and describe patterns over time.

Once the figures were drawn we moved on to the next stage of the analysis, identifying patterns that could be used to group informants. Review of the plots for each of our 26 informants revealed four distinct patterns which were labeled: satisfaction dipped at T2, satisfaction increased over time, satisfaction decreased over time and satisfaction same over time. Figure 4-2 includes the plots for each individual included within each of the pattern types so that the reader can see these groupings visually. The number of informants that had each specific plot pattern is indicated in the legend for each of the four graphs included in the Figure. 
Figure 4-2: Real-time assessment of work environment patterns

Paths are below plots with satisfaction level at T1, T2 and T3 indicated by acronyms $(D=$ dissatisfied, $M=$ mixed, $S=$ satisfied $)$.

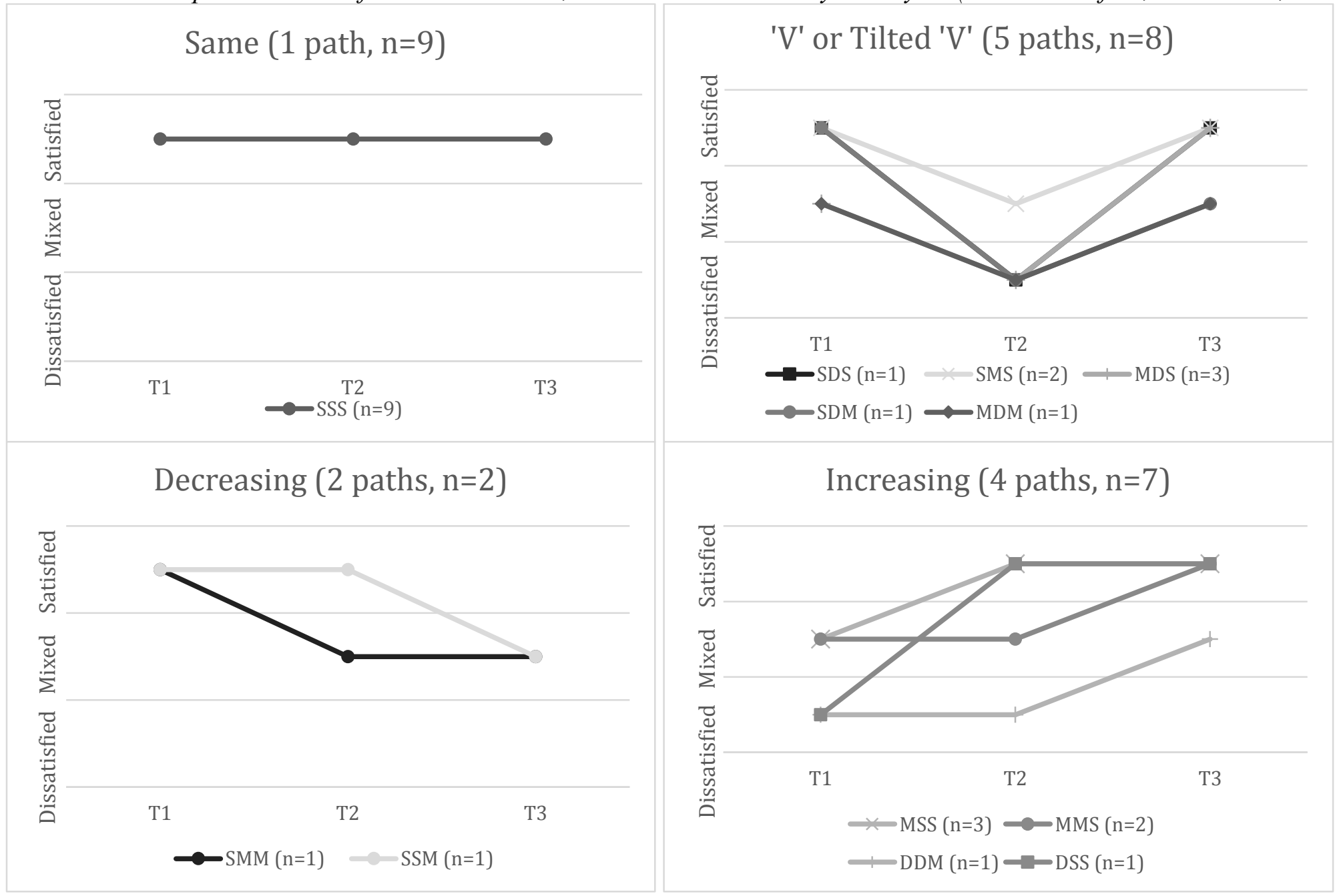


Summary data associated with this step in the analysis are also shown in the midsection of Table 4-3. The following observations can be drawn using these data. First, a plurality of respondents' satisfaction scores either dipped at T2 (i.e. 31\%) or stayed the same over time (i.e. $35 \%$ ). Those who were in the satisfaction with work environment dipped at T2 group had plots that were either "V" shaped or a tilted "V" shape which reflected the fact that the "real-time" satisfaction with work environment scores decreased from $\mathrm{T} 1$ to $\mathrm{T} 2$ and increased from $\mathrm{T} 2$ to $\mathrm{T} 3$. Although the exact paths for the dipped at $\mathbf{T 2}$ group varied, as depicted in Figure 4-2, the most common path for this pattern involved informants' levels of satisfaction with the work environment that went from mixed at $\mathrm{T} 1$ to dissatisfied at $\mathrm{T} 2$ and then climbed back to satisfied at $\mathrm{T} 3(\mathrm{n}=3)$. Interestingly, all of those in the satisfaction same over time group were consistently "satisfied" with the work environment during all three time periods (i.e. gave satisfaction scores of 4 or 5 in 2009, 2012, and 2013). For one in four (27\%) of the respondents, their satisfaction with work environment scores increased over time. Most of the increased over time group (i.e. five out of seven) went from mixed to satisfied, while one informant went from dissatisfied to satisfied and another went from dissatisfied to mixed. Relatively few respondents (i.e. $n=2$ or $8 \%$ of the sample) had satisfaction scores which decreased over time. In both of these cases informants went from satisfied to mixed. Despite the variation with respect to how informants' satisfaction with the work environment fluctuated over time, the majority of our informants (i.e. 73\%) never reported dissatisfaction with the work environment. Moreover, at the time of the final interview none of the informants were dissatisfied with the work environment, not even those $(n=7)$ who had reported dissatisfaction during their $\mathrm{T} 1$ and/or T2 interviews. 
The final step in our examination of the real-time data involved analysis to help us understand how job type and change role may influence an individual's real-time assessments of their work environment during times of change. The data in Table 4-3 suggest that there may be a relationship between job type and how individuals make assessments in "real-time" during organizational change. More specifically, a higher proportion of respondents in the nurse and non-clinical staff groups fell into the satisfaction with the hospital's work environment dipped at $\mathbf{T} 2$ group. In contrast, with one exception all the physicians we spoke to either reported that they were satisfied with their work environment at all three time periods (i.e. satisfaction stayed the same) or exhibited a pattern suggesting that they became more satisfied with their work environment over time (i.e. satisfaction increased). The fact that physicians' work role places them at the top of the hospital's organizational ladder, while the roles occupied by the nurses and the non-clinical staff tend to place them in the middle or the bottom of the organizational hierarchy, suggests that hierarchical level (as reflected in this case by job type) impacts how employees make assessments in "real-time" during organizational change.

Surprisingly, despite what we expected from our reading of the literature, we could find no evidence to support the idea that an individual's role in the change process is linked to their "real-time" assessments of their work environment during time of change. This would suggest that while the change management role one occupies may impact their retrospective sensemaking of change in a positive fashion, it does not impact how they evaluate their situation at the time. 


\section{Retrospecitve Accounts Versus Real-time Assessments}

Finally, we compared each individual's "retrospective accounts of changes to the work environment over time" data (i.e. changed-better, changed-worse, changed-mixed and no change) with their "real-time assessment of the work environment over time" (i.e. satisfaction dipped at T2, same over time, increased and decreased) data. This analysis led us to identify three additional patterns that described how individuals' retrospective accounts of change compared to their real-time assessments: consistent, inconsistent positive retrospective, and inconsistent - negative retrospective. How individuals were categorized into these three groupings is shown in Table 4-4 and described below.

Table 4-4: Real-time assessment of work environment versus retrospective accounts of change

\begin{tabular}{|c|c|c|c|c|c|}
\hline \multirow{6}{*}{ 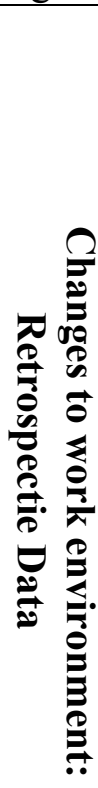 } & \multicolumn{5}{|c|}{$\begin{array}{c}\text { Assessments of work environment: } \\
\text { Real-time data }\end{array}$} \\
\hline & & $\begin{array}{l}\text { Increased } \\
\text { over time }\end{array}$ & $\begin{array}{l}\text { Decreased } \\
\text { over time }\end{array}$ & $\begin{array}{l}\text { Dipped at } \\
\text { Time } 2\end{array}$ & $\begin{array}{l}\text { No change } \\
\text { over time }\end{array}$ \\
\hline & $\begin{array}{l}\text { Changed - } \\
\text { better }\end{array}$ & $\mathrm{n}=5$ & - & $n=3$ & $\mathrm{n}=5$ \\
\hline & $\begin{array}{l}\text { Changed - } \\
\text { worse }\end{array}$ & -2 & $\mathrm{n}=1$ & $\mathrm{n}=2$ & $n=2$ \\
\hline & $\begin{array}{l}\text { Changed - } \\
\text { mixed }\end{array}$ & -1 & - & $\mathrm{n}=2$ & $\mathrm{n}=1$ \\
\hline & No change & $1=2$ & $\mathrm{n}=1$ & $\mathrm{n}=1$ & $\mathrm{n}=1$ \\
\hline
\end{tabular}

Note: '-' indicates that zero respondents fell into this category

\section{Key}

\section{Consistent}

Inconsistent - negative

retrospective

Inconsistent - positive

retrospective

Unclassifiable 
The consistent group ( $\mathrm{n}=9$ or $35 \%$ of the individuals in the sample) includes informants whose retrospective accounts of change grouping (e.g., changed-better) was similar to the pattern they demonstrated when we looked at the "real-time assessment of the work environment over time" data (e.g., satisfaction increased). This group included four types of individuals: (1) those who retrospectively felt their work environment had changed for the better over time and whose real-time assessments of the work environment (i.e. satisfaction scores) also increased over time $(n=5) ;(2)$ those who retrospectively made sense of changes to the work environment as being for the worse and who also reported a decrease in their real-time work satisfaction scores over time $(n=1)$; (3) those who retrospectively made sense of work environment changes in a mixed way and who reported real-time assessments of the work environment that dipped at T2 $(n=2)$; and (4) those who gave the same satisfaction with work environment score during the $\mathrm{T} 1, \mathrm{~T} 2$, and $\mathrm{T} 3$ interviews who also, when asked to reflect on how they felt that the work environment at the hospital had changed over time, stated that they had not observed any changes $(\mathrm{n}=1)$. The consistent group represents an interesting pattern in that they reported the same pattern of response regardless of the type of data we were using to do the classification. This could mean that either the individuals in the consistent group are less likely to use conceptual biases when evaluating their situation during times of change or that they use the same set of cognitive biases both retrospectively and when evaluating their situation in real-time. The diversity of patterns within the consistent group, and the fact that the individuals who perceived that the work environment had become worse over time were in this group, supports the idea that these individuals (or at 
least some of them) have a preferred cognitive style that they apply indiscriminately to a variety of situations.

The remaining respondents ( $58 \%$ of the sample) retrospectively made sense of the changes to their work environment in a way that did not line up with how they evaluated their work environment in real-time. These informants were approximately evenly split between two groups: inconsistent - positive retrospective $(\mathrm{n}=9)$ and inconsistent negative retrospective $(\mathrm{n}=6)$. In the first case, the individuals' retrospective view of how their work environment had changed over time painted a more positive picture than was expected from examination of their real-time satisfaction with the work environment ratings. In the second case, the individuals' retrospective view of how their work environment had changed over time was more negative than would be expected by looking at their real-time satisfaction with the work environment ratings.

The inconsistent - positive retrospective group included eight individuals who felt the work environment had changed for the better when making sense of it retrospectively, but who did not show an increase in satisfaction according to their realtime assessments; these remained the same over time $(\mathrm{n}=5)$ or dipped at $\mathrm{T} 2(\mathrm{n}=3)$. The one other person in the inconsistent-positive retrospective group felt that the work environment had not changed, when retrospectively sensemaking, but cited real-time assessments of their satisfaction that decreased over time. For those individuals in the inconsistent - positive retrospective group, their sensemaking seemed to put a "positive" spin on changes to their work environment that were not viewed as positively when they were happening. 
The inconsistent - negative retrospective group $(\mathrm{n}=6$, or $23 \%)$ included two informants who retrospectively felt the work environment had not changed, but who reported increasing satisfaction scores, and two informants who had real-time assessments of the work environment that remained stable over time but retrospectively stated that the work environment at the hospital had changed for the worse over time. The final two members of the inconsistent - negative retrospective group made sense of the work environment change as for the worse and reported satisfaction scores that dipped at T2. The composition of the inconsistent - negative retrospective group suggests that when these individuals are asked to reflect back on their experiences during times of change, their view is more negative than the assessments that they provided as the change was occurring. We might infer that the individuals in this group were trying to "put a positive face on things" as they were happening but that the cumulative changes to their work environment over time had exhausted their ability to cope in this manner.

Finally, we felt unable to classify two of our informants into any of these three patterns using the data we had collected. In one case the informant's retrospective sensemaking pattern was classified as changed-mixed and their real-time assessment showed no change over time. In the second case, the informant had a real-time assessment of the work environment that dipped at T2 but made sense of the work environment retrospectively as not changing over time.

As a final step in our analysis, we examined how job type and change role might influence the patterns noted above. Examination of the data in Table 4-3 suggests that one's role in the change process might explain some of the variation observed in our sample with respect to how individuals make sense of change retrospectively versus how 
they assess the situation in real-time. The majority of change agents $(n=3)$ reported retrospective views of the work environment that were "consistent" with their real-time assessment of the work environment - a proportion with this view that is notably greater than the proportion of the change recipient group displaying this pattern. The remainder of the change agents $(n=2)$ made sense retrospectively in a manner that, while inconsistent from their real-time assessments, demonstrated a positive bias (i.e. inconsistent-positive retrospective). No one in the change agent group was classified as having an inconsistent - negative retrospective outlook. Change receipients, on the other hand, were fairly evenly distributed across the three groupings (consistent, inconsistent positive retrospective, and inconsistent - negative retrospective). These findings suggest that change agents and change recipients may pay attention to different cues when sensemaking about change. Theoretically, these differences could be because change agents are likely to have very different levels of awareness as to what went on during change as well as access to different types of information when sensemaking than the change recipients. These notions will be discussed further in the discussion section.

There were also notable differences in the degree to which retrospective and realtime views of work environment lined up that seemed to be associated with job type. More specifically, the real-time assessments of the managers in the sample were mostly "consistent" (67\%) with their retrospective sensemaking; physicians (67\%) tended to have inconsistent views that reflected a more positive view of the work environment retrospectively than was suggested by their real-time ratings (i.e. inconsistent-positive retrospective), and the majority of those in non-clinical support (43\%) job grouping reported inconsistent views that reflected retrospective sensemaking of the work 
environment that was more negative than their real-time assessments (i.e. inconsistent negative retrospective). The pattern displayed by those in the nurse group was the most diverse, with $43 \%$ reporting a pattern that was inconsistent - negative retrospective and another $43 \%$ reporting a pattern that was consistent, with the remaining $14 \%$ providing a set of retrospective and real-time responses that were inconsistent-positive retrospective. While it is possible that these retrospective/real-time differences in perception could be related to the disparate types of information available to individuals in different jobs when engaging in sensemaking about change, in this case we also suspect that professioncentrism (i.e. defined by Lockett et al., 2014, as an orientation towards one's professional group, which may limit one's viewpoint) might also impact how one filters and makes sense of cues in the environment.

\section{Discussion}

Below we identify and discuss a number of key observations from this study including the idea that how one experiences change depends on the type of data looked at, the type of job they perform, and their role in the change process (agent, recipient).

This study is fairly unique in that we had the opportunity to collect both real-time and retrospective views of how employees who are exposed to reorienting change characterized their work environment over time. The fact that for most of the people in our sample these two different types of data tell a very different story with respect to the informants' experience of change is one of the key findings from this study. More specifically, over half of the employees who participated in this longitudinal case study retrospectively had a view of how their work environment had changed since 2009 that was inconsistent from how they had rated their satisfaction with the work environment in 
2009, 2012, and 2013 (i.e. real-time assessments of work environment). In one third of the cases, the employees' retrospective sensemaking about the work environment was more positive than their perceptions at the time. The rest of the respondents $(23 \%)$ gave a more negative assessment of their satisfaction with the work environment when sensemaking retrospectively than their assessments in real-time. The most likely explanation for this discrepancy is that people's retrospective evaluation of something that happened in the past - even something as important as their satisfaction with their work environment during times of change - are not accurate. This notion is consistent with the definition of sensemaking (Weick, 1995). To understand why this might be the case we draw further from the sensemaking perspective and supplement this with ideas from the cognition and attribution literatures.

Sensemaking is not about compiling the most accurate account of events, but instead is concerned with constructing plausible explanations of ambiguous or confusing events (Maitlis \& Christianson, 2014). It may be, therefore, that our findings reflect the fact that change agents use a different sensemaking process than change recipients to "make plausible sense retrospectively" of reorienting change. This interpretation of our findings can be supported by the data as follows. First, change role (i.e. agent, recipient) had no discernible impact on an employee's real-time evaluation of their work environment, but did influence how they viewed changes to the work environment retrospectively. Second, the employees' role in the change process also impacted whether or not the inconsistency between their real-time and retrospective assessments of the work environment reflected a more positive (change agents) or a more negative (change recipients) retrospective view of how the work environment had changed over time. For 
change agents, the fact that the retrospective accounts of change reflected a positive bias could be reflective of their desire to "make sense" of the organizational change in a manner that highlights the positive impacts of the reorientation that they were responsible for. When talking about how the work environment had changed since 2009, the change agents were also more likely to identify factors that could be linked to strategic reorienting change (i.e. new $\mathrm{CEO}$, improved focus and direction for the organization). The retrospective accounts of change recipients, on the other hand, that were more negative in nature are consistent with the idea that those on the receiving end of change used a sensemaking process that highlighted the negative implications of change on them personally (i.e. turnover of people from the organization). The change recipients also demonstrated much less consensus regarding "how" they felt the environment had changed and were more focused on how the change impacted them and their job. In fact, both groups appeared to focus on relationships and people when describing how the work environment had changed over time and there was barely any mention by respondents in either group of changes to the work itself, even though most of the changes were implemented in order to streamline processes and increase efficiency.

The differences in real-time versus retrospective data are also consistent with cognition theory that states that an individual's perceptions of a particular situation may be influenced by cognitive biases (Valle Santos \& Garcia, 2006). One type of cognitive bias, popular among marketing researchers, is the "halo effect", which refers to "distortions produced in perception by affective overtones" (Valle Santos \& Garcia, 2006, p. 756). The "halo effect" may provide an explanation for the differences observed between the change agent and change recipient groups in this study. The change agents 
tended to report more positive retrospective accounts of the change - a finding which could be a manifestation of a "halo effect" related to the change agent's positive affect toward the change (which they led). The proportion of the change recipient group, on the other hand, that was more negative retrospectively could be seen as recipients exhibiting the "halo effect" but with a negative affect towards the change (which they were not in control of). This negative/positive split is somewhat consistent with findings from other research on managerial perceptions, which shows that individuals at higher levels within an organizational hierarchy (like the change agents in our sample) tend to report fewer deficiencies or issues in the organization than those at lower levels (Mezias, Grinyer, \& Guth, 2001; Payne \& Pugh, 1976).

The findings are also consistent with attribution theory. Attribution is the process by which individuals explain the causes of behavior and events. The attribution process is prone to bias and errors and "our perceptions of causality are often distorted by our needs and certain cognitive bias" (Heider, 2013, p. 2). The findings from this study are consistent with the use of a self-serving bias by the change agents at the hospital and an actor/observer bias on the part of the change recipients (Heider, 2013). In the first case, the hospital's management team are responsible for the effective functioning of the hospital. As such, to protect their self-images, they need to believe that any change to the hospital has improved the work environment over time - a bias that may have contributed to the fact that this group were more likely to retrospectively evaluate changes to the work environment in a positive manner. In the second case, the change recipients make attributions that are consistent with the fact that they are observers (rather than actors) in the change process. In a situation when an observer experiences something negative, they 
will tend to blame the situation or circumstances. The lower proportion of change recipients (compared to change agents) with retrospective views of the work environment as changing for the better over time is consistent with the idea that if the change recipient (i.e. observer) has experienced something negative (change within the hospital), they are likely to retrospectively blame the circumstances (work environment).

A second key finding from this study with relevance to organizational change theory is that individuals' job types appeared to be related to a number of differences with respect to their satisfaction with the work environment over time, as well as their retrospective accounts of how the work environment had changed. There are two potential reasons for this. First and foremost is the fact that this study focused on work environment, a construct that by definition may vary across different areas within the same organization. Accordingly, it is plausible that individuals from different job types have objectively different work environments and experienced different changes to their respective work environments as part of the reorientation change. Second, we observed that the physician group tracked differently and tended to have stronger within-group consensus than the other job types. This is the only group in our sample that included both change recipients and change agents. Our data suggest that the "change recipient" and "change agent" categorizations, traditionally utilized in the organizational change literature, do not apply to all change stakeholder groups within an organization. Other work on organizational change in healthcare contexts has noted the unique, and often times challenging, role that physicians play in the change process (Callan et al., 2007). Physicians tend to have more power and higher status within the organization than other job groups. Although managers tend to be change agents in healthcare organizations, 
physicians' status within the organization provides them with more control over the extent to which they adopt, and are impacted by, changes imposed by management. Perhaps physicians in our sample represent a third type of change role that is not yet accounted for in the "agent" versus "recipient" terminology commonly used in the change research (Oreg, Vakola, \& Armenakis, 2011).

Despite the efforts made to rigorously analyze our data and present findings in a transparent yet concise manner, there are four limitations to this study. First, this study focused exclusively on the work environment. While this decision is supported by the literature (Klein et al., 2001) which states that an individual's view of their work environment encapsulates their views of a number of other constructs micro and macro levels, additional research is needed to determine if this is indeed the case. It is possible that the examination of longitudinal and retrospective data related to other concepts at either the individual (e.g., job satisfaction) or organizational (e.g., organizational culture) level may have resulted in different patterns and findings.

A second limitation of this study is related to the implications that our longitudinal approach had on our sample selection. Because our analysis relied on data collected over three periods of time, we were unable to include employees in our sample that may have begun working for Community Hospital after the T1 (i.e. 2009) interviews. The views of these staff would be valuable, especially given the large proportion of interviewees that mentioned turnover in their explanations as to how the work environment had changed. However, diversifying the sample by including individuals who did not partake in the T1 interviews would have led to challenges related to the 
comparability of data, and our primary interest was looking at the process of individual's perceptions of their work environment "over time".

The third limitation of this study is its inability to draw statistical inference. In particular, no claims can be made regarding causality or generalizability of the findings from this study based on our use of qualitative interview data from 26 organizational members. To increase the transferability of our findings we utilized two strategies recommended by Lincoln and Guba (1985) and Shah and Corley (2006), and provided detailed information about our sample site (i.e. Community Hospital) and detailed tables and figures to illustrate our analytical procedures and findings. Such strategies allow readers to draw their own conclusions about the extent to which particular findings may be transferable to other organizational contexts.

Finally, we acknowledge that the patterns observed in the data are open for interpretation and debate. It is our hope, however, that the findings from this study provide necessary information that can start a discussion on how an individual's retrospective sensemaking of change compare to their real-time assessments over time throughout change.

\section{Conclusion}

Scholars contend that cognitive processes from the computational school of thought (e.g., cognitive bias and attribution errors) occur in tandem with cognitive processes from the interpretive school of thought (e.g., senesmaking) (Hodgkinson \& Healey, 2008). The extant organizational cognition research on the subject orgnaizational change, however, has not yet explored the dynamics between the two types of cognitive

processes. Instead, studies tend to focus on each type of cognitive process in isolation. In 
particular, the growing body of empirical work on sensemaking about organizational change does not currently include any studies that consider other cognitive dynamics (such as cognitive bias) that could be at play. This, therefore, is the theoretical contribution of our study in that our approach, which involved the comparison of realtime and retrospective data at the individual level, allowing us to empirically explore the theoretical connection between two different streams of cognition (i.e. interpretive sensemaking and computational - cognitive bias).

This investigation of individuals' sensemaking about their work environment during a reorienting organizational change has demonstrated some fascinating differences with respect to individuals' real-time assessments and their retrospective sensemaking about their work environment over the course of an organizational change. In particular, the discrepancies across individuals' real-time and retrospective views of their work environment, which are consistent with the definition of sensemaking and may be attributable to cognitive and attributional biases at play, raised many questions regarding how individuals experience the process of reorienting change. More specifically, our data supports the idea that an individual's perceptions of how change unfolds over time is dependent on whom you ask (change agent versus recipient versus physicians) and how you ask them (in real-time versus retrospectively).

These findings can hopefully serve as motivation for other researchers in this area to undertake work that extends these ideas and contributes to our knowledge of how change unfolds over time - at the individual level - and the relative validity of real-time versus retrospective data. Two potential avenues for future research, based on the findings of this study, are as follows. First, our understanding of the impacts, outcomes, 
and the process of change would be expanded if researchers considered different types of internal stakeholders. In particular, future studies could explore and identify other change roles that exist in addition to the traditional change agent and change recipient typology (Oreg et al., 2011). Second, our findings suggest that much is still unknown about how the process of organizational change unfolds in "real-time". Findings from this study highlighted a major inconsistency between how individuals made sense of change retrospectively and how it unfolded with respect to their real-time satisfaction with their work environment. Although this pattern can be explained via sensemaking and/or cognitive biases, it is concerning that much empirical work on organizational change (in general - not just that about sensemaking) relies on retrospective, not real-time data at the individual level (Amis et al., 2004). Accordingly future research in this field would benefit from additional studies that compare both types of data to identify how the actual and the retrospective views of change overlap and differ.

This study also has a number of implications for practice. Findings from this study of reorienting change at Community Hospital show a potential bias related to how individuals view change retrospectively. More specifically, while change agents were more apt to be positive in their retrospective accounts of changes to the work environment, change recipients (in comparison to agents) were at times more critical when asked to look back in time and reflect on their experiences. Organizations and managers seeking to implement change should carefully consider how they intend to measure the success of a change, as our findings suggest that solely relying on qualitative retrospective sensemaking by either change agents or change recipients may not result in an accurate representation of the change outcomes. In order to overcome this 
retrospective bias, it is important that organizations include multiple metrics for change success, which consider the impact of the change in multiple areas of the organization, and are measured at multiple points in time throughout the duration of the change. The use of a comprehensive assessment system may also allow the change agents to identify areas within the organization that may be struggling with the change. Identifying such groups during, and not just at the end of, large scale change would allow managers to intervene and potentially assist the struggling groups.

\subsection{Conclusion}

Findings from the "Retrospective versus Real-time" paper contribute to the primary objective of this thesis (to understand how individuals make sense of organizational change over time from an emic (i.e. insider) perspective) in three ways. First, the findings with respect to the differences between real-time assessments and retrospective sensemaking indicate that how individuals make sense of change over time varies where assessments made "in the moment" of change often differ from sense made "looking back" over a period of change. Second, cognitive bias and attribution theory, which are not typically used to analyze sensemaking (an interpretive process that does not claim to be accurate), show how individuals retrospective sensemaking about change, in a number of cases, appeared to involve the use of cognitive bias and/or attribution errors. Finally, how one makes sense of change over time, and how this compares to their in the moment assessments, appeared at least in part to be connected to job type and change role (i.e. change agent versus change recipient). 


\section{Chapter 5: "Coping” Paper}

This chapter presents the third and final of the three papers in this thesis. This paper is referred to as the "Coping" paper throughout this thesis and is formally entitled "Dealing with excessive change: An emic reflection of coping and sensemaking over time"

\section{$5.1 \quad$ Introduction}

The study reported in this paper seeks to contribute to a more comprehensive understanding of how individuals make sense of organizational change over time by considering the extent to which ones' strategy for coping with excessive change overlaps with their style for sensemaking about change. Accordingly the three part research objective for this paper is to understand: (1) (a) individuals' strategies for coping with excessive organizational change and (b) how these strategies vary over time; (2) (a) how individuals make sense of excessive organizational change and (b) how this sensemaking varies over time; and (3) the relationship between the strategies an individual uses to cope with excessive organizational change and how they make sense of excessive organizational change.

\subsection{Abstract}

The current understanding of how individuals cope with organizational change over reflects a primarily etic (or researcher/outsider) based view of this process. This interpretive case study seeks to uncover an emic (or insider) view of coping and posits that coping (from cognitive appraisal theory) and sensemaking are overlapping processes that individuals use to make sense of and respond to organizational change. Key findings 
are presented from our analysis of longitudinal panel interview data for the same 24 informants collected over the course of a five year period characterized by excessive organizational change. Five stable sensemaking styles were identified; each style involved the use of a consistent affect towards organizational change sensemaking frame as well as a consistent locus of control over organizational change sensemaking frame over time. The coping strategies described by informants varied and were mostly consistent with emotion-focused and appraisal-focused coping styles from the literature. Problem-focused coping styles (or coping by getting involved) were uncommon overall and their use decreased over time. Finally, mapping sensemaking styles and coping styles for each informant led to the identification of five patterns, or stories about how individuals cope with and make sense of excessive change over time.

\section{3 "Coping" paper}

\section{Introduction}

Over the course of the last century, researchers and practitioners alike have dedicated considerable attention to issues surrounding the management of organizational change (Burke, Lake, \& Paine, 2009; Burnes, 2004). A relatively recent addition to the academic literature in this area is the idea of "excessive change" (Stensaker, Meyer, Falkenberg, \& Haueng, 2001, 2003). According to Stensaker et al. (2001: p. 3), excessive change is organizational change that occurs when an organization (1) "pursues several, seemingly unrelated and sometimes conflicting changes at the same time", or (2) "introduces new changes before the previous change is completed and evaluated". Excessive change reflects the daily reality for many managers and individuals who are 
tasked with implementing changes at an ever-increasing pace. The relevance of the excessive change concept is supported by others who have noted the dynamic, fluid (Oswick, Grant, Michelson, \& Wailes, 2005), overlapping, and simultaneous (Klarner, By, \& Diefenbach, 2011; Kiefer, 2002) nature of modern organizational change.

Unfortunately, for the individuals tasked with implementing organizational change (i.e. "change agents"), as well as those on the receiving end of the change process (i.e. "change recipients"), existing research is fairly consistent in finding that organizational change has undesirable impacts on individuals regardless of their role in this process. More specifically, research has linked the role of change agent to increased workloads and stress (Thomas \& Dunkerly, 1999; Wheatley, 1992) while change recipients may experience a decline in physical health and well-being (Hansson, Vingard, Arnetz, \& Anderzen, 2008). It follows, therefore, that research into how individuals cope over time with excessive organizational change may provide both researchers and practitioners with insights into how to best support those on the leading and receiving ends of such initiatives. Such knowledge should, in turn, enhance organizations' ability to more effectively implement needed change.

This paper addresses this gap in our knowledge by summarizing a research study undertaken to understand how individuals make sense of, and cope with, excessive organizational change over time. Our study is theoretically grounded in two very different but complementary literatures: the cognitive appraisal theory of stress (Lazarus \& Folkman, 1984) and sensemaking (Weick, 1995).

“Coping” refers to how individuals emotionally and behaviorally deal with 
stressful situations (Lazarus \& Folkman, 1984). According to the cognitive appraisal theory of stress (Lazarus \& Folkman, 1984), coping is part of a cognitive process that occurs when individuals encounter stress. In the context of organizational change, individuals who cope better with change are (1) less likely to experience negative implications of the change (Rafferty \& Griffin, 2006), and (2) more likely to be supportive of organizational change (Kruglanski, Pierro, Higgins, \& Cappoza, 2007). Either or both of these conditions should increase the likelihood of successful change management in the context of excessive change. A review of the extant empirical literature on how individuals cope with organizational change indicates that this work employs predominantly quantitative and variance based methods. While the variance approach to studying how people cope with organizational change has a number of benefits (e.g., generalizability of findings), it is driven from an etic (i.e. outsider/researcher) centered view of phenomena (Morris, Kwok, Ames, \& Lickel, 1999; Van de Ven \& Poole, 2005). As such, it is not the best approach to take when researching how individuals experience and cope with organizational change over time. Such a topic is instead better suited to an emic (i.e. insider/informant) perspective (Denison, 1996), such as the one employed in the research study discussed in this paper. Research of an emic nature involves the use of process-based methods and tends to use qualitative data to capture the insider view of informants' experiences over time (Van de Ven \& Poole, 2005).

Research on individual sensemaking about organizational change also seems to have relevance to our understanding of how individuals cope with organizational change over time, as the theory and ideas that underlie sensemaking are very similar to those that 
underlie the coping/cognitive appraisal process. "Sensemaking" refers to a cognitive process that individuals utilize to create meaning and understanding of ambiguous or confusing situations (Maitlis \& Christianson, 2014) - adjectives which certainly seem to apply to organizational change. The modest body of research on individuals' sensemaking about organizational change, which almost always employs emic processoriented methods, has yielded a number of interesting findings about how individuals make sense of, and respond to, organizational change. Results from our review of the literature on sensemaking about organizational change suggest, however, that how individuals cope with organizational change has yet to be considered from a sensemaking perspective.

The theoretical similarity between the coping and sensemaking processes, in tandem with the need for more emic research that explores how individuals cope over time with excessive organizational change, serve as the motivation for this paper. To explore this issue we undertook a process-oriented case study at an organization undergoing large-scale organizational change. This study involved the evaluation of longitudinal interview data which was collected over a five year period from the same 24 informants. Our analysis used two different theoretical lenses (coping/cognitive appraisal theory and sensemaking theory) to explore (1) the stability of informants' strategies for coping with excessive change over time, (2) the stability of informants' strategies for making sense of excessive change over time, and (3) how these coping strategies and sensemaking strategies relate to one another over time.

This paper is structured as follows. First, the literature review familiarizes the reader with relevant theory and research related to the two sensitizing concepts employed 
in our analysis: coping and sensemaking. Second, the objective of this study, which was derived from the identification of a gap in the organizational change literature, is presented. Next the methodology section explains the case organization, data collection steps, and data analysis procedures. The findings section presents and discusses key findings from our data analysis. Finally, the conclusion section identifies the study's limitations as well as the relevant implications of the findings for both researchers and practitioners.

\section{Literature Review}

Sensitizing concepts are theories, frameworks and ideas from the literature that serve as starting points for data interpretation by helping the researcher to see, organize and understand experiences reported in the data (Charmaz, 2006). The two parts of this literature review serve to familiarize the reader with the paper's two sensitizing concepts: coping and sensemaking.

\section{Coping Theory and Relevant Research}

Lazarus and Folkman's (1984) cognitive appraisal model was selected as one of the sensitizing concepts in this study because it is both seminal and enduring. The key ideas from the cognitive appraisal model underlie much of the extant work on psychological coping (Connor-Smith \& Flachsbart, 2007) and it is commonly cited in studies about how individuals cope with organizational change (i.e. virtually all the studies reviewed below). Literature relevant to this study is summarized below.

Coping and the cognitive appraisal process. According to Lazarus and Folkman's (1984) cognitive appraisal theory of stress (also called the transactional stress 
model), appraisal and coping are all "transactional processes", meaning they involve the dynamic interaction between the individual and the environment over time. The cognitive appraisal theory of stress acknowledges that, while an individual or group can influence or change aspects of the environment, the reverse is also possible (i.e. the environment can influence or change individuals and groups) (Lazarus, 1995). The three iterative stages of this theory (i.e. stress, appraisal, and coping) are described further below.

According to Lazarus and Folkman (1984: p. 21), stress occurs when a person perceives the demands of their environment as "taxing or exceeding his or her resources and endangering his or her well-being." The term "stressor" is used to refer to specific demands or factors that cause stress (Rauschenbach, Krumm, Thielgen, \& Hertel, 2013). Research has noted that for many employees, organizational change can be considered an environmental demand (i.e. a stressor) that arouses stress (Hansson et al., 2008).

Appraisal, the second stage of the stress process, consists of two parts: primary and secondary appraisal. Lazarus (1995) notes that primary appraisal occurs when an individual assesses the environmental stress according to: (1) actual harm that has occurred (i.e. harm), (2) potential threat that could occur in the future (i.e. threat), or (3) challenge and the corresponding possibility for positive outcomes (i.e. challenge). During secondary appraisal the individual assesses the resources that are available to help them cope with the assessed harm, threat, or challenge (Mishra \& Spreitzer, 1998). Organizational change scholars posit that how one appraises a change initiative (i.e. harm/threat/challenge) is predictive of whether or not they will behave in a way that supports or hinders the change implementation (Mishra \& Spreitzer, 1998). 
Lazarus (1995) conceptualizes coping, which involves the use of cognitive and behavioral strategies to deal with stress, as the final stage of the stress appraisal process. There are many ways to categorize coping strategies. The two most common types of coping strategies, based on the work of Lazarus and Folkman (1984), are labeled problem-focused and emotion-focused. Problem-focused coping is active and involves one's attempts to resolve difficulties resulting from the stress. Problem-focused coping includes strategies such as seeking out resources or advice and engaging in actions aimed at alleviating the cause of the stress (Lazarus \& Folkman, 1984). Emotion-focused coping, on the other hand, is passive in nature and involves emotional regulation as a means to minimize the experience of negative emotions (Lazarus, 1995; Mishra \& Spreitzer, 1998). Emotion-focused strategies include such diverse activities as emotional outbursts (e.g., crying), avoidance, and the use of social supports (Conner-Smith \& Flachsbart, 2007).

Moos and Billings (1982) proposed a third type of coping called "appraisalfocused coping", which involves strategies aimed at changing one's appraisal of the situation. Appraisal-focused coping occurs when individuals adapt how they appraise stressors in a manner that facilitates either acceptance or cognitive restructuring (e.g., finding humour and positive aspects) (Moos \& Billings, 1982). The key difference between "appraisal-focused" and "emotion-focused" coping is that the latter is concerned with how individuals deal with negative emotions (i.e. how one feels) while the former involves changes to the primary and secondary appraisal steps as a way to minimize the perception of stress (i.e. how one thinks).

Research on coping with organizational change. Research on coping with organizational change has been undertaken by researchers in the area of organizational 
development and change for some time now (Bouckenooghe, 2010; Oreg, Vakola, \& Armenakis, 2011). Researchers in these areas have focused much of their attention on individuals' attitudes about, and reactions to, organizational change (Choi, 2011) and typically use variance-based research methodologies (Oreg et al., 2011).

Our review of the extant literature determined that most of the research in the area of "coping with organizational change" also uses variance-based approaches and typically includes coping as a variable within models that consider individuals' perceptions of, and responses to, organizational change over time. These studies typically conceptualize coping as a moderator or mediator (Amiot, Terry, Jimmieson, \& Callan, 2006; Fugate, Harrison, \& Knicki, 2011; Fugate, Knicki, \& Prussia, 2008; Judge, Thoresen, Purik, \& Welbourne, 1999; Lawrence \& Callan, 2011; Teo, Pick, Newton, Yeung, \& Chang, 2013). For example, in their longitudinal study of managers' responses to change, Judge et al. (1999) used a self-developed scale to measure coping with change and found coping to be a mediator between managers' dispositional traits and early career outcomes. Comparatively fewer organizational change studies have conceptualized coping as an independent variable (Riolli \& Savicki, 2006), dependent variable (Fugate, Knicki, \& Scheck, 2002; Kruglanski et al., 2007) or control variable (Lattuch \& Young, 2011; Rafferty \& Griffin, 2006). In Fugate et al.'s (2002) study, coping strategies served as dependent variables from a longitudinal dataset that captured individuals' coping strategies over four stages of a merger. Their findings confirmed hypotheses about the complexity of coping strategy dynamics over time, and highlighted the prevalence of social support and appraisal-focused coping in their sample. Lattuch and Young (2011), more recently, used confirmatory factor analysis to assess young professionals' 
perceptions of organizational change. They included the internal and external coping resources of personality and leader support (respectively) as control variables, which were found to reduce stress among their sample of young professionals.

While most of the academic literature on coping with organizational change employs variance-based etic approaches, there are three exceptions. The first exception is research that provides conceptual frameworks (but not empirical work) on the topic of coping with organizational change. Mishra and Spreitzer (1998), for example, proposed a conceptual model that used Lazarus and Folkman's (1984) stress appraisal theory to elucidate how survivors respond to downsizing. The second exception is work that looks at coping with change that focuses on identifying and understanding the aspects of change that individuals appraise as stressful (e.g., Robinson \& Griffiths, 2005; Smollan, 2015). The third exception includes studies that use the term coping when investigating individual responses to change in a more general sense (e.g., process-oriented sensemaking work by Stensaker et al., 2003 and Stensaker and Meyer, 2012). Finally, it is noteworthy that our review of the literature uncovered very few sensemaking studies that considered how individuals cope with change, an unexpected finding given the number of conceptual similarities between the ideas beneath sensemaking and the cognitive appraisal model of coping.

\section{Sensemaking and Related Research}

The second part of this literature review begins by describing the sensemaking process (Weick, 1995) and identifying how it parallels the coping and cognitive appraisal 
process. This is followed by a description of empirical work in this area with relevance to this paper.

The sensemaking process. Sensemaking is conceptualized to occur across three iterative processes called triggering, interpretation, and enactment (Maitlis \& Christianson, 2014; Sandberg \& Tsoukas, 2015). The first stage, triggering, occurs when the sensemaking process is triggered by unexpected events or ambiguous situations (e.g., organizational change) (Maitlis \& Christianson, 2014). Interpretation, the second stage, involves the use of frames, also called mental models, schemas, or lenses (Kaplan, 2008), to develop information "into a more complete and narratively organized sense of the situation or event" (Sandberg \& Tsoukas, 2015: S14). The third stage, enactment, involves ones' action or inaction (Sandberg \& Tsoukas, 2015) resulting from their newly established "sense" of the situation (Weick, Sutcliffe, \& Obstfeld, 2005). Triggering, interpretation, and enactment are theoretically conceptualized as a recurring cycle that ceases after one resolves both the initial confusing situation and any concurrent unexpected or ambiguous events (Sandberg \& Tsoukas, 2015).

\section{Research on sensemaking about organizational change. A significant} proportion of the body of work on organizational sensemaking looks at sensemaking during, and about, organizational change (Maitlis \& Christianson, 2014). We recently undertook a comprehensive review of the literature on sensemaking about organizational change (references to be added after review) which determined that such studies tend to adopt process-oriented methodologies in order to look at how individuals make sense of change (Van de Ven \& Poole, 2005). While researchers have considered sensemaking about organizational change, there is little to no dialogue around coping, a finding that 
mirrors what we observed in our review of research on coping. Sensemaking about change studies that do use the term "coping" tend to refer broadly to how individuals respond to change (e.g., Stensaker \& Meyer, 2012; Stensaker et al., 2003) and do not explore the coping process.

Mapping the sensemaking and coping appraisal processes. Weick (1995) and other scholars (Shepherd, Patzelt, \& Wolfe, 2011) have mentioned connections between sensemaking and coping. The link between these two schools of thought is shown in Figure 5-1 and can be articulated as follows. According to the cognitive appraisal theory of stress (Lazarus \& Folkman, 1984), how individuals cope with an event is related to how they appraise the event and their perceptions of potential consequences. When applied to the context of organizational change, this suggests that how individuals respond to change (i.e. the event) is related to their sensemaking about the change (i.e. their appraisal process) (Mishra \& Spreitzer, 1998). It would appear, therefore, that organizational change may act as both a "trigger" and a "stressor" that simultaneously activates individuals" "appraisal" and "interpretation" processes which would, in turn, lead to "coping" and "enactment" activities (or inactivity). This would suggest that one's strategy for "coping" with organizational change could just as easily be conceptualized as the "enactment" of their sensemaking. This sensemaking/coping link, however, has not yet been substantively explained or empirically investigated. This paper seeks to inform our theoretical understanding of this issue by exploring the idea that the coping and sensemaking processes are overlapping cognitive processes that occur when individuals experience organizational change. 
Figure 5-1: Comparing the coping and sensemaking processes

\section{The Coping Process:}

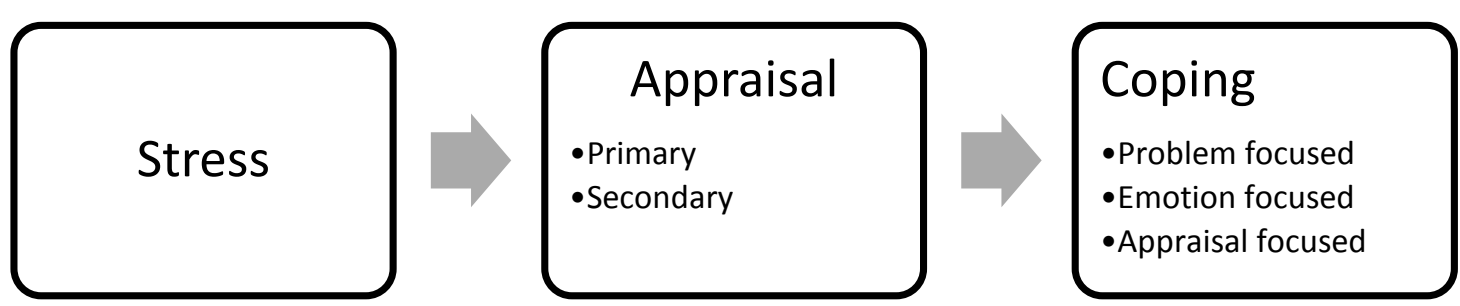

\section{The Sensemaking Process:}

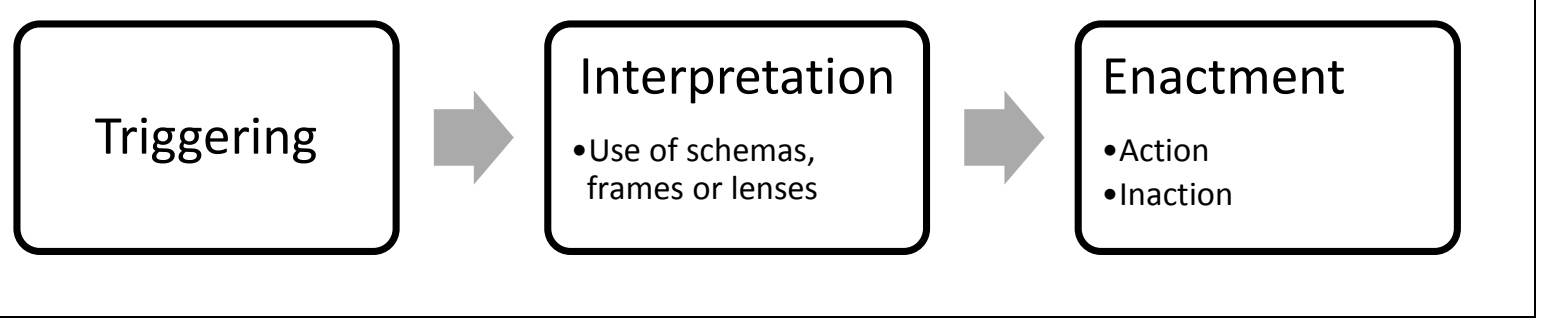

\section{Research Objective}

The research summarized in this paper was undertaken to increase our understanding of how individuals make sense of, and cope with, excessive organizational change over time. More specifically, we seek to understand: (1) (a) individuals' strategies for coping with excessive organizational change and (b) how these strategies vary over time; (2) (a) how individuals make sense of excessive organizational change and (b) how this sensemaking varies over time; and (3) the relationship between the strategies an individual uses to cope with excessive organizational change and how they make sense of excessive organizational change.

Three overlapping research gaps served to motivate the current study. The first gap is the lack of research on coping with organizational change that reflects an emic (or 
insider) view. The second, overlapping gap in the literature relates to the absence of studies that consider the extent to which coping (i.e. cognitive appraisal) and sensemaking represent parallel cognitive processes employed by individuals during organizational change. Although research has considered how individuals cope with change, much of what is known is derived from studies that utilize variance methods and rely heavily on quantitative survey data to understand how individuals emotionally and behaviorally deal with change. While the fact that much of the coping with organizational change research takes an etic or researcher-centric view of the phenomena has some benefits, such as facilitating comparison of findings across studies, it also presents challenges. The most problematic of these challenges, from our perspective, is the fact that the coping strategies considered (i.e. the survey items) using etic methodologies are predetermined and do not fully reflect the types of strategies that individuals may actually use to cope with organizational change over time. Given the process nature of coping and the noted connection between individuals' sensemaking and coping processes, it may be that longitudinal research on coping with change that employs an emic process-based approach will reveal novel and unique insights that would contribute to a more comprehensive theoretical understanding of how individuals cope with, and make sense of, organizational change over time. This idea relates to the third gap, which is the lack of longitudinal research in this area that employs panel data (i.e. collects data from the same individual over a long period of time). This means that the extant research has not yet investigated how the strategies people use to cope with and make sense of excessive change might change over time. 


\section{Method}

A process-oriented interpretive case study was deemed the best approach given our research objectives. The rationale for this is two-fold. First, case studies are suitable when boundaries between the phenomenon of interest and the context are not clear (Myers, 2009; Yin, 2009), which is true for sensemaking and coping with excessive organizational change. Second, a process case study is useful for answering "how" questions relating to social processes over time (e.g., how do individuals cope with excessive change over time?) (Langley, 1999; Yin, 2009). As is the case with any rigorous qualitative research study, our data analysis and findings were intertwined, in that the data drove each step in analysis (Charmaz, 2006; Myers, 2009). To increase the readability of the paper, we divide our discussion of the methodology followed in this paper into two sections. Details on the case organization, data collection, and the grounded theory data analysis procedures used in this study are provided in the methodology section below. Details on analysis triggered by our findings are, on the other hand, offered in the findings section as appropriate. For greater detail of the case organization and the changes it has undergone the reader is directed to Authors (reference to be provided after the paper is reviewed).

\section{Case Organization}

The case organization for this study is a primary care hospital in rural eastern Ontario, Canada. The hospital (herein called "Community Hospital”) provides care for residents of the surrounding farming region. Currently about 340 individuals are employed by Community Hospital, a key place of employment for this region. A suite of 
inpatient, outpatient, and diagnostic imaging and laboratory services are available at Community Hospital.

Over the past decade the hospital has encountered a number of external pressures for change related to: (1) the aging population and its predicted impacts on both the supply and demand sides of healthcare (Statistics Canada, 2012), (2) technological advances that impact the delivery of patient care, (3) shifts in funding structures and governance mechanisms (e.g., Zeytinoglu, Denton, Davies, Baumann, Blythe, \& Boos, 2007), (4) the increasing demand for patient centered care models, and (5) the turnover of key leaders at the provincial and federal levels.

In order to cope with these external pressures for organizational change, Community Hospital initiated a planned transformational change that lasted approximately a decade. The fact that the employees of Community Hospital have been subjected to a high number of significant organizational changes in the past several years (described below and in Figure 5-2) means that Community Hospital qualified as an extreme or revelatory case (Charmaz, 2006) within the healthcare context. Their involvement in our research could, therefore, yield unique insights into the phenomena of interest (i.e. coping with excessive organizational change over time). Details on the key changes that took place at the hospital from 2009 to 2013 (the time period that served as the focus for this study) are provided below. 
Figure 5-2: Timeline of change and data collection

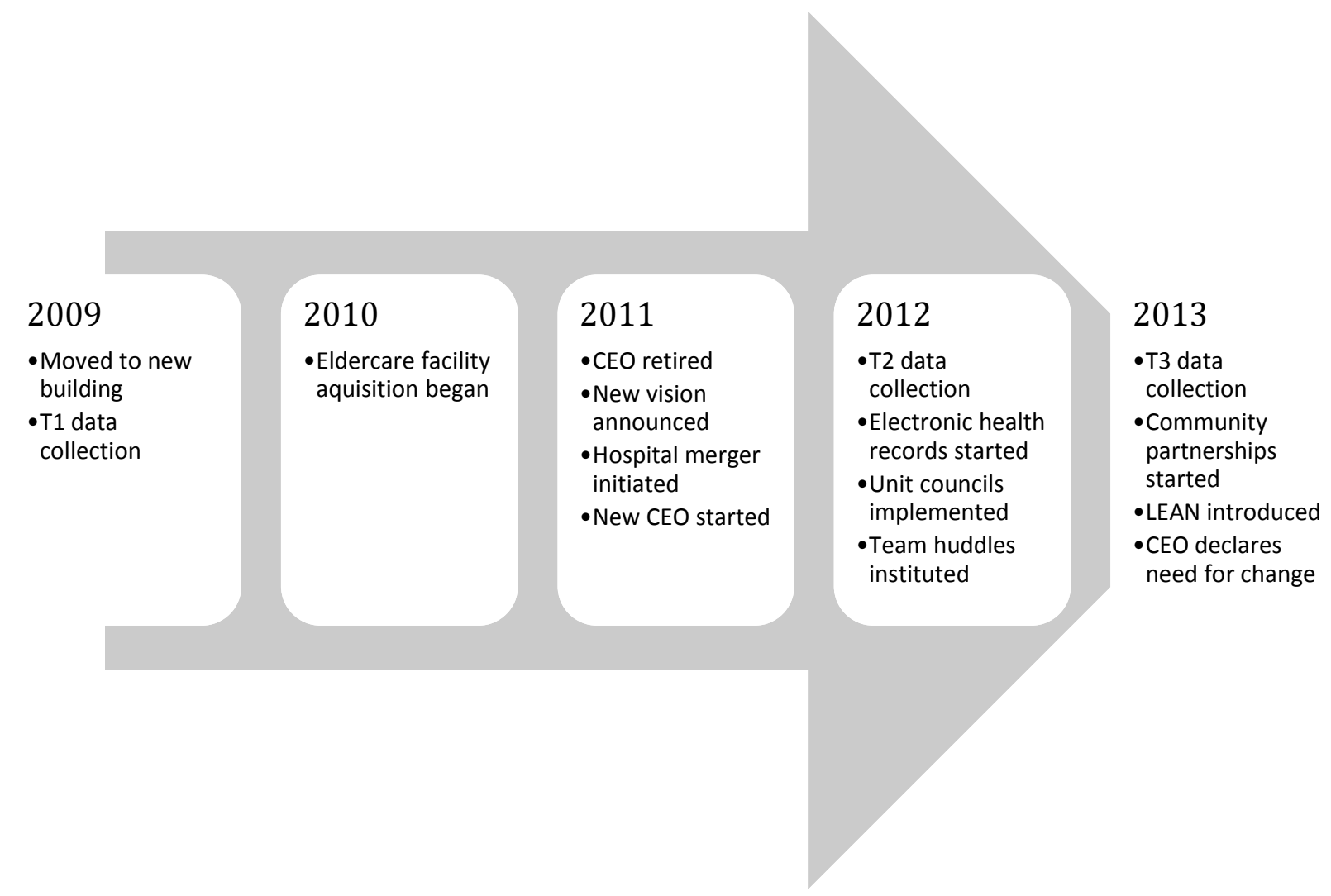

Pre-2009. In 2002 Community Hospital commenced fundraising in order to build a new hospital with cutting edge IT capabilities and medical equipment. A new CEO was brought on board in 2004 to lead the hospital through this transformational change. The new CEO made significant changes to the hospital's eight-person management team (i.e. between 2004 - 2007 five new managers were hired).

2009. In March of 2009 , soon after the hospital's $60^{\text {th }}$ anniversary celebration, the new building opened (i.e. "moved to new building"). It was at about this time that results from a survey (coordinated by a third party) reported low job satisfaction among hospital staff and managers. In response to these findings the CEO asked the authors to design and undertake an in-depth "staff satisfaction" study. Interviews and a quantitative staff survey 
were conducted between June and September of 2009. In December of 2009 the results from this Time 1 (T1) data were formally presented and distributed to hospital employees.

2010-2011. In June of 2011, and after about 1.5 years of "encouragement" from the board of directors, the $\mathrm{CEO}$ retired (i.e. "CEO retired"). Her legacy would live on, however, through the new vision she developed for Community Hospital: "that Community Hospital would be a Centre of Excellence for Rural Health and Education in Ontario" (i.e. "New vision announced"). Strategic partnerships with a variety of local and regional healthcare providers were key to operationalizing this vision. Accordingly in 2010 Community Hospital began acquiring an eldercare facility (i.e. "Eldercare facility acquisition began"). Next in early 2011 Community Hospital initiated a merger with a nearby urban hospital (i.e. letter of intent signed by both organizations and publicly shared) (i.e. "hospital merger initiated"). Finally, in September of 2011, the new CEO officially began (i.e. "new CEO started").

2012-2013. After the new CEO, another external hire, began his tenure new changes were introduced at a considerable pace. In 2012 the new CEO introduced a number of changes to work processes and structures aimed at strengthening the organizational culture and helping with the delivery patient-centered care. For example, unit councils for nursing staff (i.e. "unit councils"), departmental team huddles (i.e. "team huddles"), and technological advances such as the electronic health record (i.e. "Electronic Health Records") were all instituted under his leadership. Between April and June of 2012 Time 2 (T2) data (interviews) were collected. 
Following these changes in 2012, even more changes were initiated in 2013. For instance the hospital formalized a number of relationships with other healthcare organizations that started to rent units built next door to the hospital (i.e. "community partnerships started"). Around the same time LEAN was implemented in the emergency department (i.e. "LEAN introduced"). In September of 2013, the CEO called a town hall meeting with all staff members to inform them that low patient volumes would require that the hospital make changes to ensure its survival (i.e. " $C E O$ declares need for change due to low patient volumes"). The CEO did not provide specifics at the time as to how these changes were to be implemented. In September and October of 2013 Time 3 (T3) data (interviews) were collected.

\section{Data Collection}

Semi-structured one-on-one interviews (Gioia et al., 2013) were selected as the primary means of data collection because of the important role of interviews for process approaches and sensemaking (Langley, 1999). The sample used for this study was derived from the larger sample as part of the ongoing work the researchers performed with Community Hospital. Informants were acquired through the following procedure. The authors conducted an organization-wide survey at Community Hospital in 2009. The methods for seeking voluntary survey participation included: emails, organizational memos, information mailed with paystubs, and announcements made at organization wide meetings and events. The survey was completed by $25 \%$ of the 340 hospital employees $(\mathrm{n}=83)$. The last survey question asked respondents if they were interested in partaking in a follow-up interview. If yes, they were asked to provide their name and contact information, which were subsequently used by the authors to set up the interviews. 
When each interview was complete, the interviewer asked individuals for permission to contact them again for further follow-up. The researchers contacted those individuals who agreed to further follow-up again in both 2012 and 2013 for two more interviews. Longitudinal data is needed in order to look at how individuals make sense of and cope with the excessive change "over time". It was necessary, therefore, that individuals participated in interviews at all three points in time including 2009 (T1), 2012 (T2), and 2013 (T3) in order to be included in the sample.

Overall, 24 individuals met the sample criteria. The sample distributions $(\mathrm{n}=24)$ with respect to gender ( $75 \%$ female) and job type ( $8 \%$ manager, $21 \%$ physician, $25 \%$ nurse, $13 \%$ clinical support, 30\% non-clinical support) mirrored the hospital workforce. The sample also varies in terms of how many years informants have worked for Community Hospital. At the time of the third interview, the respondents in our sample had spent between 4.5 and 52 years at the hospital. The average organizational tenure of our sample is 16 years.

All interviews were conducted by the first author using a pilot-tested script. For T1 most interviewees selected an in-person interview, on site, in a private room at the hospital, and only a few interviewees opted for a phone interview. By T3, however, all interviewees opted to be interviewed over the phone. Our discussions with the respondents suggested that this shift could likely be attributed to an increase in informants' workloads over time. Respondents reported that they found it easier to arrange a phone interview on their personal time rather than to schedule an in-person interview during or before/after work hours. 
Each interview took between 20 and 80 minutes (45 minutes on average) and was audio recorded and transcribed. The interview script included questions regarding workers' backgrounds, general work experiences, the work environment at the hospital, and their perceptions vis a vis changes at the hospital. This paper focuses on the data from the part of the interview relating to organizational change. To explore how informants coped with excessive change at Community Hospital, the interview asked the following questions during each of the T1, T2, and T3 interviews: "How do you personally cope with the changes that have been occurring at Community Hospital?" Follow-up clarification questions were posed by the interviewer as needed to elucidate informants' responses (e.g., "Can you explain more?”) The transcribed responses to the above interview question totaled 72 pages single-spaced.

\section{Data Analysis}

Grounded theory data analysis techniques were used by the researchers in order to identify themes and patterns in the data that represent the informants' (i.e. emic) experience (Charmaz, 2006; Myers, 2009). Such an approach has been recognized by others as well-suited for undertaking process-oriented research on organizational change (Langley, 1999). Data were sorted and coded (i.e. labels assigned to pieces of text from the transcriptions) in QSR-NVivo Version 10, a software tool for qualitative data analysis. Langley (1999) recommends that researchers employing grounded theory techniques to analyze process data compare many "incidents of text" in order to identify categories and themes related to the meanings informants assign to the phenomena of interest. The informants' transcribed responses to the interview questions about coping serve as these "incidents" in this analysis. In total there were 72 incidents of data (24 informants $\mathrm{x} 3$ 
interviews per informant), or 24 sets (i.e. 24 informants) of 3 incidents (i.e. 3 interviews per informant).

The data analysis primarily involved the use of three iterative grounded theory coding practices: initial coding, focused coding, and theoretical coding. In initial coding (Charmaz, 2006) researchers assign labels to each incident of data. These labels, or initial codes, are emergent (i.e. not based on any predetermined framework). The initial codes seek to remain close to the data and can involve the use of verbatim terms from the informants (Charmaz, 2006). Next, the focused coding step seeks to "sort, synthesize, integrate and organize large amounts of data" (Charmaz, 2006: p. 46). Focused coding allows the researchers to examine the data and initial codes to identify higher-level categories that could be used to group initial codes. Finally, theoretical coding allows the researcher to assign data to categories that facilitate the exploration of potential theoretical relationships in the data (Charmaz, 2006). This coding step serves to "lend form to the focused codes" in an explanatory way (Charmaz, 2006: p. 63), and may involve the use of extant theory or drive the development of new theory. We conducted initial, focused, and theoretical coding on the data twice. The first time we used "coping" as the sensitizing concept, and the second time we used "sensemaking" as the sensitizing concept. While these three coding practices served as the foundation of our analysis we also employed other steps, which are explained as the relevant findings are presented.

\section{Findings}

The fact that we seek answers to three different research objectives required us to analyze the data through three very different lenses. We present our data analysis and key 
findings with respect to objective one, how informants cope with organizational change over time ("coping with organizational change") first. This is followed by a summary of the key findings associated with our analysis of the data with respect to research objective two, how informants' make sense of change over time ("sensemaking about organizational change"). Finally, we summarize our analysis and findings with respect to objective three which seeks to better understand the relationship between how employees cope with excessive change and their sensemaking around this same phenomena ("coping and sensemaking patterns"). In the interest of parsimony and readability, we discuss findings as they are presented (rather than in a separate discussion section).

\section{Coping With Organizational Change}

To address our first research objective, we employed four steps. Steps one through three involved initial, focused, and theoretical coding, respectively, on the interview data using "coping" as our sensitizing concept (i.e. the third part of the cognitive appraisal process pictured in Figure 5-1). Step four looked at the coding results for each informant over time and identified patterns.

In total, 29 initial codes and 7 focused codes were identified. The focused codes, the most common initial codes, and exemplary quotes for each are included in Table 5-1. How do informants cope with excessive change? Our analysis determined that they coped by "offering input", "socializing", "passively accepting change", "disengaging from change", "engaging with change", "practicing optimism", and "enjoying the change". For the sake of clarity in the rest of the paper we use the term "coping strategies" to refer to 
these seven focused codes and use bold and italicized font when referring to a specific

coping strategy (i.e. focused code).

Table 5-1: Resulting data structure (coping with organizational change)

\begin{tabular}{|c|c|c|c|}
\hline $\begin{array}{l}\text { Theoretical } \\
\text { code } \\
\text { (coping } \\
\text { style) }\end{array}$ & $\begin{array}{l}\text { Focused } \\
\text { code } \\
\text { (coping } \\
\text { strategy) }\end{array}$ & $\begin{array}{l}\text { Initial Codes } \\
\text { (action) }\end{array}$ & Sample quote \\
\hline \multirow{4}{*}{$\begin{array}{l}\text { Problem- } \\
\text { focused } \\
\text { coping }\end{array}$} & \multirow[t]{2}{*}{$\begin{array}{l}\text { Offering } \\
\text { input }\end{array}$} & Offering solutions & $\begin{array}{l}\text { "If it's something that I can change and I can } \\
\text { see a huge flaw then I try to point it out" }\end{array}$ \\
\hline & & $\begin{array}{l}\text { Suggest a different } \\
\text { way to do it }\end{array}$ & $\begin{array}{l}\text { "I try and say oh I don't like how that's } \\
\text { working, maybe we could do this differently," }\end{array}$ \\
\hline & \multirow[t]{2}{*}{$\begin{array}{l}\text { Engaging } \\
\text { with change }\end{array}$} & Contribute & $\begin{array}{l}\text { "I'm helping...I have sat down for hours at } \\
\text { length, and have handed some stuff in" }\end{array}$ \\
\hline & & Get involved & $\begin{array}{l}\text { "I'll generally roll up my sleeves and pick a } \\
\text { fight and get involved" }\end{array}$ \\
\hline \multirow{6}{*}{$\begin{array}{l}\text { Emotion- } \\
\text { focused } \\
\text { coping }\end{array}$} & \multirow[t]{2}{*}{ Socializing } & Vent to a friend & $\begin{array}{l}\text { "The nurses who work very closely with me. We } \\
\text { vent to each other." }\end{array}$ \\
\hline & & Talk about it & $\begin{array}{l}\text { "I spoke with the Health Nurse, I talked to the } \\
\text { EAP, I talked to the Corporate" }\end{array}$ \\
\hline & \multirow[t]{4}{*}{$\begin{array}{l}\text { Disengaging } \\
\text { from change }\end{array}$} & $\begin{array}{l}\text { Focus on life } \\
\text { outside of work }\end{array}$ & $\begin{array}{l}\text { "Try to let go of the place when I'm not here. } \\
\text { Spending time on family life, just find something } \\
\text { else to think about." }\end{array}$ \\
\hline & & Set boundaries & $\begin{array}{l}\text { "they're changes that occur at the hospital, } \\
\text { they're not necessarily changes that occur in } \\
\text { my life, so it's relatively easy to keep work at } \\
\text { work, and home at home" }\end{array}$ \\
\hline & & Withdraw & $\begin{array}{l}\text { "I sometimes just have to withdraw and think } \\
\text { that's my style" }\end{array}$ \\
\hline & & $\begin{array}{l}\text { Don't pay } \\
\text { attention to } \\
\text { changes }\end{array}$ & "Try not to let it affect me." \\
\hline \multirow[t]{5}{*}{$\begin{array}{l}\text { Appraisal- } \\
\text { focused } \\
\text { coping }\end{array}$} & $\begin{array}{l}\text { Passively } \\
\text { accepting } \\
\text { change }\end{array}$ & Go with the flow & $\begin{array}{l}\text { "I've always been a guy that goes with the flow, } \\
\text { so I didn't really... I didn't allow myself to get } \\
\text { totally frustrated about things." }\end{array}$ \\
\hline & \multirow[t]{2}{*}{$\begin{array}{l}\text { Practicing } \\
\text { optimism }\end{array}$} & Stay positive & $\begin{array}{l}\text { "I'm one of those positive people that tries to } \\
\text { keep everything as positive as they can" }\end{array}$ \\
\hline & & $\begin{array}{l}\text { Focus on the end } \\
\text { goal }\end{array}$ & $\begin{array}{l}\text { "I try to keep looking more into the future of } \\
\text { why we're doing this... where we want to end } \\
\text { up" }\end{array}$ \\
\hline & \multirow[t]{2}{*}{$\begin{array}{l}\text { Enjoying the } \\
\text { change }\end{array}$} & Love the change & $\begin{array}{l}\text { "I love change actually to me it's like food so I } \\
\text { cope" }\end{array}$ \\
\hline & & $\begin{array}{l}\text { Excited for } \\
\text { changes }\end{array}$ & $\begin{array}{l}\text { "It's like you're getting a new toy or something } \\
\text { and you're really excited but not quite sure how } \\
\text { to put it together" }\end{array}$ \\
\hline
\end{tabular}


The third step in our analysis of the how individuals coped with excessive change involved theoretical coding. To do this, we examined our informants' coping strategies (i.e. the seven focused codes in Table 5-1) using the coping styles identified by Lazarus and Folkman (1984) (i.e. Cognitive Appraisal Theory) and Moos and Billings (1982) (i.e., appraisal focused coping) as our sensitizing lens. This analysis involved two steps: (1) examine how people talked about how they coped with change (i.e. their responses) and our focused codes (i.e. our "coping strategies"), and (2) determine the extent to which these coping strategies are similar to, or different from, the theoretical definitions of problem-focused, emotion-focused, and appraisal-focused coping used in the literature. The results of this mapping process are shown in Table 5-1 and discussed below. To be consistent with the terms used in the theory, we refer to the results of this stage of the analysis using the term "coping style".

Our analysis determined that there is a high degree of correspondence between the coping styles identified in the literature and those used by our informants to cope with excessive change. The problem-focused coping style includes two of our focused codes: engaging with change and offering input. Analysis of the data indicated that the informants who used these two strategies were coping by engaging in behavior that was directed at the source of their stress (i.e. the organizational changes) in a manner consistent with problem-focused coping (Lazarus \& Folkman, 1984). For instance, one informant explained that for him, getting involved is a way to cope as follows: "I'll tend to become involved with trying to affect whatever is happening, to change whatever has happened." The socializing and disengaging from change coping strategies were both assigned to the emotion-focused coping style because our analysis determined in both 
cases individuals used these strategies in order to minimize the impact on themselves and others of the negative emotions that can go along with excessive organizational change (Lazarus \& Folkman, 1984). According to one informant who coped by disengaging from the change by setting boundaries: "You can't worry... I try not to take anything home with me. I guess that's probably the biggest way that I would cope with it”. Finally, the enjoying the change, practicing optimism and passively accepting change coping strategies were all grouped within the appraisal-focused coping style, as our analysis showed that in all three cases the individuals coped by changing how they thought about (i.e. appraised) the organizational changes (Moos \& Billings, 1982). One example of the use of this coping style in our sample is captured in one informant's description of how she coped by maintaining a sunny disposition towards organizational change: "Typically I've looked at [change] as a positive thing; I couldn't wait to get into the new building."

Finally, we examined the extent to which coping styles were consistent or stable over time at the individual level. This was done as follows. First, we used informants' T1, T2, and T3 interview data to classify how each informant coped with organizational change in each of these time periods (i.e. their coping style). Second, for each informant we compared how the informant coped at T1 to how they coped at T2 and T3 (i.e. assessed the stability of their coping style over time). We then used these findings to divide our informants into two groups: those who used the same coping style at all three time periods, and those who used different coping styles at different points in time. About half of the informants $(n=13)$ had one dominant style for coping with organizational change that they mentioned consistently in all three interviews (i.e. seven informants consistently used an appraisal-focused coping style, five consistently used an emotion- 
focused style and one consistently used a problem-focused style). The remaining 11 informants, however, used a different coping style at $\mathrm{T} 1$ to what they used at $\mathrm{T} 2$ and $\mathrm{T} 3$ (i.e. coping style changed from $\mathrm{T} 1$ to $\mathrm{T} 2$ but was consistent from $\mathrm{T} 2$ to $\mathrm{T} 3$ ). Closer examination of the interview transcripts and their coping style patterns over time for these 11 informants led to the identification of two groups based on the coping style used at T1. Details on these two groups are provided below.

The first group includes the four informants who used an appraisal-focused coping style (usually the practicing optimism coping strategy) at T1 followed by the emotion-focused coping style (most typically the coping strategy of disengaging from the change) at $\mathrm{T} 2$ and $\mathrm{T} 3$. In these four instances, the shift in coping style from $\mathrm{T} 1$ to $\mathrm{T} 2$ appeared to be linked to the informants' feelings of disillusionment or fatigue with the excessive change at Community Hospital, a theme that permeated their interview transcripts in $\mathrm{T} 2$ and $\mathrm{T} 3$ (but not $\mathrm{T} 1$ ).

The second group includes seven individuals who used a problem-focused coping style (i.e. engaging with change or offering input) at T1, followed by either emotionfocused coping $(\mathrm{n}=4)$ or appraisal-focused coping $(\mathrm{n}=3)$ at both $\mathrm{T} 2$ and $\mathrm{T} 3$. The data analysis revealed that in the early stages of the change (i.e. at T1), these seven individuals coped by attempting to contribute actively to the change efforts. As time went on, however, and the change continued at an often overwhelming pace (i.e. by T2 and T3), these individuals either started to use more passive coping styles (e.g., passively accepting coping strategy from appraisal-focused coping style) or coped by disengaging from the change (e.g., disengaging from the change coping strategy consistent with emotion-focused coping style). Again, analysis of the data helps us understand why these 
seven people changed their coping strategy over time. More specifically, our examination of the transcripts revealed that in all seven cases, informants perceived that the implementation of organizational change was intense at T1 (most used the word "intense" multiple times during the T1 interviews) and stressful. It would appear, then, that these seven informants abandoned the problem-focused coping strategies that they were using when we talked to them at $\mathrm{T} 1$ because these strategies had not really helped them cope with the strains associated with excessive change. Instead, they adopted (T2) and continued to use (T3) passive or disengaged coping strategies as the change continued unabated over time.

The following observations can be drawn from our analysis of the data through a "coping with excessive change" lens. First, over half of informants we interviewed ( $\mathrm{n}=$ 13) used the same coping style throughout the change process (i.e. T1, T2, and T3). More specifically, these informants consistently used emotional-focused or appraisal-focused coping styles to cope with the demands and strains associated with excessive organizational change. Second, virtually no one we talked to used a problem-focused coping style to cope with the changes they were experiencing. Third, those informants who did use a problem-focused coping style $(n=8)$ only used this approach at the beginning of the change process. The fact that all but one of these eight informants appeared to abandon the use of problem focused-coping strategies over time, and adopt coping styles that either helped them deal with the emotional aspects of change (i.e. disengaged from the change) or how they thought about change (tried to view the changes positively), reinforces the idea that problem-focused coping strategies do not 
seem to help employees cope over time with the strains associated with excessive organizational change.

\section{Sensemaking About Organizational Change}

To address our second research objective we employed the same four steps as described above (i.e. initial coding, focused coding, theoretical coding, and identification of patterns over time) to analyze informants' responses to the interview question about coping (see above). In this case, however, we used "sensemaking" as our sensitizing concept and focused our analysis on how informants interpreted or framed the excessive change that they were coping with (i.e. the second part of the sensemaking process pictured in Figure 5-1).

In total, 14 initial codes and 5 focused codes were identified. The focused codes, the most common initial codes, and exemplary quotes for each are included in Table 5-2. How do informants frame the organizational changes that they were coping with? Our analysis revealed that they use the following frames as lenses through which to view change: "change is good", "change is difficult", "change is part of life", "change is something I drive" and/or "change is out of my control". In the interest of clarity in the text below, we use the term "sensemaking frames" to refer to these five focused codes, and bold and italicized font when referring to specific sensemaking frames. 
Table 5-2: Resulting data structure (sensemaking about organizational change)

\begin{tabular}{|c|c|c|c|}
\hline $\begin{array}{l}\text { Theoretical } \\
\text { code }\end{array}$ & $\begin{array}{l}\text { Focused code } \\
\text { (senesmaking } \\
\text { frame) }\end{array}$ & Initial codes & Sample quote \\
\hline $\begin{array}{l}\text { Positive } \\
\text { affect } \\
\text { towards } \\
\text { change }\end{array}$ & $\begin{array}{l}\text { Change is } \\
\text { good }\end{array}$ & $\begin{array}{l}\text { Change is an } \\
\text { opportunity } \\
\text { I like change }\end{array}$ & $\begin{array}{l}\text { "I'm actually a change encourager } \\
\text { because I see technological change } \\
\text { as a potential positive" } \\
\text { "I like change, especially when } \\
\text { they are in the advancement and } \\
\text { just going ahead" }\end{array}$ \\
\hline $\begin{array}{l}\text { Negative } \\
\text { affect } \\
\text { towards } \\
\text { change }\end{array}$ & $\begin{array}{l}\text { Change is } \\
\text { difficult }\end{array}$ & $\begin{array}{l}\text { Change is } \\
\text { frustrating }\end{array}$ & $\begin{array}{l}\text { "There is the odd time that I have } \\
\text { had a melt-down...there's a lot of } \\
\text { high stress activities going on" } \\
\text { "Obviously change frustrates } \\
\text { me..." }\end{array}$ \\
\hline $\begin{array}{l}\text { Detached } \\
\text { (no affect) } \\
\text { towards } \\
\text { change }\end{array}$ & $\begin{array}{l}\text { Change is part } \\
\text { of life }\end{array}$ & $\begin{array}{l}\text { Change is not } \\
\text { something I really } \\
\text { focus on } \\
\text { Change is part of } \\
\text { life }\end{array}$ & $\begin{array}{l}\text { "I tend not to really be change } \\
\text { averse so I'm not sure it really } \\
\text { stood out in the forefront of my } \\
\text { mind" } \\
\text { "I have no problem coping with } \\
\text { them at all, as I mentioned, it's just } \\
\text { another thing" }\end{array}$ \\
\hline $\begin{array}{l}\text { Internal } \\
\text { locus of } \\
\text { control over } \\
\text { change }\end{array}$ & $\begin{array}{l}\text { Change is } \\
\text { something I } \\
\text { drive }\end{array}$ & $\begin{array}{l}\text { Change is } \\
\text { something I chose } \\
\text { to get involved in } \\
\text { I manage change }\end{array}$ & $\begin{array}{l}\text { "I'm not going to sit here for the } \\
\text { next three years and complain } \\
\text { about this, I'm going to do } \\
\text { something to make a difference" } \\
\text { "I try to manage the change of all } \\
\text { the things that are happening...I } \\
\text { feel like I'm in control of what's } \\
\text { happening." } \\
\text { "It hasn't been an issue...I try to be } \\
\text { a change agent and support } \\
\text { change" }\end{array}$ \\
\hline $\begin{array}{l}\text { External } \\
\text { locus of } \\
\text { control over } \\
\text { change }\end{array}$ & $\begin{array}{l}\text { Change is out } \\
\text { of my control }\end{array}$ & $\begin{array}{l}\text { Change is } \\
\text { something that } \\
\text { happens to me/us }\end{array}$ & $\begin{array}{l}\text { "You know what things are going } \\
\text { to change, that's life, there will } \\
\text { never be an area in healthcare of } \\
\text { anywhere probably where there } \\
\text { isn't going to be change" } \\
\text { "we either embrace it and accept it } \\
\text { or it drags you down for the rest of } \\
\text { your life" }\end{array}$ \\
\hline
\end{tabular}

In the third step, theoretical coding, we searched for higher-level categories that could be used to explain theoretical relationships in the data. This analysis involved two 
steps: (1) review the data and identify themes that relate to theoretical categories, and (2) categorize the data according to these theoretical categories. Two themes emerged that were useful for understanding the relationships in the data with respect to the frames (or focused codes) that individuals used when sensemaking about excessive organizational change. The first theme was emotion or affect to reflect analysis that showed that, when making sense of excessive change, informants often used an emotionally evaluative lens (e.g., change is good). The second theoretical theme was related to the amount of control informants perceived that they had over the change. In this case, our analysis suggested that informants typically framed change as either something they felt control over or something that was outside of their control. Based on these two themes we created two theoretical categories: "affect towards organizational change" and "locus of control over organizational change". We used these two categories to create five theoretical codes that correspond with each of the five focused codes - these theoretical codes can be found in the leftmost column of Table 5-2, and are used to create a matrix that aides us in displaying our findings with respect to how employees make sense of excessive organizational change (see Figure 5-3).

The first category, "affect towards organizational change", refers to the emotionally evaluative component of individuals' sensemaking about organizational change (Carver \& Scheier, 2011). This category is reflected in the three sensemaking frames that are on the $y$ axis of Figure 5-3, each of which refers to the emotional (or nonemotional) lens through which change is viewed. More specifically, the change is good sensemaking frame utilizes a "positive affect towards change" when making sense of excessive change. The change is difficult sensemaking frame, on the other hand, refers to 
sensemaking about excessive change that is characterized by a "negative affect towards change". Finally, the change is part of life sensemaking frame corresponds with an absence of affect towards change. In this case, sensemaking is "detached towards change" and is void of an emotionally evaluative component.

The second category, "locus of control over organizational change", refers to an individual's belief regarding the influence they have on organizational changes that impact them. It is based on the locus of control concept, which refers to an individual's belief regarding the influence they have on events that impact them (Rotter, 1966). Locus of control over organizational change is reflected in the two sensemaking frames on the $x$ axis of Figure 5-3. More specifically, the change is something I drive sensemaking frame is consistent with an "internal locus of control" and the change is out of my control sensemaking frame is consistent with an "external locus of control".

Next, in order to classify the data according to these theoretical codes, we reviewed the incidents of data at each focused code for each informant and categorized each incident (i.e. one incident $=$ one interview response from either T1, T2, or T3) according to affect and/or locus of control. Interestingly, for all incidents of data there were both an affective element as well as a locus of control element to the informants' sensemaking about excessive change. This means that when making sense of excessive change, informants used two frames (one based on affect and another based their locus of control over the change). Based on this analysis we were able to identify five "sensemaking styles" that individuals employed to make sense of excessive change. Each "sensemaking style" represents the combination of two different sensemaking frames (or focused codes) where one of the two frames relates to "affect towards change" and the 
other frame corresponds with "locus of control over change". We named these styles "a frustration at work", "another facet of work life", "a fun part of life at work", "a tough part of my job" and "an interesting part of my job".

The sensemaking frame combinations represented by each "sensemaking style" are mapped out in Figure 5-3. The "frustration at work" sensemaking style frames excessive organizational change as difficult and out of my control. This sensemaking style is typified in one nurse's explanation of her frustrations with the move to the new hospital: "Up in the offices it was planned very well on paper. But bring it down to reality and nobody really helps. Nobody figures it out that this would have worked better and they want no input from us". The second sensemaking style, which interprets change as "another facet of work life", frames change as part of life and as out of my control. For example, one informant explains that "these things are temporary, some of these things I cannot change. The things that I might be able to change, I'll work on. And if you cannot change them, no point in getting your shirt in a knot; you may as well accept it." The third sensemaking style positions organizational changes as "a fun part of life at work" - something outside of my control but also something good. A clinical support staff member described excessive change this way: "it is not quick in which you feel like you are left behind. No, the pace of the changes is quite good for me" and later he positioned change as something that was controlled by others (i.e. external locus of control) when he explained that "they also do quite a good job in terms of communicating changes coming." The fourth sensemaking style, named "a tough part of my job" frames organizational change as something I drive that is also difficult. This style was apparent in the transcript of our interview with a manager who explained how 
she found excessive change to be challenging: "I feel like I'm in control of what's happening... moving into the new building there was a certain group of people that I was supposed to be responsible for but I didn't know what their role was... so there is lots of things to look at". The final sensemaking style framed change as both something I drive and $\boldsymbol{a}$ part of life, and is labeled "an interesting part of my job". This style was adopted by an informant who described how 'I change my workflows. I don't think it destabilizes me much, there's something new going on. It takes a while to get it into my head to change how I'm doing things and then let's move on." Interestingly, none of our informants (even the change agents in our sample) made sense of organizational change as something good that they influence or drive.

Figure 5-3: Sensemaking styles based on dual sensemaking frames

\begin{tabular}{|c|c|c|c|c|}
\hline & \multicolumn{2}{|c|}{ Locus of control over organizational change } \\
\hline & & & Internal & External \\
\hline & & & Change is something I drive & Change is out of my control \\
\hline \multirow{3}{*}{$\frac{\frac{\text { Affect towards }}{\text { organizational }}}{\text { change }}$} & | & $\begin{array}{l}\text { Change is } \\
\text { good }\end{array}$ & & $\begin{array}{l}\text { "A fun part of life at work" } \\
n=5\end{array}$ \\
\hline & $\mid$ & $\begin{array}{l}\text { Change is } \\
\text { part of life }\end{array}$ & $\begin{array}{l}\text { "An interesting part of my job" } \\
n=1\end{array}$ & $\begin{array}{l}\text { "Another facet of work life" } \\
n=3\end{array}$ \\
\hline & : & $\begin{array}{l}\text { Change is } \\
\text { difficult }\end{array}$ & $\begin{array}{l}\text { "A tough part of my job" } \\
n=4\end{array}$ & $\begin{array}{l}\text { "A frustration at work" } \\
n=11\end{array}$ \\
\hline
\end{tabular}

N.B. each arrow represents 1 informant whose sensemaking style shifted over time, these informants are included in the " $n$ " for their dominant sensemaking style (i.e. style apparent in 2 of their 3 interviews. 
Finally, we examined the extent to which the sensemaking styles were consistent or stable over time at the individual level. This was done as follows. First, we used informants' T1, T2, and T3 interview data to classify how each informant made sense of organizational change at each point in time (i.e. their sensemaking style). We then used these findings to divide our informants into two groups: those who had the same sensemaking style at all three time periods, and those who used different sensemaking styles at different points in time. Nearly $80 \%$ of individuals $(\mathrm{n}=19)$ made sense of organizational change with the same sensemaking style (i.e. consistent affect towards change as well as a consistent locus of control) in all of their three interviews. The distribution of these 19 individuals across the five sensemaking styles was as follows: for ten informants, excessive change was consistently interpreted as "a frustration at work"; five informants consistently made sense of change as "a fun part of life at work"; two informants consistently viewed change as "another facet of work life"; and two informants consistently made sense of organizational changes as "a tough part of my job".

The remaining five informants, however, used two different sensemaking styles over the course of their three interviews (e.g., their sensemaking style changed from T1 to T2 but was consistent from T2 to T3). The sensemaking style patterns for these five informants are indicated with arrows on Figure 5-3. The arrows indicate informants' sensemaking style at T1 (i.e. the origin cell of the arrow) as well as their sensemaking style at T3 (i.e. the destination cell for the arrow). For some informants their style shifted between $\mathrm{T} 1$ and $\mathrm{T} 2$, while for others the sensemaking style changed from $\mathrm{T} 2$ to $\mathrm{T} 3$. The interval during which the sensemaking style change occurred is indicated by the position of the arrow on the borderline between the two cells. For example, the vertical arrow on 
the far right is mostly in the "another facet of work life" cell, indicating that this informant's sensemaking style shifted from "another facet of work life" (the upper cell) to "a frustration at work" (the lower cell) between T2 and T3.

Closer examination of the informants' interview transcripts and the sensemaking style patterns over time (see Figure 5-3) led to the identification of two groups based on the type of sensemaking frame that changed over time. The first group includes the two informants whose locus of control over organizational change frame shifted from internal (i.e. change is something I drive) at $\mathrm{T} 1$ and $\mathrm{T} 2$ to external (i.e. change is out of my control) at T3. For both individuals, this shift could be attributed to the fact that each of them occupied roles that were heavily involved in the implementation of change at T1 and T2 (i.e. they drove the change), but not at T3 (a period when these two individuals were no longer directly responsible for change implementation). The second group included three individuals whose sensemaking about organizational change varied over time with respect to their emotional or affective sensemaking frame. All three went from detached (i.e. change is part of life) to negative (i.e. change is difficult). Two were detached in their sensemaking about change at T1, and negative at T2 and T3. Both of these individuals were relatively new to the organization at $\mathrm{T} 1$ and had no vested interest in the changes that were occurring. Over time and with increased exposure to change, these individuals' sensemaking around change became more negative as reflected in their responses in the $\mathrm{T} 2$ and $\mathrm{T} 3$ interviews. The other informant was detached from the change at T1 and T2 and negative in how they made sense of change at T3. This shift seemed to be related to a significant change that was introduced in this individual's 
department between $\mathrm{T} 2$ and $\mathrm{T} 3$ (a period of time that included few changes for most other departments).

We elected to categorize these five individuals according to their dominant sensemaking style (i.e. their style from two of the three interviews). Our rationale for this choice is that the one time period where their sensemaking about change was different varied in context from the other two time periods (as described above). Our analysis of the data suggests that it was this difference in context that impacted how these informants made sense of the change in the manner outlined above. Accordingly, we considered that these five individuals made sense of change as follows: "A tough part of my job" $(n=2)$, "a frustration at work" $(\mathrm{n}=1)$ "an interesting part of my job" $(\mathrm{n}=1)$, and "another facet of work-life" $(\mathrm{n}=1)$. The totals in Figure 5-3 reflect this re-categorization.

A few observations from our analysis of the data through a "sensemaking about excessive change" lens are as follows. First, most individuals (n=19) used a consistent sensemaking style over a period of time wrought with excessive organizational change (i.e. remained consistent with respect to how they made sense of this change). Second, the majority of informants ( $\mathrm{n}=19)$ consistently made sense of excessive change as something outside of their control (i.e. demonstrated an external locus of control). In two other cases, the individuals' sensemaking shifted over time from a frame where change was viewed as something they influenced, to a frame where change was conceptualized as being outside of their control. The fact that by T3 only three individuals in the sample framed change as something they personally influenced or drove, while the rest $(\mathrm{n}=21)$ ultimately viewed change as something that controlled them, shows the impact of prolonged periods of excessive organizational change on individual sensemaking. Third, 
nearly two thirds of the sample $(\mathrm{n}=15)$ made sense of excessive change as a negative emotional experience (i.e. negative affect- change is difficult). Finally, one in five of our informants always framed excessive change at the hospital as something good (i.e. positive affect) that is nonetheless outside of their control (i.e. external locus of control). Taken together, these findings suggest that for most individuals $(n=19)$ excessive organizational change is experienced as something negative that one has little control over. Finally, it is noteworthy that even those few $(n=5)$ individuals who made sense of change as something positive also felt that they had little control over how it would "roll out."

\section{Coping and Sensemaking Patterns}

The third stage of the analysis mapped findings from the sensemaking and coping phases of our study in order to determine how informants' coping styles overlapped with their sensemaking styles. This mapping allowed us to explore our assumption that these two sensitizing concepts (sensemaking and coping) describe similar processes. To meet this objective, we used a visual mapping strategy (Langley, 1999) which has been shown to be particularly helpful for presenting data analysis and findings according to a number of dimensions (e.g., sensemaking styles/frames and coping styles over time) simultaneously. The visual mapping process resulted in the framework outlined in Figure 5-4, which presents our findings using the sensemaking styles framework initially presented in Figure 5-3. Below, we clarify for the reader precisely how the preliminary findings are visually represented in Figure 5-4 as it does condense a substantial amount of information and findings into one diagram. 
Figure 5-4: Final data structure, coping style patterns mapped onto sensemaking styles $(\mathrm{n}=24)$

\begin{tabular}{|c|c|c|c|}
\hline & \multicolumn{2}{|c|}{ Locus of control over organizational change } \\
\hline & & Internal & External \\
\hline \multirow{3}{*}{$\begin{array}{c}\text { Affect } \\
\text { towards } \\
\text { organizatio } \\
\text { nal change }\end{array}$} & 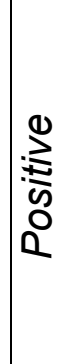 & & $\begin{array}{c}\text { "fun because I say it's fun" } \\
\text { Make sense of change as } \\
\text { "A fun part of life at work" ( } n=5) \\
\text { Cope using appraisal-focused style } \\
(3 \text { A-A-A) } \\
(2 \text { P-A-A) }\end{array}$ \\
\hline & $\begin{array}{l}0 \\
0 \\
\frac{1}{0} \\
\frac{\pi}{0} \\
0 \\
0\end{array}$ & $\begin{array}{c}\text { "another item on my to-do list" } \\
\text { Makes sense of change as } \\
\text { "An interesting part of my job" }(n=1) \\
\text { Copes using problem-focused style } \\
(1 \text { P-P-P) }\end{array}$ & $\begin{array}{c}\text { "just another obstacle for me at } \\
\text { work" } \\
\text { Make sense of change as } \\
\text { "Another facet of work life" (n=3) } \\
\text { Cope using either appraisal-focused or } \\
\text { emotion-focused style } \\
(1 \mathrm{~A}-\mathrm{A}-\mathrm{A}) \\
(1 \mathrm{P}-\mathrm{A}-\mathrm{A}) \\
(1 \mathrm{~A}-\mathrm{E}-\mathrm{E})\end{array}$ \\
\hline & 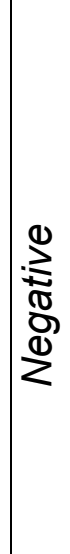 & $\begin{array}{c}\text { "a stressful part of what I have to } \\
\text { do" } \\
\text { Make sense of change as } \\
\text { "A tough part of my job" (n=4) } \\
\text { Cope using emotion-focused style } \\
(1 \mathrm{E}-\mathrm{E}-\mathrm{E}) \\
\text { (3 P-E-E) }\end{array}$ & $\begin{array}{l}\text { "a frustration we try and deal with" } \\
\text { Make sense of change as } \\
\text { "A frustration at work" }(n=11) \\
\text { Majority }(n=8) \text { cope using emotion- } \\
\text { focused style; minority }(n=3) \text { cope } \\
\text { using appraisal-focused style } \\
(3 \text { A-A-A) } \\
(4 \text { E-E-E) } \\
(3 \mathrm{~A}-\mathrm{E}-\mathrm{E}) \\
(1 \mathrm{P}-\mathrm{E}-\mathrm{E})\end{array}$ \\
\hline
\end{tabular}

N.B. X-X-X paths represent coping style at T1-T2-T3 where $\mathrm{A}=$ appraisal focused coping style, $\mathrm{P}=$ problem focused coping style and $\mathrm{E}=$ emotion focused coping style 
We use the following data display conventions in 5-4. First we show "coping patterns" (i.e. the coping styles for individuals across T1, T2, and T3) using a three-letter sequence where each letter refers to how we classified the informant's coping style at each of the three time periods included in the study. We use a "P" to indicate that the informant was considered to have used a problem-focused coping style, an "A" to reflect our view that they used an appraisal-focused coping style, and an "E" to represent a response that was coded as the use of an emotion-focused coping style. This means, for example, that the coping pattern "P-A-A" describes an informant whose coping was problem-focused at T1, and then appraisal-focused at T2 and T3. These coping patterns are indicated inside of parentheses within the cell which represents how this informant made sense of the change (i.e. sensemaking style cell). The number to the left of the coping pattern indicates the number of informants who exhibited that particular coping pattern and sensemaking style combination. For example, the "a tough part of my job" cell (lower left on the matrix) shows how the four informants who made sense of change as negative and outside of their control (i.e. "a tough part of my job" sensemaking style) coped with change over time. The "(1 E-E-E)" means that one of these four coped using what we classified as emotion-focused coping style at all three interviews whereas the "(3 P-E-E)" indicates that the other three coped through the use of a problem-focused style at T1 followed by the emotion-focused coping methods at T2 and T3

After we created Figure 5-4 we examined the figure and the corresponding data in order to identify patterns between how informants coped with and made sense of excessive change over time. Five such patterns were identified and relate to five different stories that the data tells about how individuals make sense of, and cope with, excessive 
change. The five stories relate to the coping styles that overlap with each of the five sensemaking styles and are described further below.

The first story is about how, for many $(\mathrm{n}=11)$ informants, excessive change acts as "a frustration we try to deal with". This pattern refers to the largest group in our sample (i.e. make sense of change as both outside of their control and difficult or stressful). A common thread across these sets of interviews is that organizational change at the hospital is something difficult for the informant and those around them. One individual explains that they are "not the only one feeling the stress of change; everybody is feeling overwhelmed with the changes that take place". Most of these individuals cope with the frustrations that accompany excessive change by trying to suppress the experience of the negative emotions (i.e. emotion-focused coping). For example, in their interviews, one person talked about coping by socializing and venting to co-workers in a "[expletive] session, because you have that chance to vent and it's nice". A minority of these individuals $(n=3)$, however, coped by altering how they think about these changes (i.e. appraisal-focused coping style).

The second story is about the relatively small number of informants $(n=3)$ who make sense of excessive organizational change as "just another obstacle for me at work" (i.e. do not get emotional about the changes but nonetheless feel that what is happening is outside of their control). The three informants in this group cope with all the changes that are going on by either thinking about it differently (i.e. appraisal-focused style, $n=2$ ), or by trying to deal with the negative feelings (i.e. emotion-focused, $n=1$ ). The following quote from one interviewee typifies this group: "There is always going to be change. You cannot control [it] so you have to control how you act and react". 
The third story pertains to the handful of informants $(n=5)$ who talk about excessive change as something that is "fun because I say it's fun". This group is fairly homogenous in that they consistently make sense of excessive change as something they cannot control but that is, at the same time, enjoyable. Organizational change is described as something unavoidable: “Change happens everywhere, you can't get away from change”. These informants typically cope with changes by altering how they appraise or think about the changes. One of these informants explained their method for coping with change as follows: "I look for opportunities... whenever there's change, there is new opportunities and I find those new opportunities interesting”.

Story number four is about how, for some individuals $(n=4)$, the lived experience of excessive change involves change that is "a stressful part of what I have to do". This group of informants differs from their colleagues in the four groupings discussed previously in that they make sense of change as something that they influence or drive. Despite their internal locus of control with respect to the change, they also view the excessive change their organization is going through as something that is difficult or negative. It is also noteworthy that everyone in this group copes by engaging in behaviours to minimize the intensity of negative emotions (i.e. emotion-focused coping) associated with the change. For example, one informant described coping by withdrawing and focusing on life outside of work: "I've got lots of outside interests. I have good friends that are supportive. I think that's the biggest thing for me in getting through this."

The fifth and final story narrates excessive change as "another item on my to-do list". This story refers to the unique pattern observed in the data analysis for one of our informants. This individual was the only person who made sense of change as both 
something within their control and something non-emotional (i.e. detached affect). When the interviewer first asked this informant how they coped with change, they were unsure and remarked, “Interesting question. I haven't really thought about how I cope with them..." but later explained, "Because I'm a part of the leadership, I'm usually very much part of that change". Interestingly, this person was also the only individual in our sample who consistently coped with change by getting involved with, or contributing to, the changes at the hospital (i.e. problem-focused coping style).

\section{Conclusion}

The literature review showed how, theoretically, the cognitive appraisal and sensemaking processes could reflect overlapping or parallel cognitive processes in the context of organizational change (see Figure 5-1). Our dual analysis of the data examined longitudinal panel interview data through the lenses of coping and sensemaking. The sensemaking analysis looked at how individuals frame or interpret change (i.e. the second part of the sensemaking process - which parallels the appraisal stage of the cognitive appraisal process). The coping analysis, on the other hand, examined how individuals cope with organizational change (i.e. the third part of the cognitive appraisal process which maps to the enactment stage of sensemaking). The patterns or "five stories" that emerged from our data (as depicted in Figure 5-4) demonstrate a connection between how an individual frames or interprets change, and how they cope with it and provide support for the contention that coping (as per cognitive appraisal theory) can be conceptualized as the enactment phase of sense making. These findings suggest that, at the very least, coping and sensemaking are overlapping processes that individuals engage in when experiencing excessive change. 
Three conclusions can be drawn from this process-based emic study of how individuals make sense of, and cope with, excessive organizational change. First, individuals appear to prefer coping with excessive organizational change by adopting strategies that are consistent with emotion-focused and appraisal-focused coping styles from the field of psychology. Problem-focused coping, or coping by engaging in the change, was barely used and even less so over time (i.e. from T1 to T3), suggesting that coping by getting involved is not an effective approach for individuals dealing with excessive organizational change. Second, when making sense of excessive change, individuals also utilized fairly consistent styles over time. These sensemaking styles can be differentiated according to the individuals' stable affect towards change (positive, detached or negative) and their stable locus of control over organizational change (internal or external). Finally, our findings showed that sensemaking and coping act as overlapping cognitive processes in the context of organizational change. This paper is the first, to our knowledge, to empirically investigate this theoretical overlap between the cognitive appraisal process and the sensemaking process.

When undertaking the study described in this paper, we took steps to mitigate two potential issues associated with our research methodology. The two limitations associated with our research methodology, and how we addressed them, are summarized as follows. First, unlike the variance-based etic studies of coping with organizational change, the findings from this process-based emic study of sensemaking and coping with organizational change are not generalizable. The interpretive nature of our study means that instead of conducting research that is statistically generalizable, we strove to produce findings that are "transferable" (Shah \& Corley, 2006). In order to maximize the reader's 
ability to assess when and how these findings may be transferable to other contexts of interest, we provided detailed information on the context of this research (i.e. Community Hospital and its excessive changes) and used figures and tables to make it easier for the reader to understand our analytic steps and show how the findings emerged from the data (Lincoln \& Guba, 1985; Shah \& Corley, 2006).

The second limitation of this study is related to scope. A major contribution of this study is the notion that sensemaking and cognitive appraisal theory represent parallel cognitive processes that individuals use during organizational change. Our data, however, focused specifically on one part of the sensemaking process (i.e. interpretation) and one part of the cognitive appraisal process (i.e. coping). This can be considered a limitation in that the focus on "coping" during our data collection and analysis meant that our data did not allow us to make broader inferences with respect to the other stages of the sensemaking and cognitive appraisal processes. For example, we were unable to determine whether our informants appraised the excessive changes as a harm, threat, or challenge because these categories did not emerge naturally from the data - which was focused on coping. Nonetheless, we feel that the focus on coping was important in order to make a meaningful and clear contribution to theory in the areas of individuals and change and sensemaking about excessive organizational change.

\section{Implications for Research}

It is our hope that this paper serves to motivate future research that investigates the extent to which the cognitive appraisal process and the sensemaking process represent parallel processes in the context of organizational change. These studies could use 
different types of data to consider the extent to which the appraisal part of the cognitive appraisal process overlaps with the interpretation part of the sensemaking process. Scholars could explore the cause and effect (or as we call it, the "chicken or the egg") dynamics with the overlapping aspects of the "sensemaking" and "cognitive appraisal" processes. For instance, does interpretation (sensemaking) lead to coping (cognitive appraisal theory), or does appraisal (cognitive appraisal theory) lead to enactment (sensemaking)? Another complementary avenue for future research on the subject of individuals and change is research that considers rich longitudinal panel data over time in order to look at different aspects of how individuals experience excessive change over time. This research could consider the connection between sensemaking and other relevant notions like resilience at the individual level.

\section{Implications for Practice}

The findings from this study contain a number of practical implications for those tasked with implementing organizational change (or managing excessive change). For example, managers and leaders of organizational change might benefit from assessing or considering how individuals in their organization view organizational change (i.e. affect towards change, locus of control over organizational change), and how this might relate to how individuals respond to the organizational changes underway. The connection between individuals' sensemaking styles and their coping styles indicates that how one makes sense of change is connected to how they respond to change. More specifically, when determining a strategy for implementing organizational change, change agents could experiment with approaches aimed at identifying individuals who have an internal locus of change control and detached affect towards change (i.e. those potentially more 
likely to engage in the change when coping,) as well as approaches that aim to frame the change as something that individuals do have control over (i.e. sensegiving an internal locus of change control). Finally, every effort should be made to ensure that the organization listens to those employees who use problem-focused coping styles to cope with the stress associated with excessive organizational change, as the data from this study suggests that in the absence of a positive feedback loop, such individuals change their approach to one that is more passive in nature.

\subsection{Conclusion}

Findings from the "Coping" paper contribute to the primary objective of this thesis (to understand how individuals make sense of organizational change over time from an emic (i.e. insider) perspective) in three ways. First, findings related to the sensemaking frames indicate that individuals tend to make sense of change using a consistent affect (positive, negative or detached) and locus of control toward organizational change over time. Second, findings support the initial contention that coping can be conceptualized as the third stage of sensemaking (i.e. enactment). Taken together with the specific coping styles observed in the data this means that individuals make sense of excessive change by interpreting it (using stable affect and locus of control frames over time) and then responding to it (i.e. enactment) through the use of particular coping styles. Third, the way that one enacts their sensemaking (i.e. their coping styles) was prone to change over time whereby individuals reported the use of more passive and disengaged coping strategies over the course of the five year study. 


\section{Chapter 6: Conclusion}

There are a number of ways that the research included in this thesis is poised to make a contribution to our knowledge of how individuals make sense of organizational change. Likewise, there are some aspects of these papers that could be viewed as limitations. The purpose of this final chapter is to revisit the key ideas from the three papers included in this thesis in order to clarify their limitations and contributions to research and practice in the area of organizational change. This chapter has five sections. First, the key findings from the Literature Review, which motivated the objective of this thesis, are reiterated. Second, four figures that conceptualize the overarching contributions of the three papers are presented. Next, the limitations of the research presented in this thesis are discussed. Finally, implications for future research, as well as practice, based on the findings from the three papers, are identified and explained.

\subsection{Research on sensemaking about organizational change}

The literature review provided in Chapter One of this thesis presented the results from a comprehensive search for empirical and conceptual articles on the topic of sensemaking about organizational change. In total, 66 articles were identified and reviewed, including 50 empirical articles and 16 conceptual articles. The review of the empirical articles determined seven themes: three that describe how findings from this body of work are related to sensemaking, and four that highlight how findings relate specifically to organizational change. These themes, which are reiterated below, were originally detailed in Chapter One and were also briefly or partially described in the Literature Reviews for each of the three papers. The goal of this section of the chapter is 
to re-familiarize the reader with the key findings from the literature review and the critique of this literature that served to motivate the three papers included in this thesis.

\subsubsection{Themes from the extant literature}

The empirical work on sensemaking about organizational change contains a number of studies that include findings with particular implications for the conceptual aspects of sensemaking. These studies included findings specifically related to: (1) One of Weick's (1995) seven sensemaking properties (e.g., sensemaking is grounded in social identity - Apker, 2004; Chreim, 2006; Gioia \& Thomas, 1996; Thurlow \& Helms-Mills, 2009), (2) the process of sensemaking (e.g., Isabella, 1990; Rouleau, 2005; Weber \& Manning, 2001), and/or (3) the use of lenses or frames for sensemaking (e.g., Balogun \& Johnson, 2004; Bean \& Eisenberg, 2006; Chaudhry et al., 2011; Chreim \& Tafaghod, 2012); Guiette \& Vandenbempt, 2013; Lockett et al., 2014; Luscher \& Lewis, 2008; Sonenshein, 2009).

Four additional themes emerged to describe findings from the extant literature on sensemaking about organizational change, findings that relate more directly to organizational change. These four themes can be used to differentiate between four different but overlapping streams of research currently active in the area of sensemaking about organizational change: (1) sensemaking and individuals reactions to organizational change (e.g., Balogun et al., 2015; Bartunek et al., 2006; Chreim, 2006; Kyriakidou, 2011; Greenberg, 1995; Landau \& Drori, 2008; Riesenmy, 2010; Smollan, 2014; Stensaker \& Falkenberg, 2007; Stensaker \& Meyer, 2012; Stensaker et al., 2008), (2) change implementation and sensegiving (i.e. influencing the sensemaking of others) (e.g., Gioia \& Chittipeddi, 1991; Gioia et al., 1994; Hensmans, 2015; Kezar, 2013; Marmenout, 
2010), (3) middle managers' role as change sensegivers (e.g., Balogun, 2003, 2006;

Balogun \& Johnson, 2004, 2005; Dutton et al., 2001; Hope, 2010; Rouleau \& Balogun, 2011), and (4) sensemaking about change through narrative, discourse and stories (e.g., Abolafia, 2010; Brown \& Humphreys, 2003; Dawson et al., 2014; Dunford \& Jones, 2000; Gazi, 2013; Heracleous \& Barrett, 2001; Reissner, 2011; Sonenshein, 2010;

Teulier \& Rouleau, 2013).

\subsubsection{Critique of the extant literature}

The main critique of the empirical work on sensemaking about organizational change that served to motivate this thesis is the lack of studies that examine sensemaking about organizational change over time at the individual level. The detailed examination of the methodological approaches for the 50 studies on sensemaking about organizational change (included in the literature review chapter) found that many studies use contextualism (Pettigrew, 1990) and involve research designs that use multiple types of data to capture longitudinal aspects of organizational change (e.g., observations over time coupled with interviews). The individual-level data (e.g., interviews) in these studies, however, was typically collected at one point in time or over a relatively short period of time during the period of intense change implementation (e.g., multiple interviews over the course of ten months). The extant work on sensemaking about organizational change, while valuable, is limited in its utility because these findings about how individuals make sense of change over time reflect a short period of time in comparison with the 2 to 15 years (Smith, 2003) it takes to implement organizational change. This critique is consistent with that of other notable scholars (Langley et al., 2013; Van de Ven \& Poole, 2005), who have also identified the absence of individual level process studies of 
organizational change as something that contributes to a gap in the current understanding of organizational change.

The three studies included in this thesis looked at individual-level sensemaking about organizational change over a period of five years during a planned organizational change initiative at the case organization (Community Hospital). Each of the three papers analyzed data from three interviews with each of the 26 informants over the course of five years in order to explore three different individual-level sensemaking dynamics over time. The one exception to this is the coping paper, which included only 24 informants because data for two of the informants was incomplete (i.e. they did not provide responses to the interview questions related to the sensitizing concept for this paper). The "Retrospective versus Real-Time" paper looked at the parallel cognitive processes of sensemaking and cognitive bias over time, and considered how cognitive bias could be used to explain differences between informants' retrospective sensemaking (looking back over time) and their real-time assessments (captured throughout the five years). The "Sensemaking Lenses" paper looked at the lenses that individuals use for making sense of significant organizational change over time, and introduced two concepts named "sensemaking scope" and "sensemaking constancy" to describe individuals' sensemaking lens dynamics over time. Finally, the "Coping” paper posited sensemaking and coping with organizational change as overlapping cognitive processes at the individual level and explored how individuals' styles for coping with excessive change over time related to their strategies for making sense of (or framing) organizational change over time. 


\subsection{Contribution of thesis}

The relevance of the phenomenon of sensemaking about organizational change to our understanding of how individuals experience change (a popular topic in both the academic and practitioner literatures), coupled with access to a rich longitudinal dataset, poise this thesis to make a number of contributions to our understanding of organizational change and how individuals experience and make sense of this change over time. The contribution of this thesis is rooted in the unique longitudinal individual-level panel data set that captured 26 informants' sensemaking over the course of five years during a planned organizational change initiative. This section of the chapter includes four figures that visually represent how each of the three papers included in this thesis complement one another in their focus and findings.

The first figure is Figure 6-1. This figure shows the sensemaking process and maps out how each of the three papers relates to a different stage in this iterative cognitive process. First, the "Retrospective Versus Real-time" paper looked at the first stage of sensemaking: sensemaking cues and triggers. More specifically, the reasons that informants provided for how the work environment changed over time (e.g., turnover, changes to the physical work environment, new CEO) can be conceptualized as triggers for sensemaking about change, because these reasons highlight the specific changes that led informants to view their work environment as having changed over the previous five years. Second, the "Sensemaking Lenses" paper, which focuses on the lenses that individuals use to make sense of organizational change over time, contributes to our understanding of the second stage of sensemaking (i.e. "interpretation”). More specifically, this paper considers how individuals use lenses and frames to guide their 
interpretation stage when sensemaking about organizational change. Finally, findings from the "Coping" paper contribute to the knowledge about the enactment stage of sensemaking, in that how individuals cope with organizational change is conceptualized as their enactment or action stage of sensemaking. In particular, the findings from this paper indicated that individuals cope with excessive change (i.e. enact their sensemaking about change) by either focusing on changing how they think about change (i.e. appraisal-focused coping style) or through trying to minimize the experience of negative emotions that accompany the change (i.e. emotion-focused coping style), and that they tend to avoid getting involved with the changes as a means of coping (i.e. virtually no one used problem-focused coping style).

Figure 6-1: Contributions to our understanding of the sensemaking process over time

\section{Sensemaking Process:}

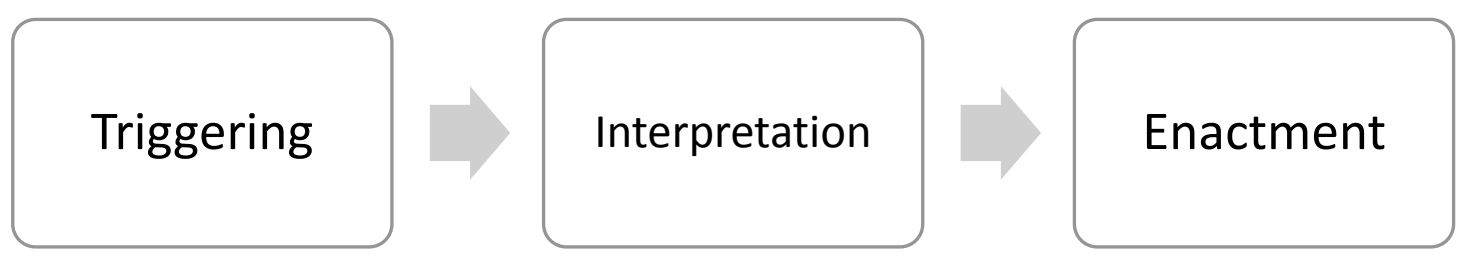

\section{Contributions of this thesis:}

Retrospective vs. Real-time Paper:

Aspects of change that act as triggers (turnover, new CEO, physical changes to workplace, etc.)
Sensemaking Lenses Paper:

How sensemaking lenses act over time (sensemaking scope and sensemaking constancy)
Coping Paper:

Coping with excessive change (appraisalfocused or emotionfocused)

The next three figures (Figures 6-2, 6-3, and 6-4), which are somewhat more abstract than the first figure, conceptualize the contributions of this thesis in terms of how each of the three papers considers a different parallel cognitive process that is at play 
when individuals make sense of organizational change over time. Figure 6-2 shows how the "Retrospective Versus Real-time" paper considers sensemaking, a cognitive process from the interpretivist perspective, alongside attribution and cognitive biases, which represent cognitive processes from a computational cognition perspective. Interpretive cognitive processes, like sensemaking, are typically not considered in concert with computational cognitive processes because both differ in terms of their basic assumptions about the cognitive processes of the human mind (Hodgkinson \& Healey, 2008). Pairing the two different cognition approaches in one study represents a pluralist stance and by considering both computational and interpretive cognitive processes, this paper contributes to the literature by broadening our understanding of how these two divergent perspectives compare in real life situations.

Figure 6-2: Parallel macro level cognitive processes in "Retrospective versus Real-time" paper

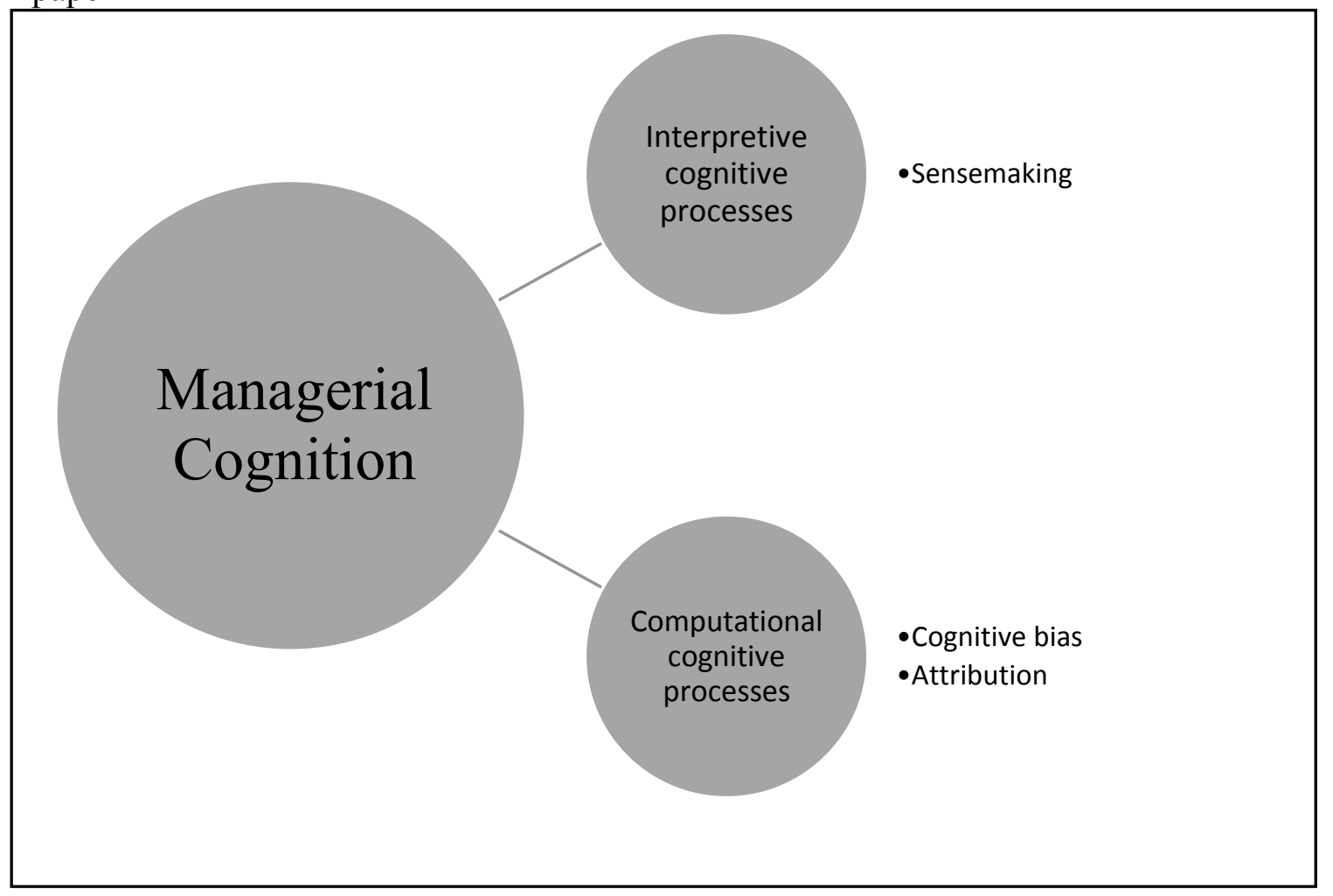


Figure 6-3 illustrates how the "Sensemaking Lenses" paper looks specifically at the interpretation process that occurs within the sensemaking process. This paper contributes to our understanding of the "re-framing" process that is commonplace in the empirical work on sensemaking about change. More specifically, when looking at individuals lenses for making sense of change over time, it became apparent that "reframing" during organizational change only occurs temporarily during change implementation.

Figure 6-3: Processes within a process in the "Sensemaking Lenses" paper

\section{The Sensemaking Process:}

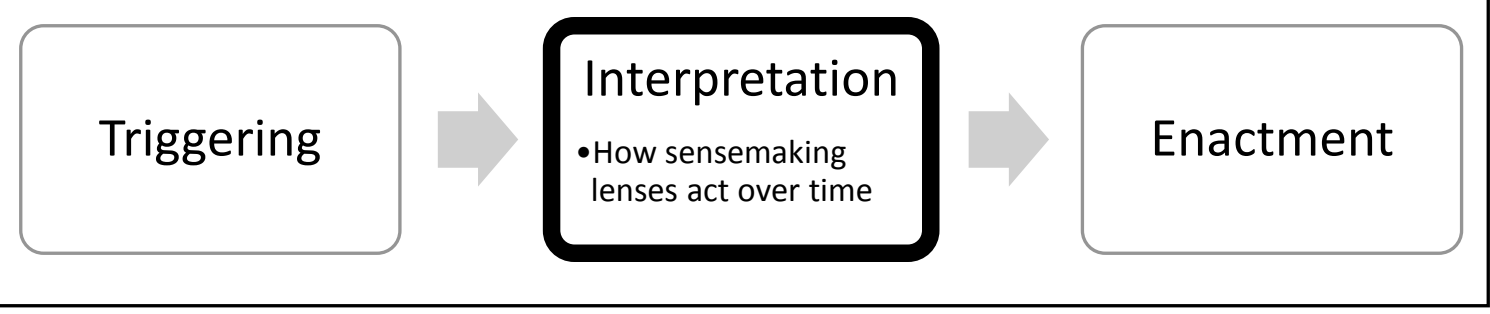

Finally, Figure 6-4 visualizes how the "Coping" paper compares sensemaking and the coping or cognitive appraisal process. This paper contributes to our understanding of how individuals experience organizational change by demonstrating how sensemaking and coping/cognitive appraisal act as two as overlapping cognitive processes that occur during excessive organizational change. The overlap can be conceptualized as follows. First, organizational change acts as both a stressor and a trigger that jump-starts both the cognitive appraisal process and the sensemaking process. Next, our analysis showed that individuals use dual frames to make sense of organizational change according to both affect towards change (positive, detached, or neutral), and locus of control over organizational change (internal or external). Finally, individuals' coping behaviours, which were typically consistent with the literature's definitions of appraisal-focused 
coping or emotion-focused coping, can be considered individuals' enactment stage of sensemaking. Our analysis in this paper showed how the frames that individuals used to interpret (i.e. sensemake about) excessive change were empirically connected with particular styles for coping with excessive change.

Figure 6-4: Parallel processes in the "Coping" paper

\section{The Coping Process:}

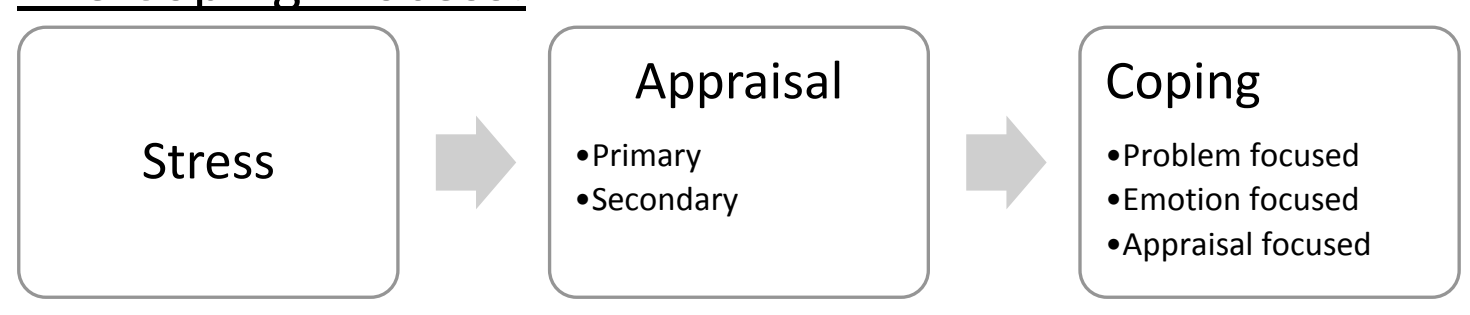

\section{The Sensemaking Process:}

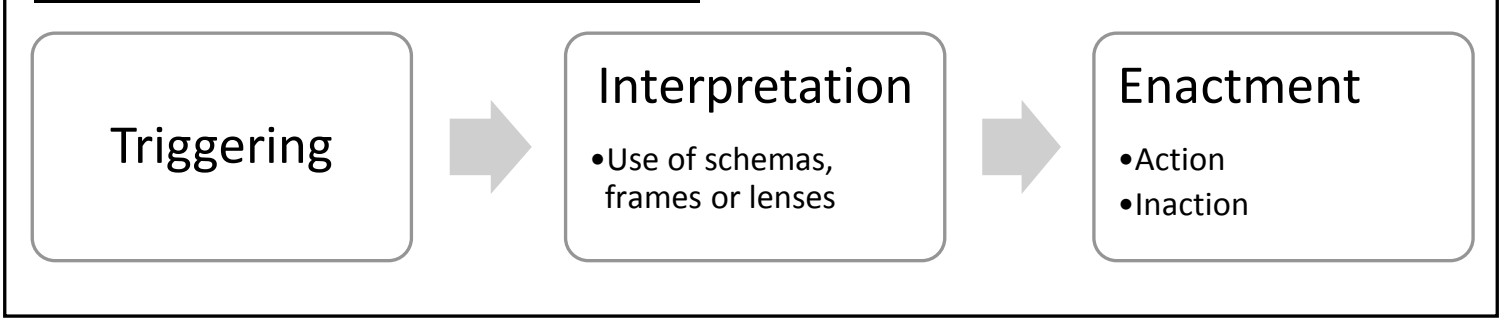

\subsection{Limitations}

Four of the most substantial possible limitations of this thesis are discussed below. Included in this discussion is an explanation of the steps undertaken to mitigate the potential negative impact of each particular limitation on the overall quality of this study.

The first limitation of this study is regarding the generalizability of these findings to other organizations. It is possible that the same study conducted at another organization, even another hospital, would have different results. The findings from this thesis could reflect a number of context-specific characteristics. In accordance with the interpretive approach employed within this thesis, however, the purpose of this research 
is not to maximize generalizability (Gioia et al., 2013; $\mathrm{Ng} \&$ Hase, 2008). Instead of seeking findings that are generalizable to broader organizational populations, this thesis seeks to produce research outputs (e.g., typologies and theoretical concepts) that are “transferable" (Lincoln \& Guba, 1985; Shah \& Corley, 2006). Transferability involves the readers' judgment as to when findings may apply in another context - this judgment is made possible if the researchers provide thick description of the research context and analysis procedures (Shah \& Corley, 2006). The strategies employed to ensure transferability were described in the methodology chapter and reiterated in the limitations section of each paper. The approach taken in this thesis is consistent with what Lee and Baskerville (2012, p. 756) call "generalizing from empirical statements to theoretical statements", in that each paper used empirical data to develop theories or theoretical concepts. Furthermore, the use of strategies to increase transferability of findings (noted above) facilitates the reader's ability to "generalize theoretical statement to empirical statements" (i.e. transfer theory developed in each paper to other contexts) (Lee \& Baskerville, 2012).

The second potential limitation of this research involves the use of sensitizing concepts. Hall and Callery (2001) warn researchers against the qualitative misstep of applying a theoretical framework to a coding scheme too early in the process. Rather than allowing categories and themes to emerge from the data, it is believed that such a premature action results in researchers force-fitting data into the theoretical categories from the literature. To the untrained eye, the use of sensitizing concepts described in this proposal could be a red flag. However, Charmaz (2006) clarifies that sensitizing concepts are useful in providing a starting point for looking at the data, but should not serve as ad- 
hoc frameworks for analyzing the data. The practices of initial coding and reflexivity employed in this thesis were critical in order to avoid the "force-fitting" of data to preconceived theoretical frameworks and models of sensitizing concepts. Transparency was also utilized during the presentation of findings in that numerous tables and figures were included so that the reader can follow the line of analytical inquiry used by the researcher regarding when and how theoretical coding schemes are employed.

The third potential limitation is the composition of the interview sample. In particular, the various job types included in the sample could be cause for concern given the extant research on sensemaking and professional identity. This research has shown that physician and nurse professional identities are strongly connected to sensemaking (Hotho, 2008; Kreindler, Down, Star, \& Gottschalk, 2012) and to their experiences of organizational change (Reissner, 2010; Terry \& Callan, 1998; Van dijk \& Van dick, 2009). Fortunately, the use of Nvivo's person classification function meant that the researcher was able to determine (and report for the reader) the extent to which findings in each paper of this thesis are consistent with job type. In these cases, the papers integrated sources from the complementary literature related to professional identity (e.g., the "Retrospective Versus Real-time" paper incorporated job type as a larger focus of the analysis when findings according to job type became an apparent pattern).

A final limitation is that the use of an even richer and more temporally expanded data set could yield different insights related to sensemaking lens dynamics. For instance, had this thesis analyzed five or six interviews with the same individuals over the course of 10 or 15 years, perhaps the findings would have gone in a different direction (e.g., different lenses in the "Sensemaking Lenses" paper or different coping patterns or 
"stories" about sensemaking and coping from the "Coping" paper). Given the heavy reliance of existing empirical studies on interview data that is retrospective or longitudinal but over a short-term period (i.e. less than two years) when investigating lenses for sensemaking about change, this thesis's ability to consider a longer span of sensemaking dynamics at the individual-level is a contribution. However, this is not to say that this thesis comprehensively "fills this gap". Rather it is, hopefully, the start to a fascinating stream of research that seeks to extend our understanding of individual level sensemaking about change over time.

\subsection{Implications for future research}

A number of detailed implications for future research are identified and described in each of the three papers included in this thesis. This section of the conclusion chapter, therefore, presents and explains two broad and overarching implications that the research included in this thesis has for future research on the topic of sensemaking about organizational change. The first implication is that scholars interested in increasing our understanding of organizational change are encouraged to consider how their studies can capture the emic view of the phenomena at the individual level over time. At the very least, it is hoped that this thesis serves to raise awareness on the issues related to the current methodological approaches that are popular in this area (e.g., retrospective interviews at one point in time, or interviews over a short period of time during change). Calling attention to this issue may serve to motivate others to consider how alternate research designs and/or the use of panel data may better elucidate how individuals experience organizational change over time. 
The second overarching implication is that future research should consider how more pluralistic approaches may expand our theoretical understanding of the individuallevel processes that are at play during organizational change. More specifically, this thesis looked at the parallel processes of sensemaking and cognitive bias in one paper and mapped the coping and cognitive appraisal process onto the sensemaking process in another. These papers show that coupling other individual level processes from psychology or other neighbouring disciplines with sensemaking might be helpful in enlightening our understanding of how individuals experience change over time.

\subsection{Implications for practice}

Detailed implications for those tasked with implementing organizational change are included in each of the three papers that form part of this thesis. This section, therefore, summarizes the key implications for change management practice that arose out of each paper. Two papers suggest significant implications for the implementation process, whereas the third paper included more direct implications for how organizational change initiatives are evaluated. All three are explained below.

Two of the primary implications for those tasked with implementing organizational change initiatives are as follows. First, leaders and managers should consider that people demonstrate a relatively high level of stability when focusing on the implications of change on themselves and those around them - as was evidenced in the findings from the "Sensemaking Lenses" paper. When devising a strategy for implementing change, it would be wise to map out the potential implications (good and bad) for those at different parts of the organization and then use this map to drive or adjust the implementation strategy. A second implication for those charged with carrying 
out organizational change initiatives is that they should bear in mind that individuals do not typically cope with excessive change by getting involved (i.e. problem-focused coping). Rather, our findings suggest that coping with excessive organizational change is usually emotion-focused or appraisal-focused. Perhaps providing "coping outlets" as part of the change initiative and using these to drive individuals towards problem focused coping would help to facilitate individuals coming to terms with and supporting the change. For example, the organization could provide informal and formal opportunities for socializing and venting and then figure out how to use the information individuals share to alter the implementation path and perhaps divert away from change failure. It is possible that a strategy like this would lead individuals to feel that their emotion-focused coping was actually helping to fix problems and that might lead them to shift to problemfocused coping on a more consistent basis (i.e. the opposite of what was apparent in the "Coping" paper findings).

The final overarching implication for practice is related to how organizations evaluate the effectiveness of organizational change initiatives. Findings from the "Retrospective Versus Real-time" paper suggest that leaders and those evaluating change should carefully consider when they ask (i.e. at the end of the change versus throughout), and who they ask (i.e. change agents versus change recipients) about the success of the change, as both dimensions appeared to be related to the divergent perspectives espoused by the informants. More specifically, a more comprehensive approach to evaluating organizational change effectiveness should consider all types of information (i.e. metrics taken throughout the change and at the end, as well as the views of both change agents and change recipients). This approach would provide a more complete picture of how the 
change initiative is unfolding over time and, hopefully, would provide leaders with critical information that would allow them to change course and avert change failure. 


\section{References}

Abolafia, M. Y. (2010). Narrative construction as sensemaking: How a central bank thinks. Organization Studies, 31(3), 349-367.

Aguirre, D., \& Alpern, M. (2014, June 6). 10 principles of leading change management. Strategy \& Business. Retrieved from http://www.strategybusiness.com/article/00255?gko $=9 \mathrm{~d} 35 \mathrm{~b}$

Ahuja, M. K., \& Thatcher, J. B. (2005). Moving beyond intentions and toward the theory of trying: Effects of work environment and gender on post-adoption information technology use. MIS quarterly, 29(3), 427-459.

Allard-Poesi, F. (2005). The paradox of sensemaking in organizational analysis. Organization, 12(2), 169-196.

Amis, J., Slack, T., \& Hinings, C. R. (2004). The pace, sequence, and linearity of radical change. Academy of Management Journal, 47(1), 15-39.

Amiot, C. E., Terry, D. J., Jimmieson, N. L., \& Callan, V. J. (2006). A longitudinal investigation of coping processes during a merger: Implications for job satisfaction and organizational identification. Journal of Management, 32(4), 552574.

Apker, J. (2004). Sensemaking of change in the managed care era: A case of hospitalbased nurses. Journal of Organizational Change Management, 17(2), 211-227.

Balogun, J. (2003). From blaming the middle to harnessing its potential: Creating change intermediaries. British Journal of Management, 14(1), 69-83.

Balogun, J. (2006). Managing change: Steering a course between intended strategies and unanticipated outcomes. Long Range Planning, 39(1), 29-49. 
Balogun, J., Bartunek, J. M., \& Do, B. (2015). Senior managers' sensemaking and responses to strategic change. Organization Science, 26(4), 960-979.

Balogun, J., \& Johnson, G. (2004). Organizational restructuring and middle manager sensemaking. Academy of Management Journal, 47(4), 523-549.

Balogun, J., \& Johnson, G. (2005). From intended strategies to unintended outcomes: The impact of change recipient sensemaking. Organization studies, 26(11), 15731601.

Balogun, J., Jacobs, C., Jarzabkowski, P., Mantere, S., \& Vaara, E. (2014). Placing strategy discourse in context: Sociomateriality, sensemaking, and power. Journal of Management Studies, 51(2), 175-201.

Bartunek, J. M., Balogun, J., \& Do, B. (2011). Considering planned change anew: Stretching large group interventions strategically, emotionally, and meaningfully. Academy Of Management Annals, 5(1), 1-52.

Bartunek, J. M., Rousseau, D. M., Rudolph, J. W., \& DePalma, J. A. (2006). On the receiving end sensemaking, emotion, and assessments of an organizational change initiated by others. Journal of Applied Behavioral Science, 42(2), 182-206.

Bean, C. J., \& Eisenberg, E. M. (2006). Employee sensemaking in the transition to nomadic work. Journal of Organizational Change Management, 19(2), 210-222.

Bean, C. J., \& Hamilton, F. E. (2006). Leader framing and follower sensemaking: Response to downsizing in the brave new workplace. Human Relations, 59(3), 321-349. 
Beech, N., \& Johnson, P. (2005). Discourses of disrupted identities in the practice of strategic change: The mayor, the street-fighter and the insider-out. Journal of Organizational Change Management, 18(1), 31-47.

Boeker, W. (1997). Strategic change: The influence of managerial characteristics and organizational growth. Academy of Management Journal, 40(1), 152-170.

Bouckenooghe, D. (2010). Positioning change recipients' attitudes toward change in the organizational change literature. Journal of Applied Behavioral Science, 46(4), $500-531$.

Brown, a. D., Colville, I., \& Pye, A. (2014). Making sense of sensemaking in organization studies. Organization Studies, 36(2), 265-277.

Brown, A. D., Gabriel, Y., \& Gherardi, S. (2009). Storytelling and change: An unfolding story. Organization, 16(3), 323-333.

Brown, A.D., \& Humphreys, M. (2003). Epic and tragic tales: Making sense of change. Journal of Applied Behavioral Science, 39(2), 121-144.

Burke, W., Lake, D., \& Paine,J. (2009). Preface, in Organisation change: A comprehensive reader:,(pp. xv-xvii). San Francisco, CA: Jossey-Bass.

Burnes, B. (2004). Kurt Lewin and the planned approach to change: A reappraisal. Journal of Management Studies, 41(6), 977-1002.

Burnes, B. (2009). Managing Change, (5th edn) London: FT/Prentice Hall.

Burnes, B., \& Cooke, B. (2012). The past, present and future of organization development: Taking the long view. Human Relations, 65(11), 1395-1429.

By, R. T., Burnes, B., \& Oswick, C. (2011). Change management: The road ahead. Journal of Change Management, 11(1), 1-6. 
Callan, V. J., Gallois, C., Mayhew, M. G., Grice, T. A., Tluchowska, M., \&Boyce, R. (2007). Restructuring the multi-professional organization: professional identity and adjustment to change in a public hospital. Journal of Health and Human Services Administration, 448-77.

Canadian Institute for Health Information (CIHI) (2009). Healthcare in Canada. Retrieved from http://secure.cihi.ca/cihiweb/products/HCIC_2009_Web_e.pdf.

Carver, C. S., \& Scheier, M. F. (2011). Self-regulation of action and affect. In K. D. Vohs \& R. F. Baumeister (Eds.), Handbook of self-regulation: Research, theory, and applications (2nd ed., pp. 3-21). New York, NY: Guilford.

Cederlund, C. (2015). Managing meaning in complex business networks. Industrial Marketing Management, 48, 89-100.

Charmaz, K. (2000). Grounded theory methodology: Objectivist and constructivist qualitative methods, In N. K. Denzin and Y. Lincoln (ed.) Handbook of Qualitative Research 2nd ed., (pp. 509-535). Thousand Oaks, CA: Sage.

Charmaz, K. (2006). Constructing grounded theory: A practical guide through qualitative analysis. California: Sage.

Charmaz, K. (2009). Shifting the grounds: Grounded theory in the 21 st century. In J.M .Morse (Ed.). Developing grounded theory: The second generation, (pp. 125140). California: Left Coast Press.

Chaudhry, A., Coyle-Shapiro, J. A., \& Wayne, S. J. (2011). A longitudinal study of the impact of organizational change on transactional, telational, and balanced psychological contracts. Journal of Leadership \& Organizational Studies, 18(2), 247-259. 
Chaudhry, A., Wayne, S. J., \& Schalk, R. (2009). A sensemaking model of employee evaluation of psychological contract fulfillment: When and how do employees respond to change? Journal of Applied Behavioral Science, 45(4), 498-520.

Chreim, S. (2006). Postscript to change: Survivors' retrospective views of organizational changes. Personnel Review, 35(3), 315-335.

Chreim, S., \& Tafaghod, M. (2012). Contradiction and sensemaking in acquisition integration. Journal of Applied Behavioral Science, 48(1), 5-32.

Choi, M. (2011). Employees' attitudes toward organizational change: A literature review. Human Resource Management, 50(4), 479-500.

Clayton, S. (2015, November 10). Change management meets social media. Harvard Business Review Online. Retrieved from: https://hbr.org/2015/11/changemanagement-meets-social-media

Collins, H. (2004). Interactional expertise as a third kind of knowledge. Phenomenology and the Cognitive Sciences, 3(2), 125-143.

Choi, M. (2011). Employees' attitudes toward organizational change: A literature review. Human Resource Management, 50(4), 479-500.

Clayton, S. (2015, November 10). Change management meets social media. Harvard Business Review Online. Retrieved from: https://hbr.org/2015/11/changemanagement-meets-social-media

Collins, H. (2004). Interactional expertise as a third kind of knowledge. Phenomenology and the Cognitive Sciences, 3(2), 125-143. 
Connor-Smith, J. K., \& Flachsbart, C. (2007). Relations between personality and coping: A meta-analysis. Journal of Personality and Social Psychology, 93(6), 1080-1107.

Corley, K. \& Gioia, D. (2004). Identity ambiguity and change in the wake of a corporate spin-off. Administrative Science Quarterly, 49, 173-208.

Creswell, J. (1998). Qualitative inquiry and research design: Choosing among five traditions. Thousand Oaks, CA: Sage.

Das, T. K., \& Kumar, R. (2010). Interpartner sensemaking in strategic alliances: Managing cultural differences and internal tensions. Management Decision, 48(1), 17-36.

Dawson, R. (2000). Knowledge capabilities as the focus of organisational development and strategy. Journal of Knowledge Management, 4(4), 320-327.

Dawson, P., Sykes, C., McLean, P., Zanko, M., \& Marciano, H. (2014). Stories affording new pathways: Bridging the divide between aged and disability care. Journal of Organizational Change Management, 27(5), 819-838.

Denison, D.R. (1996). What is the difference between organizational culture and organizational climate? A native's point of view on a decade of paradigm wars. Academy of Management Review, 21(3), 619-654.

Denzin, N.K., \& Lincoln, Y.S. (Eds.). (2011). Handbook of qualitative research, 4th Ed. Thousand Oaks, CA: Sage.

Dunford, R., \& Jones, D. (2000). Narrative in stractegic change. Human Relations, 53(9), $1207-1226$. 
Dutton, J. E., Ashford, S. J., O'Neill, R. M., \& Lawrence, K. A. (2001). Moves that matter: Issue selling and organizational change. Academy of Management Journal, 44(4), 716-736.

Eisenhardt, K. M. (1989). Building theories from case study research. Academy of Management Review, 14(4), 532-550.

Fendt, J., \& Sachs, W. (2008). Grounded theory method in management research: Users' perspectives. Organizational Research Methods, 11(3), 430-455.

Fisher, K., \& Hutchings, K. (2013). Making sense of cultural distance for military expatriates operating in an extreme context. Journal of Organizational Behavior, 34(6), 791-812.

Fontana, A., \& Frey, J. H. (2005). The interview: From neutral stance to political involvement, In N. K. Denzin \& Y. S. Lincoln (Eds.), The Sage handbook of qualitative research (3rd Ed.), (pp. 695-727). Thousand Oaks, CA: Sage.

Ford, J.D., Ford, L.W., \& D'Amelio, A. (2008). Resistance to change: The rest of the story. Academy of Management Review, 33(2), 362-377.

Fugate, M., Harrison, S., \& Kinicki, A. J. (2011). Thoughts and feelings about organizational change: A field test of appraisal theory. Journal of Leadership \& Organizational Studies, 18(4), 421-437.

Fugate, M., Kinicki, A. J., \& Prussia, G. E. (2008). Employee coping with organizational change: An examination of alternative theoretical perspectives and models. Personnel Psychology, 61(1), 1-36.

Fugate, M., Kinicki, A. J., \& Scheck, C. L. (2002). Coping with an organizational merger over four stages. Personnel Psychology, 55(4), 905-928. 
Gazi, I. (2013). Finding a space for story: sensemaking, stories and epistemic impasse. Journal of Organizational Change Management, 26(1), 29-48.

Gephart, J. J., Harrison, D. A., \& Trevino, L. K. (2010). Bad apples, bad cases, and bad barrels: Meta-analytic evidence about sources of unethical decisions at work. Journal of Applied Psychology, 95(1), 1-31.

Gioia, D. A., \& Chittipeddi, K. (1991). Sensemaking and sensegiving in strategic change initiation. Strategic Management Journal, 12, 433-448.

Gioia, D. A., \& Thomas, J. B. (1996). Identity, image and issue interpretation: Sense making during strategic change in academia. Administrative Science Quarterly, 41(3), 370-403.

Gioia, D. A., Thomas, J. B., Clark, S. M., \& Chittipeddi, K. (1994). Symbolism and strategic change in academia: The dynamics of sensemaking and influence. Organization Science, 5, 363-383.

Gioia, D.A., Schultz, M., \& Corley, K.G. (2012). Organizational identity, image and adaptive instability. Academy of Management Review, 25, 63-81.

Gioia, D. A., Corley, K. G., \& Hamilton, A. L. (2013). Seeking qualitative rigor in inductive research notes on the Gioia methodology. Organizational Research Methods, 16(1), 15-31.

Glaser, B., \& Strauss, A. (1967). The discovery of grounded theory. Chicago, IL: Aldine. Goulding, C. (2002). Grounded theory: A practical guide for management, business and market researchers. Thousand Oaks, California: Sage.

Gover, L., \& Duxbury, L. (2012). Organizational faultlines: Social identity dynamics and organizational change. Journal of Change Management, 12(1), 53-75. 
Government of Ontario (2012). Ontario's action plan for health care (ISBN 978-1-44358942-0). Queen's Printer for Ontario. Ministry of Health and Long Term Care.

Grant, A. M., Dutton, J. E., \& Rosso, B. D. (2008). Giving commitment: Employee support programs and the prosocial sensemaking process. Academy of Management Journal, 51(5), 898-918.

Greenberg, D. N. (1995). Blue versus gray: A metaphor constraining sensemaking around a restructuring. Group \& Organization Management, 20(2), 183-209.

Guiette, A., \& Vandenbempt, K. (2013). Exploring team mental model dynamics during strategic change implementation in professional service organizations: A sensemaking perspective. European Management Journal, 31(6), 728-744.

Gulati, R. (2007). Tent poles, tribalism, and boundary spanning: The rigor-relevance debate in management research. Academy of Management Journal, 50(4), 775782.

Hall W.A., \& Callery P. (2001). Enhancing the rigor of grounded theory: incorporating reflexivity and relationality. Qualitative Health Research, 11(2), 257-272.

Hansson, A.S., Vingard, E., Arnetz, B., \& Anderzen, I. (2008). Organizational change, health, and sick leave among health care employees: A longitudinal study measuring stress markers, individual, and work site factors. Work \& Stress, 22(1), 69-80.

Haselton, M., Nettle, D., \& Murray, D.R. (2015). The evolution of cognitive bias. In D. Buss (ed.) The Handbook of Evolutionary Psychology, (2 $\left.{ }^{\text {nd }} e d n\right)$, (pp. 968-987). New Jersey: Wiley. 
Heider, F. (2013). The psychology of interpersonal relations. Oxford, England: The Psychology Press, Taylor and Francis.

Hensmans, M. (2015). The Trojan horse mechanism and reciprocal sense-giving to urgent strategic change. Journal of Organizational Change Management, 28(6), 10381075.

Heracleous, L., \& Barrett, M. (2001). Organizational change as discourse:

Communicative actions and deep structures in the context of information technology implementation. Academy of Management Journal, 44(4), 755-778.

Hernes, T., Hendrup, E., \& Schäffner, B. (2015). Sensing the momentum: A process view of change in a multinational corporation. Journal of Change Management, 15(2), 117-141.

Hodgkinson, G. P., \& Healey, M. P. (2008). Cognition in organizations. Annual Review of Psychology, 59, 387-417.

Hope, O. (2010). The politics of middle management sensemaking and sensegiving. Journal of Change Management, 10(2), 195-215.

Hotho, S. (2008). Professional identity - product of structure, product of choice: Linking changing professional identity and changing professions. Journal of Organizational Change Management, 21(6), 721-742.

Huber, G.P., Sutcliffe, K.M., Miller, C.C., \& Glick, W.H. (1993). Understanding and predicting organizational change. In G.P. Huber and W.H Glick’s (eds.) Organizational change and redesign (pp. 215-265). New York: Oxford University Press. 
Isabella, L. A. (1990). Evolving interpretations as a change unfolds: How managers construe key organizational events. Academy of Management Journal, 33(1), 741.

Judge, T. A., Thoresen, C. J., Pucik, V., \& Welbourne, T. M. (1999). Managerial coping with organizational change: A dispositional perspective. Journal of Applied Psychology, 84(1), 107-122.

Kaplan, S. (2008). Framing contests: Strategy making under uncertainty. Organization Science, 19(5), 729-752.

Katz, R. (1982). The effects of group longevity on project communication and performance. Administrative Science Quarterly, 27, 8-104.

Kaur, K., Forducey, P.G., Smith, L., \& Scheideman-Miller, C. (2004). Organisational design and implementation of a tele-rehabilitation system in Oklahoma. International Journal of Healthcare Technology \& Management, 6(1), 1-1.

Keil, M., Depledge, G., \& Rai, A. (2007). Escalation: The role of problem recognition and cognitive bias. Decision Sciences, 38(3), 391-421.

Kennedy, M. T. (2008). Getting counted: Markets, media, and reality. American Sociological Review, 73(2), 270-295.

Kezar, A. (2013). Understanding sensemaking/sensegiving in transformational change processes from the bottom up. Higher Education, 65(6), 761-780.

Kiefer, T. (2002). Understanding the emotional experience of organizational change: Evidence from a merger. Advances in Developing Human Resources, 4(1), 39-61. 
Klarner, P., By, R. T., \& Diefenbach, T. (2011). Employee emotions during organizational change-Towards a new research agenda. Scandinavian Journal of Management, 27(3), 332-340.

Klein, K. J., Conn, A. B., Smith, D. B., \& Sorra, J. S. (2001). Is everyone in agreement? An exploration of within-group agreement in employee perceptions of the work environment. Journal of Applied Psychology, 86(1), 3-16.

Kottak, C. (2006). Mirror for Humanity. McGraw-Hill: New York.

Kuntz, J. R., \& Gomes, J. F. (2012). Transformational change in organisations: A selfregulation approach. Journal of Organizational Change Management, 25(1), 143 162.

Kraft, A., Sparr, J. L., \& Peus, C. (2015). The ritical role of moderators in leader sensegiving: A literature review. Journal of Change Management, 15(4), 308-331.

Kreindler, S.A., Down, D.A., Star, N.D., \& Gottschalk, T. (2012). Silos and social identity: The social identity approach as a framework for understanding and overcoming divisions in health care. The Milbank Quarterly, 90(2), 347-374.

Kruglanski, A. W., Pierro, A., Higgins, E. T., \& Capozza, D. (2007). “On the Move” or "Staying Put": Locomotion, need for closure, and reactions to organizational change. Journal of Applied Social Psychology, 37(6), 1305-1340.

Kyriakidou, O. (2011). Relational perspectives on the construction of meaning: A network model of change interpretation. Journal of Organizational Change Management, 24(5), 572-592.

Landau, D., \& Drori, I. (2008). Narratives as sensemaking accounts: The case of an R\&D laboratory. Journal of Organizational Change Management, 21(6), 701-720. 
Langley, A. (1999) Strategies for theorizing from process data. Academy of Management Review, 24(4), 691-710.

Langley, A. N. N., Smallman, C., Tsoukas, H., \& Van de Ven, A. H. (2013). Process studies of change in organization and management: unveiling temporality, activity, and flow. Academy of Management Journal, 56(1), 1-13.

Langley, A., \& Abdallah, C. (2011). Templates and turns in qualitative studies of strategy and management. In Donald D. Bergh, David J. Ketchen (ed.) Building Methodological Bridges (Research Methodology in Strategy and Management, Volume 6)(pp. 201-235), Emerald Group Publishing Limited.

Lattuch, F., \& Young, S. (2011). Young professionals' perceptions toward organizational change. Leadership \& Organization Development Journal, 32(6), 605-627.

Lawrence, S. A., \& Callan, V. J. (2011). The role of social support in coping during the anticipatory stage of organizational change: A test of an integrative model. British Journal of Management, 22(4), 567-585.

Lazarus, R. S., \& Folkman, S. (1984). Stress, appraisal, and coping. Springer publishing company.

Lazarus, R. S. (1995). Psychological stress in the workplace. Occupational stress: A handbook, 1, 3-14.

Lee, A. S., \& Baskerville, R. L. (2012). Conceptualizing generalizability: New contributions and a reply. MIS quarterly, 36(3), 749-761.

Lee, S. Y. D., Weiner, B. J., Harrison, M. I., \& Belden, C. M. (2013). Organizational transformation a systematic review of empirical research in health care and other industries. Medical Care Research and Review, 70(2), 115-142. 
Lincoln, T. S., \& Guba, E. G. (1985). Naturalistic Inquiry. Beverly Hills, CA: Sage.

Lincoln, Y.S., Guba, E.G., \& Lynham, S.A. (2011). Paradigmatic controversies, contradictions and emerging confluences, revisited, In N.K Denzin \& Y.S. Lincoln, Eds. Sage Handbook of Qualitative Research, 4th Edition. Thousand Oaks, CA: Sage.

Locke, K. (1996). Rewriting the discovery of grounded theory after 25 years? Journal of Management Inquiry, 5(3), 239-245.

Locke, K. M. (2001). Grounded theory in management research. Thousand Oaks, CA: Sage.

Lockett, A., Currie, G., Finn, R., Martin, G., \& Waring, J. (2014). The influence of social position on sensemaking about organizational change. Academy of Management Journal, 57(4), 1102-1129.

Lowe, A. (2001). Casemix accounting systems and medical coding. Journal of Organizational Change Management, 14(1), 79-101.

Luscher, L. S., \& Lewis, M. W. (2008). Organizational change and managerial sensemaking: Working through paradox. Academy of Management Journal, 51(2), 221-240.

Maclean, M., Harvey, C., Sillince, J., \& Golant, B. D. (2014). Living up to the past? Ideological sensemaking in organizational transition. Organization, 21(4), 543567.

Maitlis, S., \& Christianson, M. (2014). Sensemaking in organizations: Taking stock and moving forward. The Academy of Management Annals, 8(1), 57-125. 
Maitlis, S., \& Sonenshein, S. (2010). Sensemaking in crisis and change: Inspiration and insights from Weick (1988). Journal of Management Studies, 47(3), 551-580.

Marmenout, K. (2010). Employee Sensemaking in Mergers: How Deal Characteristics Shape Employee Attitudes. The Journal of Applied Behavioral Science, 46(3), 329-359.

Marshak, R.J. (2002). Changing the language of change: How new contexts and concepts are challenging the ways we think and talk about organizational change. Strategic Change, 11, 279-286.

Mason, M. (2010). Sample size and saturation in PhD studies using qualitative interviews. Qualitative Social Research, 11(3). Retrieved from http://www.qualitative-research.net/index.php/fqs/article/view/1428/3027

Mezias, J. M., \& Starbuck, W. H. (2003). Studying the accuracy of managers' perceptions: A research odyssey. British Journal of Management, 14(1), 3-17.

Mezias, J., Grinyer, P., \& Guth, W. D. (2001). Changing collective cognition: A process model for strategic change. Long Range Planning, 34(1), 71-95.

Miles, M. B., \& Huberman, A. M. (1994). Qualitative data analysis: An expanded sourcebook. Sage.

Mishra, A. K., \& Spreitzer, G. M. (1998). Explaining how survivors respond to downsizing: The roles of trust, empowerment, justice, and work redesign. Academy of Management Review, 23(3), 567-588.

Monin, P., Noorderhaven, N., Vaara, E., \& Kroon, D. (2013). Giving sense to and making sense of justice in postmerger integration. Academy of Management Journal, 56(1), 256-284. 
Moon, M. Y. (2009). Making sense of common sense for change management buy-in. Management Decision, 47(3), 518-532.

Moos, R. H., \& Billings, A. G. (1982). Conceptualizing and measuring coping resources and processes. In L. Goldberger \& S. Breznitz (Eds.). Handbook of stress: Theoretical and clinical aspects, (pp. 212-230). New York: Free Press.

Morgan, G., \& Smircich, L. (1980). The case for qualitative research. Academy of Management Review, 5(4), 491-500.

Morris, M.W., Kwok, L., Ames, D. \& Lickel, B. (1999). Views from inside and outside: Integrating emic and etic insights about culture and justice judgment. Academy of Management Review, 24(4), 781-796.

Morrison, E. W., \& Milliken, F. J. (2000). Organizational silence: A barrier to change and development in a pluralistic world. Academy of Management review, 25(4), 706-725.

Morse, J., Noerager Stern, P., Corbin, J., Bowers, B., Charmaz, K., \& Clarke, A. (2009). Developing grounded theory. Walnut Creek, CA: Left Coast Press.

Morse, J.M. (1994). Designing funded qualitative research. In Norman K. Denzin \& Yvonna S. Lincoln's (Eds.), Handbook of qualitative research (2nd ed.) (pp.22035). Thousand Oaks, CA: Sage.

Myers, M. D. (2009). Qualitative Research in Business and Management. Sage.

Nadler, D., \& Tushman, M. (1989). Organisational framebending. Academy of Management Executive, 3, 194-202. 
Ng, K., \& Hase, S. (2008). Grounded suggestions for doing a grounded theory business research. Electronic Journal of Business Research Methods , 6(2), 155-170.

Nicolini, D. (2007). Stretching out and expanding work practices in time and space: The case of telemedicine. Human Relations, 60(6), 889-920.

Nigam, A., \& Ocasio, W. (2010). Event attention, environmental sensemaking, and change in institutional logics: An inductive analysis of the effects of public attention to Clinton's health care reform initiative. Organization Science, 21(4), $823-841$.

Oreg, S., Vakola, M., \& Armenakis, A. (2011). Change recipients' reactions to organizational change A 60 -year review of quantitative studies. The Journal of Applied Behavioral Science, 47(4), 461-524.

Oswick, C., Grant, D., Michelson, G., \& Wailes, N. (2005). Looking forwards: discursive directions in organizational change. Journal of Organizational Change Management, 18(4), 383-390.

Payne, R. L., Pugh, D. S., \& Dunnette, M. (1976). Handbook of industrial and organizational psychology. Chicago, IL: Rand McNally.

Pettigrew, A. M. (1990). Longitudinal field research on change: Theory and practice. Organization Science, 1(3), 267-292.

Pratt, M. G. (2000). The good, the bad, and the ambivalent: Managing identification among Amway distributors. Administrative Science Quarterly, 45(3), 456-493.

Pratt, M. G. (2008). Fitting oval pegs into round holes: Tensions in evaluating and publishing qualitative research in top-tier North American journals. Organizational Research Methods, 11(3), 481-509. 
Rafferty, A. E., \& Griffin, M. A. (2006). Perceptions of organizational change: A stress and coping perspective. Journal of Applied Psychology, 91(5), 1154-1162.

Ran, B., \& Golden, T. J. (2011). Who are we? The social construction of organizational identity through sense-exchanging. Administration \& Society, 43(4): 417-445.

Rauschenbach, C., Krumm, S., Thielgen, M., \& Hertel, G. (2013). Age and work-related stress: A review and meta-analysis. Journal of Managerial Psychology, 28(7/8), 781-804.

Reissner, S. (2010). Change, meaning and identity at the workplace. Journal of Organizational Change Management, 23(3), 287-299.

Reissner, S. C. (2011). Patterns of stories of organisational change. Journal of Organizational Change Management, 24(5), 593-609.

Ridley, D. (2012). The literature review: A step-by-step guide for students. Sage.

Riesenmy, K. R. (2010). Physician sensemaking and readiness for electronic medical records. The Learning Organization, 17(2), 163-177.

Riolli, L., \& Savicki, V. (2006). Impact of fairness, leadership, and coping on strain, burnout, and turnover in organizational change. International Journal of Stress Management, 13(3), 351-377.

Robinson, O., \& Griffiths, A. (2005). Coping with the stress of transformational change in a government department. Journal of Applied Behavioral Science, 41(2), 204221.

Romanow, R. (2002). Building on values: The future of healthcare in Canada (ISBN: 0662-33043-9). Canada: Government of Canada Publications. 
Romanow, R. (2007). Canada's health temperature. Justice Emmet Hall Memorial Lecture. Presentation to the National Healthcare Leadership Conference, Toronto, Canada.

Rotter, J. B. (1966). Generalized expectancies for internal versus external control of reinforcement. Psychological monographs: General and applied, 80(1), 1-28.

Rouleau, L. (2005). Micro-practices of strategic sensemaking and sensegiving: How middle managers interpret and sell change every day. Journal of Management Studies, 42(7), 1413-1441.

Rouleau, L., \& Balogun, J. (2011). Middle managers, strategic sensemaking, and discursive competence. Journal of Management Studies, 48(5), 953-983.

Sandberg, J., \& Tsoukas, H. (2015). Making sense of the sensemaking perspective: Its constituents, limitations, and opportunities for further development. Journal of Organizational Behavior, 36(S1), S6-S32.

Savall, H., Zardet, V., Bonnet, M., \& Peron, M. (2008). The emergence of implicit criteria actually used by reviewers of qualitative research articles: Case of a European journal. Organizational Research Methods , 11 (3), 510-540.

Senturia, T., Flees, L., \& Maceda, M. (2008). Leading change management requires sticking to the PLOT. London: Bain \& Company.

Shah, S. K., \& Corley, K. G. (2006). Building better theory by bridging the quantitativequalitative divide. Journal of Management Studies, 43(8), 1821-1835.

Sharma, G., \& Good, D. (2013). The work of middle managers: Sensemaking and sensegiving for creating positive social change. Journal of Applied Behavioral Science, 49(1), 95-122. 
Shepherd, D. A., Patzelt, H., \& Wolfe, M. (2011). Moving forward from project failure: Negative emotions, affective commitment, and learning from the experience. Academy of Management Journal, 54(6), 1229-1259.

Sinkovics, R. R., Penz, E., \& Ghauri, P. N. (2008). Enhancing the trustworthiness of qualitative research in international business. Management International Review, $48(6), 689-714$.

Smith, M.E. (2003). Changing an organisations culture: Correlates of success and failure. Leadership \& Organization Development Journal, 24(5): 249-261.

Smollan, R. K. (2014). The emotional dimensions of metaphors of change. Journal of Managerial Psychology, 29(7), 794-807.

Smollan, R. K. (2015). Causes of stress before, during and after organizational change: a qualitative study. Journal of Organizational Change Management, 28(2), 301-314.

Sonenshein, S. (2009). Emergence of ethical issues during strategic change implementation. Organization Science, 20(1), 223-239.

Sonenshein, S. (2010). We're changing-Or are we? Untangling the role of progressive, regressive, and stability narratives during strategic change implementation. Academy of Management Journal, 53(3), 477-512.

Spratt, A.D., \& Dickson, K.E. (2008). Change factors affecting the transition to an EMR system in a private physicians' practice: An exploratory study. Academy of Health Care Management Journal, 4(2), 41-88.

Statistics Canada (2012). The Canadian Population in 2011: Age and Sex (ISBN: 978-1100-20670-7). Ottawa, ON: Statistics Canada. Retrieved July 13, 2012 from: 
http://www12.statcan.gc.ca/census-recensement/2011/as-sa/98-311-x/98-311x2011001-eng.cfm\#a2

Statistics Canada, (2010). Healthy people, healthy places (ISBN:978-1-100-14436-8).

Ottawa, ON: Statistics Canada. Retrieved April 10, 2012 from: http://www.statcan.gc.ca/pub/82-229-x/2009001/demo/int1-eng.htm

Steigenberger, N. (2015). Emotions in sensemaking: A change management perspective. Journal of Organizational Change Management, 28(3), 432-451.

Stensaker, I., \& Falkenberg, J. (2007). Making sense of different responses to corporate change. Human Relations, 60(1), 137-177.

Stensaker, I. G., \& Meyer, C. B. (2011). Change experience and employee reactions: Developing capabilities for change. Personnel Review, 41(1), 106-124.

Stensaker, I. G., \& Meyer, C. B. (2012). Change experience and employee reactions: Developing capabilities for change. Personnel Review, 41(1), 106-124.

Stensaker, I., Falkenberg, J., \& Gronhaug, K. (2008). Implementation activities and organizational sensemaking. Journal of Applied Behavioral Science, 44(2), $162-$ 185.

Stensaker, I., Meyer, C. B., Falkenberg, J., \& Haueng, A. C. (2003). Excessive change: Coping mechanisms and consequences. Organizational Dynamics, 31(3), 296312.

Stensaker, I., Meyer, C., Falkenberg, J., \& Haueng, A. C. (2001, August). Excessive change. In Academy of Management Proceedings (Vol. 2001, No. 1, pp. G1-G6). Academy of Management. 
Strauss, A., \& Corbin, J. (1990). Basics of qualitative research: Grounded theory procedures and techniques. Newbury Park, CA: Sage.

Terry, D.J., \& Callan, V.J. (1998). In-group bias in response to an organizational merger. Group Dynamics: Theory, Research, and Practice, 2(2), 67-81.

Teo, S. T., Pick, D., Newton, C. J., Yeung, M. E., \& Chang, E. (2013). Organisational change stressors and nursing job satisfaction: The mediating effect of coping strategies. Journal of Nursing Management, 21(6), 878-887.

Teulier, R., \& Rouleau, L. (2013). Middle managers' sensemaking and interorganizational change initiation: Translation spaces and editing practices. Journal of Change Management, 13(3), 308-337.

Thomas, R., \& Dunkerley, D. (1999). Careering downwards? Middle managers' experiences in the downsized organization. British Journal of Management, 10(2), 157-169.

Thomas, J. B., Clark, S. M., \& Gioia, D. A. (1993). Strategic sensemaking and organizational performance: Linkages among scanning, interpretation, action, and outcomes. Academy of Management Journal, 36(2), 239-270.

Thurlow, A., \& Helms-Mills, J. H. (2009). Change, talk and sensemaking. Journal of Organizational Change Management, 22(5), 459-479.

Tsoukas, H., \& Chia, R. (2002). On organizational becoming: Rethinking organizational change. Organization Science, 13 (5): 567-582.

Vaara, E., \& Monin, P. (2010). A recursive perspective on discursive legitimation and organizational action in mergers and acquisitions. Organization Science, 21(1), 322. 
Valle Santos, M., \& Teresa Garcia, M. (2006). Organizational change: The role of managers' mental models. Journal of Change Management, 6(3), 305-320.

Van de Ven, A. H., \& Sun, K. (2011). Breakdowns in implementing models of organization change. Academy of Management Perspectives, 25(3), 58-74.

Van de Ven, A.H., \& Poole, M.S. (2005). Alternative approaches for studying organizational change. Organization Studies, 26(9), 1377-1404.

Van der Heijden, A., Cramer, J. M., \& Driessen, P. P. J. (2012). Change agent sensemaking for sustainability in a multinational subsidiary. Journal of Organizational Change Management, 25(4), 535-559.

Van Dijk, R., \& Van dick, R. (2009). Navigating organizational change: Change leaders, employee resistance and work-based identities. Journal of Change Management, $9(2), 143-163$.

Van Vuuren, M., \& Elving, W. J. L. (2008). Communication, sensemaking and change as a chord of three strands: Practical implications and a research agenda for communicating organizational change. Corporate Communications: An International Journal, 13(3), 349-359.

Vlaar, P. W., van Fenema, P. C., \& Tiwari, V. (2008). Cocreating understanding and value in distributed work: How members of onsite and offshore vendor teams give, make, demand, and break sense. MIS quarterly, 32(2), 227-255.

Wagner, S. M., Lukassen, P., \& Mahlendorf, M. (2010). Misused and missed use Grounded thoery and objective hermeneutics as methods for research in industrial marketing. Industrial Marketing Management , 39, 5-15. 
Weber, P. S., \& Manning, M. R. (2001). Cause maps, sensemaking, and planned organizational change. Journal of Applied Behavioral Science, 37(2), 227-251.

Weick, K. E. (1969). The social psychology of organizing. Reading, MA: AddisonWesley.

Weick, K. (1995). Sense-making in organizations. Thousand Oaks, CA: Sage.

Weick, K. E. (1988). Enacted sensemaking in crisis situations (p. 306). National Emergency Training Center.

Weick, K. E. (2010). Reflections on enacted sensemaking in the Bhopal disaster. Journal of Management Studies, 47(3), 537-550.

Weick, K. E. (2011). Reflections: Change Agents As Change Poets - On Reconnecting Flux and Hunches. Journal Of Change Management, 11(1), 7-20.

Weick, K.E., Sutcliffe, K.M., \& Obstfeld, D. (2005). Organizing and the process of sensemaking. Organization Science, 16(4), 409-421.

Wetzel, R., \& Dievernich, F. E. (2014). Mind the gap. The relevance of postchange periods for organizational sensemaking. Systems Research and Behavioral Science, 31(2), 280-300.

Wheatley, M. (1992). Leadership and the new science. San Francisco: Berrett-Koehler.

Whelan-Berry, K. S., Gordon, J. R., \& Hinings, C. B. (2003). Strengthening organizational change processes recommendations and implications from a multilevel analysis. Journal of Applied Behavioral Science, 39(2), 186-207.

Whiteman, G., \& Cooper, W. H. (2011). Ecological sensemaking. Academy of Management Journal, 54(5), 889-911. 
Wright, C. R., Manning, M. R., Farmer, B., \& Gilbreath, B. (2000). Resourceful sensemaking in product development teams. Organization Studies, 21(4), 807825.

Wrzesniewski, A., Dutton, J. E., \& Debebe, G. (2003). Interpersonal sensemaking and the meaning of work. Research in Organizational Behavior, 25, 93-135.

Yin, R. K. (2009). Case study research: design and methods. Sage.

Zeytinoglu, I.U., Denton, M., Davies, S., Baumann, A., Blythe, J., \& Boos, L. (2007). Associations between work intensification, stress and job satisfaction: The case of nurses in Ontario. Industrial Relations, 62(2), 201-225. 


\section{Appendix A: T1 Interview Script}

\section{Preamble}

Thanks again for agreeing to take part in this follow up study. Just as a reminder, this study is a follow up to the previous study in which you participated, and looks specifically how the organization can effectively transition to the new workplace and continue to be a place where people are proud to work. The interview today will be audio taped to support the analysis of the data. Audio files will be stored on a password protected PC and will be deleted once the data has been coded and analyzed. Names and other identifying information will not be recorded or shared with the funder (Community Hospital). You will only be identified by a code number assigned to you. Are you happy to go ahead?

If they are unhappy, try to identify and allay their concerns. If you cannot, end the interview and thank them for their time.

\section{Turn on the recorder and ask again.}

For the benefit of the recording can I ask you to confirm that you are happy to proceed with the interview.

\section{Background Information}

The first couple of questions give us some background information on you and what you do at work. This information will give us the context to help us interpret the data.

1. BRIEFLY describe your role at work. [Get enough information so we can put them into one of the seven groups, and then sub categorize... i.e. where I the hospital do they work? What is their actual job entail.]

Groups $=\quad$ (1) Medical Leaders and Senior Managers,

(2) Physicians, Dentists, Midwives,

(3) RNs,

(4) RPNs,

(5) Professional Clinical Support (Pharmacy, Physiotherapy and Diagnostic Imaging),

(6) Other Clinical Support (Front line patient/family interaction - Ward

Clerk, Business Unit Clerks, Medical Records, Finance Clerks, Staffing

Clerks, Food Services, Central Sterilization Room), and

(7) Corporate and Facility Support (Housekeeping, Plant maintenance and operation Materials Management, Human Resources, Finance, Administrative Assistants).

2. How long have you been in this role? Years

3. What percentage of your typical work day is spent dealing with patients? $\%$

4. How many other hospitals have you worked for before Community Hospital? Number

5. Generational cohort... ask them if they are a Boomer (1947-1964), Generation X (19651980) and Generation Y (1981 or later) 


\section{Section One: Working at Community Hospital}

This first set of questions will focus on your experiences working for Community Hospital.

1. First, I am interested in what initially attracted you to work for Community Hospital. Specifically, why did you take a job with the hospital?

2. In retrospect,

a. How happy are you with your decision to work for Community Hospital?

Ask them to use a scale to indicate their level of happiness where 5 is very happy, 4 is happy, 3 indicates a mixed opinion, happy about some things, unhappy about others, 2 is unhappy, and 1 is very unhappy

Specifically,

b. What do you consider to be the most rewarding aspect of your work at Community Hospital? Why do you say this? (Prompts: the work itself, pay and benefits, colleagues....).

c. What do you consider to be the most frustrating aspect of your work at Community Hospital? Why do you say this? (Prompts: work expectations, your immediate supervisor)

3. Overall, how satisfied would you say you are with the work environment at Community Hospital?

Ask them to use a scale to indicate their level of satisfaction where 5 is very satisfied, 4 is satisfied, 3 indicates a mixed opinion, satisfied about some things, dissatisfied with others, 2 is dissatisfied, and 1 is very dissatisfied

Specifically,

a. What aspects of your work environment do you find satisfying?

b. What aspects of your work environment do you consider to be frustrating?

c. Is there anything that the hospital could do to increase your feelings of satisfaction with the work environment within Community Hospital?

4. Why do you remain at Community Hospital? (Prompts: the work, the compensation, the job security)

5. Can you give me an example of a case where Community Hospital met (or exceeded) your expectations? What did they do? How did this make you feel?

6. Can you give me an example of a case where Community Hospital did not live up to your expectations? What did they do? How did this make you feel?

7. What, if anything, can the hospital do: 
a. $\quad$ to help you do your job better? (Prompts: communication, resources .... )

b. to make Community Hospital a better place to work (i.e. communication, resources, training)

The last several questions in this section of the interview focus on stress within the workplace and what causes you to feel stressed

8. What things about your job cause you to feel stressed?

9. What can your organization do to help you feel less stressed?

10. What kinds of personal strategies have you found work to reduce your levels of stress?

\section{Section Two: The Change Process at Community Hospital/The Effects of Change}

All hospital have been affected by a phenomenal amount of change in the last several decades changes in priorities, governance, personnel, funding, facilities. Community Hospital is no exception. The next few questions focus on change at Community Hospital.

11. Which individual or group would you say is in charge of major change initiatives at Community Hospital?

12. Please think back over the last year. Could you please tell me what you felt was the most significant change that took place at the hospital - the one that had the most effect on your personally.

a. What was it about this change that made it significant for you?

13. Have you changed your behaviour at work to respond to this change? If yes, how?

14. How has this change affected how you feel about Community Hospital?

15. What has been the most difficult or frustrating aspect for you personally of this change?

16. What has been the most rewarding aspect for you personally of these changes?

17. How do you personally cope with the changes that have been occurring at Community Hospital?

18. What has Community Hospital done to help you cope with the changes that have been occurring at the hospital?

19. What else could the hospital do to help you cope with the changes that have been occurring?

20. What, if anything, can management at Community Hospital do to improve how change is managed at Community Hospital?

21. If you could give the hospital one recommendation with respect to an area within the hospital that needs change, what would it be? 


\section{Section Three: The Organizational Culture at Community Hospital}

Organizational culture is not about the rules and policies but instead describes the way things really work within the organization. It is one of the first things a new comer notices when they come into the workplace. A culture can be driven, enthusiastic, people centered, reactive, proactive, etc. Research has also shown that the culture of the organization can be one of the organizations greatest strengths or a major source of problems. The next few questions focus on the culture at Community Hospital.

22. Could you give me three words to describe the organizational culture at Community Hospital today? (First three words you think of)

23. Now give me three words to describe what you consider to be the "ideal" organizational culture?

24. If you think back a year ago, would you say the culture is about the same or different?

If yes:

a. Has the change been for the better or the worse? Why do you say this?

b. Why do you think the culture has changed?

\section{Section Four: Working with others at Community Hospital}

Our colleagues at work are critical to how we feel about our work, our ability to get our work done, our mental health, and our experiences at work. The next questions focus on the people that you are working with.

\section{Professional Practice}

Think of an individual who does a job such as the one you are currently doing who you would consider to be "excellent at their job"

25. How do they behave towards their colleagues?

- What do they do?

- What do they not do?

26. How do they behave towards their patients and the patient's families?

- What do they do?

- What do they not do? (Ask only of clinical staff)

27. How do they behave towards the students at the hospital?

- What do they do?

- What do they not do? (Ask only of clinical staff) 
Now, think of an individual who does a job such as the one you are currently doing who you would consider to be "ineffective" - "not that good at their job"

28. How do they behave towards their colleagues?

- What do they do?

- What do they not do?

29. How do they behave towards their patients and the patient's families?

- What do they do?

- What do they not do? (Ask only of clinical staff)

30. How do they behave towards the students at the hospital?

- What do they do?

- What do they not do? (Ask only of clinical staff)

\section{$\underline{\text { Supportive Colleague }}$}

31. Now, think of a colleague that you really like to work with. Why do you like working with them?

- What do they do?

- What do they not do?

32. Now think of a colleague that you really do not like to work with. Why do you not like working with them?

- What do they do?

- What do they not do?

\section{Leadership Team}

33. Now, think of a leader who you think is doing an excellent job? Why do you consider them an excellent leader?

- What do they do?

- What do they not do?

- Is the person in a leadership position within the organization or not?

34. Now think of a leader who you do not think is doing an excellent job? Why do you consider them a poor leader?

- What do they do?

- What do they not do?

- Is the person in a leadership position within the organization or not? 


\section{Section Five: Demographic Changes and Community Hospital}

As you know, we are entering a seller's market for labour and it will become more difficult for employers in all sectors to recruit and retain qualified staff. . Shortages of trained professionals are predicted to be high. The next set of questions is designed to help us understand how you feel these shortages may affect Community Hospital.

35. In your opinion, what are the major problems/challenges that Community Hospital will face over the course of the next decade because of changing demographics? (Prompt Recruitment, retention, workloads, salaries, succession planning?)

36. In your opinion, is Community Hospital doing a good job of addressing these issues? It would be helpful if you began by awarding their performance to date a grade (i.e. give them an A if they are doing an excellent job, a B if they are doing some things well but have room for improvement, an $\mathrm{F}$ is they are not addressing these issues adequately).

a. Grade:

b. Why did you give them the grade you did?

c. What are they doing right?

d. What could they do better?

e. What issues are they missing (i.e. just not dealing with even though they are important)?

37. Moving forward, what kinds of changes do you think Community Hospital must make in order to become a more attractive and competitive employer? (Prompt, working conditions, supervisory practices).

38. What barriers will the hospital face making the changes you have recommended?

\section{Wrap Up}

Thank you very much for taking part in this interview.

Is there anything important that I missed? Do you have any questions that you wanted to ask me?

Would you like to receive a copy of the results of this study?

If yes: Could you give me an e-mail address so I can send it to you? 


\section{Appendix B: T2 Interview Script}

\section{When initially contacting an individual who has volunteered for interview:}

Adjust wording depending how respondent volunteered (i.e. via survey, voicemail, email, etc.). This can also be adjusted and used in email correspondence with volunteers.

$\mathrm{Hi} \_$_ My name is Laura Gover from the Sprott School of Business, Carleton University. I am working with Dr. Linda Duxbury and your new CEO, [CEO NAME], on the Improving Our Workplace Initiative, which is aimed at finding ways to make the hospital become a better place to work. Thank you for volunteering to be interviewed. The interview will take approximately 45-60 minutes of your time and is anonymous, names and other identifying information will not be shared with COMMUNITY HOSPITAL. We would like to schedule your interview at a time that is convenient to you in the next one or two weeks. Could you suggest a few times that you would be available and willing to participate in the interview? Or, if you are available now we can have the interview right now?

\section{When calling for scheduled interview:}

Hi This is Laura Gover from the Sprott School of Business, Carleton University. I am calling for the interview we scheduled. Is now still an ok time for the interview?

\section{Reschedule if necessary or proceed.}

Thank you for volunteering to take part in this brief interview. Before we begin I would like to take a moment to tell you a bit about this interview. You have been identified as someone who can provide us with insight into the challenges of improving the work environment at COMMUNITY HOSPITAL. This interview will take approximately 45-60 minutes of your time and is anonymous, names and other identifying information will not be shared with COMMUNITY HOSPITAL. We will ask you questions designed to help us gain a deeper understanding about your experiences of change at COMMUNITY HOSPITAL, relationships between groups at the hospital and ways to improve the work environment. The information that you give us will help us to identify aspects of the work environment at COMMUNITY HOSPITAL that can be improved and how. The results of these interviews will be shared with staff and physicians and then acted on to make improvements.

Do you have any questions before we begin the interview?

\section{Try to answer any questions the interviewee asks.}

Thanks again for agreeing to take part in this interview. The interview today will be recorded to support the analysis of the data. Audio files will be stored on a password protected PC and will be deleted once the data has been coded and analyzed. Names and other identifying information will not be recorded or shared with COMMUNITY HOSPITAL. Are you happy to go ahead?

If they are unhappy, try to identify and calm their concerns. If you cannot, proceed without recording and take detailed notes. 


\section{Section One: Background}

The first couple of questions give us some background information on you and what you do at work. This information will give us the context to help us interpret the data.

1) [Only ask this if we don't already know the answer from the survey] What is your role at COMMUNITY HOSPITAL? (Get enough information to determine which below job type applies)

a) Senior Manager

b) Medical Leader

c) Physician, Dentist, Midwife

d) $\mathrm{RN}$

e) RPN

f) Professional Clinical Support (Pharmacy, Physiotherapy and Diagnostic Imaging)

g) Other Clinical Support (Front line patient/family interaction - Ward Clerk, Business Unit Clerk, Medical Records, Finance Clerk, Staffing Clerk, Food Services, Central Sterilization Room)

h) Corporate and Facility Support (Housekeeping, Plant maintenance and operation Materials Management, Human Resources, Finance, Administrative Assistant)

2) What unit or department are you in?

3) Have you participated in previous research with Dr Linda Duxbury and myself?

a) Survey in June 2009

b) Interviews Summer and Fall 2009

c) Watch results presentation in Feb. 2010

d) Focus groups in May/June 2010

\section{Section Two: Work at COMMUNITY HOSPITAL}

In this first part of the interview we want to ask you about the current work environment at COMMUNITY HOSPITAL. The questions in this part of the interview help us to understand how individuals treat one another at the hospital, and how to potentially improve the work environment and relationships at the hospital.

4) a) [Only ask this if we don't already know the answer from the survey] Overall, how satisfied would you say you are with the work environment at COMMUNITY HOSPITAL?

[Ask them to use a scale to indicate their level of satisfaction where 5 is very satisfied, 4 is satisfied, 3 indicates a mixed opinion, satisfied about some things, dissatisfied with others, 2 is dissatisfied and 1 is very dissatisfied]

b) What aspects of your work environment do you find satisfying?

c) What aspects of your work environment do you consider to be frustrating?

d) Is there anything that COMMUNITY HOSPITAL could do to increase your feelings of satisfaction with the work environment?

e) Is there anything that you personally can do to improve the work environment at COMMUNITY HOSPITAL? 
5) At the start of this interview you said that you are a 'PROFESSION TITLE', what does it mean to be a PROFFESSION TITLE HERE? (Prompt: what is your purpose? What is the goal of PROFESSION TITLE(s)?)

6) As a group, what values do PROFFESSION TITLE(s) hold?

\section{[Only ask Questions 7-11 if interviewee is physician or manager]}

For the next few questions we would like you to describe specific behaviours, actions and activities that you feel 'typify' each of COMMUNITY HOSPITAL's organizational values: commitment to quality, working together, compassion and respect. The behaviours that you and others provide us with will help us to understand what COMMUNITY HOSPITAL's values mean in action. Once these interviews are complete we will compile an aggregate list of these behaviours so that people working in the hospital have a better idea of how to behave in different situations with different groups. It is hoped that this initiative will help increase the sense of team at COMMUNITY HOSPITAL

Note: Make sure that you get specific behaviours. Use following up questions to get the actual behaviours, actions etc. rather than general descriptors such as "they were respectful".

7) a) Can you think of someone that you think has a high commitment to quality? Why do you think that they have high commitment to quality? What kinds of things do they do at work? How do they behave?

b) Can you think of someone that you think does not "walk the talk" with respect to commitment to quality? Why do you think that they have a lower level of commitment to quality? What kinds of things do they do at work? How do they behave?

8) a) Can you think of someone that you think values working together? This does not need to be the same person you thought of for the previous question. Why do you think that they value working together? What kinds of things do they do at work? How do they behave?

b) Can you think of someone that you think does not "walk the talk" with respect to working together? Why do you think that they do not value working together? What kinds of things do they do at work? How do they behave?

9) a) Can you think of someone that you think values compassion? Why do you think that they value compassion? What kinds of things do they do at work? How do they behave?

b) Can you think of someone that you think does not "walk the talk" with respect to compassion? Why do you think that they do not value compassion? What kinds of things do they do at work? How do they behave? 
10) a) Can you think of someone that you think values respect? Why do you think that they value respect? What kinds of things do they do at work? How do they behave?

b) Can you think of someone that you think does not "walk the talk" when it comes to respect? Why do you think that they do not value respect? What kinds of things do they do at work? How do they behave?

11) a) Are there any additional behaviours that are important for fostering positive relationships between Physicians and Managers at COMMUNITY HOSPITAL?

b) What about behaviours that demonstrate someone is not 'walking the talk' with respect to fostering positive relationships?

12) We are interested in what your thoughts are on 'quality' at COMMUNITY HOSPITAL.

a) How would you personally define quality healthcare?

b) Is there an emphasis on quality at COMMUNITY HOSPITAL?

c) If yes, who emphasizes it?

d) Would you say the emphasis on quality at COMMUNITY HOSPITAL has increased decreased or stayed the same over time?

13) We want to know what your thoughts are on having a common goal for the hospital. One potential way to improve relationships within organizations is to establish a common goal that everyone can work towards. This goal energizes and unites individuals that work for and with the organization

a) Do you think it is possible for COMMUNITY HOSPITAL to have a common and uniting goal?

b) If yes, can you suggest a common goal that all members of COMMUNITY HOSPITAL could work towards? One that you could get behind in particular. (Prompt: Feel free to be creative and think outside the box, a common goal can be a word or two or an entire sentence. We just want to know what you think might be a uniting and energizing goal for COMMUNITY HOSPITAL)

\section{Section Three: Organizational Culture}

Organizational culture describes the way things really work within the organization (not how the rules and policies say things should work). It is one of the first things a new comer notices when they come into the workplace.

14) [Only ask this if we don't already know the answer from the survey]

a) What are 3 words that describe the culture at COMMUNITY HOSPITAL today?

b) What are 3 words that describe what you consider to be the ideal organizational culture? 
15) [Only ask this if we don't already know the answer from the survey]

If you think back a couple years ago to around the time right after COMMUNITY

HOSPITAL opened the new building, would you say the culture at

COMMUNITY HOSPITAL has changed?

a) Yes - the culture now is better than before

b) Yes - the culture now is worse than before

c) Yes - the culture now is different but not better or worse than before

d) No - the culture has not changed

e) I don't know

f) I was not at COMMUNITY HOSPITAL when we moved into the new building

16) Why do you think the culture has (or has not) changed?

17) Organizational cultures can be rooted in the past (i.e. individuals frequently discuss issues from the past), they can be focused on the present (i.e. everyone has so much to do they are just focused on now) or they can be future oriented (i.e. everyone is very focused on the next steps and plans for the organizations future). a) Would you say COMMUNITY HOSPITAL's culture is more oriented in the past, present or future?

b) Why do you think COMMUNITY HOSPITAL has a 'past/present/future orientation'?

c) Can you give us an example?

\section{Section Four: Change Management}

Healthcare organizations are constantly undergoing change, (i.e. new technologies, new facilities, arrangements with other healthcare organizations, changes in leadership).

COMMUNITY HOSPITAL has undergone significant change over the past several years. Over the coming years the frequency and intensity of change in healthcare is expected to increase. This next part of the interview is designed to help us understand how change has been managed at COMMUNITY HOSPITAL.

18) Can you please give me three words to describe the nature of change in the healthcare sector?

19) Can you please give me three words to describe the nature of change at COMMUNITY HOSPITAL?

20) Which individual or group would you say is in charge of major change initiatives at $\mathrm{WMDH}$ ?

21) a) Please think back over the last year. Could you please tell me what you felt was the most significant change that took place at the hospital - the one that had the most effect on your personally.

b) What was it about this change that made it significant for you. 
22) Have you changed your behaviour at work to respond to this change? If yes, how?

23) How has this change affected how you feel about WMDH?

24) What has been the most difficult or frustrating aspect for you personally of this change?

25) What has been the most rewarding aspect for you personally of this changes?

26) How do you personally cope with the changes that have been occurring at WMDH?

27) What has WMDH done to help you cope with the changes that have been occurring at the hospital?

28) What else could the hospital do to help you cope with the changes that have been occurring?

29) What, if anything, can management at WMDH do to improve how change is managed at $\mathrm{WMDH}$ ?

30) If you could give the hospital one recommendation with respect to an area within the hospital that needs change, what would it be?

[If they didn't fill out the survey or if we cannot connect their survey/interview responses (i.e. they called/emailed me to volunteer for interview) then they will be asked here to complete the resilience measure (Question 9 from the survey)]

\section{Section Five: Wrap-up}

Thank you very much for taking part in this interview. We just have a couple of quick wrap-up questions for you regarding your potential future involvement with our work.

31) Would you like to receive a copy of the results of this study? If yes: Could you give me an e-mail address so I can send it to you?

32) We are very interested in the outcomes of Improving Our Workplace Initiative. Would it be ok for us to contact you in a year or so to ask you about any changes to the work environment at COMMUNITY HOSPITAL? If yes, how do you prefer to be contacted? Phone? Email?

33) Do you have any questions or comments you would like to make? Is there anything we missed?

Thank you again for taking part in this interview. 


\title{
Appendix C: T3 Interview Script
}

\author{
When initially contacting an individual who has volunteered for follow-up \\ interview: \\ Adjust wording depending how respondent is being contacted (i.e. voicemail or email). \\ $\mathrm{Hi}$
}

My name is Laura Gover from the Sprott School of Business at Carleton University. I am working with Dr. Linda Duxbury from Carleton University on a study funded by the Canadian Institutes for Health Research about change and COMMUNITY HOSPITAL. As you may remember this study is longitudinal, which means we are interested in looking at changes at COMMUNITY HOSPITAL over time. I am contacting you today because, as you may recall, you participated in (one OR two) previous interview(s) (in 2009 OR in 2009 and 2012) that (was OR were) done as part of this initiative and the last time we spoke you agreed to participate in a (second OR third) follow-up interview. Your opinion is, therefore, critical as it allows us to look at changes at the hospital over time.

We are now contacting you to try and schedule your final follow-up interview. The interview will take approximately 20-40 minutes of your time and is anonymous, names and other identifying information will not be shared with COMMUNITY HOSPITAL. As before, we will send you a copy of our findings and provide you with a \$5 Tim Horton's gift card as tokens of our gratitude. The interview can be completed via telephone or in person (in a private room on site at COMMUNITY HOSPITAL) at a time that is convenient to you in the next couple of weeks. Are you still interested in participating in a follow-up interview? If so, could you suggest a few times that you would be available and willing to participate in the interview?

Please do not hesitate to contact us with any questions. Thank you again for your continued support of this initiative.

\section{When calling for scheduled interview:}

Hi , This is Laura Gover from the Sprott School of Business, Carleton University. I am calling for the interview we scheduled. Is now still an ok time for the interview?

\section{Reschedule if necessary or proceed.}

Thank you for volunteering to take part in this interview. Before we begin I would like to take a moment to tell you a bit about this interview. The interview will take approximately 20-40 minutes of your time and is anonymous, names and other identifying information will not be shared with COMMUNITY HOSPITAL. As you may remember this study is longitudinal, which means we are interested in following your perspective of changes at COMMUNITY HOSPITAL over time. Many of the questions I will ask you today are the same as questions that I have asked you in your prior interview(s). This design allows us to compare your answers and to look at changes over time. The information that you give us will help us to understand how the hospital copes with change and what aspects of the work environment have changed or stayed the same over time. As before, we will send you a copy of our findings once the data analysis is complete. Do you have any questions before we begin the interview?

\section{Try to answer any questions the interviewee asks.}


Thanks again for agreeing to take part in this interview. The interview today will be recorded to support the analysis of the data. Audio files will be stored on a password protected PC and will be deleted once the data has been coded and analyzed. Names and other identifying information will not be recorded or shared with COMMUNITY HOSPITAL. Are you happy to go ahead?

If they are unhappy, try to identify and calm their concerns. If you cannot, proceed without recording and take detailed notes.

\section{Section One: Background}

1) First we would like to get some background information on you and what you do at work. This information gives us context to help us interpret the data. We spoke about this in our 2012 interview and you said you were a (JOB TYPE) in (UNIT/DEPARTMENT). Has anything about your work role or department/unit changed since the last time we spoke?

\section{Section Two: Work at COMMUNITY HOSPITAL}

In this first part of the interview we want to ask you about the current work environment at COMMUNITY HOSPITAL. The questions in this part of the interview help us to understand how individuals treat one another at the hospital, and how to potentially improve the work environment and relationships at the hospital.

2) a) Overall, how satisfied would you say you are with the work environment at WMDH?

[Ask them to use a scale to indicate their level of satisfaction where 5 is very satisfied, 4 is satisfied, 3 indicates a mixed opinion, satisfied about some things, dissatisfied with others, 2 is dissatisfied and 1 is very dissatisfied]

b) What aspects of your work environment do you find satisfying?

c) What aspects of your work environment do you consider to be frustrating?

d) As I mentioned previously, we have your views on work environment from the prior interview(s).

(i) If you compare 2012 to now, has your work environment changed? If yes, how?

(ii) [Ask only if participant did 2009 interview] If you compare 2009 to now, has your work environment changed? If yes, how?

d) Is there anything that COMMUNITY HOSPITAL could do to increase your feelings of satisfaction with the work environment?

e) Is there anything that you personally can do to improve the work environment at COMMUNITY HOSPITAL?

\section{Section Three: Organizational Culture}

The next few questions are about organizational culture, you may remember that we have talked about this in our previous interview. Just as a reminder, organizational culture describes the way things really work within the organization (not how the rules and policies say things should work). It is one of the first things a new comer, such as a new employee, notices when they come into the workplace. We have asked you about the organizational culture at COMMUNITY HOSPITAL before and would like to talk to you about it some more today. 
3) a) What are 3 words that describe the culture at COMMUNITY HOSPITAL today?

b) What are 3 words that describe what you consider to be the ideal organizational culture?

4) If you think back to about a year ago, to around the time of our last interview would you say the culture at COMMUNITY HOSPITAL has changed?

[Have interviewee select one of the below options]

a) Yes - the culture now is better than before

b) Yes - the culture now is worse than before

c) Yes - the culture now is different but not better or worse than before

d) No - the culture has not changed

e) I don't know

5) Why do you think the culture has (or has not) changed?

6) This next question is about culture and change. Would you say that the culture at COMMUNITY HOSPITAL:

[Have interviewee select one of the below options]

a) Promotes and/or facilitates change

b) Hinders change

c) Has no impact on change

7) Why do you say this? (referring to \#6)

\section{Section Four: Change Management}

Healthcare organizations are constantly undergoing change, (i.e. new technologies, new facilities, arrangements with other healthcare organizations, changes in leadership).

COMMUNITY HOSPITAL has undergone significant change over the past several years. Over the coming years the frequency and intensity of change in healthcare is expected to increase. This next part of the interview is designed to help us understand how COMMUNITY HOSPITAL has managed and coped with change.

8) Which individual or group would you say is in charge of major change initiatives at $\mathrm{WMDH}$ ?

9) a) Please think back over the last year. Could you please tell me what you felt was the most significant change that took place at the hospital - the one that had the most effect on your personally.

b) What was it about this change that made it significant for you?

c) Have you changed your behaviour at work to respond to this change? If yes, how?

d) How has this change affected how you feel about WMDH?

e) What has been the most rewarding aspect for you personally of this change?

f) What has been the most difficult or frustrating aspect for you personally of this change? 
10) How do you personally cope with the changes that have been occurring at WMDH?

11) What has WMDH done to help you cope with the changes that have been occurring at the hospital?

12) What else could the hospital do to help you cope with the changes that have been occurring?

13) What, if anything, can management at $\mathrm{WMDH}$ do to improve how change is managed at $\mathrm{WMDH}$ ?

14) If you could give the hospital one recommendation with respect to an area within the hospital that needs change, what would it be?

15) As an organization, this hospital has faced a number of changes over the years. a) In your opinion what factors may have enhanced COMMUNITY HOSPITAL's ability to deal with change? (Prompt: Is there anything that has made the hospital better at dealing with change? These things could be broad and general or specific.)

b) And what factors may have diminished COMMUNITY HOSPITAL's ability to deal with change? (Prompt: Is there anything that makes it more challenging for the hospital to deal with change? These things could be broad and general or specific.)

The next couple of questions have to do with change in the healthcare sector. They refer to the healthcare sector in general, rather than Community Hospital specifically.

16) First, which individual or group would you say is in charge of major change initiatives in the healthcare sector?

17) What are the main drivers for change in the healthcare sector?

18) What are the main barriers to change in the healthcare sector?

19) If you could give the Government of Ontario one recommendation with respect to an area within healthcare that needs change, what would it be?

\section{Section 5: Wrap-up}

Thank you very much for taking part in this interview. We have a couple of wrap-up questions for you.

20) Would you like to receive a copy of the results of this study? If yes: Could you give me an e-mail address so I can send it to you?

21) Do you have any questions or comments you would like to make? Is there anything we missed?

Thank you again for taking part in this interview. 


\section{Appendix D: Examples of Observations Conducted}

\begin{tabular}{|l|l|l|}
\hline Event & Group present & Date \\
\hline Focus groups & $\begin{array}{l}\text { Leadership, staff, } \\
\text { physicians }\end{array}$ & May 2010 \\
\hline $\begin{array}{l}\text { Community Forum led by third party } \\
\text { consultant (onsite at Community Hospital) }\end{array}$ & $\begin{array}{l}\text { Community members, } \\
\text { some staff }\end{array}$ & January 2011 \\
\hline $\begin{array}{l}\text { Community Forum led by third party } \\
\text { consultant (Offsite at local Legion) }\end{array}$ & $\begin{array}{l}\text { Community members, } \\
\text { some staff }\end{array}$ & January 2011 \\
\hline $\begin{array}{l}\text { Community Ambassador breakfast led by } \\
\text { third party consultant (Offsite at local } \\
\text { restaurant) }\end{array}$ & $\begin{array}{l}\text { Community leaders, CEO, } \\
\text { some Board members }\end{array}$ & January 2011 \\
\hline Board Orientation & New board members, CEO & August 2010 \\
\hline Board meeting & $\begin{array}{l}\text { Board of Directors, some } \\
\text { staff }\end{array}$ & June 2011 \\
\hline Board Retreat & Board of directors & August 2009 \\
\hline CEO Selection Committee Meetings & $\begin{array}{l}\text { CEO Selection Committee } \\
\text { and Recruiter }\end{array}$ & $\begin{array}{l}\text { May, June and } \\
\text { July 2011 }\end{array}$ \\
\hline CEO Interviews & $\begin{array}{l}\text { CEO Selection } \\
\text { Committee, Recruiter and } \\
\text { Candidates }\end{array}$ & June 2011 \\
\hline
\end{tabular}




\section{Appendix E: Examples of Available Documents}

\section{Corporate documents:}

\begin{tabular}{|c|c|c|}
\hline Document & Intended Audience & Date \\
\hline $\begin{array}{l}\text { Physician Engagement group - terms of } \\
\text { reference draft }\end{array}$ & $\begin{array}{l}\text { Physician } \\
\text { engagement group }\end{array}$ & Jan 2011 \\
\hline $\begin{array}{l}\text { RFP Assessment Tool - for evaluating } \\
\text { consultant proposals }\end{array}$ & Board of directors & Nov 2010 \\
\hline RFP Selection Meeting Agenda & Board of directors & Nov 2010 \\
\hline $\begin{array}{l}\text { RFP Presentation Assessment - for } \\
\text { evaluating consultant proposals }\end{array}$ & Board of directors & Nov 2010 \\
\hline $\begin{array}{l}\text { Actual 'RFP' for Community } \\
\text { Consultations }\end{array}$ & $\begin{array}{l}\text { Consulting } \\
\text { Companies }\end{array}$ & Oct 2010 \\
\hline Centre for Rural Health and Education & $\begin{array}{l}\text { Board, Sr } \\
\text { Managers }\end{array}$ & Jan 2011 \\
\hline Pre-reading for board retreat & Board members & Aug 2010 \\
\hline Board Orientation & $\begin{array}{l}\text { New board } \\
\text { members }\end{array}$ & Aug 2010 \\
\hline Community Hospital's Strategic Plan & Board members & $\begin{array}{l}\text { June } 2006 \text { (updated } \\
\text { 2009) }\end{array}$ \\
\hline Community Hospital's Annual Report & General & $2009-2010$ \\
\hline LHIN \& Community Hospital Deck & Unclear & $\begin{array}{l}\text { Sept } 2008 \text { (received at } \\
\text { board orientation) }\end{array}$ \\
\hline Annual Report & General & $2008-2009$ \\
\hline Population Health Deck & Unclear & $\begin{array}{l}\text { Unclear (received at } \\
\text { board orientation) }\end{array}$ \\
\hline Population Health Status Deck & Unclear & May 2010 \\
\hline Community Logo Description & General & $\begin{array}{l}\text { Summer } 2009(?) \\
\text { (received at board } \\
\text { orientation) }\end{array}$ \\
\hline Board of Directors policies & Board of directors & $\begin{array}{l}\text { Unclear (received at } \\
\text { board orientation) }\end{array}$ \\
\hline Community Hospital Bylaws & Board of directors & $\begin{array}{l}\text { June } 2008 \text { (received at } \\
\text { board orientation) }\end{array}$ \\
\hline Common acronyms & Unclear & $\begin{array}{l}\text { Unclear (received at } \\
\text { board orientation) }\end{array}$ \\
\hline Strategic Information Management Poster & Sr Managers (?) & $\begin{array}{l}\text { Sept } 2007 \text { (received at } \\
\text { board orientation) }\end{array}$ \\
\hline CEO Competency Requirements & $\begin{array}{l}\text { CEO Selection } \\
\text { Committee }\end{array}$ & Spring 2011 \\
\hline Physician Engagement framework & $\begin{array}{l}\text { Physician } \\
\text { engagement group }\end{array}$ & Fall 2010 \\
\hline Physician engagement decision checklist & $\begin{array}{l}\text { Physician } \\
\text { engagement group }\end{array}$ & Fall 2010 \\
\hline 'Butterfly' document draft (Center of & Board of directors, & April 2011 \\
\hline
\end{tabular}




\begin{tabular}{|c|c|c|}
\hline Excellence plan) & leadership & \\
\hline Media release - VP Senior Services & Media/Public & May 2011 \\
\hline 'Inside Scoop' recap of staff forum & Staff & May 2011 \\
\hline 'Keeping Connected' Newsletter & Community & Fall 2009 \\
\hline Bookmark & General & Received June 2011 \\
\hline ‘Pulse Check' staff newsletter & Staff & May 2011 \\
\hline 'Keeping Connected' Newsletter & Community & Winter 2010 \\
\hline CEO recruitment brief for candidates & CEO candidates & May 2011 \\
\hline CEO recruitment 1 pg description & CEO candidates & May 2011 \\
\hline Financial Statements & Board of directors & $\begin{array}{l}\text { March } 2011 \text { (received } \\
\text { during board meeting) }\end{array}$ \\
\hline Accountability agreement deck & Board of directors & $\begin{array}{l}\text { June } 2011 \text { (received } \\
\text { during board meeting) }\end{array}$ \\
\hline Media release - 'centre for excellence' & Media/Public & $\begin{array}{l}\text { June } 2011 \text { (received } \\
\text { during board meeting) }\end{array}$ \\
\hline $\begin{array}{l}\text { Media Release - 'job zone' to be new } \\
\text { tenant }\end{array}$ & Media/Public & $\begin{array}{l}\text { June } 2011 \text { (received } \\
\text { during board meeting) }\end{array}$ \\
\hline $\begin{array}{l}\text { Medical advisory committee (MAC) } \\
\text { meeting minutes }\end{array}$ & Board of directors & $\begin{array}{l}\text { June } 2011 \text { (received } \\
\text { during board meeting) }\end{array}$ \\
\hline MAC objectives 2011-2012 & Board of directors & $\begin{array}{l}\text { June } 2011 \text { (received } \\
\text { during board meeting) }\end{array}$ \\
\hline Board objectives and year end report & Board of directors & $\begin{array}{l}\text { June } 2011 \text { (received } \\
\text { during board meeting) }\end{array}$ \\
\hline Foundation board chair report & Board of directors & $\begin{array}{l}\text { June } 2011 \text { (received } \\
\text { during board meeting) }\end{array}$ \\
\hline Quality committee minutes & Board of directors & $\begin{array}{l}\text { June } 2011 \text { (received } \\
\text { during board meeting) }\end{array}$ \\
\hline ECFAA compliance report & Board of directors & $\begin{array}{l}\text { June } 2011 \text { (received } \\
\text { during board meeting) }\end{array}$ \\
\hline Performance management quarterly report & Board of directors & $\begin{array}{l}\text { May } 2011 \text { (received } \\
\text { during board meeting) }\end{array}$ \\
\hline Concern/compliment procedure & Staff & $\begin{array}{l}\text { May } 2011 \text { (received } \\
\text { during board meeting) }\end{array}$ \\
\hline Accreditation summary & $\begin{array}{l}\text { Board of directors, } \\
\text { sr managers }\end{array}$ & $\begin{array}{l}\text { Sept } 2010 \text { (received } \\
\text { during board meeting) }\end{array}$ \\
\hline Board meeting evaluation form & Board of directors & $\begin{array}{l}\text { June } 2011 \text { (received } \\
\text { during board meeting) }\end{array}$ \\
\hline Board meeting agenda & Board of directors & $\begin{array}{l}\text { June } 2011 \text { (received } \\
\text { during board meeting) }\end{array}$ \\
\hline $\begin{array}{l}\text { Media Release - Community Hospital } \\
\text { enters into arrangement with Urban } \\
\text { Hospital }\end{array}$ & Media/Public & $\begin{array}{l}\text { June } 2011 \text { (received } \\
\text { during board meeting) }\end{array}$ \\
\hline $\begin{array}{l}\text { Letter of intent between Urban Hospital } \\
\text { and Community Hospital }\end{array}$ & Urban Hospital & $\begin{array}{l}\text { June } 2011 \text { (received } \\
\text { during board meeting) }\end{array}$ \\
\hline
\end{tabular}




\begin{tabular}{|l|l|l|}
\hline $\begin{array}{l}\text { Final version of 'Center of Excellence' } \\
\text { document }\end{array}$ & Staff and public & $\begin{array}{l}\text { June 2011 (received } \\
\text { during board meeting) }\end{array}$ \\
\hline Minutes from May board meeting & Board of directors & $\begin{array}{l}\text { May 2011 (received } \\
\text { during board meeting) }\end{array}$ \\
\hline
\end{tabular}

\section{Other text documents:}

\begin{tabular}{|c|c|c|c|}
\hline Document & Author & Intended Audience & Date \\
\hline $\begin{array}{l}\text { Discussion Guide for } \\
\text { Community Forum }\end{array}$ & Hay Group* & Community & Jan 2011 \\
\hline $\begin{array}{l}\text { Hay Group } \\
\text { Proposal/Presentation }\end{array}$ & Hay Group* & Board of Directors & Nov 2010 \\
\hline $\begin{array}{l}\text { KPMG } \\
\text { Proposal/Presentation }\end{array}$ & KPMG* & Board of Directors & Nov 2010 \\
\hline Champlain LHIN Deck & LHIN & Public & $\begin{array}{l}\text { Aug } 2010 \text { (received at } \\
\text { board orientation) }\end{array}$ \\
\hline Romanow Report & Government & Public & $\begin{array}{l}\text { Nov } 2002 \text { (received at } \\
\text { board orientation) }\end{array}$ \\
\hline $\begin{array}{l}\text { LHIN Eastern Counties } \\
\text { Clinical Distribution Plan }\end{array}$ & LHIN & $\begin{array}{l}\text { Eastern County } \\
\text { Hospitals }\end{array}$ & $\begin{array}{l}\text { July } 2009 \text { (received at } \\
\text { board orientation) }\end{array}$ \\
\hline $\begin{array}{l}\text { LHIN Integrated health } \\
\text { service plan }\end{array}$ & LHIN & Unclear & $\begin{array}{l}\text { Nov } 2009 \text { (received at } \\
\text { board orientation) }\end{array}$ \\
\hline LHIN Vision & LHIN & Unclear & $\begin{array}{l}\text { May } 2010 \text { (received at } \\
\text { board orientation) }\end{array}$ \\
\hline OHA governance guide & $\begin{array}{l}\text { Ontario } \\
\text { Hospital } \\
\text { Association } \\
\end{array}$ & Board of directors & $\begin{array}{l}\text { Nov } 2002 \text { (received at } \\
\text { board orientation) }\end{array}$ \\
\hline Letter from physician & Physician & $\begin{array}{l}\text { Chair of the Board } \\
\text { of Directors }\end{array}$ & $\begin{array}{l}\text { June } 2009 \text { (received in } \\
\text { June } 2009 \text { interview) }\end{array}$ \\
\hline $\begin{array}{l}\text { Proposal for } \\
\text { interview/survey study }\end{array}$ & $\begin{array}{l}\text { Linda } \\
\text { Duxbury }\end{array}$ & $\mathrm{CEO}$ & April 2009 \\
\hline $\begin{array}{l}\text { Emails from past CEO re: } \\
\text { Federal Grant application } \\
\text { and general info about } \\
\text { Community Hospital }\end{array}$ & $\begin{array}{l}\text { CEO from } \\
2004-11\end{array}$ & Linda and me & Aug 2010 \\
\hline $\begin{array}{l}\text { Emails from Community } \\
\text { Hospital }\end{array}$ & Staff & $\mathrm{Me}$ & $\begin{array}{l}\text { During interviews } \\
\text { (June - Nov 2009) and } \\
\text { focus groups (May } \\
\text { 2010) }\end{array}$ \\
\hline KPMG Audit findings & KPMG* & Board of directors & $\begin{array}{l}\text { June } 2011 \text { (received } \\
\text { during board meeting) }\end{array}$ \\
\hline $\begin{array}{l}\text { Physician engagement } \\
\text { agreement }\end{array}$ & $\begin{array}{l}\text { Urban } \\
\text { Hospital }\end{array}$ & $\begin{array}{l}\text { Physician } \\
\text { engagement group }\end{array}$ & Unclear (fall 2010?) \\
\hline CEO recruitment Agenda & $\begin{array}{l}\text { Odgers- } \\
\text { Bernstein } \\
\text { Group } * * *\end{array}$ & $\begin{array}{l}\text { CEO selection } \\
\text { committee }\end{array}$ & May 2011 \\
\hline
\end{tabular}




\begin{tabular}{|l|l|l|l|}
\hline CEO work plan & $\begin{array}{l}\text { Odgers- } \\
\text { Bernstein } \\
\text { Group } * * *\end{array}$ & $\begin{array}{l}\text { CEO selection } \\
\text { committee }\end{array}$ & April 2011 \\
\hline Physician engagement deck & $\begin{array}{l}\text { Shawn } \\
\text { McGuire** }\end{array}$ & $\begin{array}{l}\text { Board of } \\
\text { Directors/physician } \\
\text { engagement group }\end{array}$ & June 2011 \\
\hline Letter of Commitment & $\begin{array}{l}\text { Urban } \\
\text { Hospital }\end{array}$ & $\begin{array}{l}\text { Board of directors, } \\
\text { sr managers }\end{array}$ & June 2011 \\
\hline $\begin{array}{l}\text { Patient Comments received } \\
\text { from January - Sept 2009 }\end{array}$ & $\begin{array}{l}\text { Patients } \\
\text { (n=446) }\end{array}$ & $\begin{array}{l}\text { Community } \\
\text { Hospital }\end{array}$ & Fall 2009 \\
\hline $\begin{array}{l}\text { News Paper Articles on } \\
\text { Community Hospital }\end{array}$ & $\begin{array}{l}\text { Local Paper } \\
\text { and Ottawa } \\
\text { Citizen }\end{array}$ & Public & ongoing \\
\hline
\end{tabular}

*Hay Group and KPMG are third party consultants

** Shawn McGuire is a physician from another hospital who specializes in physician engagement and began work with the Physician Engagement group at Community Hospital

***Odgers-Bernstein Group is the headhunting firm that coordinated the search and selection process for the new CEO 